\title{
Kereru in Urbanised Landscapes
}

\section{Monica Awasthy}

A thesis submitted to

Victoria University of Wellington

in fulfilment of the requirements for the degree of

Doctor of Philosophy in Ecology and Biodiversity

Victoria University of Wellington

Te Whare Wānanga o te Ūpoko o te Ika a Māui

2012 



\section{ABSTRACT}

Urban areas are quickly supplanting other land covers on a global scale as a direct result of a rapid human population growth and associated anthropogenic disturbances. Although the concept of a city as an ecosystem is now widely accepted, relatively little is still known about how wildlife responds to urbanised landscapes. In addition, the factors affecting habitat selection of highly mobile avian species within urbanised landscapes have seldom been quantified at multiple spatial scales. Understanding the human social aspects of urban ecology is also vital to wildlife conservation because as the majority of the world's population continues to shift into cities, they are becoming increasingly "disconnected" from nature. However, people can contribute both directly through involvement in wildlife research, and indirectly through knowledge acquisition and environmental awareness.

The kereru (New Zealand pigeon, Hemiphaga novaseelandiae) is a large, highly mobile, fruit-eating pigeon endemic to New Zealand. Although once in nationwide decline, kereru appear to have slowly increased in numbers across New Zealand, most notably in urbanised landscapes. Kereru recovery may be due to the control of mammalian predators and competitors, as well as a reflection of the kereru's ability to adapt to and exploit novel suburban habitat. However, little is known about how kereru select amongst urbanised habitat, the impacts of injuries sustained within this habitat on post-rehabilitation success or how researchers can integrate urban residents into the conservation of kereru. This thesis aims to (1) advance current knowledge of kereru ecology within urbanised landscapes and to explore the concept of kereru as an "urban 
adapted" species, and (2) to examine the role of people in urban avian ecology, from the perspectives of both the researcher and the public.

I applied a multi-scale approach to examine habitat selection by kereru at regional (first-order), winter range (second-order), and site (third-order) levels, using a citizengenerated dataset and by monitoring a marked and radio-tagged population in Wellington City. At the first-order of selection, citizens' sightings of kereru revealed that birds selected areas with intermediate levels of building and road coverage when possum (Trichosurus vulpecula) control measures were undertaken. Radio-telemetry of kereru revealed that habitat selection within Wellington's residential ecosystems occurred at the third- but not second-order of selection. Sites within winter ranges were selected based upon the presence of a native food source, conspecifics and possum control. My results suggest that possum control may be creating a buffered "safe zone" for kereru within suburban areas whereby predation risk is lowered, or more likely, competition for native food sources is reduced.

While it is encouraging to see increasing numbers of kereru in urbanised areas, this environment is often the cause of injuries not normally sustained in the wildlands. I monitored kereru during the early post-release period following rehabilitation in two variably urbanised landscapes. Results of my modelling suggested that the sex of the bird, release site, severity of the injury sustained, and the time of year a bird was released were important determinants of early rehabilitation success.

This thesis ends with a study that integrated local school children into my field research as part of a conservation education program. Using kereru as a focal species, I tested whether incorporating biological researchers into the classroom and hands-on experiences with radio-telemetry of wild birds in local green space increased wildlife knowledge, environmental awareness and intentions to act amongst children. No 
significant increases in wildlife knowledge were found in either treatment group, however those children who participated in exercises with researchers in local green space demonstrated, and retained, higher levels of nature awareness than groups who participated in the schoolyard.

In summary, applying multiple methods and considering both the biological and social aspects of urban avian ecology have allowed me to gain a more holistic picture of the kereru's ability to adapt to urbanised landscapes and how people living in cities can contribute towards the conservation of kereru. 


\section{ACKNOWLEDGMENTS}

I am most grateful to my supervisor Wayne Linklater for all of his help and seemingly unending enthusiasm. Thanks also to my second supervisor K.C. Burns for playing a huge part in guiding my professional development (and for often providing much needed comic relief!).

Building a large field project from scratch such as this would not have been possible without the assistance of Ralph Powlesland (DOC) and Peter Reese (OSNZ). I am grateful for your advice, great company and your willingness to assist me in the field during the early learning stages of the fine art of kereru capture!

A most heartfelt thank you to Gesine Pufal and Ilse Corkery for being the best field assistants and friends I could have asked for. I am also lucky to have had many wonderful volunteers over the years and I am sincerely grateful to all of them: Rosalynn AndersonLederer, Ros Batchelor, Laura Bunning, Jacquie Byrd, Hilary Cresko, Barnaby Dixson, James Fearnley, Will Grant, Peter King, and Laci Prucinsky. I also had the good fortune to convince visiting academics (also expert ornithologists) to do field work with me.

Erick Greene and his wife Anne were great help catching kereru during their visit to New Zealand, while Darryl Jones spent a number of days mist-netting at Otari-Wilton's Bush during his sabbatical here. Darryl was also the lucky winner of a kereru that shot its entire tail out upon hitting the mist net!

There are many organisations that played a big part in this thesis as well. Thanks to the Kereru Discovery Project partners: Te Papa Museum of New Zealand, Wellington Zoo Trust, Karori Sanctuary Trust, and the Department of Conservation.

Thank you to Rewi Elliot and the staff at Otari-Wilton's Bush for all your patience and assistance during mist-netting and radio-tracking of Wellington kereru. Many of these radio-tracking escapades lead me through the neighbouring suburbs, and so I thank the residents of Wilton (and surrounding suburbs) for all the cups of tea I've had while trying to gain access to private gardens!

I am also extremely grateful to the many citizen scientists who contributed kereru sightings over the years, without whom, the broad-scale habitat selection study would not have been possible. Hokimate Harwood (Te Papa) and Raewyn Empson (Zealandia/Karori Wildlife Sanctuary) also regularly provided additional sightings from the public.

The work on rehabilitated kereru would not have been possible without the wonderful staff at Nga Manu Nature Reserve, especially Bruse Bensemen and Rhys Mills, and Karin Wiley at Native Bird Rescue Wellington Trust. 
Mairead de Roiste, Andrew Rae, Micheal Hund and Stephen Hartley were all pivotal to the GIS portions of this thesis. Staff at Wellington City Council and Greater Wellington Regional Council also provided me with additional data whenever required.

Thank you to the many Linklater Lab group members who have come and gone throughout the years. In particular, fellow Ph.D. students: Rosalynn Anderson-Lederer, Beaux Berkley, Barnaby Dixson, Megan English, Roan Plotz and Gaius Wilson.

This last year would not have been possible without the support of the SBS technical team, especially the incredible Chris Thorn. If you have to work full time while finishing a thesis, do it with these guys! The SBS administration team has also been amazing, so thank you Mary Murray, Sandra Taylor, Paul Marsden and Patricia Stein. Thanks also to Phil Lester for being an amazing and supportive Head of School! Belinda Tuari (Faculty of Science) deserves a special thank you for re-enrolling me more times than I care to mention without question $:$.

Finally, and most importantly, I thank my family. My parents and my sister have always been my biggest supporters from afar. I also thank the Dixson family for providing muchneeded respite from my work, most often over delicious Sunday dinners. But my most heartfelt gratitude goes to Barnaby Dixson for his unconditional support, help with my field work, awesome editing skills and gentle pushes to keep moving forward in those moments when it all seemed too difficult. I couldn't have done this without you.

Funding was generously provided by a Wellington Zoo Research Fellowship, Corporate Express Scholarship, Environment and Heritage Grant from New Zealand Lotteries (to Wellington Zoo), Centre for Biodiversity and Restoration Ecology at Victoria University of Wellington, Nga Manu Trust Scholarship, and Hutton Fund of the Royal Society of New Zealand. This research was conducted under Victoria University of Wellington Animal Ethics Permit \#2006R24, Victoria University of Wellington Human Ethics Permit \#15533, Department of Conservation Research Permit \#WE/253/RES and Department of Conservation Banding Permits \#2007/01 and 2008/063. 


\section{TABLE OF CONTENTS}

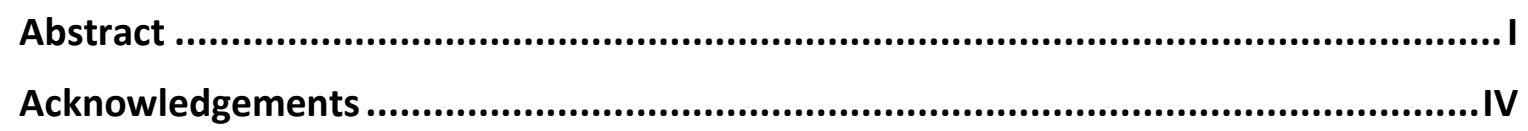

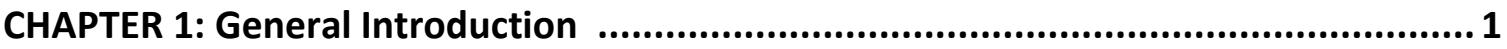

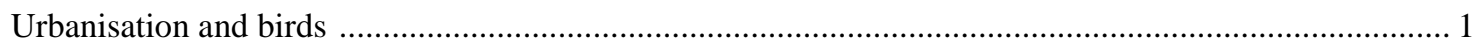

Avian responses to urbanisation .................................................................................................. 3

Effects of urbanisation on avian species ..................................................................................... 3

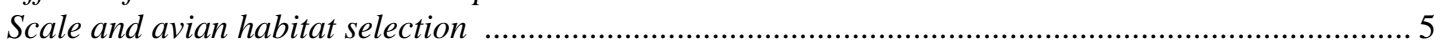

The human dimensions of urban avian ecology ............................................................................. 7

Kereru (New Zealand pigeon; Hemiphaga novaeseelandiae) as a case study...................................... 9

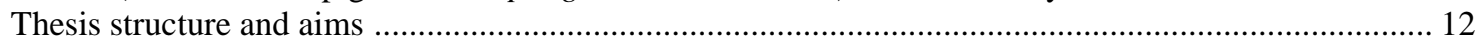

\section{CHAPTER 2: Using citizen science to investigate kereru habitat selection within an}

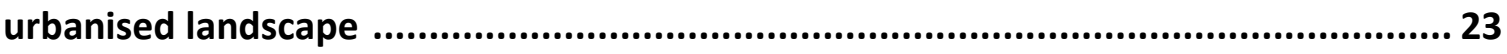

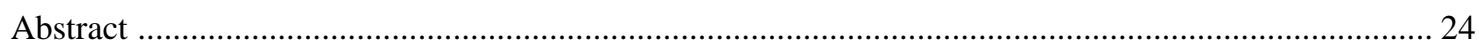

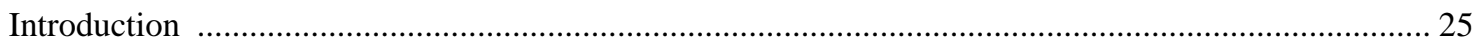

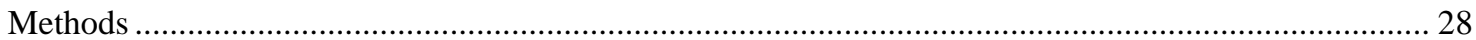

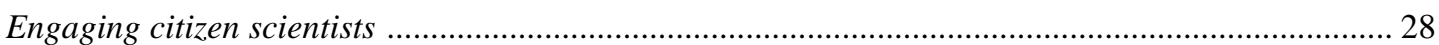

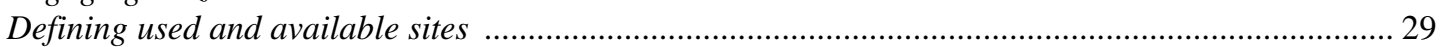

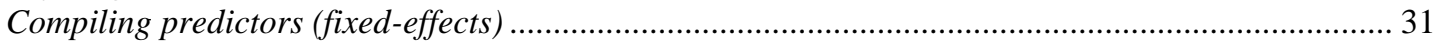

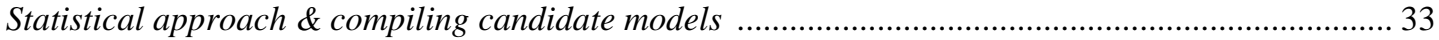

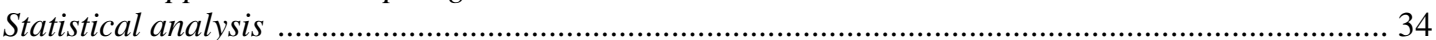

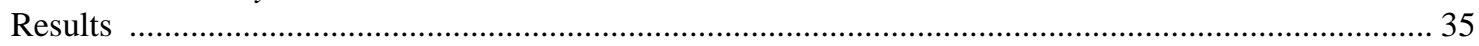

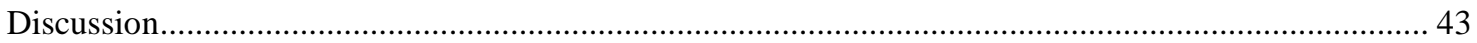

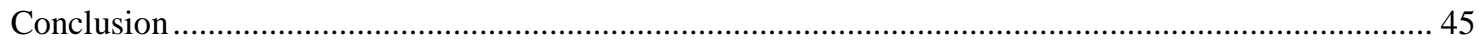

CHAPTER 3: Multi-scale habitat selection by kereru in a suburban landscape ............ 51

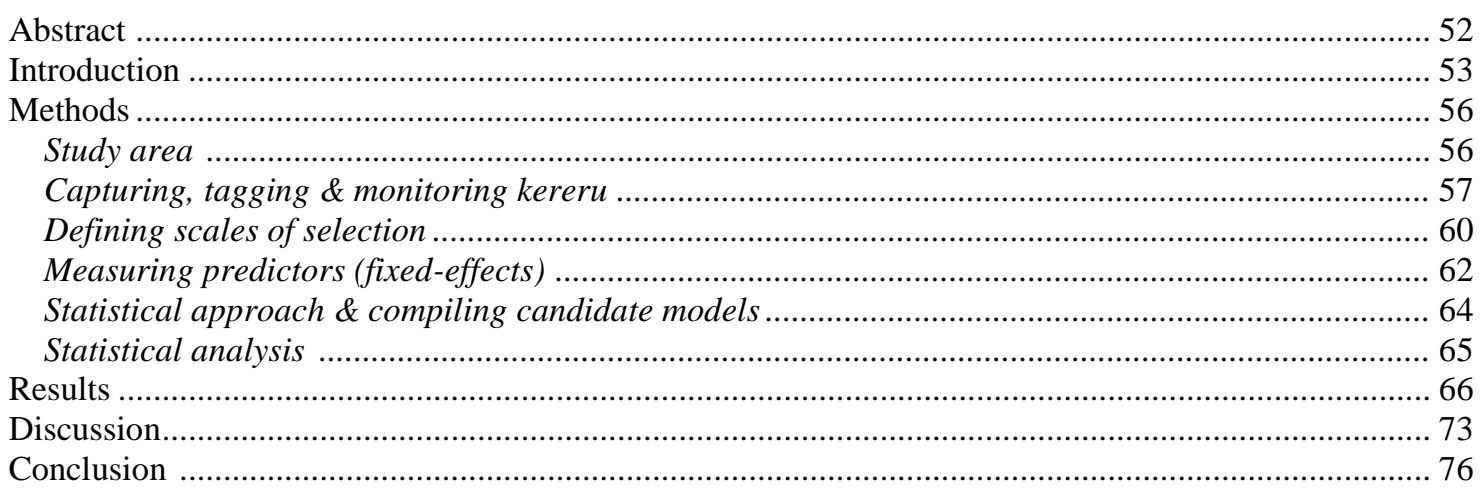




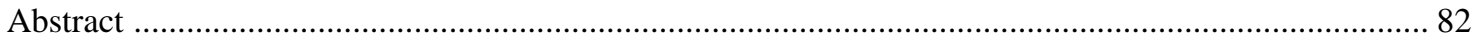

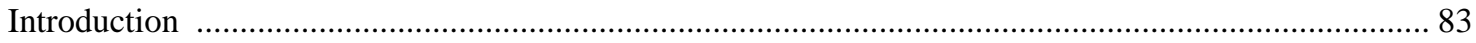

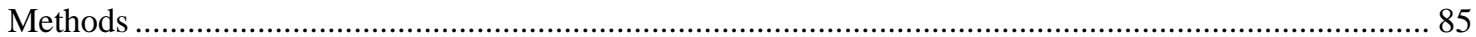

Rehabilitation, release \& monitoring of kereru ......................................................................... 85

Compiling the candidate hypotheses .................................................................................................. 90

Compiling the candidate model set \& statistical approach ........................................................ 94

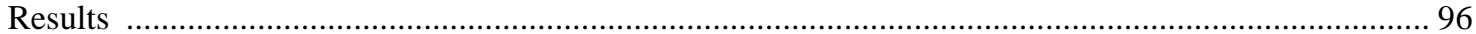

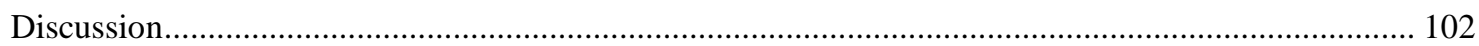

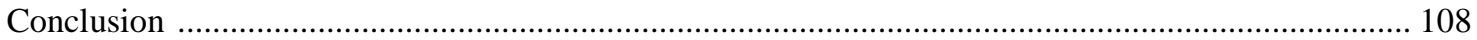

\section{CHAPTER 5: Enhancing an urban conservation education program with children} through local wildlife research experience ......................................................... 112

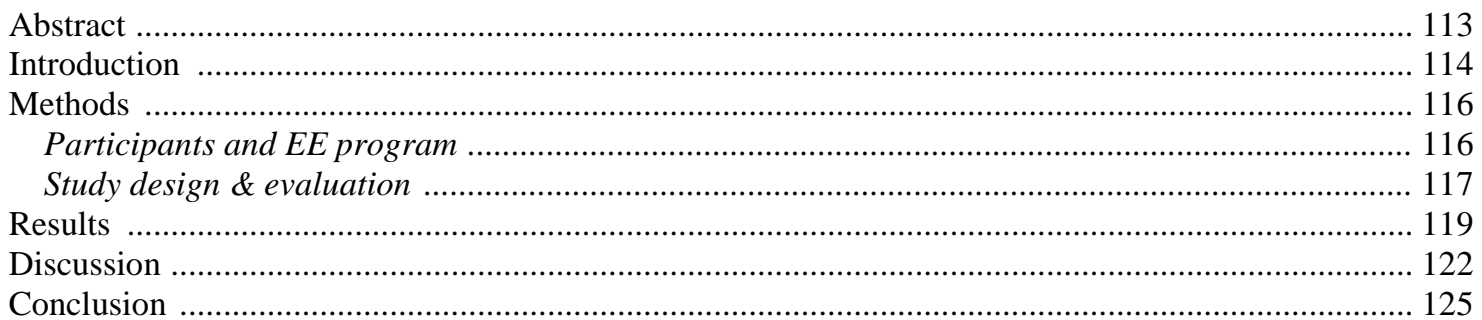

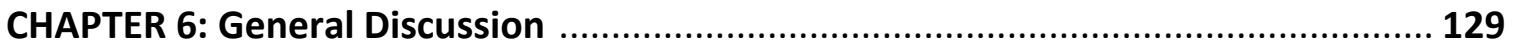

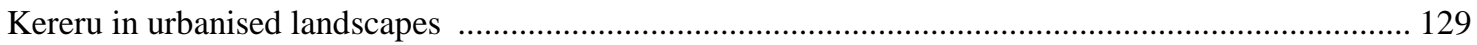

The importance of multi-scale habitat selection ...................................................................... 129

Classifying the response of kereru to urbanisation .................................................................. 132

The human dimension of urban avian ecology ............................................................................ 134

The role of wildlife rehabilitation ................................................................................................ 134

Citizen science and environmental education ............................................................................ 135

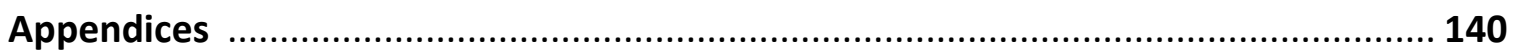

Appendix 1. Table of kereru studies 1981-2010 ...................................................................... 140

Appendix 2. Attaching tail-mounted transmitters ........................................................................... 144

Appendix 3. Sexing kereru using DNA, morphometrics and plumage ............................................. 148

Appendix 4. Table of food sources known to be eaten by kereru ......................................................... 156

Appendix 5. Fright moult in kereru results in complete loss of tail feathers .................................... 169

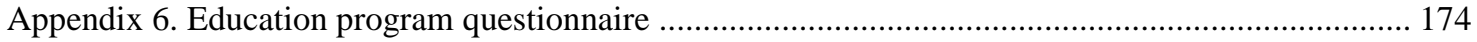




\section{CHAPTER 1. General Introduction}

\section{Urbanisation and birds}

The world's human populations are becoming increasingly urbanised, with $78 \%$ of the inhabitants of the more developed nations now living in or near cities (United Nations 2007, 2011; Obaid 2007). In developed countries expansion is occurring away from city centres into suburbs and it is expected that this population will rise globally to $86 \%$ by the year 2050 (United Nations 2011). For example, Australasia is one of the most urbanised regions in the world. Over $85 \%$ of New Zealanders now live in cities and their surrounds (Bayley \& Goodyear 2001; Freeman \& Buck 2003), and it is projected that by the year 2050 over $90 \%$ of the population of New Zealand will be urbanised (Statistics Zealand 2006). This type of rapid expansion creates gradients of human densities where urbanised land area increases at a higher rate than human population size (Marzluff et al. 2001b).

As human populations continue to grow and dominate ecosystems the species composition of these ecosystems is dramatically altered (Marzluff et al. 2001b; Vitousek et al. 1997). Humans increase the heterogeneity of the landscape by introducing exotic species, modifying landforms, and building extensive infrastructure. Urbanised landscapes are dominated by buildings, roads and other paved areas, that are interspersed with newly created “green" space such as parks, gardens and remnant patches of forest (Garden et al. 2006; McDonnell \& Pickett 1990). Urbanisation rapidly and dramatically alters the structure of the landscape through extensive habitat loss and fragmentation (Alberti et al. 2003; Marzluff \& Ewing 2001; Vitousek et al. 1997), causes declines in native biodiversity (Blair 1996; Czech \& Krausman 1997), and at its extreme can lead to local species extinctions (Czech et al. 2000; Goddard et al. 2009). 
The urban landscape may at first appear to be highly fragmented. Miller et al (2001) however, described a new way of thinking about fragmentation and patchiness in urban matrices, where often the effects of human settlement represent more of a "perforation" of landscapes rather than fragmentation. Fragmentation typically results in the large-scale conversion of land-cover types and discrete habitat patches surrounded by a highly-altered matrix, whereas perforation results in a landscape speckled with disturbance points, such as individual houses and gardens or clustered developments. These types of areas are typically attributed to suburban or exurban areas of the developing world, where landscape modifications due to population growth are greatest (United Nations 2007, 2011).

Residential gardens are arguably one of the most important urban green spaces supporting native biodiversity in cities across the world (Goddard et al. 2009). Within developing countries gardens contribute almost half the available green space in many urban areas (Evans et al. 2009), with estimates varying from 22-27\% in UK cities (Evans et al. 2009; Loram et al. 2007), and up to 36\% in New Zealand cities (Dunedin; Mathieu et al. 2007). These individual parcels of land however, are being managed by private home owners and are highly variable in vegetative structure and composition at small spatial scales (Savard et al. 2000). Garden cultivation and the variety of native and exotic plant species can have benefits for suburban wildlife (reviewed in McKinney 2002), but the removal of deadwood, shrubbery and the creation of open lawns can also have detrimental effects on many birds (Marzluff \& Ewing 2001). Thus, an understanding of the role of private and managed, as well as public lands, is required to gain a complete picture of wildlife responses to suburban habitats, particularly since the abundance and diversity of species are greater in suburban than other urban areas (Clergeau et al. 1998). 


\section{AVIAN RESPONSES TO URBANISATION}

Many terms have been used to describe a species response to, and ability to persist, within built landscapes. Some of the first terminology used to describe this response were urbaniphobous, urbanoneutral and urbanophilous (Wittig et al. 1985). Similarly, Blair (2001) and McKinney (2002) classified organisms as urban avoiders, urban adaptors, or urban exploiters. Both sets of terms acknowledge that species can be eliminated, adapt or increase in response to urbanisation, although the concept assumes uniformity of landscape structure. The urban environment, however, is a complex mosaic composed of built structures interspersed with green patches, and is best described as an urban-to-rural gradient of human densities (Alberti et al. 2001; McDonnell \& Pickett 1990). Thus, categorising a species in these ways is seldom accurate. In their review of the ecology of Australian urban fauna, Garden et al (2006) introduced terminology to include the spatial complexity of the urban environment, where species are either matrix-occupying, matrix sensitive, or urban sensitive. In these definitions, matrix-occupying species often dominate the built environment, matrixsensitive perceive more barriers and risk within the built environment, and urban sensitive are unable to persist in the built environment (Garden et al. 2006). Thus, each of these terms allows for flexibility between the levels of urbanisation when categorising the species within them, as not all species utilise, or respond to urbanisation uniformly (e.g. an animal may forage within a city, but nest outside of it).

\section{EFFECTS OF URBANISATION ON AVIAN SPECIES}

There is an immense and growing literature documenting avian responses to urbanisation (Marzluff et al. 2001a). Birds have been a particularly popular study species, as they are common residents found along the urban-rural gradient (Marzluff et al. 2001b; Ortega-Álvarez \& MacGregor-Fors 2011). As the built environment intensifies, species composition is dramatically altered. In general, avian biomass tends to increase with 
increased urbanisation, however species richness and diversity decreases (Figure 1; Chace \& Walsh 2006; McKinney 2002). A small number of species, most often exotic, become dominant due to their ability to exploit human resources (i.e. feral pigeons) and success in out-competing native species (Major et al. 1996). In general, urbanisation tends to select omnivorous, granivorous and cavity nesting species (Chace \& Walsh 2006). In terms of vegetation, native fauna are more abundant where native flora are retained (Chace $\&$ Walsh 2006; Lerman \& Warren 2011).

Despite avian survivorship and reproduction in urban areas being significantly impacted by risk of collision with man-made objects, changes in predator assemblage, food supply, and disease (Chace \& Walsh 2006 and the references therein), urbanised landscapes now host an increasing variety of native wildlife that were previously only associated with rural and undeveloped wildlands (Ditchkoff et al. 2006; Jokimaki et al. 2005). In particular, numbers and diversity of avian species have been shown to be greater in suburban than urban areas (Clergeau et al. 1998), although some studies have demonstrated variation from this pattern (e.g., Ortega-Alvarez \& MacGregor-Fors 2009). There is also evidence that highly mobile species, for example Flying-foxes in Australia, are able to navigate highly fragmented or perforated urbanised landscapes to exploit novel and remnant native food sources (McDonald-Madden et al. 2005). Thus, urbanisation leads to a reduction and loss of native habitat, but may also create new habitat types that have the potential to support a diverse range of bird species. 


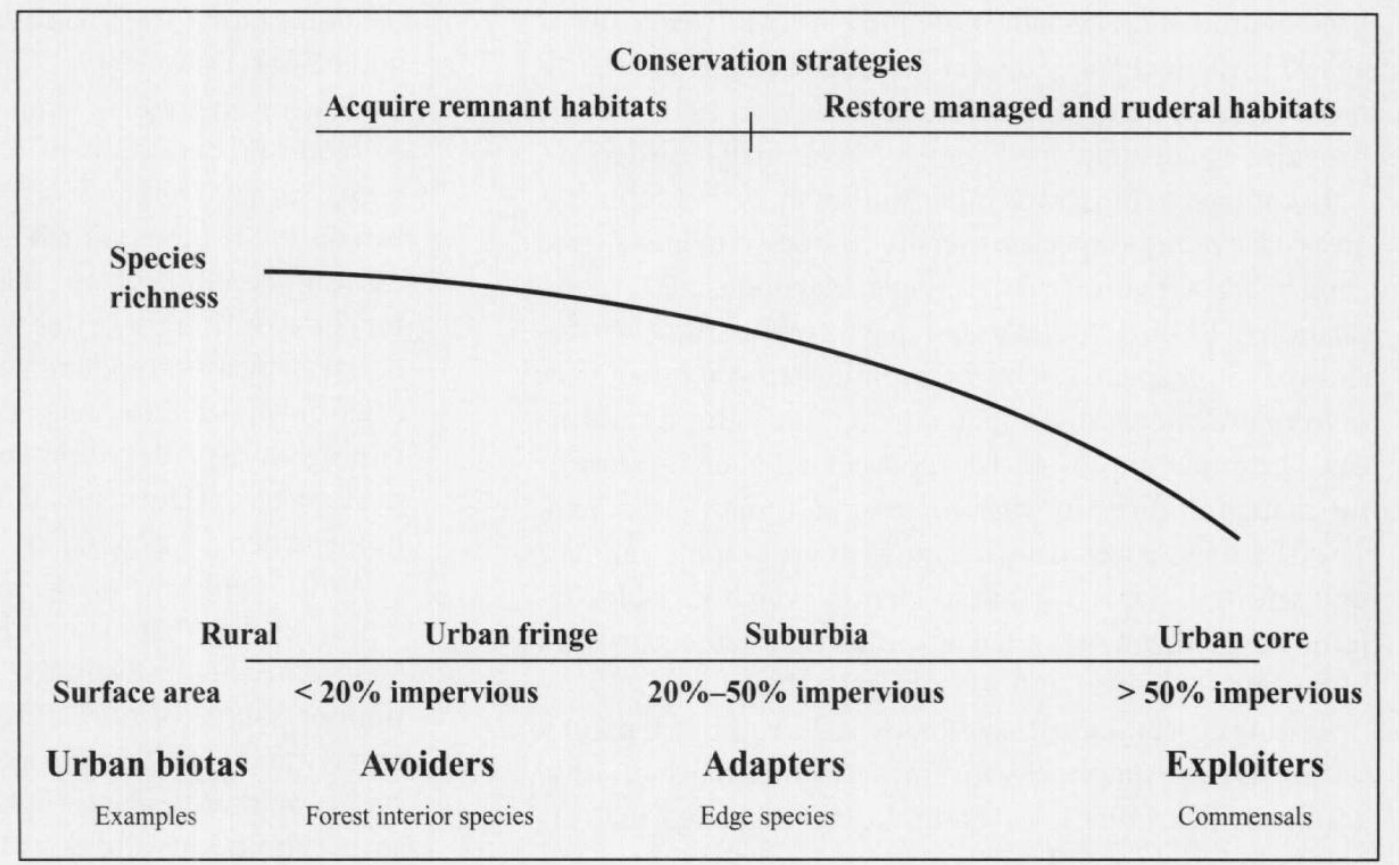

Figure 1. Species richness and composition changes across the urban-rural gradient (reproduced from McKinney 2002).

\section{SCALE \& AVIAN HABITAT SELECTION}

An often overlooked problem in urban ecology is understanding how landscape change that is made at one spatial scale, might alter the response of animals at differing scales. Here, I adopt Hostetler's (2001) use of the term response to mean the ability of an animal to utilise structural objects in a landscape. Animals perceive and respond to habitat structure at varying scales in a spatial heirarchy (Hostetler 2001; Hostetler \& Holling 2000; Kotliar \& Wiens 1990). Hierarchy theory divides complex ecosystems into discrete, ranked levels of organisation (Allen \& Starr 1982; O'Neill et al. 1986). Simply defined, the largest area in which an organism responds to habitat structure is the spatial extent, whereas the minimum resolution at which an organism responds to objects in a landscape is the spatial grain (Kotliar \& Wiens 1990; Wiens 1989). Often, the terms micro-habitat, macro-habitat, fine scale, course scale, local level, and landscape level are also used to describe spatial resolution (Oliver \& Lollback 2010; Tremblay et al. 2009). Johnson (1980) described the 
following hierarchical levels of selection between grain and extent, where higher order selections are contingent upon lower order ones. First-order selection is the selection of a tract of landscape within a region. Second-order selection is the selection of a home range area, wintering area, or stop-over site within the landscape. Third-order selection is the usage of various patches within the area. Fourth-order selection is the actual procurement of food items within a habitat patch. Given that habitat selection occurs at multiple scales, and that urbanisation can elicit differing responses by birds, it is surprising that avian studies have largely focussed upon single scales of selection (Hostetler 2001; Hostetler \& Holling 2000).

The scale at which humans manage urbanised habitat directly affects how birds respond to habitat structure. In Hostetler \& Hollings' (2000) example, a large bodied Redtailed hawk's (Buteo jamaicensis) home range selection is affected by broad-scale landscape management by both city councillors and residential home owners, while a small-bodied Carolina wren's (Thyothorus ludovicianus) home range would likely be affected by fine-scale management of private gardens. Thus, what is considered a food patch within a home range of one avian species could constitute the entire home range of another. Multi-scale analysis is therefore particularly important within suburban landscapes because many of the decisions regarding habitat structure are being made at the level of the landowner, that is, habitat on private lands is being micro-managed.

Many authors have suggested that higher-order rather than lower-order habitat factors are more important in determining avian community composition (Clergeau et al. 2001; Evans et al. 2009; Lerman \& Warren 2011), while others have found that variation in the abundance and diversity of winter birds is driven by lower-order habitat variables (Caprio et al. 2009; Pearson 1993). While scale-dependent differences in habitat selection exist both between and across species, few studies have considered the responses to habitat across multiple spatial scales in a single species. 


\section{The human dimensions of urban avian ecology}

Understanding the human social aspects of urban ecology is vital to wildlife conservation for two main reasons: First, urban areas are quickly supplanting other land covers on a global scale as a direct result of a rapid human population growth and associated anthropogenic disturbances (Obaid 2007). Although the concept of a city as an ecosystem is now widely accepted, relatively little is still known about how wildlife responds to urbanised landscapes (Grimm et al. 2000; McDonnell \& Pickett 1990). Second, as the majority of the world's population continues to shift into cities, they are becoming increasingly “disconnected” from nature (Louv 2005).

The naturalist Edward O. Wilson (1984), calls biophilia the "innate tendency [of people] to focus on life and lifelike processes." Despite the pervasive importance of biophilia in shaping our daily lives, many urban citizens experience an "extinction of experience", whereby the connection to nature is lost alongside declines in biodiversity (Pyle 1978). Conservation action depends on people's experience with nature. However, the way in which people living in urban areas perceive nature differs from those living in less built-up environments (Goddard et al. 2009). For many urban residents the majority of their interactions with nature will be with non-native species such as feral pigeons (Columba livia), a phenomenon known as the 'pigeon paradox' (Dunn et al. 2006). While these human experiences with nature are clearly recognised as essential components of successful urban ecological and conservation programs, few scientists integrate human aspects into their research (Alberti et al. 2003).

Citizen science involves the participation of non-scientists in scientific research by integrating public outreach and scientific data collection (Cooper et al. 2007; Trumbull et al. 2000). The earliest citizen science project was the Christmas Bird Count run by the National Audubon Society (U.S.A.) in 1900, an event which still occurs to the present day (Butcher et 
al. 1990; National Audobon Society 2012). Since then, the number of citizen science projects has dramatically increased (Mayor et al. 2009; Silvertown 2009). The diversity of citizen science projects has expanded in recent years, however the majority of studies remained focused on birds (Bonney et al. 2009; Sullivan et al. 2009). As a result, citizen science has been particularly successful in advancing scientific knowledge in avian studies (Bonney et al. 2009 and the references therein; Sullivan et al. 2009). Specifically, citizen science studies of avian species have been successful in quantifying distributions, breeding, disease, and environmental effects (reviewed in Bonney et al. 2009). Researchers studying urban ecosystems benefit from citizen science through voluntary participants who provide large scale data sets, which often encompass inaccessible private property. Participating in these projects has the potential to motivate local conservation action and more environmentally responsible behaviour in citizen scientists due to knowledge acquisition and thus indirectly science education (Cooper et al. 2007).

People living in urban areas are less 'connected' with the natural world (Miller 2005), but their early life experiences and perceptions of nature may be essential to conservation (Tanner 1980). In addition to the benefits offered by participating in citizen science projects, several recent studies have also highlighted the need for increasing practical ecological and conservation-based studies in schools (Brewer 2002a, 2002b; Evans et al. 2006). However, the typical approach to environmental education (EE) has been a focus on "wilderness", with urban-living children typically learning inside the classroom (Fisman 2005). Urban greenspaces near schools and schoolyards themselves, however, also offer opportunities to teach about nature and local conservation issues (Brewer 2002a). Indeed such opportunities may better engage interest because sustained contact with a given place and direct contact with nature best cultivates children's environmental knowledge and concern (Sobel 1998) and develops ecological literacy (Orr 1989). By beginning this process at a young age, scientists 
could be installing conservation values that will be carried through to adulthood and thus creating future scientists and citizen scientists.

\section{Kereru as a case study}

The kereru (also known as kuku, kukupa, New Zealand Pigeon; Hemiphaga novaeeselandiae ) is a large-bodied, arboreal fruit-eating pigeon endemic to New Zealand (550-850g, Clout 1990; 650g, Heather \& Robertson 2005). Kereru display a similar morphology to other pigeons in the Columbidae family, with a small head, a straight softbased bill and loosely attached feathers (Heather \& Robertson 2005). They are considered sexually monomorphic (Heather \& Robertson 2005), although some sex differences in bill and wing length have been reported (Gill 2006). There is also anecdotal evidence that sex differences exist in body mass, tail shape, and plumage. Most field studies of kereru to date have used behaviour to determine individual sex (Campbell 2006; Clout et al. 1995a; Flux et al. 2001; James 1995; Powlesland et al. 2003; Thorsen et al. 2004), but these observations have been limited to the breeding season when male and female kereru have distinct temporal patterns of nest attentiveness (James 1995).

Kereru are widely distributed on the mainland and utilise a variety of habitats, ranging from coastal to montane landscapes (Clout et al. 1986; Robertson et al. 2007). Their preferred vegetation consists mainly of native forest and scrub but also mixed native and exotic forest (Higgins \& Davies 1996). They also frequent modified habitat such as pastures and urban areas. Kereru are highly mobile and can have home ranges of up to 20-30 ha throughout a year with a core area of 1-2 ha, although they can also be sedentary in areas that contain a year-round food supply (Mander et al. 1998; see Appendix 1). Juvenile kereru occupy larger home ranges than adults (Bell 1996), but the timing of departure from the natal territory is still unknown. 
It has been suggested that food availability drives kereru occurrence and movements more so than habitat type (Higgins \& Davies 1996), however the scale-dependent relationships between foraging decisions, patch use and home range placement remain poorly understood, particularly in urbanised landscapes. Nevertheless, many radio-telemetry studies have found strong links between seasonal movements and home range placement, and the availability of favoured food sources. Where seasonal food sources are widely scattered, kereru are capable of moving long distances between them, often over boundaries of parks and reserves (Clout et al. 1991). For example, in a study of 54 kereru captured at Pelorus Bridge Scenic Reserve in Marlborough, Clout et al (1991) found that about half the birds feeding on deciduous foliage in the spring moved 2-18 km away to nearby native forest in early summer. These movements were apparently linked to feeding on favoured food sources (Clout et al. 1986). In contrast, studies across the rural-suburban gradient in Banks Peninsula have shown a more sedentary population, with the majority of tagged birds remaining within the study sites due to the apparent year-round availability of both exotic and native food sources (Campbell 2006; Schotborgh 2005).

Studies conducted on kereru movements and home ranges have been limited to the use of radio-telemetry. Recent use of satellite telemetry has confirmed that kereru are capable of making much longer flights. In a study in Invercargill, three of the four tagged kereru made flights of up to $33 \mathrm{kms}$ over the Foveaux Strait to Stewart Island (Powlesland et al. 2011). These movements appear to have been related to the start of the breeding season (Powlesland et al. 2011).

Kereru are herbivorous (Higgins \& Davies 1996; McEwen 1978) and depend on fruit from native trees, but are also known to eat a high percentage of exotic plant species in modified habitats, such as cherry and plum trees (both Prunus spp) when the fruits of native trees are not available (Harwood 2002; Karan 2000). Fruits have also been observed to 
comprise up to $90 \%$ of the kereru diet in the Auckland region (Dijkgraaf 2002). The proportion of exotic and native species and food types in the kereru diet varies with local availability and regional changes in forest composition. In the northern city of Auckland, kereru were observed to frequently consume exotic species in the winter months (Harwood 2002; Karan 2000) whereas kereru in the southern city of Dunedin consumed a larger proportion of exotic species in the summer months (Dunn 1981). Previous studies have also shown foliage to comprise a large portion of kereru diet, supplemented occasionally by flowers (Clout et al. 1986; Dunn 1981).

Unlike other members of the Columbidae family, fruit doves like the kereru, lack crop stones which are used to grind up food. Thus, kereru play an important ecological role as arboreal frugivores because they do not damage the seeds of the fruits they eat and defecate them intact (Clout \& Tilley 1992; McEwen 1978; Wotton 2008). Thus, they are considered one of the most important seed dispersers of large fruited species in New Zealand's forests (Clout \& Hay 1989; Lee et al. 1991; Wotton 2007).

In 1921, kereru (and parea or Chatham Island pigeon; Hemiphaga chathamensis) were given the status of "protected threatened endemic" species under the Animal Protection and Game Act, and eventually attained absolute protection under the Wildlife Act 1953. In the decades that followed, although widespread and locally common, kereru were considered threatened due to illegal hunting, habitat degradation and poor reproductive success (Clout et al. 1995b). In recent years, kereru were removed from the threatened species list, most likely due to a decrease in mammalian predation pressure (Miskelly et al. 2008; Powlesland \& Miskelly 9 July 2008).

Urbanisation coupled with the introduction of mammalian competitors and predators, especially human-commensal species, have caused the decline of many native and endemic bird populations in New Zealand (Duncan \& Blackburn 2004; Miskelly et al. 2005; Norton \& 
Miller 2000). Despite this historically negative outlook, recent reports have shown a slow and steady increase in bird distribution and abundance in the Wellington Region, primarily due to the control of introduced mammals, plantings, and avian re-introductions into an urban predator-free wildlife sanctuary (Froude 2009; Miskelly et al. 2005; Moylan 2010).

Kereru appear to have slowly increased in numbers across New Zealand (26\% increase between OSNZ surveys from 1969-79 to 1994-04; Powlesland \& Miskelly 2008), most notably in urbanised landscapes such as Wellington City and its surrounds (Froude 2009; Moylan 2010). Kereru recovery may be due to the control of mammalian predators and competitors (Powlesland \& Miskelly 2008), as well as a reflection of the kereru's ability to adapt to and exploit novel suburban habitat. Since kereru are highly mobile and capable of flying long distances, yet remain sedentary for long periods of time at favoured food sources, it is reasonable to expect that habitat selection is occurring at multiple scales. However, little is known about how kereru select amongst urbanised habitat and even less is known about their behaviour. Further, kereru are frequently injured from car and window strikes in these habitats (Cousins 2010; Daglish 2005), yet their ability to recover and successfully behaviourally reintegrate among conspecifics following rehabilitation is still unknown. Finally, their iconic status and ecological, perhaps keystone, role in forest ecosystems make kereru an ideal focal species for involving people in their conservation for both the researcher (citizen science) and the public (education).

\section{Thesis aims and structure}

The overall aims of this thesis are: (1) to advance current knowledge of kereru ecology within urbanised landscapes and to explore the concept of kereru as an "urban adapted" or "matrix-sensitive" species, and (2) to examine the role of people in urban avian ecology, from the perspectives of both the researcher and the public. To achieve this, I integrated methodological approaches that span the disciplines of the biological and social 
sciences, compared competing models as hypotheses for kereru habitat selection across multiple spatial scales, and harnessed fortuitous opportunities provided by wildlife rehabilitation to study little known behaviours in kereru.

I begin in Chapter 2 with an examination of broad-scale (first-order selection; Johnson 1980) habitat selection patterns by kereru using a large citizen-generated sightings dataset. I applied an information-theoretic approach to compare competing models as hypotheses in order to determine whether kereru selected sites based upon historically important (or 'non-urban') predictors, or if human-modified features of the landscape were stronger determinants of selection and thus indicated potential urban adaptation.

In Chapter 3, I build upon this data by examining kereru habitat selection through a marked population at two finer scales: winter range and site selection (second- and thirdorder selection; Johnson 1980). I tested whether previous knowledge documenting habitat selection by kereru across varied habitat types also predicted habitat selection within an urbanised landscape. I applied the large body of existing research on kereru ecology in concert with my own hypotheses relating to modified features to develop a suite of candidate models. Taken together Chapters 2 and 3 provide some of the first data on habitat selection by kereru at multiple scales within an urbanised landscape, and provide insight into the kereru's status as an "urban adaptor" or "matrix sensitive" species.

During my field research many of the marked individuals I was tracking were injured and taken into rehabilitation centres. This presented a fortuitous opportunity to examine the the riskier side of urban living for kereru, as this environment is the cause of injuries not normally sustained in the wildlands. Rehabilitation also often occurs without any measure of outcomes and the conservation value of the exercise remains a source of debate among scientists and those who are concerned with animal welfare. Thus, in Chapter 4 I examined early post-release settlement behaviour of rehabilitated kereru within two variably urbanised 
landscapes. I assessed the effects of individual characteristics, rehabilitation experience, release characteristics and post-release experience as proximate measures of rehabilitation success.

Finally, I end in Chapter 5 with a study that integrated local school children into my field research as part of a conservation education program. I demonstrate how experience in local urban wildlife research can increase school children's awareness of nature within their own neighbourhood. I also discuss how environmental education programs can be enhanced through collaborations between local researchers and schools, and can contribute towards the creation of environmentally responsible and scientifically aware adults.

I conclude the thesis in Chapter 6 by presenting a synthesis of my main findings and discuss how well kereru fit within current definitions of an "urban adapted" or "matrix sensitive" species based upon their habitat selection and behaviour. My thesis highlights the need for urban wildlife research to include human dimensions, in concert with classical ecological approaches, to gain a 'bigger-picture' perspective of urban avian ecology.

This thesis is presented in the style of four separate research chapters that are formatted for submission to peer-review journals, followed by six appendices. This style inevitably results in some repetition, particularly in the methods and some of the introductory sections. However, the advantage of this style is that specific research questions can be addressed within a broader theme, and detail specific to each chapter (such as reference lists) are grouped for simplicity. 


\section{References}

Alberti, M., E. Botsford, and A. Cohen. 2001. Quantifying the urban gradient: Linking urban planning and ecology in J. M. Marzluff, R. Bowman, and R. Donnelly, editors. Avian ecology and conservation in an urbanizing world. . Kluwer Academic Publishers., Boston, MA, USA.

Alberti, M., J. M. Marzluff, E. Shulenberger, G. Bradley, C. Ryan, and C. Zumbrunnen. 2003. Integrating humans into ecology: opportunities and challenges for studying urban ecosystems. BioScience 53:1169-1179.

Allen, T. F. H., and T. B. Starr 1982. Hierarchy: perspectives for ecological complexity. University of Chicago Press, Chicago, IL.

Bayley, A., and R. Goodyear. 2001. New Zealand: An urban/rural profile. Statistics New Zealand. Powerpoint presentation available at: http://www.stats.govt.nz/browse_for_stats/people_and_communities/geographicareas/urban-rural-profile.aspx.

Bell, R. 1996. Seed dispersal by kereru (Hemiphaga novaeseelandiae) at Wenderholm Regional Park. Unpubl. M.Sc. thesis. University of Auckland.

Blair, R. B. 1996. Land use and avian species diversity along an urban gradient. Ecological Applications 6:506-519.

Blair, R. B. 2001. Birds and butterflies along urban gradients in two ecoregions of the U.S. Pages 33-56 in J. L. Lockwood, and M. L. McKinney, editors. Biotic Homogenization. , Norwell (MA): Kluwer.

Bonney, R., C. B. Cooper, J. Dickinson, S. Kelling, T. Phillips, K. V. Rosenberg, and J. Shirk. 2009. Citizen Science: A Developing Tool for Expanding Science Knowledge and Scientific Literacy. BioScience 59:977-984.

Brewer, C. 2002a. Conservation education partnerships in schoolyard laboratories: a call back to action. Conservation Biology 06:577-579.

Brewer, C. 2002b. Outreach and partnership programs for conservation education where endangered species conservation and research occur. Conservation Biology 16:4-6.

Butcher, G. S., M. R. Fuller, L. S. McAllister, and P. H. Geissler. 1990. An Evaluation of the Christmas Bird Count for Monitoring Population Trends of Selected Species. Wildlife Society Bulletin 18:129-134.

Campbell, K. L. 2006. A study of home ranges, movements, diet and habitat use of kereru (Hemiphaga novaeseelandiae) in the southeastern sector of Banks Peninsula, New Zealand. Unpubl. M.Sc. thesis. Lincoln University, New Zealand.

Caprio, E., I. Ellena, and A. Rolando. 2009. Assessing habitat/landscape predictors of bird diversity in managed deciduous forests: a seasonal and guild-based approach. Biodiversity and Conservation 18:1287-1303. 
Chace, J. F., and J. J. Walsh. 2006. Urban effects on native avifauna: a review. Landscape and Urban Planning 74:46-69.

Clergeau, P., J. Jokimaki, and J. P. L. Savard. 2001. Are urban bird communities influenced by the bird diversity of adjacent landscapes? Journal of Applied Ecology 38:11221134.

Clergeau, P., J. P. L. Savard, G. Mennechez, and G. Falardeau. 1998. Bird abundance and diversity along an urban-rural gradient: a comparative study between two cities on different continents. Condor 100:413-425.

Clout, M. N. 1990. The kereru and its forests. Birds International 2:10-19.

Clout, M. N., K. Denyer, R. E. James, and I. G. McFadden. 1995a. Breeding success of New Zealand pigeons (Hemiphaga novaeseelandiae) in relation to control of introduced mammals. New Zealand Journal of Ecology 19:209-212.

Clout, M. N., P. D. Gaze, J. R. Hay, and B. J. Karl. 1986. Habitat use and spring movements of New Zealand pigeons at Lake Rotoroa, Nelson Lakes National Park. Notornis 33:37-44.

Clout, M. N., and J. R. Hay. 1989. The importance of birds as browsers, pollinators and seed dispersers in New Zealand forests. New Zealand Journal of Ecology 12:27-33.

Clout, M. N., B. J. Karl, and P. D. Gaze. 1991. Seasonal movements of New Zealand pigeons from a lowland forest reserve. Notornis 38:37-47.

Clout, M. N., B. J. Karl, R. J. Pierce, and H. A. Robertson. 1995b. Breeding and survival of New-Zealand pigeons Hemiphaga novaeseelandiae. Ibis 137:264-271.

Clout, M. N., and J. A. V. Tilley. 1992. Germination of miro (Prumnopitys ferruginea) seeds after consumption by New Zealand pigeons (Hemiphaga novaeseelandiae). New Zealand Journal of Ecology 30:25-28.

Cooper, C. B., J. Dickinson, T. Phillips, and R. Bonney. 2007. Citizen science as a tool for conservation in residential ecosystems. Ecology and Society 12:11. [online] URL:http://www.ecologyandsociety.org/vol12/iss12/art11/.

Cousins, R. A. 2010. Kereru (Hemiphaga novaeseelandiae) - Impact injuries, morphometrics, moult and plumage. Unpubl. M.Sc. thesis. Massey University, New Zealand.

Czech, B., and P. R. Krausman. 1997. DIstribution and causation of species endangerment in the United States. Science 277:1116-1117.

Czech, B., P. R. Krausman, and P. K. Devers. 2000. Economic associations among causes of species endangerment in the United States. BioScience 50:593-601. 
Daglish, L. 2005. City pigeons : Kererū (Hemiphaga novaeseelandiae) in the urban Dunedin environment : abundance, habitat selection and rehabilitation outcomes. Unpubl. M.Sc. thesis. University of Otago.

Dijkgraaf, A. C. 2002. Phenology and frugivory of large-fruited species in northern New Zealand and the impacts of introduced mammals. Unpubl. Ph.D. thesis. University of Auckland, New Zealand.

Ditchkoff, S., S. Saalfeld, and C. Gibson. 2006. Animal behavior in urban ecosystems: Modifications due to human-induced stress. Urban Ecosystems 9:5-12.

Duncan, R. P., and T. M. Blackburn. 2004. Extinction and endemism in the New Zealand avifauna. Global Ecology and Biogeography 13:509-517.

Dunn, P. L. 1981. The feeding ecology of the New Zealand Pigeon. Unpubl. M.Sc. thesis. University of Otago, Degree.

Dunn, R. R., M. C. Gavin, M. C. Sanchez, and J. N. Solomon. 2006. The pigeon paradox: Dependance of global conservation on urban nature. Conservation Biology 20:18141816.

Evans, K. L., S. E. Newson, and K. J. Gaston. 2009. Habitat influences on urban avian assemblages. Ibis 151:19-39.

Evans, S., S. Dixon, and J. Heslop. 2006. Pupils' knowledge of birds: how good is it and where does it come from? School Science Review 88:93-98.

Fisman, L. 2005. The effects of local learning on environmental awareness in children: An empirical evaluation. The Journal of Environmental Education 36:39-50.

Flux, I. A., R. G. Powlesland, P. J. Dilks, and A. D. Grant. 2001. Breeding, survival, and recruitment of Chatham Island pigeon (Hemiphaga chathamensis). Notornis 48:197206.

Freeman, C., and O. Buck. 2003. Development of an ecological mapping methodology for urban area in New Zealand. Landscape and Urban Planning 63:161-173.

Froude, V. A. 2009. Changes in native forest bird distribution and abundance in Wellington City Council Reserves 2001-2009. Pacific EcoLogic Ltd, Bay of Islands, New Zealand.

Garden, J., C. McAlpine, A. Peterson, D. Jones, and H. Possingham. 2006. Review of the ecology of Australian urban fauna: A focus on spatially explicit processes. Austral Ecology 31:126-148.

Gill, B. J. 2006. Post-mortem examination of the New Zealand pigeons (Hemiphaga novaeseelandiae) from the Auckland area. New Zealand Journal of Zoology 33:31-37.

Goddard, M. A., A. J. Dougill, and T. G. Benton. 2009. Scaling up from gardens: biodiversity conservation in urban environments. Trends in Ecology \& Evolution 25:90-98. 
Grimm, N. B., J. Morgan Grove, S. T. A. Pickett, and C. L. Redman. 2000. Integrated Approaches to Long-TermStudies of Urban Ecological Systems. BioScience 50:571584.

Harwood, H. P. 2002. Seasonal availability and abundance of tree fruit species utilised by kukupaa (Hemiphaga novaeseelandiae). Unpubl. M.Sc. thesis. University of Auckland.

Heather, B., and H. Robertson 2005. The Field Guide to the Birds of New Zealand. Viking, Auckland.

Higgins, P. J., and S. J. J. F. Davies, editors. 1996. Handbook of Australian, New Zealand and Antarctic birds. Vol 3. Snipe to pigeons. Oxford University, Melbourne.

Hostetler, M. 2001. The importance of multi-scale analyses in avian habitat selection studies in urban environments in J. M. Marzluff, R. Bowman, and R. Donnelly, editors. Avian ecology and conservation in an urbanizing world. Kluwer Academic Publishers, Norwell, MA.

Hostetler, M., and C. S. Holling. 2000. Detecting the scales at which birds respond to structure in urban landscapes. Urban Ecosystems 4:25-54.

James, R. E. 1995. Breeding ecology of the New Zealand Pigeon at Wenderholm Regional Park, Unpubl. M.Sc. thesis. University of Auckland, New Zealand.

Johnson, D. H. 1980. The comparison of usage and availability measurements for evaluating resource preferences. Ecology 61:65-71.

Jokimaki, J., M. L. Kaisanlahti-Jokimaki, A. Sorace, E. Fernandez-Juricic, I. RodriguezPrieto, and M. D. Jimenez. 2005. Evaluation of the "safe nesting zone" hypothesis across an urban gradient: a multi-scale study. Ecography 28:59-70.

Karan, A. 2000. Diet of kereru in an urban area: implications for weed dispersal. Unpubl. M.Sc. thesis. University of Auckland.

Kotliar, N. B., and J. A. Wiens. 1990. Multiple scales of patchiness and patch structure: a hierarchical framework for the study of heterogeneity. Oikos 59:253-260.

Lee, W. G., M. N. Clout, H. A. Robertson, and J. Bastow Wilson. 1991. Avian dispersers and fleshy fruits in New Zealand. Proc. Int. Orn. Congr. XX:1617-1623.

Lerman, S. B., and P. S. Warren. 2011. The conservation value of residential yards: linking birds and people. Ecological Applications 21:1327-1339.

Loram, A., J. Tratalos, P. H. Warren, and K. J. Gaston. 2007. Urban domestic gardens (X): the extent and structure of the resource in five major cities. Landscape Ecology 22:601-615. 
Louv, R. 2005. Last child in the woods: saving our children from nature-deficit disorder. Viking, Penguin Books., Auckland, New Zealand.

Major, R. E., G. Gowing, and C. E. Kendal. 1996. Nest predation in Australian urban environments and the role of the pied currawong, Strepera graculina. Australian Journal of Ecology 21:399-409.

Mander, C., R. Hay, and R. Powlesland. 1998. Monitoring and management of kereru (Hemiphaga novaeseelandiae). Department of Conservation Technical Series No. 15, Wellington, New Zealand.

Marzluff, J. M., R. Bowman, and R. Donnelly, editors. 2001a. Avian ecology and conservation in an urbanizing world. Kluwer Academic Publishers, Boston, MA, USA.

Marzluff, J. M., R. Bowman, and R. Donnelly. 2001b. A historical perspective on urban bird research: trends, terms, and approaches in J. M. Marzluff, R. Bowman, and R. Donnelly, editors. Avian ecology and conservation in an urbanizing world. Kluwer Academic Publishers., Boston, MA, USA

Marzluff, J. M., and K. Ewing. 2001. Restoration of fragmented landscapes for the conservation of birds: A general framework and specific recommendations for urbanizing landscapes. Restoration Ecology 9:280-292.

Mathieu, R., C. Freeman, and J. Aryal. 2007. Mapping private gardens in urban areas using object-oriented techniques and very high-resolution satellite imagery. Landscape and Urban Planning 81:179-192.

Mayor, S. J., D. C. Schneider, J. A. Schaefer, and S. P. Mahoney. 2009. Habitat selection at multiple scales. Ecoscience 16:238-247.

McDonald-Madden, E., S. G. Schreiber, D. M. Forsyth, D. Choquenot, and T. F. Clancy. 2005. Factors affecting Grey-headed Flying-fox (Pteropus poliocephalus: Pteropodidae) foraging in the Melbourne metropolitan area, Australia. Austral Ecology 30:600-608.

McDonnell, M. J., and S. T. A. Pickett. 1990. Ecosystem Structure and Function along Urban-Rural Gradients: An Unexploited Opportunity for Ecology. Ecology 71:12321237.

McEwen, W. M. 1978. The food of the New Zealand pigeon (Hemiphaga novaeseelandiae novaeseelandiae). New Zealand Journal of Ecology 1:99-108.

McKinney, M. L. 2002. Urbanization, biodiversity, and conservation. Bioscience 52:883-890.

Miller, J. R. 2005. Biodiversity conservation and the extinction of experience. Trends in Ecology \& Evolution 20:430-434. 
Miller, J. R., J. M. Fraterrigo, N. T. Hobbs, D. M. Theobald, and J. A. Wiens. 2001 Urbanization, avian communities, and landscape ecology in J. M. Marzluff, R. Bowman, and R. Donnelly, editors. Avian ecology and conservation in an urbanizing world. Kluwer Academic Publishers, Norwell, MA.

Miskelly, C., R. Empson, and K. Wright. 2005. Forest birds recolonising Wellington. Notornis 52:21-26.

Miskelly, C. M., J. E. Dowding, G. P. Elliot, R. A. Hitchmough, R. G. Powlesland, H. A. Robertson, P. M. Sagar, R. P. Scofield, and G. A. Taylor. 2008. Conservation status of New Zealand Birds, 2008. Notornis 55:117-135.

Moylan, S. 2010. Native bird monitoring report (draft copy). Greater Wellington Regional Council.

National Audobon Society. 2012. Christmas Bird Count. Available at: http://birds.audobon.org/christmas-bird-count.

Norton, D. A., and C. J. Miller. 2000. Some issues and option for the conservation of native biodiversity in rural New Zealand. Ecological Management and Restoration 1:26-34.

O'Neill, R. V., D. L. Deangelis, J. B. Wade, and T. F. H. Allen 1986. A heirarchical concept of the ecosystem. Princeton University Press, Princeton, NJ.

Obaid, T. A. 2007. The State of the World Population 2007 - Unleashing the Potential of Urban Growth. United Nations Population Fund, New York.

Oliver, D. L., and G. W. Lollback. 2010. Breeding habitat selection by the endangered Regent Honeyeater Anthochaera phrygia (Meliphagidae) at the local and landscape scale. Pacific Conservation Biology 16:27-35.

Orr, D. W. 1989. Ecological literacy. Conservation Biology 3:334-335.

Ortega-Álvarez, R., and I. MacGregor-Fors. 2011. Dusting-off the file: A review of knowledge on urban ornithology in Latin America. Landscape and Urban Planning 101:1-10.

Ortega-Álvarez, R., and I. MacGregor-Fors. 2011. Living in the big city: Effects of urban land-use on bird community structure, diversity and composition. Landscape and Urban Planning 90:189-195.

Pearson, S. M. 1993. The spatial extent and relative influence of landscape-level factors on wintering bird populations. Landscape Ecology 8:3-18.

Powlesland, R. G., and C. M. Miskelly. 9 July 2008. Kereru status re-evaluated. Kereru News No. 65 [email newsletter]. Available at:

http://www.kererudiscovery.org.nz/news/kereru-news-archive/. 
Powlesland, R. G., L. R. Moran, and D. M. Wotton. 2011. Satellite tracking of kereru (Hemiphaga novaeseelandiae) in Southland, New Zealand: impacts, movements and home range. New Zealand Journal of Ecology 35:229-235.

Powlesland, R. G., D. E. Wills, A. C. L. August, and C. K. August. 2003. Effects of a 1080 operation on kaka and kereru survival and nesting success, Whirinaki Forest Park. New Zealand Journal of Ecology 27:125-137.

Pyle, R. M. 1978. The extinction of experience. Horticulture 56:64-67.

Robertson, C. J. R., P. Hyvonen, M. J. Fraser, and C. R. Pickard 2007. Atlas of bird distribution in New Zealand 1999-2004. The Ornithological Society of New Zealand, Inc., Wellington, New Zealand.

Savard, J. P. L., P. Clergeau, and G. Mennechez. 2000. Biodiversity concepts and urban ecosystems. Landscape and Urban Planning 48:131-142.

Schotborgh, H. M. 2005. An analysis of home ranges, movements, foods and breeding of kereru (Hemiphaga novaeseelandiae) in a rural-urban landscape on Banks Peninsula, New Zealand. Unpubl. M.Sc. thesis. Lincoln University, New Zealand.

Silvertown, J. 2009. A new dawn for citizen science. Trends in Ecology \& Evolution 24:467471.

Sobel, D. 1998. Mapmaking with Children: Sense-of-Place Education for the Elementary Years. Heinemann, Portsmouth, NH.

Statistics New Zealand. 2006. New Zealand: An Urban/Rural Profile Update. Available at: http://www.stats.govt.nz/browse_for_stats/people_and_communities/geographicareas/urban-rural-profile-update.aspx.

Sullivan, B. L., C. L. Wood, M. J. Iliff, R. E. Bonney, D. Fink, and S. Kelling. 2009. eBird: A citizen-based bird observation network in the biological sciences. Biological Conservation 142:2282-2292.

Tanner, T. 1980. Significant life experiences. The Journal of Environmental Education 11:2024.

Thorsen, M., J. Innes, G. Nugent, and K. Prime. 2004. Parental care and growth rates of New Zealand pigeon (Hemiphaga novaeseelandiae) nestlings. Notornis 51:136-140.

Tremblay, J. A., J. Ibarzabal, C. Dussault, and J.-P. L. Savard. 2009. Habitat requirements of breeding Black-backed woodpeckers (Picoides arcticus) in managed, unburned boreal forest. Avian Conservation and Ecology 4:[online] URL:

http://www.ace.eco.org/vol4/iss1/art2/.

Trumbull, D. J., R. Bonney, D. Bascom, and A. Cabral. 2000. Thinking scientifically during participation in a citizen-science project. Science Education 84:265-275. 
United Nations. 2007. World urbanization prospects: the 2007 revision population database. United Nations, New York. Available at: http://esa.un.org/unup/.

United Nations. 2011. World urbanization prospects: The 2011 Revision. United Nations, New York. Available at: http://esa.un.org/unpd/wup/Documentation/highlights.htm.

Vitousek, P. M., H. A. Mooney, and J. Lubchenco. 1997. Human domination of Earth's ecosystems. Science 277:494-499.

Wiens, J. A. 1989. Spatial scaling in ecology. Functional Ecology 3:385-397.

Wilson, E. O. 1984. Biophilia. Harvard University Press, Cambridge.

Wittig, R., D. Diesing, and M. Godde. 1985. Urbanophob, urbanoneutral, urbanophil behavior of species concerning the urban habitat. Flora 177:265-282.

Wotton, D. M. 2007. Consequences of dispersal failure: kereru and large seeds in New Zealand. University of Canterbury.

Wotton, D. M. 2008. Seed retention times in the New Zealand pigeon, Hemiphaga novaeseelandiae. New Zealand Journal of Ecology 32:1-6. 


\section{CHAPTER TWO}

\section{Using citizen science to investigate kereru habitat selection within an urbanised landscape}

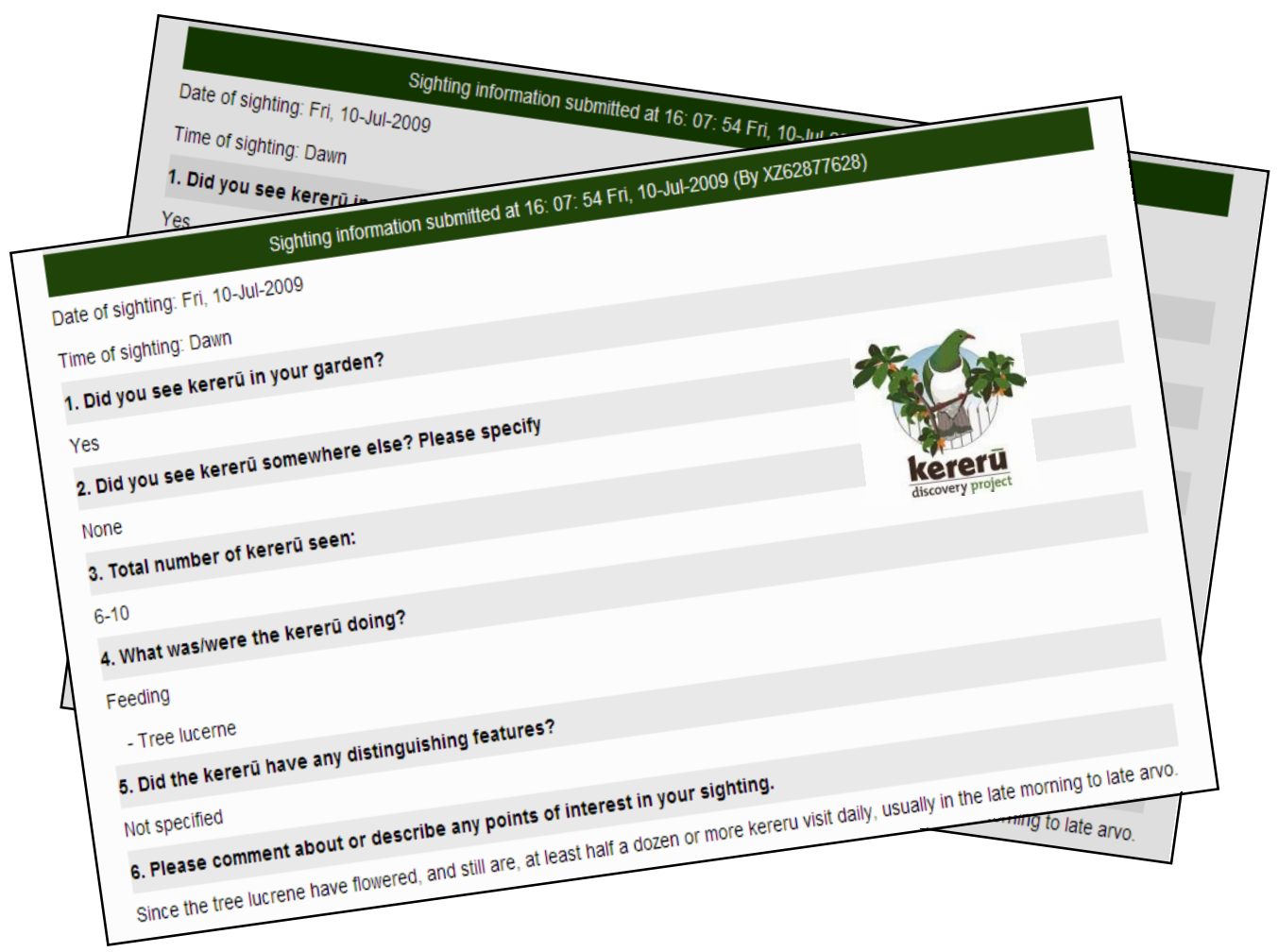

Kereru sighting forms and project logo from the Kereru Discovery Project website. Images taken from the researcher portal at: www.kererudiscovery.org.nz. 


\section{Abstract}

Monitoring wildlife in urban areas is an enormous logistical challenge, particularly given the inaccessibility of privately owned property. Researchers can overcome this obstacle by designing studies that mobilise the skills of citizens to collect data over large geographic areas, and utilise technological advances enhancing our ability to involve and communicate with citizens. In this study, I applied an online public sightings database to investigate firstorder habitat selection (regional scale) of a native bird in an urbanised landscape. Kereru (Hemiphaga novaeeslandiae; New Zealand Pigeon) are large-bodied, easily recognisable, fruit-eating pigeons that are widely dispersed, highly mobile and becoming more abundant in New Zealand's cities. A total of 843 sightings of kereru from 356 different locations throughout the Greater Wellington Region were received via the online platforms and through direct contact with the public over a five year period (2005-2009). I used aerial imagery and data in ArcGIS v.9.3 to test the historically important (or non-urban) and human-modified landscape features influencing kereru habitat choice. Within the sightings received across variably urbanised areas, kereru selected areas of medium road and building coverage. Surprisingly, kereru selected sites where possum (Trichosurus vulpecula) control was not being undertaken. These findings were explained by an interaction between possum control, building coverage and road density, whereby kereru selected areas with intermediate building and road densities when possum control was undertaken. This suggests that kereru may be shifting further into suburban areas when food competition with possums, and possibly even the threat of possums as predators, is absent. This study provides preliminary evidence for the importance of urban landscapes for kereru and highlights the value of citizen-generated data for studying avian habitat selection in urban areas. 


\section{Introduction}

Citizen science involves the participation of non-scientists in scientific research by integrating public outreach and scientific data collection (Cooper et al. 2007; Trumbull et al. 2000). There are many tangible benefits associated with involving citizens in scientific data collection. It allows researchers to obtain large datasets that cover extensive geographic areas that would be impossible to cover using traditional ecological techniques (Dickenson et al. 2010). Further, citizens can also provide fine-grained details about the composition and landscape structure of otherwise inaccessible private lands, since the information that people provide is usually from areas that they are familiar with (i.e. their homes; Wiersma 2010). Citizen science projects are also relatively inexpensive as they rely predominantly on the participation of volunteers. They also frequently employ web-based technology, which has significantly enhanced the ability for scientists to quickly disseminate and exchange information with the public and to collect data (Sullivan et al. 2009; Wiersma 2010). Thus, citizen science projects are often considered to be effective education and outreach tools that increase people's scientific literacy and awareness of the conservation issues associated with their surrounding neighbourhood (Brewer 2002; Trumbull et al. 2000).

While citizen science is emerging as valid and useful tool for ecology and conservation research, it is important to acknowledge that there are concerns among researchers regarding potential biases and inaccuracies in data collection by an untrained public. For example, people vary in their ability to correctly identify a species and accurately report field observations (Dickenson et al. 2010). Nevertheless, it is possible to address these issues conceptually and empirically through careful study design. For example, if no measure of observer skill is taken then it is critical to ensure that the amount of background knowledge required to participate in the study is simplified and standardized across participants (Dickenson et al. 2010). Further, if the study relies on the general public to volunteer their 
time, then it is recommended that the amount of effort required to participate in and complete tasks is kept as low as possible to ensure participants maintain interest in the activity (Dickenson et al. 2010).

Many of the advances in solving methodological issues in citizen science studies have come from avian research. As a result, citizen science has been particularly successful in advancing scientific knowledge in avian studies (Bonney et al. 2009 and the references therein; Sullivan et al. 2009). Specifically, citizen science studies of avian species have been successful in quantifying distributions, breeding, disease, and environmental effects (reviewed in Bonney et al. 2009). Interestingly, while birds are highly visible animals in many urban and suburban environments (Marzluff et al. 2001), very few citizen science projects consider avian habitat use within these landscapes, possibly due to concerns with biases in the density and distribution of citizens' sightings.

Urban areas are expanding rapidly around the world, with over $50 \%$ of people now living in or near cities (United Nations 2007, 2011; Obaid 2007), understanding the effects these environmental changes bring is fundamental to avian ecology. The process of urbanisation fragments the landscape by introducing exotic species, modifying landforms, and building causing habitat loss, extinctions (Goddard et al. 2009), and altering the composition of both flora and fauna. Nevertheless, urbanised landscapes now host an increasing variety of wildlife that was previously only associated with rural and undeveloped wildlands (Ditchkoff et al. 2006; Jokimaki et al. 2005). Whether the increase in wildlife within urban areas results from species response to predator avoidance or the introduction of novel food and water sources introduced on private lands remain largely unknown. Hence, quantifying wildlife response to the expansion of cities is the next big step in urban ecology.

The kereru (New Zealand pigeon, Hemiphaga novaeseelandiae) is a large-bodied, highly mobile, and easily recognisable fruit-eating pigeon endemic to New Zealand (Heather 
$\&$ Robertson 2005). Although once in nationwide decline, over the last 30 years kereru appear to have become more abundant across New Zealand (Powlesland \& Miskelly 2008), particularly in urbanised landscapes (e.g., Wellington; Froude 2009, Moylan 2010). This observed increase in numbers is suspected to be due in part to the large-scale decrease in pressure from mammalian predators (Powlesland and Miskelly 2008), and has led to a reclassification of the kereru's status as "not threatened" by the Department of Conservation (DOC; Miskelly et al. 2008). Introduced possums (Trichosurus vulpecula), rats (Rattus rattus L.) and mustelids (e.g. stoats; Mustela erminea, L.) greatly impact on kereru survival by competing for favoured food sources, depredating nests, and occasionally killing adults (Clout et al. 1995c; Prendergast 2006). Possums deplete the fruit supplies necessary for kereru to survive (Dijkgraaf 2002; Mander et al. 1998), and cause damage to mature native vegetation by defoliating trees (Nugent et al. 2001). Previous research has shown that kereru numbers increase and nesting success is significantly improved when mammalian pests are controlled (Clout et al. 1995a; James \& Clout 1996).

Kereru can display relatively sedentary behaviour for periods of weeks and even months. However, they are also capable of making long distance flights of over $10 \mathrm{~km}$ (Powlesland et al. 2011). Some of these movements occur seasonally and so are thought to be in response to the availability of favoured food sources (Clout et al. 1986; Hill 2003). In addition to playing a keystone role in the dispersal of native large-seeded trees (Clout \& Hay 1989), kereru are also known to make use of novel habitat and resources within the urban landscape (such as exotic plant species for food; Harwood 2002; Karan 2000), and thus appear to be well-adapted to human occupied and modified habitat. However, the factors affecting habitat selection of mobile native fauna in highly fragmented urbanised landscapes have seldom been quantified at large spatial scales. This is likely due to the logistical constraints in sampling across large areas within the urban setting. Citizen science is 
therefore ideally suited for research on the patterns of habitat use and selection at a broad, regional scale, particularly in urban areas. The kereru's seemingly increasing numbers in urban areas, visual conspicuousness and iconic status make it an ideal focal species for such a citizen science project. In this study, I applied a citizen-generated database to model habitat selection patterns by kereru within an urbanised landscape at a broad, regional scale (firstorder selection; Johnson 1980). Using the public sightings of kereru from within urban areas, I aimed to determine whether kereru selected these sites based upon historically important (or 'non-urban') predictors, or if human-modified features of the landscape were stronger determinants of selection and thus indicated potential urban adaptation.

\section{Methods}

\section{ENGAGING CITIZEN SCIENTISTS}

The data set was compiled from public reports of kereru within the Greater Wellington Region that were submitted through the Kereru Discovery Project (KDP) online sightings database from 2005-2009 (www.kererudiscovery.org.nz). KDP is a national initiative aimed at increasing kereru numbers in urban areas by improving biodiversity and wildlife conservation in resident's private property. Participants were recruited via project launches, national media releases, newsletters and marketing campaigns by each of the partnering organisations: Museum of New Zealand Te Papa Tongarewa, Wellington Zoo, Zealandia (formerly Karori Wildlife Sanctuary), Victoria University of Wellington, and Pukaha Mount Bruce National Wildlife Centre. Participants registered on the project website, where they gave their location in the form of a street address or public park name. Once recruited into the project, participants supplied unsolicited, ad lib sightings of kereru. Those participants who did not have access to a computer were invited to use a paper-version of the KDP data form and mail them to researchers. Additional sightings were submitted by the 
public through KDP partnering organisations, and directly to researchers via email and telephone.

\section{DEFINING USED AND AVAILABLE SITES}

Each report of a kereru that was submitted was considered a sighting, and each sighting could include single or multiple birds. Multiple sightings could be submitted over time from various locations, so that some participants continued to submit sightings from a single location (i.e., their home) while others submitted sightings from multiple locations (i.e., their homes and workplaces, schools, or local parks). Thus, the total number of kereru sightings in my final sample and the number of locations from which the sightings originated differed. However, to control for observer effort and reporting frequency, submissions from the same location were excluded from analyses, as were the total number birds reported in a given submission. Thus, my interest was solely in the locations from which kereru sightings originated and therefore constituted a presence-only dataset.

Each submitted kereru sighting was geocoded, or address matched, in ArcGIS v.9.3 by assigning latitude and longitude coordinates to street addresses in order to determine a geographic location. Since the geocoding process matches addresses to a reference database, problems can arise through inaccuracies in address submissions, such as misspelled or missing words in the addresses and multiple residences with the same address. These errors were apparent in some of the KDP website submissions, resulting in unmatched addresses. These unmatched addresses were considered by a second analysis that adjusted the matching options, such as decreasing the spelling sensitivity of the submitted address. To further ensure location accuracy and that no potentially valid submissions were excluded, uncertain results were individually manually coded. Final point locations from the kereru sightings that were successfully geocoded were defined as "used" sites. 
Since my interest was in examining patterns of habitat selection within the data derived from public sightings of kereru, I applied a stratified sampling design to generate a set of "available" sampling points that had the same spatial bias in distribution and density as the "used" sampling points for comparison using the Geospatial Modelling Environment platform (GME; Beyer 2010). To do this I first measured the distance between each used location and its nearest neighbour used location. I then selected a direction randomly from each used site and applied the distance between the nearest neighbouring used site to generate an equal number of available sites (Figure 1). Thus, available sites were a random sample of habitat with the same spatial bias imposed by citizen reporting of used sites (i.e., a stratified random sample).

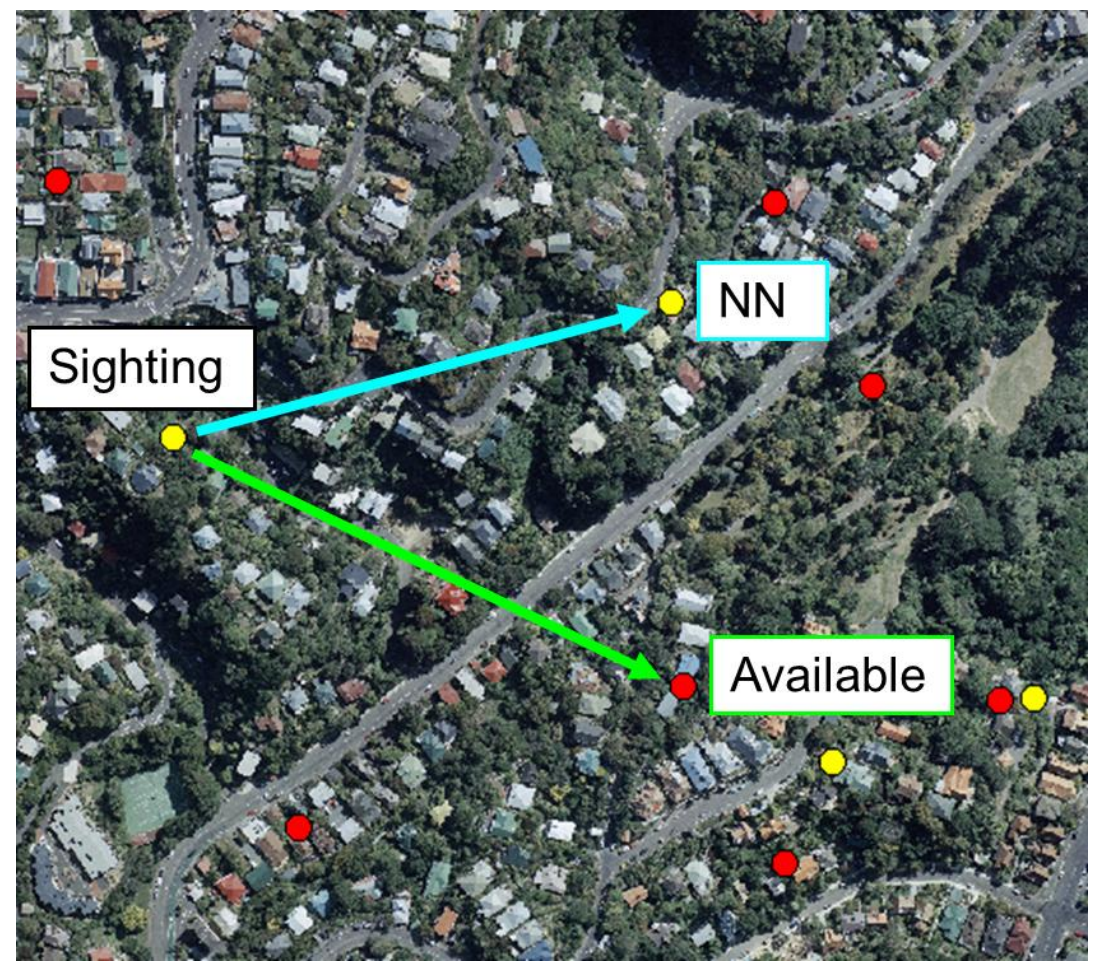

Figure 1. The stratified random sampling design used to derive a set of "available" sampling points that had the same spatial bias as the kereru sighting reports submitted by citizen scientists (i.e., the "used" sampling points). For each "used" kereru sighting location (yellow circles), an "available" site (red circles) was generated by using the distance to the nearest neighbouring used site (NN) and a random direction. 


\section{COMPILING PREDICTORS (FIXED-EFFECTS)}

For each sampling point, I quantified five predictor variables representing both natural and human-modified features of the landscape (Table 1) within a 20m point buffer using ArcGIS. These variables were chosen based upon the compilation of a priori candidate hypotheses which explored kereru habitat selection within urbanised landscapes (see next section). I chose a $20 \mathrm{~m}$ buffer distance for ecological as well as pragmatic reasons. Kereru are known to be relatively sedentary once a favoured food tree is found, often remaining within the same tree for days and thus unlikely to move more than $20 \mathrm{~m}$ between feeding and diurnal roosting locations (Pers. obs). In addition, a brief examination of the spread of kereru sighting locations on an aerial map indicated that the majority of reports originated from suburban areas (Figures $1 \& 2$ ). Given that a 20m observation radius likely captures the extent of a private suburban garden or surrounding neighbourhood, it is reasonable to assume that people reporting within this habitat type could make observations within this conservative buffer distance. 
Table 1. Predictor variables that were measured within a $20 \mathrm{~m}$ circular buffer from kereru sighting locations ("used") and stratified random point locations ("available"). All data were obtained using the ArcGIS 9.3 platform. Data on possum control areas was provided by Wellington City Council (WCC), Greater Wellington Regional Council (GWRC) and the Department of Conservation (DOC).

\begin{tabular}{lll}
\hline Variable & Units of measurement & Description \\
\hline Roads & Length $(\mathrm{m})$ & Total length of all roads measured along median line \\
Building cover & Area $\left(\mathrm{m}^{2}\right)$ & Total area of built structures \\
Possum control & Presence/absence & Possum control undertaken by WCC, GWRC, and DOC between 2005-2009 \\
Water & Presence/absence & Above-ground permanent water sources, such as rivers and ponds \\
Land cover type & LCDB2 classes* & Land cover database classifications from Land Care Research, New Zealand \\
\hline$*$ LCDB2 classifications are listed from the most historical cover type to the most modified cover type and include: (1) broadleaved indigenous \\
hardwoods, (2) indigenous forest, (3) other exotic forest and pine forest (closed canopy), (4) gorse and broom, (5) urban parkland/open space, \\
and (6) built-up area. A complete description of the land cover classes can be found at: http://www.mfe.govt.nz/issues/land/land-cover- \\
dbase/classes.html, and a User Guide at: http://www.mfe.govt.nz/issues/land/land-cover-dbase/lcdb2-user-guide.pdf [web addresses current as of \\
February 2012].
\end{tabular}




\section{STATISTICAL APPROACH \& COMPILING CANDIDATE MODELS}

I applied an Information-Theoretic (I-T) approach to compare models as competing hypotheses for habitat selection by kereru at a broad, regional scale within an urbanised landscape (i.e., first-order selection; Johnson 1980). The I-T approach works by first formulating a set of candidate models, and then selecting models to make inferences using an information criterion. The development of a set of a priori models assumes a level of careful thinking and hypothesis formulation. The I-T approach relies on current knowledge and thus is an advance on assuming nothing is known or that a null model is a useful comparison. TheI-T approach also allows for the comparison of multiple plausible models against each other. A priori models can prevent data mining, over-analysis, and the misuse of traditional multivariate analysis methods, all of which can lead to spurious relationships and Type II errors (Burnham \& Anderson 2002). Further, the ranking of the candidate models relative to each other, from useful to essentially useless, provides a quantitative measure of the plausibility and confidence in the "best" models given the data (Burnham \& Anderson 2002). In this way, the important effects may be teased apart by further examining the variables included within the "best" models. Model selection is well suited for making inferences from observational data in complex systems where experimental manipulation is not possible (Johnson \& Omland 2004).

I developed a set of ten candidate models to investigate kereru habitat selection that incorporated both the natural and human-modified features of the urban landscape. I began by constructing hypotheses that included various combinations of the landscape features that would have been historically important to kereru habitat-use: the type of land cover, the absence of mammalian competitors and predators (i.e., possums), and the presence of a water source (models $1 \& 2$; Table 2). Although natural features are important, it is also widely accepted that birds are strongly influenced by the process of urbanisation. However, the 
magnitude of these effects and whether they respond positively or negatively varies between species (Marzluff et al. 2001). I was interested in whether modifications to the landscape via urbanisation, such as the addition of built features and the introduction of mammalian pests, would predict habitat use by kereru and whether they positively (i.e. buildings as perch sites) or negatively (i.e. avoidance due to window or road strikes) responded to them. Thus, I considered the effects of impervious surfaces such as roads and buildings on their own (model 3), and together with possum control (model 4). Finally, I included five more models consisting of single predictors (models 5-9), and a global model which included all five predictors (model 10).

\section{STATISTICAL ANALYSIS}

The presence/absence of kereru was modelled using a logistic regression with a binomial response variable ( $0=$ available site, $1=$ used site) in the statistical program $\mathrm{R}$ ( $\mathrm{R}$ Core Development Team, 2010). I considered the five variables described above as explanatory covariates (fixed-effects) in my models (Table 1). Akaike's information criterion adjusted for small sample size (AICc; Burnham \& Anderson 2002) was then used to contrast and assess strength of evidence for competing models. The use of AIC in model selection provided not only a measure of the relative goodness-of-fit for each statistical model, but also included a penalty for the number of estimated parameters to avoid over-fitting (Burnham \& Anderson 2002). I selected the model with the smallest $\mathrm{AIC}_{\mathrm{c}}$ value as the best among the models being compared, where models within two $[\Delta \mathrm{AIC}]$ units of the best model were considered equally and most substantially supported, models within four to seven units received considerably less support, and greater than ten units essentially no support (Burnham \& Anderson 2002). I also examined the Akaike weights $\left(\omega_{\mathrm{i}}\right)$ to further quantify the plausibility of each model as being the best model given our data (Burnham \& Anderson 2002). 


\section{Results}

From October 2005- December 2009, a total of 557 people across New Zealand registered on the KDP website, of which 323 (58\%) were from the Greater Wellington Region. Of the 323 Wellington Region registrations, 298 (92\%) people submitted a kereru sighting at least once. Although some participants submitted sightings regularly from the same location, others submitted sightings from multiple locations. Thus, a total of 843 sightings of kereru from 356 different locations throughout the Greater Wellington Region were received via the online platforms and through direct contact with the public (Table 2). Interestingly, participants who registered with KDP were more likely to continue submitting sightings of kereru from the same location, than were those people who contributed sightings via other sources (Table 2). Of the 356 sighting locations that were submitted as street addresses, or as public green space, I successfully geocoded 319 locations for inclusion in the analysis (Figure 2).

Table 2. Summary of sightings data. Sightings submitted from "private land" included private properties such as home gardens/yards, schoolyards and sites within Zealandia (formerly Karori Wildlife Sanctuary - note that Zealandia undertakes regular and intensive mammalian pest control). Sightings submitted from "public land" included public greenspace such as local and regional parks, intact forests, or bushland managed by government agencies.

\begin{tabular}{lcccc}
\hline Source of sighting reports & $\begin{array}{l}\text { No. of sighting } \\
\text { reports } \\
\text { submitted } \\
\text { (n=843) }\end{array}$ & $\begin{array}{l}\text { No. of } \\
\text { sighting } \\
\text { locations } \\
(\mathrm{n}=356)\end{array}$ & $\begin{array}{l}\text { No. of sighting } \\
\text { locations from } \\
\text { private land } \\
\text { (n=292) }\end{array}$ & $\begin{array}{l}\text { No. of sighting } \\
\text { locations from } \\
\text { public land } \\
\text { (n=64) }\end{array}$ \\
\hline KDP online submissions (website) & $566(67 \%)$ & 126 & 104 & 22 \\
$\begin{array}{l}\text { KDP paper submissions (post) } \\
\text { Karori Sanctuary Trust online and } \\
\text { paper submissions }\end{array}$ & $145(17 \%)$ & 102 & 86 & 16 \\
$\begin{array}{l}\text { Direct submissions to partnering } \\
\text { organisations (email and phone) }\end{array}$ & $50(6 \%)$ & 78 & 64 & 14 \\
\hline
\end{tabular}




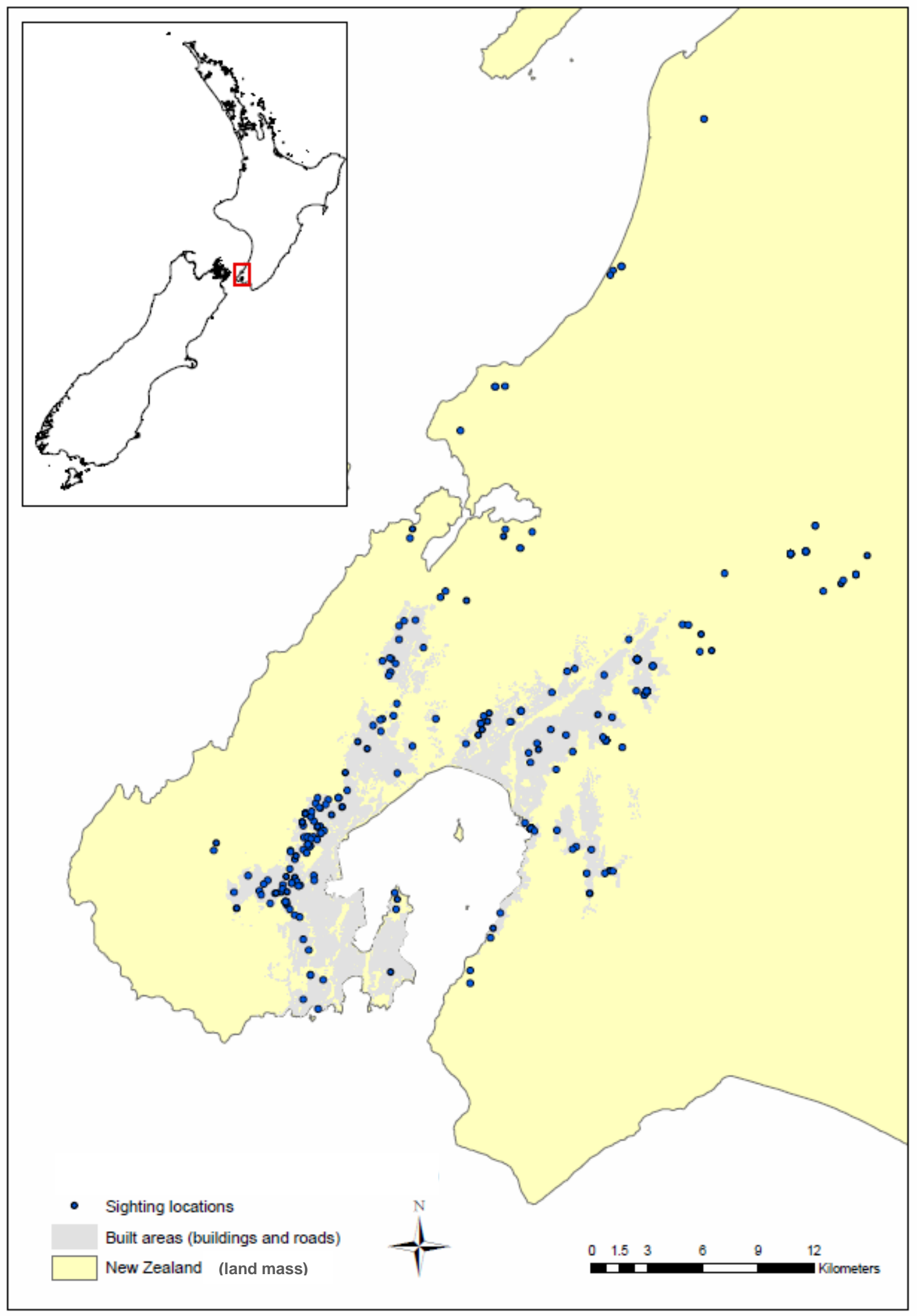

Figure 2. Map of 319 geocoded sighting locations of kereru (i.e., "used" sites) in the Greater Wellington Region that were included in habitat selection analysis. 
Only two hypotheses received substantial support and constituted the confidence set of models (i.e. $\left.\Delta \mathrm{AIC}_{\mathrm{c}}<2, \sum \omega_{\mathrm{i}}>0.95\right)$. These were the model that included roads, buildings and possum control as predictors ("Modified" $\Delta \mathrm{AIC}_{\mathrm{c}}=0, \omega_{\mathrm{i}}=0.67$; Table $3 \mathrm{~A}$ ), and the global model that included all five predictors ("Global” $\Delta \mathrm{AIC}_{\mathrm{c}}=1.49, \omega_{\mathrm{i}}=0.32$; Table $3 \mathrm{~A}$ ). Akaike weights suggested that models that included natural features (i.e., land cover and water) were implausible (i.e. $\Delta \mathrm{AIC}_{\mathrm{c}}>10, \sum \omega_{\mathrm{i}}<0.01$; Table $3 \mathrm{~A}$ ).

The greatest number of sampling points (both used and available sites) was within areas with less than $10 \mathrm{~m}$ of road coverage (Figure 3A). Kereru selected more sites within areas of intermediate gradients of road coverage (i.e., 0-40 m) than higher road densities (i.e., >41 m; Figure 3A). Likewise, kereru used more sites at medium building coverage (i.e., 200-600 $\mathrm{m}^{2}$ ) than at higher building densities (i.e., $>600 \mathrm{~m}^{2}$; Figure 3B). Contrary to my expectations, kereru were more likely to select habitat without possum control (Figure 3C). 
Table 3. Outcomes of the (A) ten candidate models for kereru habitat selection at the broad, regional scale (i.e., first-order selection; Johnson 1980), and (B) candidate model set including post-hoc analysis of the confidence set of models shown shaded in grey. The predictors included in each model, number of parameters $(\mathrm{K}), \mathrm{AIC}_{\mathrm{c}}$ values, $\mathrm{AIC}_{\mathrm{c}}$ differences $\left(\Delta_{\mathrm{i}}\right)$, and Akaike weight $\left(\omega_{\mathrm{i}}\right)$ are shown. The models are ranked from the smallest to largest $\mathrm{AIC}_{\mathrm{c}}$ value with the top two ranked "confidence set" of models (i.e. $\Delta \mathrm{AIC}_{\mathrm{c}}<2$ ) shown in bold.

\begin{tabular}{|c|c|c|c|c|c|c|}
\hline Model no. & Hypothesis, candidate set of models & Predictors (fixed-effects) & $\mathrm{K}$ & $\mathrm{AIC}_{\mathrm{c}}$ & $\Delta \mathrm{AIC}_{\mathrm{c}}$ & $\omega_{\mathrm{i}}$ \\
\hline 4 & Modified & Road + building + possum control & 4 & 840.63 & $\mathbf{0}$ & 0.67 \\
\hline 10 & Global model & Road + building + water + land cover + possum control & 10 & 842.13 & 1.49 & 0.32 \\
\hline 3 & Impervious surfaces & Road + building & 3 & 849.54 & 8.91 & 0.01 \\
\hline 6 & Buildings & Building & 2 & 857.91 & 17.27 & 0.00 \\
\hline 1 & Historical 1 & Land cover + possum control & 7 & 874.47 & 33.83 & 0.00 \\
\hline 2 & Historical 2 & Water + land cover + possum control & 8 & 875.74 & 35.11 & 0.00 \\
\hline 7 & Predation/Competition & Possum control & 2 & 876.21 & 35.57 & 0.00 \\
\hline 5 & Disturbance & Road & 2 & 876.81 & 36.17 & 0.00 \\
\hline 8 & Land cover & Land cover & 6 & 880.15 & 39.52 & 0.00 \\
\hline 9 & Water & Water & 2 & 884.55 & 43.91 & 0.00 \\
\hline Model no. & Hypotheses, including post-hoc models & Predictors (fixed-effects) & $\mathrm{K}$ & $\mathrm{AIC}_{\mathrm{c}}$ & $\Delta \mathrm{AIC}_{\mathrm{c}}$ & $\omega_{\mathrm{i}}$ \\
\hline & Post-hoc 1 & Road + building + possum control + building x possum control & 5 & 836.00 & 0 & 0.64 \\
\hline & Post-hoc 2 & Road + building + possum control + road x possum control & 5 & 837.70 & 1.70 & 0.27 \\
\hline 4 & Modified & Road + building + possum control & 4 & 840.63 & 4.63 & 0.06 \\
\hline 10 & Global model & Road + building + water + land cover + possum control & 10 & 842.13 & 6.13 & 0.03 \\
\hline 3 & Impervious surfaces & Road + building & 3 & 849.54 & 13.54 & 0.00 \\
\hline 6 & Buildings & Building & 2 & 857.91 & 21.90 & 0.00 \\
\hline 1 & Historical 1 & Land cover + possum control & 7 & 874.47 & 38.46 & 0.00 \\
\hline 2 & Historical 2 & Water + land cover + possum control & 8 & 875.74 & 39.74 & 0.00 \\
\hline 7 & Predation/Competition & Possum control & 2 & 876.21 & 40.20 & 0.00 \\
\hline 5 & Disturbance & Road & 2 & 876.81 & 40.80 & 0.00 \\
\hline 8 & Land cover & Land cover & 6 & 880.15 & 44.15 & 0.00 \\
\hline 9 & Water & Water & 2 & 884.55 & 48.54 & 0.00 \\
\hline
\end{tabular}


A.

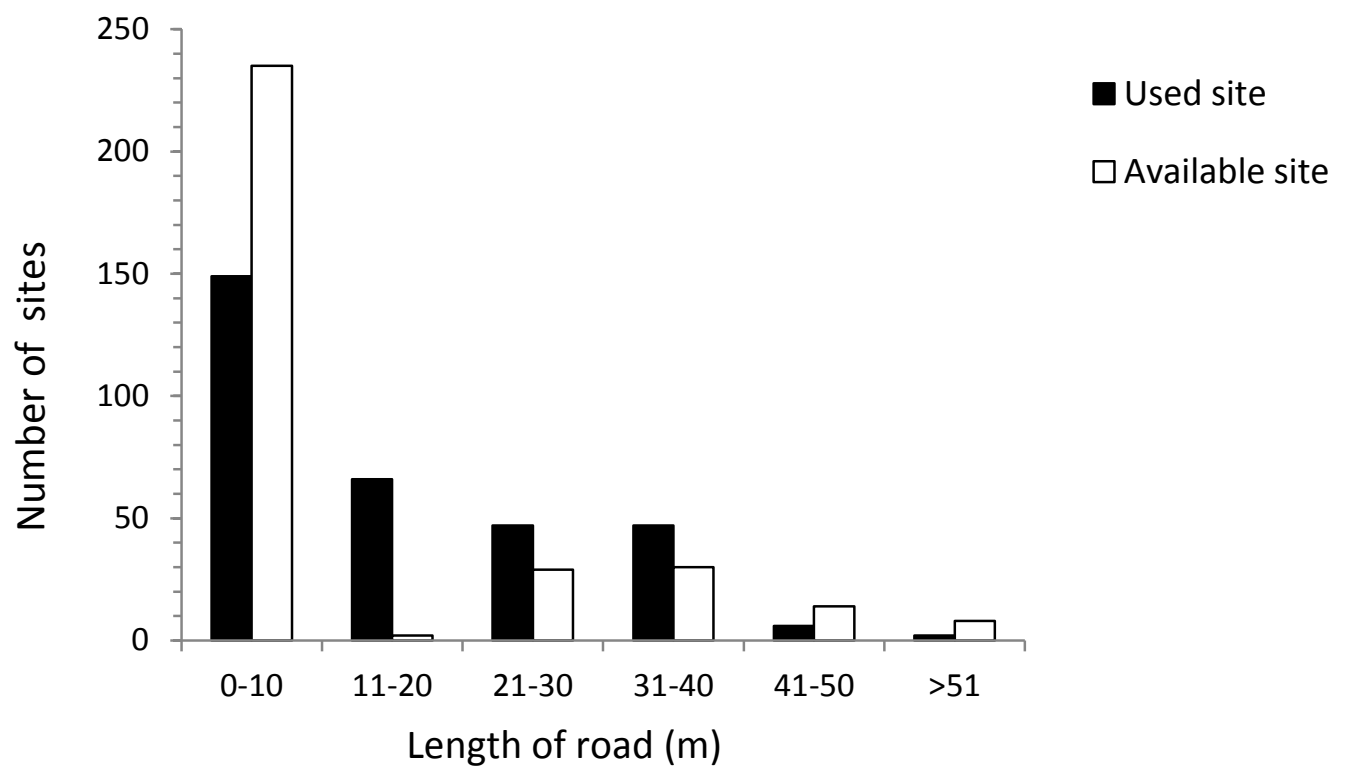

B.

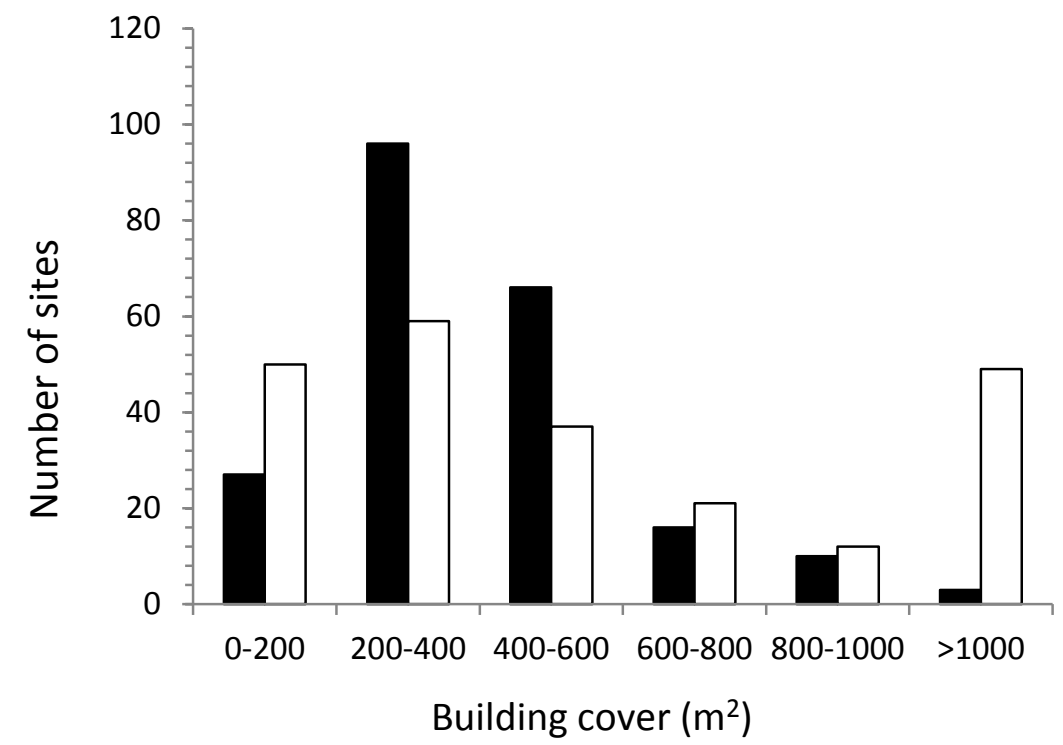

Used site

$\square$ Available site

C.

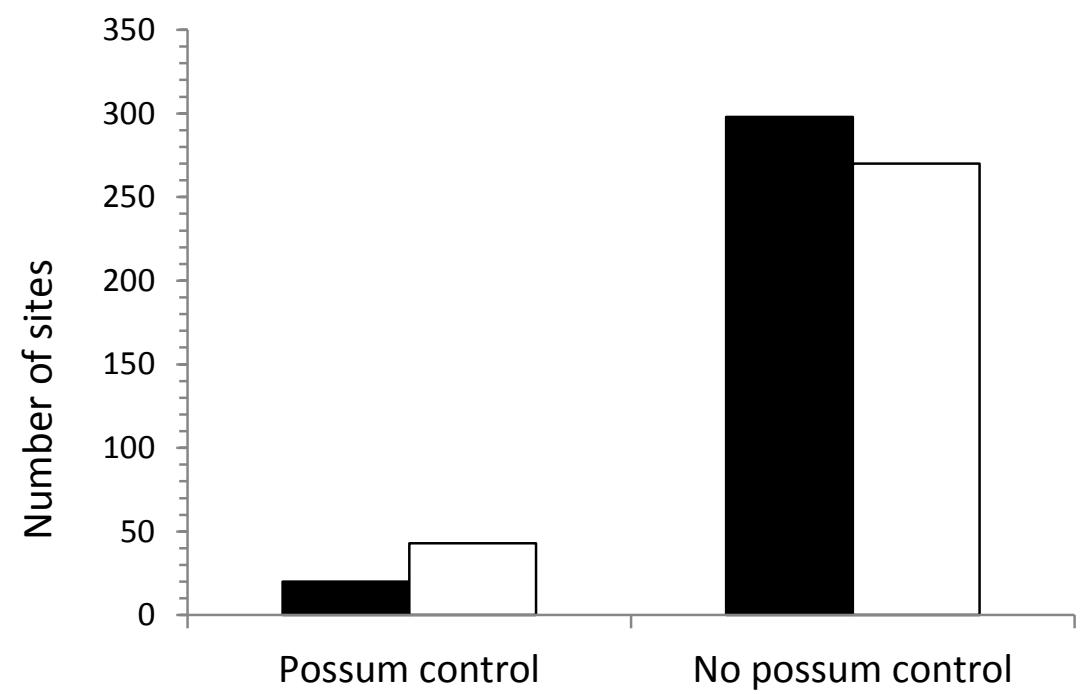

Figure 3. The number of used sites $(n=319)$ and available sites $(n=319)$ split by the variables (A) length of road $(\mathrm{m}),(\mathbf{B})$ area of building cover $\left(\mathrm{m}^{2}\right)$, and $(\mathbf{C})$ possum control areas. 
The results of my modelling suggested that there may have been interactions between the predictors in the modified landscape hypothesis. To further explore this relationship, I compared a second set of models that included two post-hoc models based upon my top "modified" model, which included interaction terms between possum control and buildings, and possum control and roads (Table 3B).

In this second set of models, the two post-hoc models improved substantially on the original confidence set of models from the first analysis ("Post-hoc 1 " $\Delta \mathrm{AIC}_{\mathrm{c}}=0, \omega_{\mathrm{i}}=0.64 \&$ "Post-hoc 2" $\Delta \mathrm{AIC}_{\mathrm{c}}=1.70, \omega_{\mathrm{i}}=0.27$; Table $\left.3 \mathrm{~B}\right)$. In areas in which possum control was undertaken, there were more likely to select sites at intermediate building densities (i.e. 400$600 \mathrm{~m} 2$; Figure 4A). Where possum control was not undertaken kereru selected sites at lower building densities (i.e. 0-200 $\mathrm{m}^{2}$; Figure 4B). The relationship between sampling locations, possum control and the density of roads followed a similar, albeit less pronounced, pattern to that observed for building coverage. In areas with possum control kereru selected sites in areas of intermediate levels of road coverage (i.e. $21-30 \mathrm{~m}$; Figure 5A), whereas in areas without possum control, kereru selected sites at intermediate road densities (i.e. 11-30m; Figure 5B). 
A.

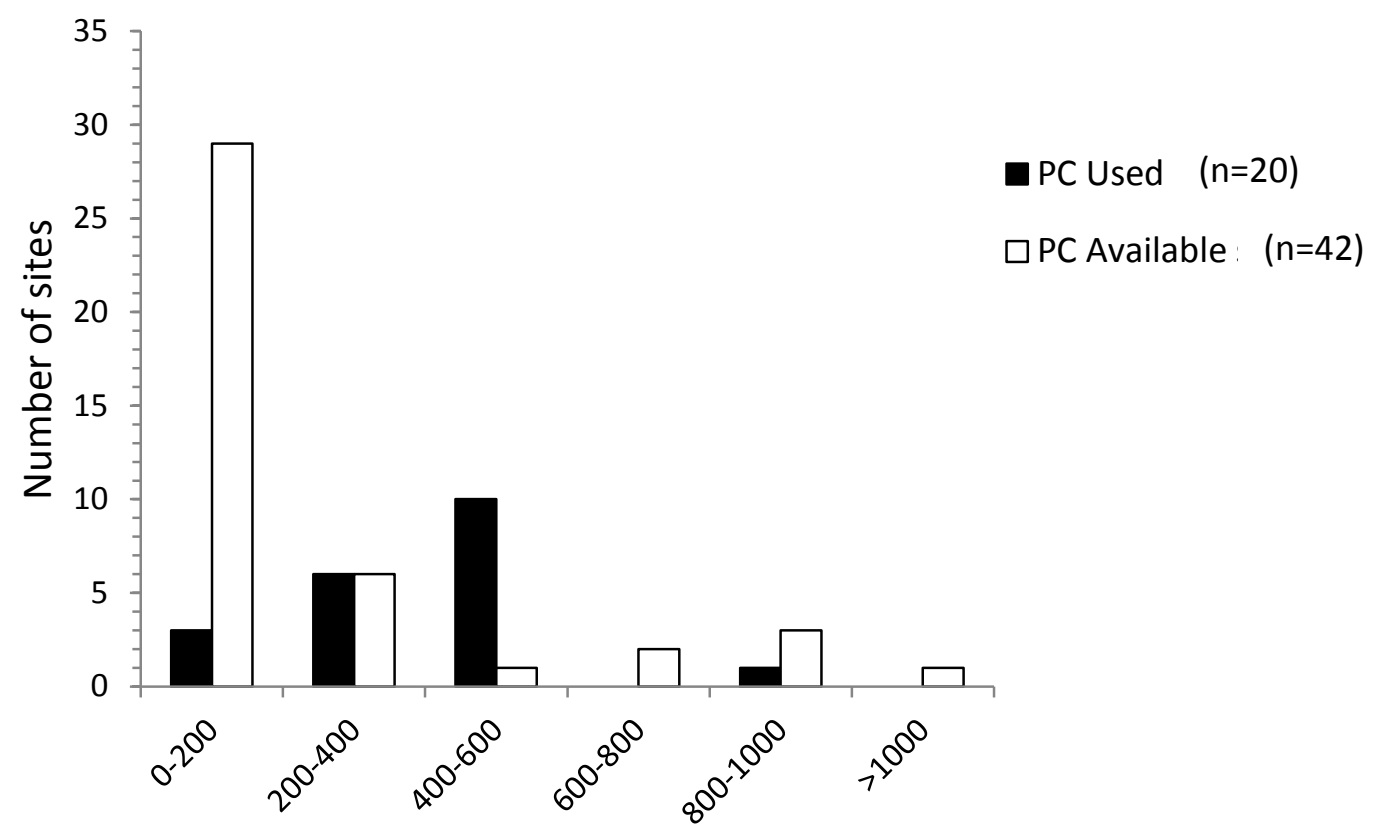

Building cover $\left(\mathrm{m}^{2}\right)$

B.

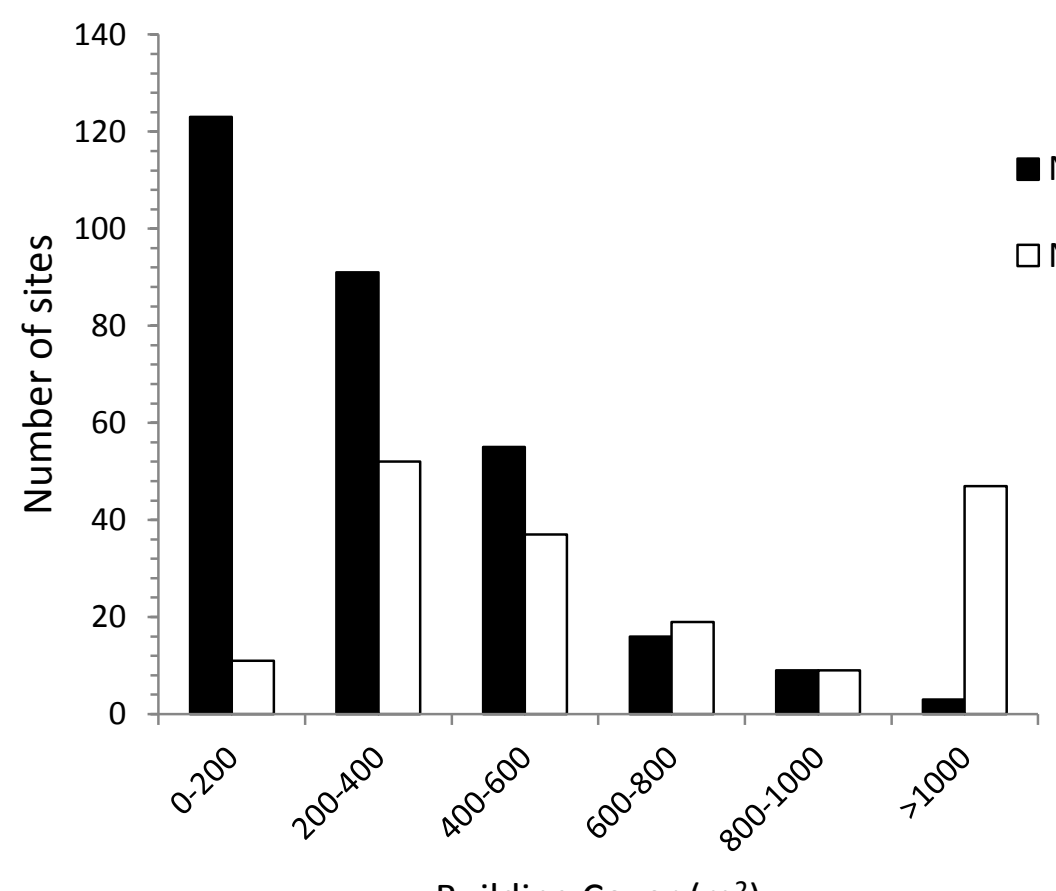

Building Cover $\left(\mathrm{m}^{2}\right)$

Figure 4. The number of used and available sites at various building densities, split by (A) possum control (PC), and (B) no possum control areas (NPC). 
A.

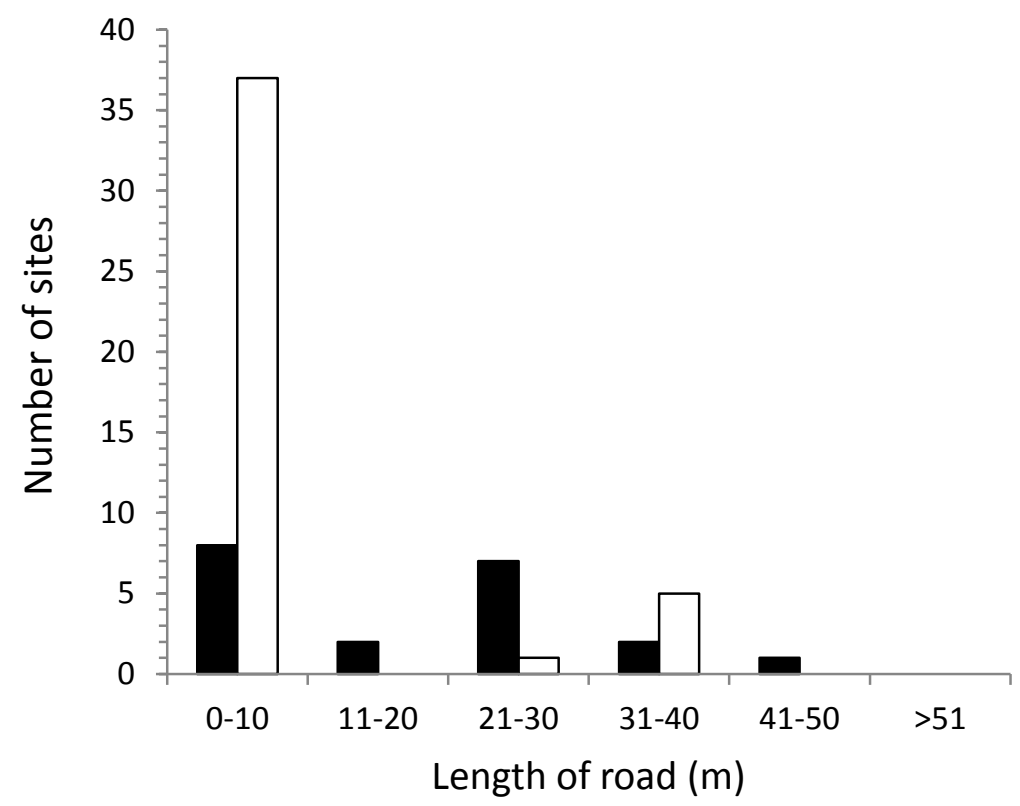

- PC Used $(n=20)$

$\square$ PC Available : $(n=43)$

B.

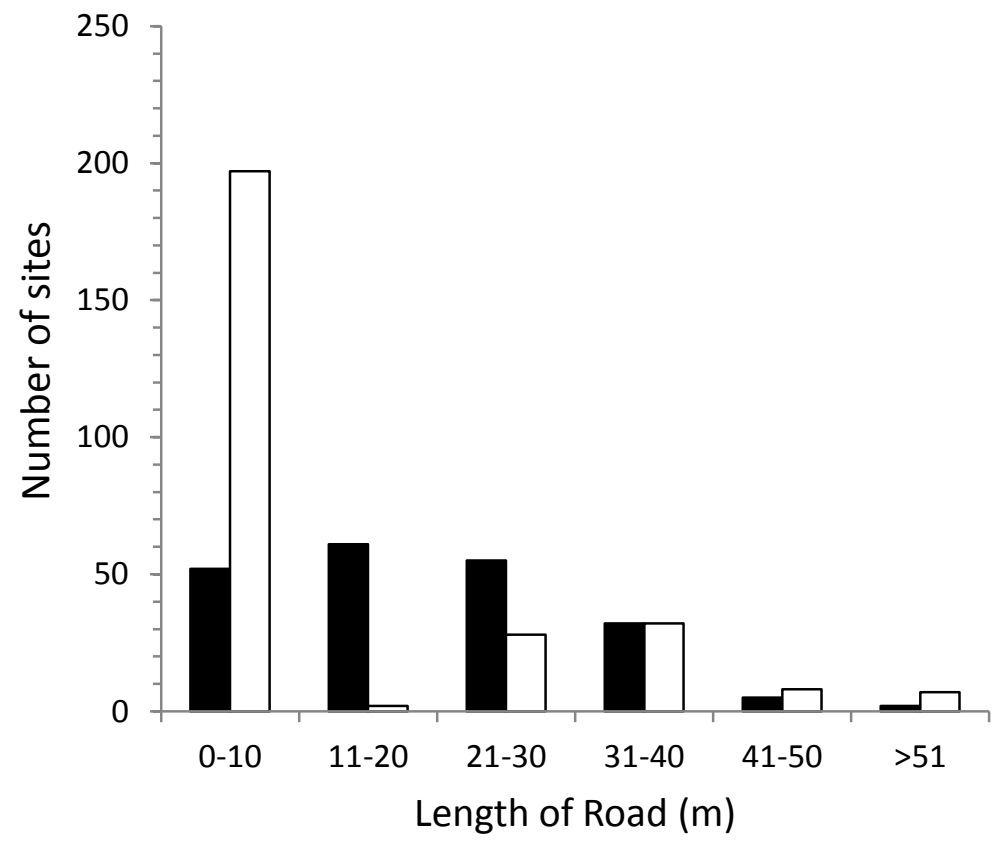

Figure 5. The number of used and available sites at various road lengths, split by (A) possum control (PC), and (B) no possum control areas (NPC). 


\section{Discussion}

In studies across the rural-urban gradient, peaks in avian species richness have been found in suburban areas, a finding that is often attributed to the intermediate disturbance hypothesis (McKinney 2002). This suburban habitat includes a mosaic of private gardens between managed parks, agriculture and other habitat types. Rather than viewing this landscape as habitat and resources that have been spatially segregated and fragmented by urban infrastructure, it may be more appropriate to view it as habitat and resources that have been perforated by urban infrastructure (i.e. a forest speckled with buildings and roads; Miller et al. 2001). This may be especially true for highly mobile avian species like kereru. In the present study, most of the kereru sightings came from suburban areas, within which the majority of these sightings were in areas characterised by intermediate building and road density. This may be because habitat heterogeneity is created by individual decisions made at the level of the landowner, such as plant cultivation that provides novel food sources (McKinney 2002; Muller \& Werner 2010). Kereru are known to consume exotic plants in urban areas when native species are seasonally unavailable (Harwood 2002). This modified suburban habitat, although not necessarily representative of historical or traditional kereru habitat, could thus be considered "suitably modified". This might explain why none of the models describing historically important habitat features received any support in model selection (i.e., models $1 \& 2$ ).

The first set of confidence models included modified features such as road and building coverage as well as whether or not possum control was being undertaken. Within the suburban landscape, kereru are frequently seen utilizing power lines, and even occasionally houses, as perching sites. Buildings and roads are a high source of mortality in birds (Cousins 2010; Klem Jr 2009), and window and car strikes are a particular problem for kereru (see Chapter 4). Interestingly, kereru do not appear to be avoiding these potentially hazardous 
features, possibly because many of their food resources are planted directly on the sides of roads and in between houses (pers. obs.). Indeed, areas of moderate building and road densities are the most favoured. Although site selection by kereru in urbanised areas appears to be driven by models that include modified features of the landscape, their responses to these features appear mixed.

Contrary to expectations, kereru were selecting more sites in areas without possum control measures than in areas with possum control. An examination of the locations from which the kereru sightings originated (Table 2) revealed that this was likely due to the majority of sighting locations originating from private gardens and possum control is largely undertaken on public lands. However, when possum control was analysed within the context of the density of impervious surfaces (buildings and roads), an interesting pattern emerged that could explain this finding. The modified model was strengthened when an interaction term between impervious surfaces and possum control was added. The selection of habitat without possum control may at first appear counter-intuitive, as it is well documented that the control of mammalian predators increases nesting success and feeding opportunities through the removal of competitors (Clout et al. 1995b; Dijkgraaf 2002; Innes et al. 2004; James \& Clout 1996; Powlesland et al. 2003). Possum control is largely undertaken in the un-built areas and intuitively one would predict that kereru would use these areas. However, in areas with possum control kereru were more often selecting sites at intermediate densities of buildings and roads, whereas in areas in which no possum control was being undertaken, kereru used more sites at lower densities of impervious surfaces. This suggests that where possum control is being undertaken there is a higher probability that a kereru will be sighted. These findings also reflect that kereru may be using suburban habitat when the threat of competition or food source depletion and possibly even predation were removed, and revert to the less built-up habitat when these threats were apparent. 
Overall, the evidence suggests that possum control is having the desired effect of improving the habitat for avian species by removing competitors and predators. This effect should also be understood in the context of habitat selection for highly mobile avian species such as kereru. The large-scale possum control undertaken by councils on public lands (i.e. reserves and parks) may be producing suburban safe-sites and improved feeding and roosting sites for kereru by reducing the overall density of possums across the region and buffering the built landscape. However, my modelling does not account for possible effects of humans and human-comensal species (e.g. cats) on the survival of kereru in urban settings. While the control of a human-introduced mammalian predator like the possum at the broad regional scale may be positively influencing habitat selection for suburban centres in kereru, there may also be negative effects at finer scales. Despite private gardens representing the largest single proportion of green space in many urban areas (Gaston et al 2005b from Mathieu et al 2007), very little is known about the cumulative effects of these individual parcels of land on the larger urban ecosystem. It is currently unknown whether or not any possum control was being undertaken on the private properties from which the sightings came. In fact, in my survey of $300 \mathrm{KDP}$ participants only $14.5 \%$ reported engaging in mammalian pest control on their private properties, the majority of which were rats and mustelids (Unpublished data). It will be important in future to collect detailed data on the behaviour of private land owners, as they relate to wider pest control measures, in order to determine if there is a cumulative effect on kereru habitat selection. 


\section{Conclusion}

Factors affecting the habitat-use of highly mobile native fauna across urbanised landscapes have seldom been quantified at large spatial scales. The sightings of kereru that I received online covered a spatial and temporal scale that far exceeded the geographic range a single researcher or even a small research team could have achieved. This allowed for patterns of kereru habitat selection to be examined at a broad regional scale (first-order selection; Johnson 1980). To my knowledge this is one of the first studies to attempt such an analysis. This may be due to concerns among researchers regarding the potential biases in the density and distribution in public sightings where data are collected opportunistically.

However, I was able to work within this bias by stratifying a random sample of available sites for comparison with the submitted sighting locations. This study therefore provides a strong case for the value of collaborations between scientists and volunteers to broaden the scope of research and enhance the ability to collect scientific data, especially in complex, humanoccupied habitats. However, to be truly effective in uncovering ecological patterns, it is recommended that citizen science be undertaken in concert with localized hypothesis driven research (Dickenson et al. 2010). Thus in Chapter 3, I further explore kereru habitat selection at a finer spatial scale (second- and third-order selection; Johnson 1980) during detailed fieldbased telemetry studies. 


\section{References}

Beyer, H. 2010. Geospatial Modelling Environment. Available at: http://www.spatialecology.com/gme.

Bonney, R., C. B. Cooper, J. Dickinson, S. Kelling, T. Phillips, K. V. Rosenberg, and J. Shirk. 2009. Citizen Science: A Developing Tool for Expanding Science Knowledge and Scientific Literacy. BioScience 59:977-984.

Brewer, C. 2002b. Outreach and partnership programs for conservation education where endangered species conservation and research occur. Conservation Biology 16:4-6.

Burnham, K. P., and D. R. Anderson 2002. Model selection and multimodel inference: A practical information-theoretic approach. Springer-Verlag, New York.

Clout, M. N., K. Denyer, R. E. James, and I. G. McFadden. 1995a. Breeding success of New Zealand pigeons (Hemiphaga novaeseelandiae) in relation to control of introduced mammals. New Zealand Journal of Ecology 19:209-212.

Clout, M. N., P. D. Gaze, J. R. Hay, and B. J. Karl. 1986. Habitat use and spring movements of New Zealand pigeons at Lake Rotoroa, Nelson Lakes National Park. Notornis 33:37-44.

Clout, M. N., and J. R. Hay. 1989. The importance of birds as browsers, pollinators and seed dispersers in New Zealand forests. New Zealand Journal of Ecology 12:27-33.

Clout, M. N., B. J. Karl, R. J. Pierce, and H. A. Robertson. 1995c. Breeding and survival of New Zealand pigeons (Hemiphaga novaeseelandiae). Ibis 137:264-271.

Cooper, C. B., J. Dickinson, T. Phillips, and R. Bonney. 2007. Citizen science as a tool for conservation in residential ecosystems. Ecology and Society 12:11. [online] URL:http://www.ecologyandsociety.org/vol12/iss12/art11/.

Cousins, R. A. 2010. Kereru (Hemiphaga novaeseelandiae) - Impact injuries, morphometrics, moult and plumage. Unpubl. M.Sc. thesis. Massey University, New Zealand.

Dickenson, J. L., B. Zuckerberg, and D. N. Bonter. 2010. Citizen science as an ecological research tool: challenges and benefits. Annual Review of Ecology and Systematics 41:149-172.

Dijkgraaf, A. C. 2002. Phenology and frugivory of large-fruited species in northern New Zealand and the impacts of introduced mammals. Unpubl. Ph.D. thesis. University of Auckland, New Zealand.

Ditchkoff, S., S. Saalfeld, and C. Gibson. 2006. Animal behavior in urban ecosystems: Modifications due to human-induced stress. Urban Ecosystems 9:5-12.

Froude, V. A. 2009. Changes in native forest bird distribution and abundance in Wellington City Council Reserves 2001-2009. Pacific EcoLogic Ltd, Bay of Islands, New Zealand. 
Goddard, M. A., A. J. Dougill, and T. G. Benton. 2009. Scaling up from gardens: biodiversity conservation in urban environments. Trends in Ecology \& Evolution 25:90-98.

Harwood, H. P. 2002. Seasonal availability and abundance of tree fruit species utilised by kukupaa (Hemiphaga novaeseelandiae). Unpubl. M.Sc. thesis. University of Auckland.

Heather, B., and H. Robertson 2005. The Field Guide to the Birds of New Zealand. Viking, Auckland.

Hill, M. T. 2003. Diet, dispersal and distribution of kereru (Hemiphaga novaeseelandiae) in a lowland podocarp-hardwood forest. Unpubl. M.Sc. thesis. Massey University.

Innes, J., G. Nugent, K. Prime, and E. B. Spurr. 2004. Responses of kukupa (Hemiphaga novaeseelandiae) and other birds to mammal pest control at Motatau, Northland. New Zealand Journal of Ecology 28:73-81.

James, R. E., and M. N. Clout. 1996. Nesting success of New Zealand Pigeons (Hemiphaga novaeseelandiae) in response to a rat (rattus rattus) poisoning programme at Wenderholm Regional Park. New Zealand Journal of Ecology 20:45-51.

Johnson, D. H. 1980. The comparison of usage and availability measurements for evaluating resource preferences. Ecology 61:65-71.

Johnson, J. B., and K. S. Omland. 2004. Model selection in ecology and evolution. Trends in Ecology \& Evolution 19:101-108.

Jokimaki, J., M. L. Kaisanlahti-Jokimaki, A. Sorace, E. Fernandez-Juricic, I. RodriguezPrieto, and M. D. Jimenez. 2005. Evaluation of the "safe nesting zone" hypothesis across an urban gradient: a multi-scale study. Ecography 28:59-70.

Karan, A. 2000. Diet of kereru in an urban area: implications for weed dispersal. Unpubl. M.Sc. thesis. University of Auckland.

Klem Jr, D. 2009. Preventing Bird-Window Collisions. The Wilson Journal of Ornithology 121:314-321.

Mander, C., R. Hay, and R. Powlesland. 1998. Monitoring and management of kereru (Hemiphaga novaeseelandiae). Department of Conservation Technical Series No. 15, Wellington, New Zealand.

Marzluff, J. M., R. Bowman, and R. Donnelly, editors. 2001. Avian ecology and conservation in an urbanizing world. Kluwer Academic Publishers, Boston, MA, USA.

McKinney, M. L. 2002. Urbanization, biodiversity, and conservation. Bioscience 52:883-890. 
Miller, J. R., J. M. Fraterrigo, N. T. Hobbs, D. M. Theobald, and J. A. Wiens. 2001 Urbanization, avian communities, and landscape ecology in J. M. Marzluff, R. Bowman, and R. Donnelly, editors. Avian ecology and conservation in an urbanizing world. Kluwer Academic Publishers, Norwell, MA.

Miskelly, C. M., J. E. Dowding, G. P. Elliot, R. A. Hitchmough, R. G. Powlesland, H. A. Robertson, P. M. Sagar, R. P. Scofield, and G. A. Taylor. 2008. Conservation status of New Zealand Birds, 2008. Notornis 55:117-135.

Moylan, S. 2010. Native bird monitoring report (draft copy). Greater Wellington Regional Council.

Muller, N., and P. Werner 2010. Urban biodiversity and the case for implementing the convention on biological diversity in towns and cities. In Urban Biodiversity and Design, eds. Muller, N., Werner, P., and Kelcey, J.G. Wiley-Blackwell, Oxford.

Nugent, G., W. Fraser, and P. Sweetapple. 2001. Top down or bottom up? Comparing the impacts of introduced arboreal possums and 'terrestrial' ruminants on native forests in New Zealand. Biological Conservation 99:65-79.

Obaid, T. A. 2007. The State of the World Population 2007 - Unleashing the Potential of Urban Growth. United Nations Population Fund, New York.

Powlesland, R. G., and C. M. Miskelly. 9 July 2008. Kereru status re-evaluated. Kereru News No. 65 [email newsletter].

Powlesland, R. G., L. R. Moran, and D. M. Wotton. 2011. Satellite tracking of kereru (Hemiphaga novaeseelandiae) in Southland, New Zealand: impacts, movements and home range. New Zealand Journal of Ecology 35:229-235.

Powlesland, R. G., D. E. Wills, A. C. L. August, and C. K. August. 2003. Effects of a 1080 operation on kaka and kereru survival and nesting success, Whirinaki Forest Park. New Zealand Journal of Ecology 27:125-137.

Prendergast, S. T. 2006. The impact of predation on the kereru (Hemiphaga novaeseelandiae) on Banks Peninsula. Unpubl. M.Sc. thesis. Lincoln University, New Zealand.

R Development Core Team. 2010. R: A Language and Environment for Statistical Computing. R Foundation for Statistical Computing, Vienna, Austria. Available at: http://www.R-project.org/.

Sullivan, B. L., C. L. Wood, M. J. Iliff, R. E. Bonney, D. Fink, and S. Kelling. 2009. eBird: A citizen-based bird observation network in the biological sciences. Biological Conservation 142:2282-2292.

Trumbull, D. J., R. Bonney, D. Bascom, and A. Cabral. 2000. Thinking scientifically during participation in a citizen-science project. Science Education 84:265-275.

United Nations. 2007. World urbanization prospects: the 2007 revision population database. United Nations, New York: Available at: http://esa.un.org/unup/. 
United Nations. 2011. World urbanization prospects: The 2011 Revision. United Nations, New York. Available at: http://esa.un.org/unpd/wup/Documentation/highlights.htm.

Wiersma, Y. F. 2010. Birding 2.0: citizen science and effective monitoring in the Web 2.0 world. Avian Conservation and Ecology 5:13 [online] URL: http://www.aceeco.org/vol15/iss12/art13/. 


\section{CHAPTER THREE}

\section{Multi-scale habitat selection by wild kereru in a suburban ecosystem}

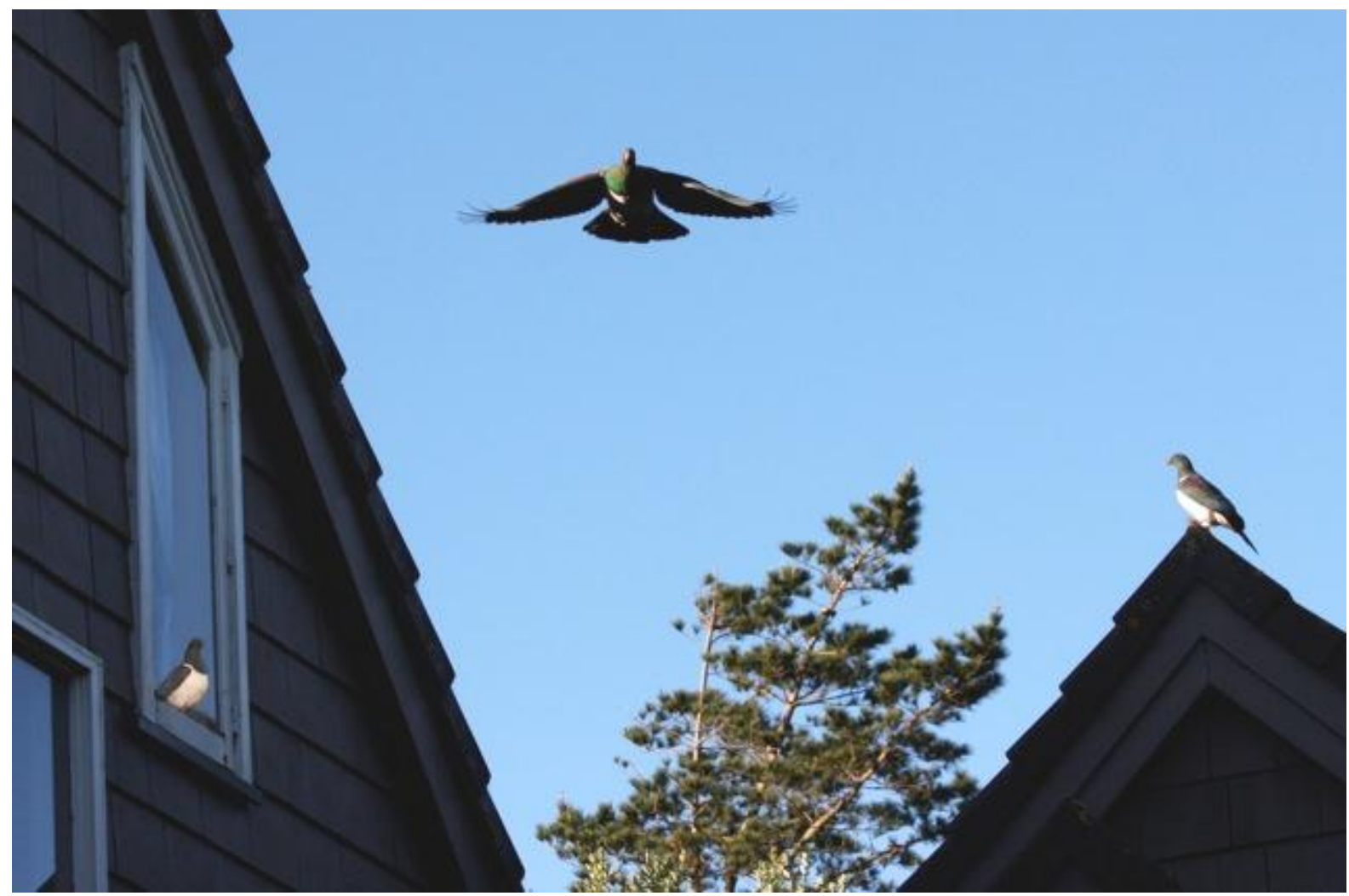

Wild kereru using residential housing as perching areas in Plimmerton. Photo by Taffy Perry. 


\section{Abstract}

The factors affecting avian habitat selection within urbanised landscapes have seldom been quantified at multiple spatial scales. In this study, I examined two scales of habitat selection by a marked group of kereru (New Zealand pigeon, Hemiphaga novaseelandiae) in a suburban area of Wellington, New Zealand. I applied an Information-Theoretic approach to compare 18 a priori hypotheses based upon previous studies of kereru ecology and my own predictions. At the second-order of selection (ranges within the landscape), there was considerable variation in winter range sizes among individual birds. The only model that was supported included the random effect for individual kereru, and no other predictors. For thirdorder selection (sites within the ranges), native vegetation, the presence of conspecifics and predators strongly influenced the sites selected within winter ranges. These results demonstrate that habitat selection for kereru within modified landscapes is occurring at a fine, rather than broad scale. This suggests that kereru are successful in urbanised areas because they are able to exploit necessary resources despite the high levels of habitat fragmentation. My study highlights the importance of examining avian habitat selection at multiple scales within complex, fragmented urban landscapes. Given that urbanisation continues to increase globally, understanding the scales at which birds select habitats will improve our ability to predict how they will respond to and survive within human modified landscapes. 


\section{Introduction}

An often overlooked problem in urban ecology is understanding how landscape change that is made at one spatial scale, might alter the response of animals at differing scales. Here, I adopt Hostetler's (2001) use of the term response to mean the ability of an animal to utilise structural objects in a landscape. Animals perceive and respond to habitat structure at varying scales in a spatial hierarchy (Hostetler 2001; Hostetler \& Holling 2000; Kotliar \& Wiens 1990). Hierarchy theory divides complex ecosystems into discrete, ranked levels of organisation (Allen \& Starr 1982; O'Neill et al. 1986). Simply defined, the largest area in which an organism responds to habitat structure is the spatial extent, whereas the minimum resolution at which an organism responds to objects in a landscape is the spatial grain (Kotliar \& Wiens 1990; Wiens 1989). Often, the terms micro-habitat, macro-habitat, fine scale, course scale, local level, and landscape level are also used to describe spatial resolution (Oliver \& Lollback 2010; Tremblay et al. 2009). Johnson (1980) described the following hierarchical levels of selection between grain and extent, where higher order selections are contingent upon lower order ones. First-order selection is the selection of a tract of landscape within a region. Second-order selection is the selection of a home range area, wintering area, or stop-over site within the landscape. Third-order selection is the usage of various patches within the area. Fourth-order selection is the actual procurement of food items within a habitat patch. Given that habitat selection occurs at multiple scales, the variability in habitat types across the urban landscape may elicit differing responses by birds. However, for the most part avian studies have focussed upon single scales of selection (Hostetler 2001; Hostetler \& Holling 2000).

Urbanised landscapes are dominated by buildings, roads and other paved areas, that are interspersed with "green" space such as parks, gardens and remnant patches of forest (Garden et al. 2006; McDonnell \& Pickett 1990). This landscape may at first appear to be 
highly fragmented. However, Miller et al (2001 ) introduced a new way of thinking about fragmentation and patchiness in urban matrices, where often the effects of human settlement represent more of a "perforation" of landscapes rather than fragmentation. Fragmentation typically results in the large-scale conversion of land-cover types and discrete habitat patches surrounded by a highly-altered matrix, whereas perforation results in a landscape speckled with disturbance points, such as individual houses or clustered developments. These types of areas are typically attributed to suburban or exurban areas, where development and population growth are greatest (United Nations 2007, 2011). Heterogeneity is further created at a finer scale as many of the decisions regarding habitat structure are being made at the level of the landowner, that is, habitat on private lands is being micro-managed. Birds may thus be responding to this habitat at multiple scales. For example, landscape cues used to establish suitable breeding territories may differ from those used to select a feeding site (Hostetler 2001). Multi-scale analysis is therefore particularly important to understanding habitat selection within urbanised landscapes.

The kereru (New Zealand pigeon, Hemiphaga novaeseelandiae) is a large-bodied, highly mobile, fruit-eating pigeon that disperses the larger seeds of many native trees and so plays an important role in New Zealand's forest ecosystems (Heather \& Robertson 2005; Mander et al. 1998). In recent years kereru have become more abundant in New Zealand's urban landscapes and have been recently re-classified as "not threatened" by the Department of Conservation (DOC; Miskelly et al. 2008). This is likely the result of a decrease in pressure from mammalian predators (Powlesland \& Miskelly 9 July 2008). However, it may also reflect the kereru's ability to adapt and make use of novel habitat and resources within the urban landscape (such as exotic plant species for food and nesting; Harwood 2002; Karan 2000). Although relatively sedentary for periods of weeks and even months, kereru are capable of making long distance flights of over $10 \mathrm{~km}$ between sites (Powlesland et al. 2011), 
often in response to the availability of favoured food sources (Clout et al. 1986; Hill 2003). Thus, kereru may be responding to different urban landscape structures at varying spatial scales.

In Chapter Two, I applied a citizen-generated dataset to examine first-order habitat selection (regional; Johnson 1980) by kereru within an urbanised landscape. Possum (Trichosurus vulpecula) control carried out at the broad regional scale was shown to be related to habitat selection so that kereru were selecting sites of intermediate building and road cover when in areas in which possum control was being undertaken. However, in areas without possum control kereru were selecting sites at lower building and road coverage. While these findings suggest that kereru may shift into suburban landscapes when the threat of predators is absent, it is important to note that this effect was observed within areas where kereru are reportedly seen by the public at the regional first-order level of habitat selection. There may be differences in habitat selection at finer resolutions. For example, at the home range scale kereru may be selecting sites as they relate to the presence or absence of possums. In contrast, at the site level kereru habitat selection may be strongly influenced by variability in the availability of preferred food sources as a result of individual garden management on private properties. Further, given the high mobility of kereru, site selection could be more important than the range as birds can fly over less desirable habitat. To this end, in this chapter I examine habitat selection by kereru at two further spatial scales: second-order selection (winter ranges within the landscape), and third-order selection (site selection within individual ranges). My aim was to test whether previous knowledge documenting habitat selection by kereru across varied habitat types predicted habitat selection within an urbanised landscape. More specifically, I asked if kereru selected habitat within urbanised landscapes based upon natural or historically important features or whether human-modified features play a more important role in selection. 


\section{Methods}

STUDY AREA

Otari Native Botanic Garden and Wilton's Bush Reserve (also known as OtariWilton's Bush; $41^{\circ} 14^{\prime} \mathrm{S}, 174^{\circ} 45^{\prime} \mathrm{E}$ ) are located just within Wellington City limits at the southern tip of the North Island of New Zealand, and encompass approximately 100 hectares of native forest and a five-hectare native botanic garden (Wellington City Council 2007). The reserve is situated within a valley that rises from 70 to 280 metres above sea level and is incised by the Kaiwharawhara Stream, making it an important part of a water catchment and a major green corridor within Wellington City (Wellington City Council 2007). Bordered by low intensity livestock farming and steep hill country to the west, the remaining suburban edges of the reserve to the north, east and south are composed of medium density, one- to two-story single family dwellings. These suburbs are characterised by patches of green (private yards and public parks composed of both native and exotic plant species) surrounded medium density buildings and roads, and are typical of the suburban landscapes of many developed countries (McDonnell \& Pickett 1990).

Bird life was greatly diminished with the loss of mature forest and with the intense hunting of such native species as kaka (Nestor meridionalis), kereru (Hemiphaga novaeseelandiae) and tui (Prosthemadera novaeseelandiae) in the $19^{\text {th }}$ century (Wellington City Council 2007). In recent years, records show that bird numbers have substantially increased in Otari-Wilton's Bush (Froude 2009). Since 2005, regular mammalian pest control has been undertaken by Wellington City Council (WCC), Greater Wellington Regional Council (GWRC) and local volunteers. Controlled species include pigs, goats, possums, feral cats, mustelids, rats and mice by a variety of methods such as shooting, trapping and poisoning (R. Elliot, pers. comm.). 


\section{CAPTURING, TAGGING \& MONITORING KERERU}

During Feb 2007-Dec 2008, I captured 11 kereru (Table 1) in canopy-height mist-net rigs (Dilks et al. 1995), which were set up near foraging or roosting sites around the visitor centre at Otari-Wilton's Bush, Wellington. The capturing of kereru was restricted to the postbreeding and suspected post-moult period in an attempt to maximise tail-mounted transmitter retention times. Thus, capture periods were divided into a 2007 and 2008 winter season.

Each bird was fitted with a light-weight tail-mounted radio-transmitter (SIRTrack Limited, Havelock North, NZ) between the two central retrices using quick-bond glue and dental floss (Appendix 2). Tail-mounted transmitters weigh less than $5 \mathrm{~g}$ and do not require re-capture for removal as they are shed by the bird during moult. In addition, all birds were marked with a unique, numbered metal leg band (size S) and coloured leg jesses of nylonreinforced PVC for visual identification of individuals in the field. Leg jesses also enabled location of marked birds after transmitter batteries were exhausted, or the transmitter was shed before the end of its battery life (battery life was approx. 14 months). Each bird was weighed and from three to five contour feathers taken for sexing using DNA the Equine Parentage and Animal Genetics Service Centre, Massey University, Palmerston North. I conducted all molecular work under the supervision of experienced technicians using the centre's non-discloseable techniques (Appendix 3). 
Table 1. Summary of 11 kereru caught and tagged during this study. Individuals were identified as juvenile (J), adult (A), male (M), and female (F). Note kereru denoted by * were caught and fitted with transmitters twice during the study period. MCP = minimum convex polygon.

\begin{tabular}{|c|c|c|c|c|c|c|c|}
\hline Band no. & Jess colour(s) & Age/Sex & $\begin{array}{l}\text { Weight at } \\
\text { capture }(\mathrm{g})\end{array}$ & Date captured & $\begin{array}{l}\text { No. of } \\
\text { months } \\
\text { tracked }\end{array}$ & $\begin{array}{l}\text { No. of } \\
\text { locations }\end{array}$ & $\begin{array}{l}95 \% \mathrm{MCP} \\
\text { (ha) }\end{array}$ \\
\hline \multirow[t]{2}{*}{ S-53665* } & -/Yellow & $\mathrm{J} / \mathrm{F}$ & 400 & 22 March, 2007 & 6 & 38 & 0.77 \\
\hline & & & 640 & 17 May, 2008 & 2 & 16 & 1.41 \\
\hline S-53666 & Blue/- & $\mathrm{A} / \mathrm{M}$ & 665 & 29 March, 2007 & 6 & 42 & 4.71 \\
\hline S-53667 & Blue/Red & $\mathrm{A} / \mathrm{M}$ & 660 & 29 March, 2007 & 2 & 17 & 0.46 \\
\hline S-53668 & White/Blue & $\mathrm{J} / \mathrm{F}$ & 415 & 19 April, 2007 & 1 & 12 & 0.12 \\
\hline \multirow[t]{2}{*}{ S-53670* } & Yellow/Green & $\mathrm{A} / \mathrm{M}$ & 631 & 8 May, 2007 & 6 & 47 & 1.71 \\
\hline & & & 685 & 10 April, 2008 & 5 & 36 & 1.42 \\
\hline \multirow[t]{2}{*}{ S-53672* } & Black/Red & $\mathrm{A} / \mathrm{F}$ & 635 & $21 \mathrm{March}, 2008$ & 2 & 61 & $83.12^{\mathrm{a}}$ \\
\hline & & & 640 & 20 May, 2008 & 5 & - & - \\
\hline S-53673 & Green/Blue & $\mathrm{A} / \mathrm{F}$ & 650 & 21 March, 2008 & 1 & 10 & 4.62 \\
\hline S-53674 & White/Black & $\mathrm{A} / \mathrm{F}$ & 620 & 3 April, 2008 & 1 & 22 & 4.96 \\
\hline S-53675 & Green/Green & $\mathrm{A} / \mathrm{M}$ & 630 & 8 April, 2008 & 4 & 13 & 0.09 \\
\hline S-53678 & Blue/Yellow & $\mathrm{A} / \mathrm{F}$ & 630 & 7 July, 2008 & 3 & 24 & 0.23 \\
\hline S-53679 & Green/Black & $\mathrm{A} / \mathrm{M}$ & 570 & 10 July, 2008 & 2 & 19 & 0.17 \\
\hline
\end{tabular}

${ }^{a}$ MCP size includes two separate tracking sessions during 2008 that followed one after the other (the bird was immediately caught and re-fitted with a second transmitter after shedding the first), thus the total number of locations is given for both tracking sessions during a single winter season. 
Kereru are known to make long distance movements, in between extended periods of fairly sedentary behaviour, usually in relation to the availability of favoured food sources (Campbell 2006; Clout et al. 1986; Clout \& Hay 1989; Hill 2003; Powlesland et al. 2011; Schotborgh 2005). In Wellington City, observations from staff at Otari-Wilton's Bush and the surrounding residents suggested that kereru numbers were highest at the end of the summer months and into the winter when many favoured plants were fruiting and slowly decreased towards the spring. Data collection was thus restricted to the winter period immediately post-breeding to (1) monitor all marked kereru when most individuals were employing similar seasonal behaviours (e.g. flock feeding), and (2) allow for maximum transmitter retention times after the suspected post-breeding moult (see Appendix 3 and Cousins 2010). In addition, many of the kereru tagged during this study eventually moved beyond the range of my ability to detect them with radio-telemetry gear on foot. This generally occurred at the onset of the breeding season (summer months), indicating that the study area was most likely a seasonal core area of activity. For this reason, I focussed data collection during the time of year when kereru activity was highest in Wellington City (i.e., winter - between the months of March and October).

Each radio-tagged individual was visually located a minimum of two times per week on foot using a radio-receiver and hand-held yagi antenna (SIRTrack Limited, Havelock North, NZ). All radio-tracking of kereru occurred during daylight hours, between 08:00 and 17:00hrs, and was not undertaken on days with severe weather (i.e,. gale force winds or torrential rain). Since it could take upwards of four hours to locate a single individual due to restricted access into private residential gardens, a maximum of two kereru were assigned for location determination each day. The order in which the kereru were located was randomly varied each week. When a bird was 
not visually sighted but known to be hidden in nearby canopy, its location was marked as the site at which the radio signal was the strongest. If a tagged kereru was encountered that was not on the tracking schedule for that day, the location was recorded and included in the final range calculations. Thus, some kereru were located more than two times per week (Table 1). All locations were marked with a hand held Garmin GPS and a maximum error of $15 \mathrm{~m}$.

\section{DEFINING SCALES OF SELECTION}

Ranges were estimated using the HRT extension (Rodgers et al. 2005) in ArcGIS (ArcView 9.3. 1999-2008) using minimum convex polygons (MCPs) with fixed area means to calculate an overall area using $95 \%$ of the points that were closest to the geographic centre of the range. It is important to recognize that cluster analysis of home ranges (Kenward 2001) is widely regarded as a more appropriate measure of annual home ranges in kereru as it accounts for the intensity of usage within core areas of the entire area repeatedly traversed by an individual and gives smaller home range sizes than MCP methods (Bell 1996; Campbell 2006; Hill 2003; Powlesland et al. 2011; Schotborgh 2005). Nevertheless, I was interested in including the overall area that kereru were familiar with during a given season and did not have sufficient temporal data to build an annual home range. Thus, MCPs are a more appropriate measure, as they represent both the used and available areas within the given time frames, and are herein referred to as "winter ranges". The relationship between the number of location points and the MCP winter range were examined using Spearman's rank correlation.

I examined habitat selection by kereru at two spatial scales: (1) second-order selection, or winter ranges, and (2) third-order selection, or the usage of various patches or sites within winter ranges (Johnson 1980). Second-order selection was 
determined by comparing random locations within each individual bird's winter range ("used sites") to random locations outside of the same home range, but within the area of all kereru home ranges in the present study, as calculated by a 95\% MCP around the outermost locations of all birds with a $20 \mathrm{~m}$ buffer ("available sites"; Figure 1a). The total number of available sites within the entire study area was equal to the total number of radio-telemtry locations for all kereru. Third-order selection was then determined by comparing kereru locations from radio-telemetry within each individual bird's winter range ("used sites") with an equal number of random sites within the same winter range ("available sites"; Figure 1b). To control for the effects of seasonal food availability, I sampled all random sites concurrently with radiotelemetry data collection.
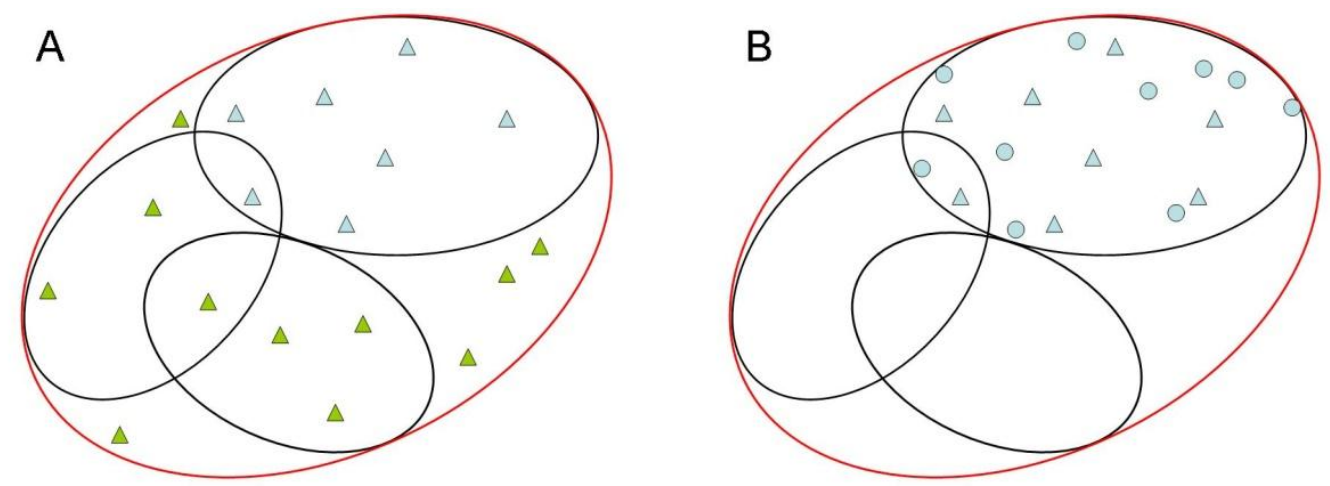

Figure 1. The sampling design for kereru habitat selection at the level of: (A) secondorder selection, or winter range selection, and (B) third-order selection, or site selection. Each black oval represents an individual bird's winter range and the encompassing red oval the total study area which includes the winter ranges of all 11 kereru. For second-order selection, random sites within each bird's winter range (blue triangles) were compared to random sites within the entire study area (green triangles). For third-order selection, kereru radio-telemetry locations (blue circles) were compared to an equal number of random sites (blue triangles) within the same winter range. 


\section{MEASURING PREDICTORS (FIXED-EFFECTS)}

Ten predictor variables were chosen to describe factors influencing habitat selection of kereru in this study (Table 2), which were guided by the compilation of $a$ priori candidate hypotheses (see next section). For each sampling point, I generated a $20 \mathrm{~m}$ radius buffer using ArcGIS, within which all variables were measured. Two techniques were used to gather data: measurements were taken using ArcGIS and observations were made in the field during radio-telemetry. Predictors that included impervious surfaces (road and building cover), landscape cover, and predator control, were quantified using aerial imagery and shapefiles provided by a variety of sources using ArcGIS (see Table 2 for varying measurement details). Features such as individual plant species or man-made objects used for activities such as perching or as a food source (native and exotic food sources, or power lines), as well as the presence of conspecifics, were determined during ground-based observations of wild kereru in the field during radio-telemetry. All of the variables measured directly in the field were recorded as presence/absence to within the pre-defined $20 \mathrm{~m}$ buffer (see Table 2 for more detail). 
Table 2. Predictor variables that were measured within a $20 \mathrm{~m}$ point buffer from kereru radio-telemetry locations and random point locations. Data was obtained through satellite imagery and shape file layers in ArcGIS (GIS), and during ground observations in the field (GO). Possum control data was provided by Wellington City Council (WCC).

\begin{tabular}{|c|c|c|c|}
\hline Variable & $\begin{array}{l}\text { Units of } \\
\text { measurement }\end{array}$ & Data source & Description \\
\hline Building cover & Area (m squared) & GIS & Total area of built structures \\
\hline Water & Presence/absence & GIS, GO & Includes only above-ground permanent sources, such as rivers and ponds \\
\hline Land cover & LCDB2 classes* & GIS, GO & Land cover database classifications from Land Care Research, N.Z. \\
\hline Native food source & Presence/absence & $\mathrm{GO}$ & Appendix 2. Native and introduced species known to be eaten by kereru \\
\hline Exotic food source & Presence/absence & GO & Appendix 2. Native and introduced species known to be eaten by kereru \\
\hline Power lines & Presence/absence & GO & Major power lines along roads, excluding single phone or power lines to buildings \\
\hline Conspecifics & Presence/absence & GO & Kereru, other than radio-tagged, within visible range of a maximum $20 \mathrm{~m}$ radius \\
\hline
\end{tabular}




\section{STATISTICAL APPROACH \& COMPILING CANDIDATE MODELS}

I applied an Information-Theoretic (I-T) approach to compare models as competing hypotheses for second- and third-order habitat selection by kereru within an urbanized landscape. The I-T approach works via two components: formulation of a set of candidate models, and selection of a model(s) for use in inference making. The development of a set of a priori models assumes a level of careful thinking and objective hypothesis formulation. A priori models can also prevent data mining, overanalysis, and the misuse of traditional multivariate analysis methods, all of which can lead to spurious relationships and Type II errors (Burnham \& Anderson 2002). Further, the ranking of the candidate models relative to each other, from useful to essentially useless, provides a quantitative measure of the plausibility and confidence in the "best" model given the data (Burnham \& Anderson 2002). In this way, the effects that may be more important than others can be teased apart by further examining the variables included within the "best" models.

Eighteen a priori candidate models were derived as hypotheses for kereru habitat selection based upon previous studies that described or predicted possible factors contributing to kereru habitat use across varying landscapes and habitat types (Table 3; see Appendix 1). Various introduced mammals are known to negatively impact kereru breeding success and survival, and so constitute two models (models 2 \& 3; Campbell et al. 2008b; Innes et al. 2004; James 1995; James \& Clout 1996; Prendergast 2006). Food availability in relation to mammalian competitors has also been considered (model 4; Dijkgraaf 2002; Powlesland et al. 2003), as well as the importance of both native and exotic food sources in urban kereru diets (Campbell et al. 2008a; models 5-7; Dunn 1981; Harwood 2002; Karan 2000). A number of studies have also been conducted along the urban-rural gradient of Banks Peninsula, and so 
constitute an additional model (model 8; Campbell 2006; Schotborgh 2005). I also considered various combinations of food sources, pest control, water availability, land cover, and the presence of conspecifics, as predictors for what would have been historically important for kereru habitat, and so they constitute four more models (models 9-12). However, since this study was conducted within an urban context, I considered two models based upon the features of the modified landscape (models 13 \& 14). I also included hypotheses informed by my own field observations of kereru using man-made structures (models $15 \& 16$ ), and the hazards that such an environment can present them (model 17). Finally, I added a model that incorporated all of the variables as fixed effects (model 18), and a base model that included only the random effect of the individual birds and no fixed effects (model 1).

\section{STATISTICAL ANALYSIS}

To account for spatial scaling differences, hypotheses for second- and thirdorder selection were considered separately through logistic multiple regression models using the lme4 package (Bates \& Maechler 2010) in the statistical program R ( $R$ Development Core Team 2010). I based the response variable on a binomial distribution $(0=$ available site, $1=$ used site $)$, and incorporated individual birds as a random effect to reflect the repeated and unbalanced number of observations of marked kereru (Gillies et al. 2006). I considered the ten variables described above as explanatory covariates (fixed-effects) in my models (Table 2). Akaike's information criterion adjusted for small sample size (AICc; Burnham \& Anderson 2002) was then used to contrast and assess strength of evidence for competing models. The use of AIC in model selection provided not only a measure of the relative goodness-of-fit for each statistical model, but also included a penalty for the number of estimated parameters to avoid over-fitting (Burnham \& Anderson 2002). I selected the model 
with the smallest $\mathrm{AIC}_{\mathrm{c}}$ value as the best among the models being compared, where models within two units of the best model were considered equally and most substantially supported, models within four to seven units received considerably less support, and greater than ten units essentially no support (Burnham \& Anderson 2002). I also examined the Akaike weights $\left(\omega_{\mathrm{i}}\right)$ to further quantify the plausibility of each model as being the best model given my data (Burnham \& Anderson 2002).

\section{Results}

Kereru winter ranges (95\% MCP) during the 2007 and 2008 seasons (March to July) were as large as 83.1 hectares, but most ranged from 0.09-4.96 hectares (Figure 2). The correlation between MCP range and sample size for kereru records was very weak and not significant $\left(n=13, R_{s}=0.533, p=0.061\right)$. Kereru moult patterns are not very well known (although see Cousins 2010), and so despite my attempt to tag kereru after the post-breeding moult, tail-mounted transmitters were continuously and sporadically dropped through-out the study. Thus, transmitter retention times were highly variable and dictated the total number of months each individual was available for monitoring (between one and eleven months; Table 1). While most kereru were caught, tagged and monitored only once, "Yellow" and "Yellow/Green" were each caught once per season for two consecutive seasons (Table 1). Although winter ranges are shown seperately for each season in Figure 2, data for both seasons for each kereru were combined for modelling. It is clear that there was pronounced overlap in the same individuals winter range from one season to the next (Figure 2). The largest MCP was that of "Black/Red", which was monitored for several months longer than other birds as it was caught and tagged twice during the same season (Figure 2). 


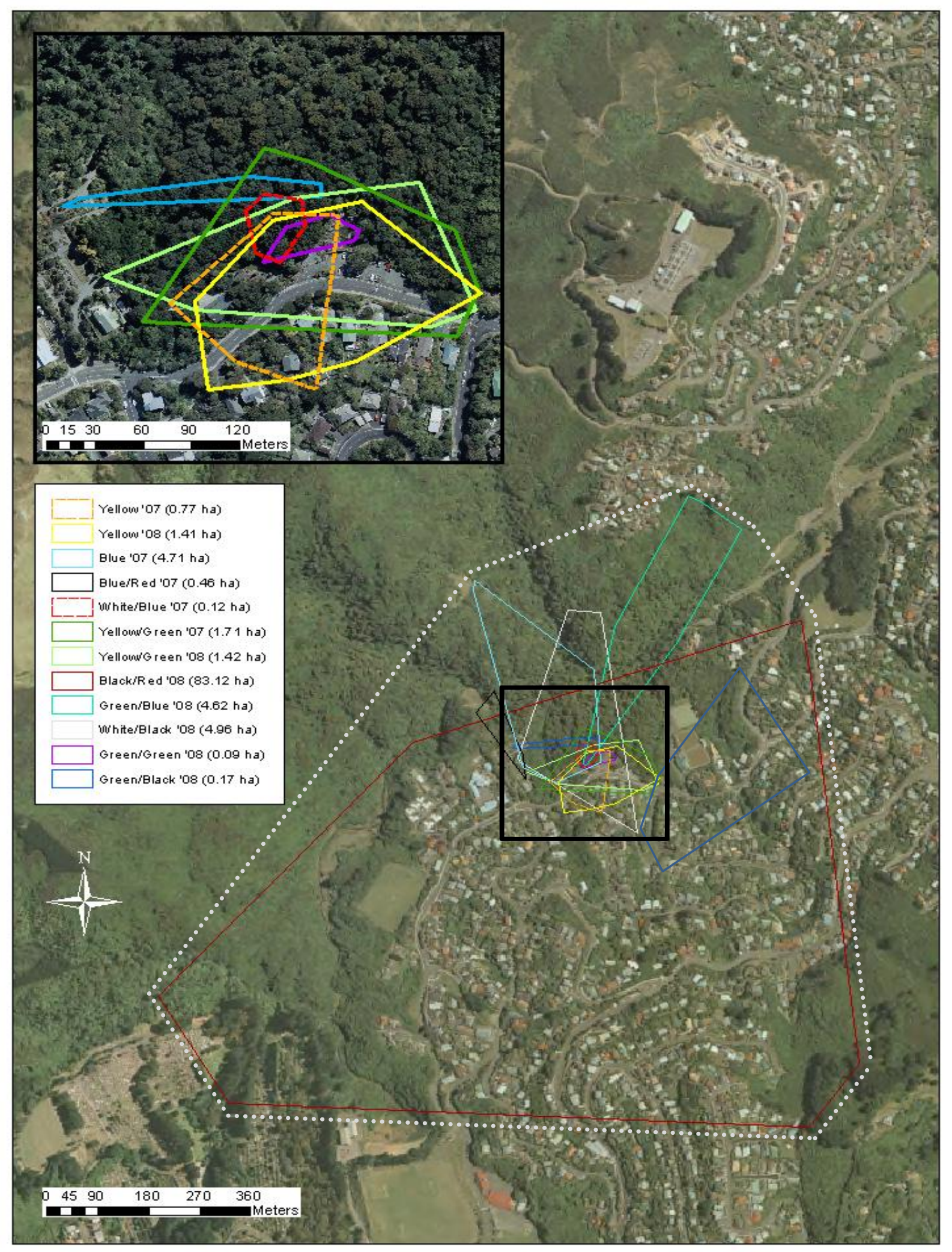

Figure 2. Winter ranges of 11 radio-tagged kereru in Wellington as determined by the $95 \%$ minimum convex polygon (MCP) method for locations obtained during 2007-08. The inset shows more detail of the smaller MCPs. Otari-Wilton's Bush is shown to the north and east of kereru ranges. Juvenile MCP ranges are given in hashed lines. The buffered MCP encompassing the winter ranges for all birds that was used to generate an available set of sampling points is shown by the dotted grey line. 
The only model that received substantial support for second-order habitat selection included the random effect for individual bird and no fixed-effects ("Base model" $\Delta \mathrm{AIC}_{\mathrm{c}}=0, \omega_{\mathrm{i}}=0.92$; Table $3 \mathrm{~A}$ ). It is important to note that possum control was also included in the confidence set of models for second-order habitat selection (i.e. $\sum \omega_{\mathrm{i}}>0.95$ ), albeit only weakly supported ("Predation" $\Delta \mathrm{AIC}_{\mathrm{c}}=6.9, \omega_{\mathrm{i}}=0.03$; Table $3 \mathrm{~A}$ ). Given the results from Chapter 2, where building and road density interacted with possum control, it is surprising that no support for models that included impervious surfaces received any support (i.e. "Impervious surfaces" $\Delta \mathrm{AIC}_{\mathrm{c}}=32.7, \omega_{\mathrm{i}}=0.00$; Table 3A). Further, given that my models were based upon the published literature on kereru ecology, which has focused heavily on habitat use and feeding preferences, it is particularly interesting that no support was found for any of these hypotheses within my study.

For third-order habitat selection, the only model that received substantial support was the hypothesis that included a native food source, possum control, and the presence of conspecifics ("Historical 4" $\Delta \mathrm{AIC}_{\mathrm{c}}=0, \omega_{\mathrm{i}}=0.98$; Table 3B). All other hypotheses received essentially no support for third-order selection models (i.e. $\Delta \mathrm{AIC}_{\mathrm{c}}>7$; Table $\left.3 \mathrm{~B}\right)$. There were differences between second- and third-order selection in the placing of the base model so that in second-order selection the base model third-order selection the base model received substantial support whereas in second-order selection it received no support.

All kereru regardless of age or sex, selected for sites that had a native food source present (Figure 3A), and sites where possum control occurred (Figure 3B). Of the feeding observations made during radio-telemetry of wild kereru across both field seasons, $92 \%$ were of native food source consumption consisting of 16 plant species (as opposed to only four introduced plant species observed; all plant species observed 
being fed upon by kereru in this study are highlighted in yellow in Appendix 4). In general, kereru were found in sites where conspecifics were present (Figure 3C). Interestingly, juvenile kereru selected a much higher proportion of sites where conspecifics were present than adults, although this is likely due to smaller ranges that were always found within adult ranges (Figure 2). 
Table 3. Outcomes of the 18 candidate models for: (A) second-order selection, or winter ranges, and (B) third-order selection, or sites within winter ranges. The fixed effects, number of parameters for each model $(\mathrm{K}), \mathrm{AIC}_{\mathrm{c}}$ values, $\mathrm{AIC}_{\mathrm{c}}$ differences $\left(\Delta_{\mathrm{c}}\right)$, and Akaike weights $(\omega)$ are shown. Models are ranked from the smallest to the largest $\mathrm{AIC}_{\mathrm{c}}$ value with the best supported hypotheses (confidence models $\omega>0.95$ ) shown in bold, and the "Base model" highlighted in grey. Note that the hypotheses upon which model \#2 is based includes studies of the effects of various predators, however I only tested for possums.

\begin{tabular}{|c|c|c|c|c|c|c|}
\hline $\begin{array}{l}\text { Model } \\
\text { no. }\end{array}$ & $\begin{array}{l}\text { Hypotheses, } \\
\text { candidate set of models }\end{array}$ & Predictors (fixed effects) & $\mathrm{K}$ & $\mathrm{AIC}_{\mathrm{c}}$ & $\Delta_{\mathrm{c}}$ & $\omega$ \\
\hline 1 & Base model & No fixed effects (random effect for bird only) & 2 & -130.5 & $\mathbf{0}$ & 0.92 \\
\hline 2 & Predation & Possum & 3 & -123.6 & 6.9 & $\mathbf{0 . 0 3}$ \\
\hline 6 & Exotic food source & Exotic & 3 & -123.5 & 7.0 & 0.03 \\
\hline 5 & Native food source & Native & 3 & -122.5 & 8.0 & 0.02 \\
\hline 16 & Roost sites & Perch tree, power line & 4 & -117.3 & 13.2 & 0.00 \\
\hline 3 & Breeding success & Possum, conspecific & 4 & -115.6 & 14.9 & 0.00 \\
\hline 7 & Food source & Native, exotic & 4 & -115.4 & 15.1 & 0.00 \\
\hline 17 & Disturbance & Roads & 3 & -114.9 & 15.6 & 0.00 \\
\hline 9 & Historical 1 & Native, possum, land cover & 8 & -108.5 & 22.0 & 0.00 \\
\hline 4 & Food availability & Native, exotic, possum & 5 & -108.4 & 22.1 & 0.00 \\
\hline 12 & Historical 4 & Native, possum, conspecific & 5 & -107.5 & 23.0 & 0.00 \\
\hline 8 & Banks Peninsula & Native, exotic, possum, land cover & 9 & -101.5 & 29.0 & 0.00 \\
\hline 10 & Historical 2 & Native, possum, land cover, conspecific & 9 & -100.2 & 30.3 & 0.00 \\
\hline 15 & Impervious surfaces & Buildings, roads & 4 & -97.8 & 32.7 & 0.00 \\
\hline 11 & Historical 3 & Native, water, possum, land cover, conspecific & 10 & -95.8 & 34.8 & 0.00 \\
\hline 14 & Modified 2 & Native, exotic, water, possum, land cover, perch tree & 11 & -90.2 & 40.3 & 0.00 \\
\hline 13 & Modified 1 & Native, exotic, water, possum, land cover, conspecific & 11 & -88.4 & 42.1 & 0.00 \\
\hline 18 & All variables & Native, exotic, water, possum, land cover, perch tree, power line, conspecific, buildings, roads & 15 & -42.3 & 88.2 & 0.00 \\
\hline
\end{tabular}




\begin{tabular}{|c|c|c|c|c|c|c|}
\hline $\begin{array}{l}\text { Model } \\
\text { no. }\end{array}$ & $\begin{array}{l}\text { Hypotheses, } \\
\text { candidate set of models }\end{array}$ & Predictors (fixed effects) & $\mathrm{K}$ & $\mathrm{AIC}_{\mathrm{c}}$ & $\Delta_{\mathrm{c}}$ & $\omega$ \\
\hline 12 & Historical 4 & Native, possum, conspecific & 5 & 364.9 & $\mathbf{0}$ & 0.98 \\
\hline 10 & Historical 2 & Native, possum, land cover, conspecific & 9 & 372.9 & 8.0 & 0.02 \\
\hline 4 & Food availability & Native, exotic, possum & 5 & 379.2 & 14.3 & 0.00 \\
\hline 3 & Breeding success & Possum, conspecific & 4 & 379.4 & 14.5 & 0.00 \\
\hline 9 & Historical 1 & Native, possum, land cover & 8 & 380.6 & 15.7 & 0.00 \\
\hline 13 & Modified 1 & Native, exotic, water, possum, land cover, conspecific & 11 & 384.5 & 19.6 & 0.00 \\
\hline 8 & Banks Peninsula & Native, exotic, possum, land cover & 9 & 386.8 & 21.9 & 0.00 \\
\hline 2 & Predation & Possum & 3 & 386.9 & 22.0 & 0.00 \\
\hline 14 & Modified 2 & Native, exotic, water, possum, land cover, perch tree & 11 & 396.4 & 31.5 & 0.00 \\
\hline 18 & All variables & Native, exotic, water, possum, land cover, perch tree, power line, conspecific, buildings, roads & 15 & 412.2 & 47.3 & 0.00 \\
\hline 5 & Native food source & Native & 3 & 418.5 & 53.6 & 0.00 \\
\hline 7 & Food source & Native, exotic & 4 & 424.6 & 59.7 & 0.00 \\
\hline 1 & Base model & No fixed effects (random effect for bird only) & 2 & 430.4 & 65.5 & 0.00 \\
\hline 16 & Roost sites & Perch tree, power line & 4 & 432.9 & 68.0 & 0.00 \\
\hline 17 & Disturbance & Roads & 3 & 443.6 & 78.7 & 0.00 \\
\hline 15 & Impervious surfaces & Buildings, roads & 4 & 448.4 & 83.5 & 0.00 \\
\hline
\end{tabular}


A.

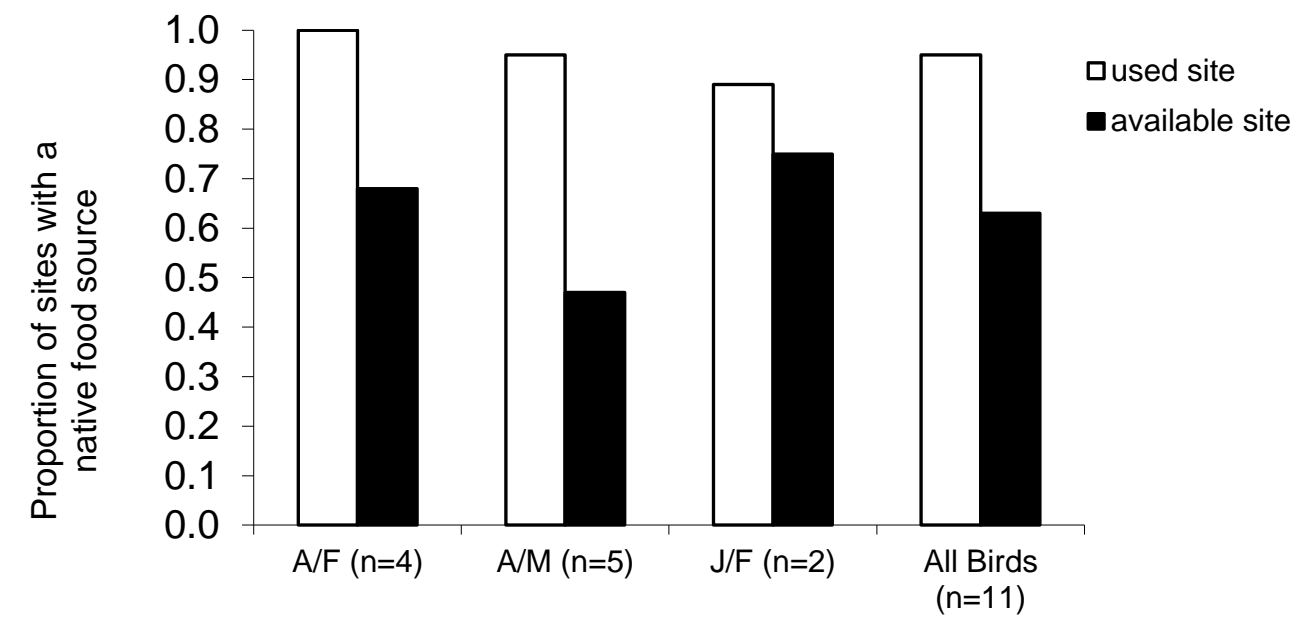

B.

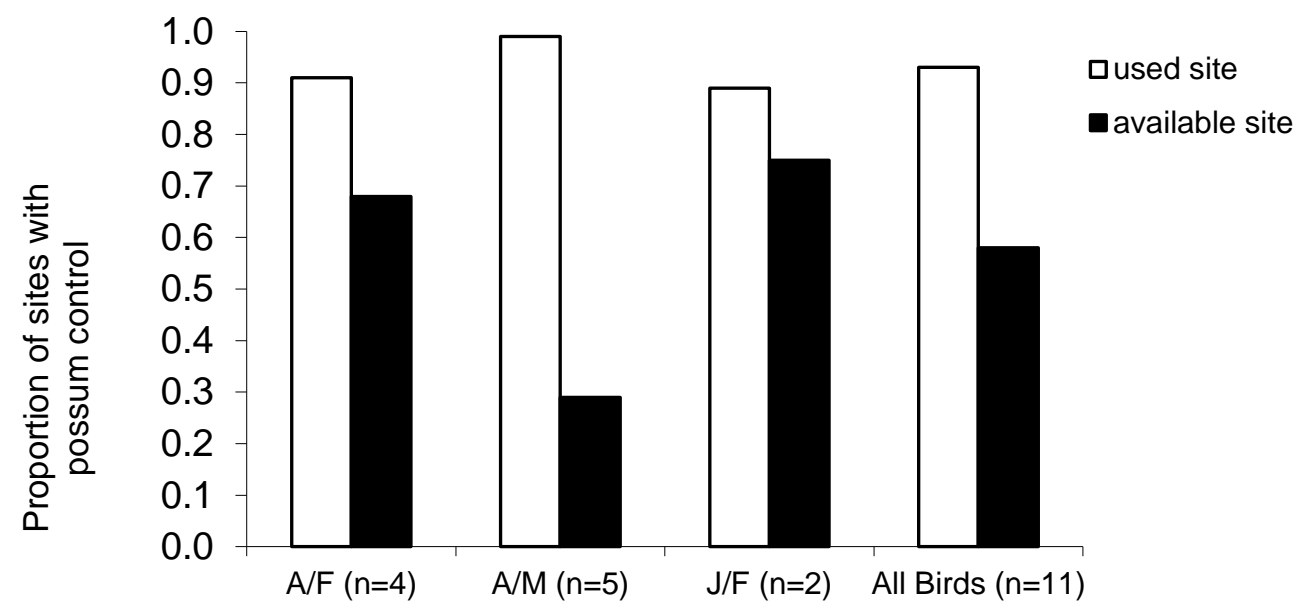

C.

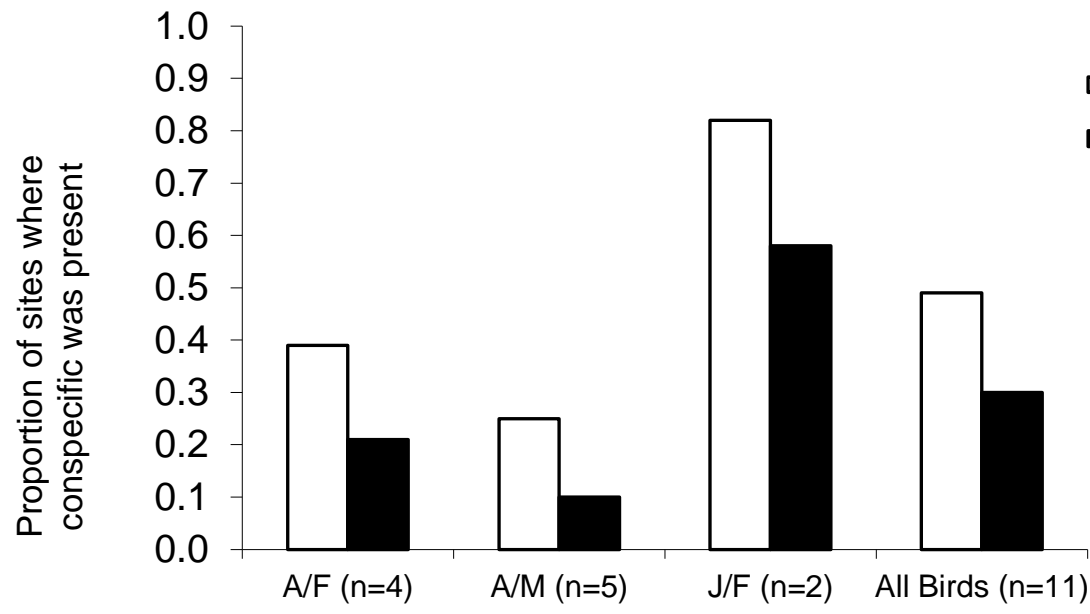

Figure 3. Proportions of sites at the third-order level of selection that had (A) a native food source present, (B) possum control occurring, and (C) a conspecific present. Data is split by adult females $(\mathrm{A} / \mathrm{F}, \mathrm{n}=4)$, adult males $(\mathrm{A} / \mathrm{M}, \mathrm{n}=5)$, juvenile females $(\mathrm{J} / \mathrm{F}, \mathrm{n}=2)$, as well as all eleven kereru included together $(n=11)$. 


\section{Discussion}

In this study radio-telemetry data were collected to determine the winter habitat selection by kereru in Wellington at the second- (winter range) and third-order (sites within the winter range). The results demonstrated that kereru select sites at the third order (within the winter range) but not at the second-order scale. Native vegetation, the presence of conspecifics and predators strongly influenced the sites selected within winter ranges. However, at the second-order level of selection (ranges), predation risk was only weakly influential in the placement of winter ranges and only the model accounting for individual variation amongst kereru received support.

A considerable amount of research has been undertaken on the use of native and introduced plants as food sources by kereru, ranging from diet composition (Campbell 2006; Hill 2003; McEwen 1978; Schotborgh 2005) to their keystone role in the dispersal of the seeds of large-fruited trees (Bell 1996; Clout \& Hay 1989; Wotton 2007). Previous studies of kereru ecology have shown that the presence of a food source is an important determinant of suitable habitat, however, the proportion of exotic and native species in the kereru diet varies with local availability and regional changes in forest composition. In the northern city of Auckland, exotic plant species were more frequently eaten in the winter (Harwood 2002; Karan 2000), whereas in southern city of Dunedin they were eaten more in the summer (Dunn 1981). Interestingly, among Wellington City kereru, the model that included exotic foods performed particularly poorly in third-order selection models. Rather, the model that included native food, in conjunction with possum control and the presence of conspecifics, received substantial support. Kereru in Wellington were selecting sites with native food sources present, and the majority of kereru feeding observations were of native food species (92\%; see highlighted species in Appendix 4). This may also reflect that the landscape in Wellington City is less modified and included a sufficient amount of native species for kereru 
feeding than in other cities. This lends support to the idea of the Wellington City landscape appearing as more of a perforated, rather than fragmented, habitat whereby novel habitat is created that remains "suitably modified" for kereru. These results follow the general pattern observed across the urban gradient, where more native bird species found where native vegetation is retained (Chace \& Walsh 2006).

Introduced possums (Trichosurus vulpecula), rats (Rattus rattus L.) and mustelids (e.g. stoats; Mustela erminea, L.) greatly impact on kereru survival by competing for favoured food sources, predating nests, and occasionally killing adults (Clout et al. 1995b; Prendergast 2006). Possums deplete the fruit supplies necessary for kereru to survive (Dijkgraaf 2002; Mander et al. 1998), and cause major damage to mature native vegetation by defoliating trees (Nugent et al. 2001). Kereru selecting sites for nesting, perching or feeding, will likely avoid those damaged by possums. Past research has shown that when mammalian pests are controlled, kereru numbers increase and nesting success is significantly improved (Clout et al. 1995a; James \& Clout 1996). I found that at third-order selection (site), kereru selected sites in which possum control was being undertaken. Interestingly, while possum control was part of the second-order confidence set of models, it had only a weak influence on the selection of winter ranges. My measure of first-order (regional) habitat selection (Chapter 2) revealed that possum control interacted with building and road density, with more sites selected at intermediate densities of buildings and roads in areas in which possum control was being undertaken. Although kereru selected sites within the suburban habitat, the majority of these sites fell within or along the periphery of the Otari-Wilton's Bush where possum control was being undertaken. Possum control by councils and the DOC is conducted at a large regional scale. By operating at this spatial scale, it is likely that control measures are reducing the overall density of possums, which in turn lessens their presence at specific sites. In addition, pest control in reserves and parks that surround suburbs may also be creating safe zones, 
where possum densities are reduced to a number too low to significantly impact kereru habitat selection, lending further support to the results found in Chapter 2.

Given the importance of controlling possums on kereru survival, other potential exotic predators and competitors should also be investigated. For example, little is known as to the extent of cat depredation of adult kereru and their nests (although see an account in Prendergast 2006). Cats are human-commensals and are the most widespread terrestrial carnivore across urbanised landscapes (Chace \& Walsh 2006). While possum control at the regional scale may be affecting kereru survival and productivity at the local level, it is unknown whether or not cats influenced kereru site selection in my study as I was unable to collect data on introduced species control level on people's private land. Future work should include quantitative measures of mammalian predators as well as competitors in order to elucidate whether selection is driven by predation threat or food competition. Research should also consider any control measures being undertaken within private lands, and how this may affect kereru habitat selection in urbanised areas.

The presence of conspecifics emerged as a strong predictor of kereru site selection. This is perhaps not surprising, as flock feeding is known among kereru. However, there is very little known about kereru sociality. Although usually quite docile, kereru are known to become aggressive and territorial over a favoured food source and will wing-beat and chase other birds away (see Chapter 4). Similar to other pigeon species, kereru will take flight or hit out strongly with their wings when threatened (Goodwin 1983; James \& Clout 1996). Interestingly, when examined by age group, there were distinct differences in site selection as it related to other kereru, which is likely due to two factors. Firstly, juvenile ranges were found within those of adults ranges. Although previous studies suggest that unpaired juveniles have larger home ranges than adults (Bell 1996), I found that during the period immediately post-fledgling (and most likely pre-dispersal) the geographic range of juveniles 
were highly restricted. For example, one of the juvenile females remained within an adult breeding territory well into her second year. Secondly, very little is known regarding the social behaviour of juveniles and whether these birds remain with closely related adults or use their conspecifics to learn from pre-dispersal. What is clear from my results however, is that sociality is important for determining third-order habitat selection by kereru and that more research into kereru social behaviour is required.

\section{Conclusion}

To fully understand avian habitat selection in urbanised areas, fine-scale habitat needs to be understood within the context of the broader landscape (Garden et al 2006). Multiple scales of habitat selection should thus be examined in order to account for the differing responses of animals to landscape structure changes by both large-scale management by governments and the fine-scale decisions made at the level of the individual landowner. The primary habitat used by kereru within urbanised landscapes are large areas of retained native vegetation (such as Otari-Wilton's Bush) and neighbouring privately owned gardens in residential areas - land that is individually managed by landowners and thus highly micromanaged. Gardens constitute the greatest proportion of green space in urban centres (Gaston et al. 2005; Mathieu et al. 2007), yet we have little information on their constitution and overall contribution to native biodiversity maintenance. It will be important therefore, for future studies to quantify in detail the make-up of private gardens in order to understand their role in the concept of "suitably modified" urban landscapes and to truly partition their effects on avian habitat selection at both the fine-scale and their cumulative broader scales. 


\section{References}

Allen, T. F. H., and T. B. Starr 1982. Hierarchy: perspectives for ecological complexity. University of Chicago Press, Chicago, IL.

ArcView 9.3. ESRI. 1999-2008. Environmental Systems Research Institute, Redlands, CA.

Bates, D., and M. Maechler. 2010. lme4: Linear mixed-effects models using S4 classes. R package version 0.999375-35. Available at: http://lme4.r-forge.r-project.org/.

Bell, R. 1996. Seed dispersal by kereru (Hemiphaga novaeseelandiae) at Wenderholm Regional Park. Unpubl. M.Sc. thesis. University of Auckland.

Burnham, K. P., and D. R. Anderson 2002. Model selection and multimodel inference: A practical information-theoretic approach. Springer-Verlag, New York.

Campbell, K. L. 2006. A study of home ranges, movements, diet and habitat use of kereru (Hemiphaga novaeseelandiae) in the southeastern sector of Banks Peninsula, New Zealand. Unpubl. M.Sc. thesis. Lincoln University, New Zealand.

Campbell, K. L., H. M. Schotborgh, K.-J. Wilson, and S. Ogilvie. 2008a. Diet of kereru (Hemiphaga novaeseelandiae) in a rural-urban landscape, Banks Peninsula, New Zealand. Notornis 55:173-183.

Campbell, K. L., K.-J. Wilson, and S. Ogilvie. 2008b. Notes on the breeding biology of kereru (Hemiphaga novaeseelandiae) on Banks Peninsula, South Is, New Zealand. Notornis 55:98-100.

Chace, J. F., and J. J. Walsh. 2006. Urban effects on native avifauna: a review. Landscape and Urban Planning 74:46-69.

Clout, M. N., K. Denyer, R. E. James, and I. G. McFadden. 1995a. Breeding success of New Zealand pigeons (Hemiphaga novaeseelandiae) in relation to control of introduced mammals. New Zealand Journal of Ecology 19:209-212.

Clout, M. N., P. D. Gaze, J. R. Hay, and B. J. Karl. 1986. Habitat use and spring movements of New Zealand pigeons at Lake Rotoroa, Nelson Lakes National Park. Notornis 33:37-44.

Clout, M. N., and J. R. Hay. 1989. The importance of birds as browsers, pollinators and seed dispersers in New Zealand forests. New Zealand Journal of Ecology 12:27-33.

Clout, M. N., B. J. Karl, R. J. Pierce, and H. A. Robertson. 1995b. Breeding and survival of New Zealand pigeons (Hemiphaga novaeseelandiae). Ibis 137:264-271.

Cousins, R. A. 2010. Kereru (Hemiphaga novaeseelandiae) - Impact injuries, morphometrics, moult and plumage. Unpubl. M.Sc. thesis. Massey University, New Zealand. 
Dijkgraaf, A. C. 2002. Phenology and frugivory of large-fruited species in northern New Zealand and the impacts of introduced mammals. Unpubl. Ph.D. thesis. University of Auckland, New Zealand.

Dilks, P., G. Elliot, and C. O'Donnell. 1995. Mist netting techniques. Ecological Management (3), Department of Conservation, Wellington.

Dunn, P. L. 1981. The feeding ecology of the New Zealand Pigeon. Unpubl. M.Sc. thesis. University of Otago, Degree.

Froude, V. A. 2009. Changes in native forest bird distribution and abundance in Wellington City Council Reserves 2001-2009. Pacific EcoLogic Ltd, Bay of Islands, New Zealand.

Garden, J., C. McAlpine, A. Peterson, D. Jones, and H. Possingham. 2006. Review of the ecology of Australian urban fauna: A focus on spatially explicit processes. Austral Ecology 31:126-148.

Gaston, K., P. Warren, K. Thompson, and R. Smith. 2005. Urban Domestic Gardens (IV): The Extent of the Resource and its Associated Features. Biodiversity and Conservation 14:3327-3349.

Gillies, C. S., M. Hebblewhite, S. E. Nielson, M. A. Krawchuk, C. L. Aldridge, J. L. Frair, D. J. Saher, C. E. Stevens, and C. L. Jerde. 2006. Application of random effects to the study of resource selection by animals. Journal of Animal Ecology 75:887-898.

Goodwin, D. 1983. Pigeons and doves of the world. Cornell University Press, Ithaca, New York.

Harwood, H. P. 2002. Seasonal availability and abundance of tree fruit species utilised by kukupaa (Hemiphaga novaeseelandiae). Unpubl. M.Sc. thesis. University of Auckland.

Heather, B., and H. Robertson 2005. The Field Guide to the Birds of New Zealand. Viking, Auckland.

Hill, M. T. 2003. Diet, dispersal and distribution of kereru (Hemiphaga novaeseelandiae) in a lowland podocarp-hardwood forest. Unpubl. M.Sc. thesis. . Massey University.

Hostetler, M. 2001. The importance of multi-scale analyses in avian habitat selection studies in urban environments in J. M. Marzluff, R. Bowman, and R. Donnelly, editors. Avian ecology and conservation in an urbanizing world. Kluwer Academic Publishers, Norwell, MA.

Hostetler, M., and C. S. Holling. 2000. Detecting the scales at which birds respond to structure in urban landscapes. Urban Ecosystems 4:25-54.

Innes, J., G. Nugent, K. Prime, and E. B. Spurr. 2004. Responses of kukupa (Hemiphaga novaeseelandiae) and other birds to mammal pest control at Motatau, Northland. New Zealand Journal of Ecology 28:73-81. 
James, R. E. 1995. Breeding ecology of the New Zealand Pigeon at Wenderholm Regional Park, Unpubl. M.Sc. thesis. University of Auckland, New Zealand.

James, R. E., and M. N. Clout. 1996. Nesting success of New Zealand Pigeons (Hemiphaga novaeseelandiae) in response to a rat (rattus rattus) poisoning programme at Wenderholm Regional Park. New Zealand Journal of Ecology 20:45-51.

Johnson, D. H. 1980. The comparison of usage and availability measurements for evaluating resource preferences. Ecology 61:65-71.

Karan, A. 2000. Diet of kereru in an urban area: implications for weed dispersal. Unpubl. M.Sc. thesis. University of Auckland.

Kenward, R. 2001. A manual for wildlife radio tagging. Academic Press, London.

Kotliar, N. B., and J. A. Wiens. 1990. Multiple scales of patchiness and patch structure: a hierarchical framework for the study of heterogeneity. Oikos 59:253-260.

Mander, C., R. Hay, and R. Powlesland. 1998. Monitoring and management of kereru (Hemiphaga novaeseelandiae). Department of Conservation Technical Series No. 15, Wellington, New Zealand.

Mathieu, R., C. Freeman, and J. Aryal. 2007. Mapping private gardens in urban areas using object-oriented techniques and very high-resolution satellite imagery. Landscape and Urban Planning 81:179-192.

McDonnell, M. J., and S. T. A. Pickett. 1990. Ecosystem Structure and Function along Urban-Rural Gradients: An Unexploited Opportunity for Ecology. Ecology 71:12321237.

McEwen, W. M. 1978. The food of the New Zealand pigeon (Hemiphaga novaeseelandiae novaeseelandiae). New Zealand Journal of Ecology 1:99-108.

Miller, J. R., J. M. Fraterrigo, N. T. Hobbs, D. M. Theobald, and J. A. Wiens. 2001 Urbanization, avian communities, and landscape ecology in J. M. Marzluff, R. Bowman, and R. Donnelly, editors. Avian ecology and conservation in an urbanizing world. Kluwer Academic Publishers, Norwell, MA.

Miskelly, C. M., J. E. Dowding, G. P. Elliot, R. A. Hitchmough, R. G. Powlesland, H. A. Robertson, P. M. Sagar, R. P. Scofield, and G. A. Taylor. 2008. Conservation status of New Zealand Birds, 2008. Notornis 55:117-135.

Nugent, G., W. Fraser, and P. Sweetapple. 2001. Top down or bottom up? Comparing the impacts of introduced arboreal possums and [']terrestrial' ruminants on native forests in New Zealand. Biological Conservation 99:65-79.

O'Neill, R. V., D. L. Deangelis, J. B. Wade, and T. F. H. Allen 1986. A heirarchical concept of the ecosystem. Princeton University Press, Princeton, NJ. 
Oliver, D. L., and G. W. Lollback. 2010. Breeding habitat selection by the endangered Regent Honeyeater Anthochaera phrygia (Meliphagidae) at the local and landscape scale. Pacific Conservation Biology 16:27-35.

Powlesland, R. G., and C. M. Miskelly. 9 July 2008. Kereru status re-evaluated. Kereru News No. 65 [email newsletter]. Available at:

http://www.kererudiscovery.org.nz/news/kereru-news-archive/.

Powlesland, R. G., L. R. Moran, and D. M. Wotton. 2011. Satellite tracking of kereru (Hemiphaga novaeseelandiae) in Southland, New Zealand: impacts, movements and home range. New Zealand Journal of Ecology 35:229-235.

Powlesland, R. G., D. E. Wills, A. C. L. August, and C. K. August. 2003. Effects of a 1080 operation on kaka and kereru survival and nesting success, Whirinaki Forest Park. New Zealand Journal of Ecology 27:125-137.

Prendergast, S. T. 2006. The impact of predation on the kereru (Hemiphaga novaeseelandiae) on Banks Peninsula. Unpubl. M.Sc. thesis. Lincoln University, New Zealand.

R Development Core Team. 2010. R: A Language and Environment for Statistical Computing. R Foundation for Statistical Computing, Vienna, Austria. Available at: http://www.R-project.org/.

Rodgers, A. R., A. P. Carr, L. Smith, and J. G. Kie. 2005. HRT: Home Range Tools for ArcGIS. Ontario Ministry of Natural Resources, Centre for Northern Forest Ecosystem Research, Thunder Bay, Ontario, Canada.

Schotborgh, H. M. 2005. An analysis of home ranges, movements, foods and breeding of kereru (Hemiphaga novaeseelandiae) in a rural-urban landscape on Banks Peninsula, New Zealand. Unpubl. M.Sc. thesis. Lincoln University, New Zealand.

Tremblay, J. A., J. Ibarzabal, C. Dussault, and J.-P. L. Savard. 2009. Habitat requirements of breeding Black-backed woodpeckers (Picoides arcticus) in managed, unburned boreal forest. Avian Conservation and Ecology 4:[online] URL: http://www.ace.eco.org/vol4/iss1/art2/.

United Nations. 2007. World urbanization prospects: the 2007 revision population database. United Nations, New York: Available at: http://esa.un.org/unup/.

United Nations. 2011. World urbanization prospects: The 2011 Revision. United Nations, New York. Available at: http://esa.un.org/unpd/wup/Documentation/highlights.htm.

Wellington City Council. 2007. Otari Native Botanic Garden and Wilton's Bush Reserve Management Plan. Wellington City Council, Wellington, New Zealand.

Wiens, J. A. 1989. Spatial scaling in ecology. Functional Ecology 3:385-397.

Wotton, D. M. 2007. Consequences of dispersal failure: kereru and large seeds in New Zealand. University of Canterbury. 


\section{CHAPTER FOUR}

\section{Early post-release settlement behaviour of rehabilitated kereru}

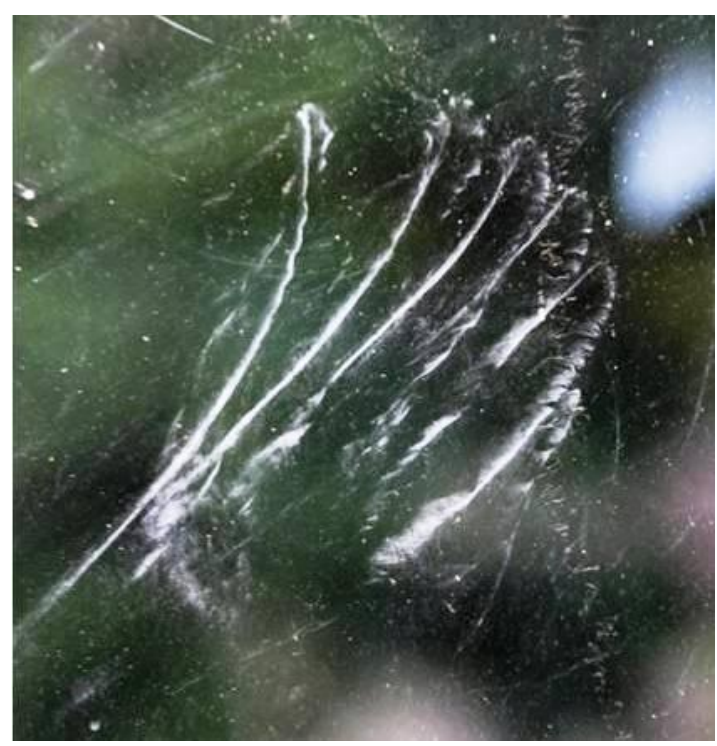

Imprint of a kereru wing after impact with a window. Photo by Taffy Parry.

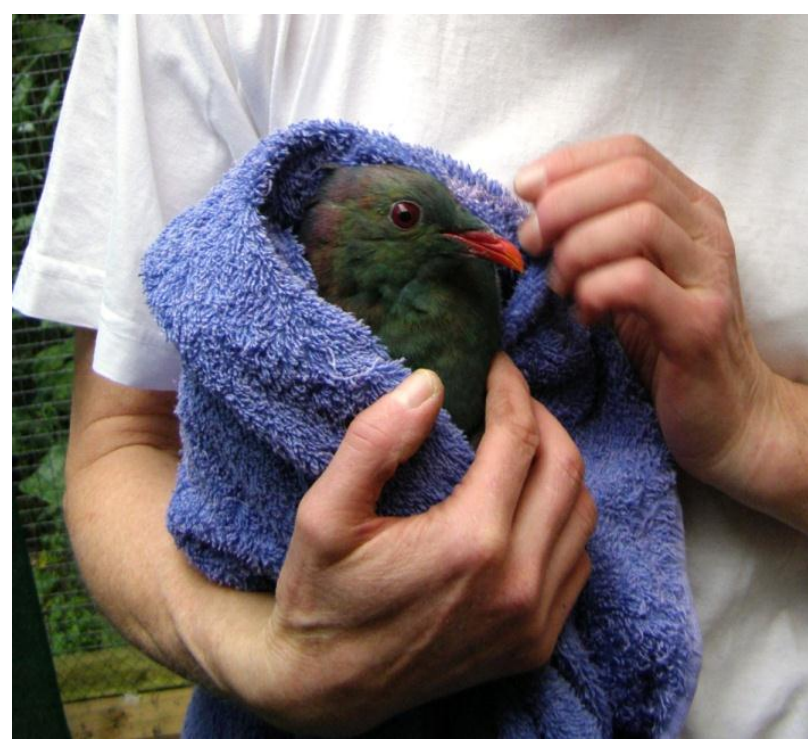

Kereru in a rehabilitation centre in Wellington. Photo by Monica Awasthy. 


\section{Abstract}

Wildlife rehabilitation is frequently cited as a viable and effective method for the conservation and management of small populations. However, many biologists are critical of the conservation value of rehabilitation programs as they are seldom empirically evaluated. In this study, kereru (Hemiphaga novaeseelandiae; New Zealand Pigeon) were monitored during the early post-release period following rehabilitation. I applied an Informationtheoretic approach to test multiple competing hypotheses for the time taken to initially settle and the linear distance travelled to settlement as early metrics of rehabilitation success. Results showed consensus between both sets of models, with the sex of the bird, the random effect of the release site, the severity of the injury sustained, and the time of year a bird was released all receiving substantial support (i.e. $\sum \omega>0.95$ ). Contrary to previous studies of rehabilitated wildlife, models that included the time spent in captivity or the level of urbanisation at the release site received no support. Models receiving moderate support also suggested that social conflict with resident conspecifics may play an early and critical role in an individual's ability to resume normal behaviours, such as feeding. These results suggest that kereru should be treated on a case-by-case basis and that the time an individual has spent in captivity should be considered as it relates to the severity of injury. It also highlights that settlement behaviour during the early post-release phase is likely an important proximate determinant of longer-term success of the rehabilitation process. 


\section{Introduction}

Large amounts of time, effort and money are invested in rehabilitating and releasing injured wildlife each year (e.g. Estes 1992). Rehabilitated wildlife release is often cited as a strategy in the conservation and management of small populations and species of public interest (Mander et al. 2003; Moore et al. 2007), or as a means of developing and testing methodologies for reintroducing threatened or endangered species through the use of common species (Molony et al. 2006; Moore et al. 2007). People's interest in rehabilitating injured wildlife can also provide biologists with fortuitous research opportunities to study the re-integration behaviour of wild animals. People are often motivated by an emotional need to assist animals, particularly those that have been affected by human actions, or those that appear to be helpless without our intervention (Howard \& Jones 2004; Moore et al. 2007). Thus, rehabilitation is often undertaken in response to anthropogenic environmental disasters such as oil spills (e.g. Estes 1998; Goldsworthy et al. 2000; Moore et al. 2007), injuries sustained from urban infrastructure such as roads and buildings (e.g. Fajardo et al. 2000), or general concerns over animal welfare.

The scientific rigour and conservation value of wildlife rehabilitation however, remains controversial as many biologists consider it to be emotionally motivated, lacking clear aims and outcomes, seldom empirically evaluated, and unnecessary for robust populations (Dubois \& Fraser 2003; Moore et al. 2007; Sharp 1996). Nevertheless, if appropriate inferences and statistical approaches are employed that account for the small sample sizes collected through such opportunistic sampling techniques, then behaviour and settlement patterns of rehabilitated wild animals can be scientifically evaluated and may add valuable information that has been lacking thus far in the debate.

It is important to recognize that many rehabilitation facilities do not have the infrastructure, labour, or financial support necessary for post-release monitoring and as a 
consequence the rehabilitation process most often ends at the point of release. The success of such programs are generally measured using release rates, calculated as the number of animals released, divided by the total number of animals admitted, minus animals dead on arrival (Miller 2000). Clearly, this assessment is limited, as release rates only give a measure of treatment success. The ultimate measures of rehabilitation success are fitness units, mainly survival to the point achieving reproductive success. However, in most cases this is logistically unfeasible and so proximate measures are often accepted as surrogates. In fact, post-release behaviour and ranging movements that mirror those of wild conspecifics have been used as a baseline or proximate measure of early rehabilitation success (e.g., monkeys; Guy et al. 2012).

A small number of post-release studies have been conducted to determine both the short- and long-term success of rehabilitation programs (for example, Anderson et al. 1996; Goldsworthy et al. 2000; Griffiths et al. 2010; Lander et al. 2002; Molony et al. 2006). However, each employed a different measure of rehabilitation success, making it difficult to draw general conclusions. While some studies defined success as survival beyond a predetermined time period (usually a few weeks; e.g., Griffiths et al. 2010), others attempted to use longer-term mark-recapture data (e.g., Goldsworthy et al. 2000) or compare survival of rehabilitated animals with their wild counterparts (e.g., Fajardo et al. 2000). Despite these differing measures, these studies provide an important base from which to generate a priori hypotheses about the proximate factors that may influence the post-release success of wildlife rehabilitation.

Kereru (Hemiphaga novaeseelandiae; New Zealand Pigeon) are one of the most common native birds admitted into rehabilitation in New Zealand each year. These large forest-dwelling, fruit eating pigeons were once in nationwide decline but have seemingly become abundant in some of New Zealand's urban landscapes (Miskelly et al. 2008), where 
they are frequently injured, rehabilitated and released. The most frequent causes of injury and death to urban kereru are window and vehicle strikes (37\% of admissions in Dunedin; Daglish 2005). Occasionally, starvation and harassment by domestic pets such as dogs and cats can also contribute to the problem. Kereru are iconic and play an important ecological, perhaps keystone, role in the dispersal of many large-seeded native fruit trees (Clout \& Hay 1989) and so can elicit a strong public response towards their conservation and rehabilitation.

Kereru can display relatively sedentary behaviour for periods of weeks and even months. However, they are also capable of making long distance flights of over $10 \mathrm{~km}$ (Powlesland et al. 2011). Some of these movements occur seasonally and so are thought to be in response to the availability of favoured food sources (Clout et al. 1986; Hill 2003). Given that many urban areas now increasingly provide suitable core feeding areas for kereru, the frequent injuries sustained within these modified landscapes could potentially offset seasonal movement patterns. Further, very little is known about kereru sociality, and conflict with conspecifics over favoured food sources may affect the ability of kereru to re-integrate into the wild. It is therefore key to understand social behavior as it relates to patterns of movement. In this study, I used post-release movements of rehabilitated kereru as an early metric for post-release success. The overall aim was to investigate the factors influencing the early settlement patterns of a rehabilitated native bird post-release.

\section{Methods}

\section{REHABILITATION, RELEASE \& MONITORING OF KERERU}

Kereru, like most native New Zealand birds, are under the legal protection of the Department of Conservation (DOC), and so approved rehabilitators must operate within permit guidelines (Mander et al. 2003). Although the DOC provides minimum standards as a guideline (Mander et al. 2003), the rehabilitation process can vary dramatically between centres. Thus, the time an animal spends in captivity is dependent upon the rehabilitator's 
protocols, which is often dictated by an animal's condition at release, the centres resources (including space), and how they release birds (i.e. soft release takes longer than hard release because the animal can depart when it chooses). As a consequence, kereru in this study were released at varying times of the year following differing rehabilitation and release protocols. During Feb 2007-Dec 2009, 11 kereru were released (Table 1) from two areas of the lower North Island of New Zealand; Nga Manu Nature Reserve (NMNR; 40 $51^{\prime} \mathrm{S}, 175^{\circ} 03^{\prime} \mathrm{E}$ ), a 14 hectare reserve of coastal lowland swamp bordered by residential areas and pastureland of the Waikanae township, and various sites around the highly fragmented, dense residential suburbs of Wellington City with Native Bird Rescue Wellington Trust (NBRWT; $\left.41^{\circ} 17^{\prime} \mathrm{S} 174^{\circ} 46^{\prime} \mathrm{E}\right)$. The level of urbanisation at each release site varied from wildlands to suburban areas (Figure 1). 


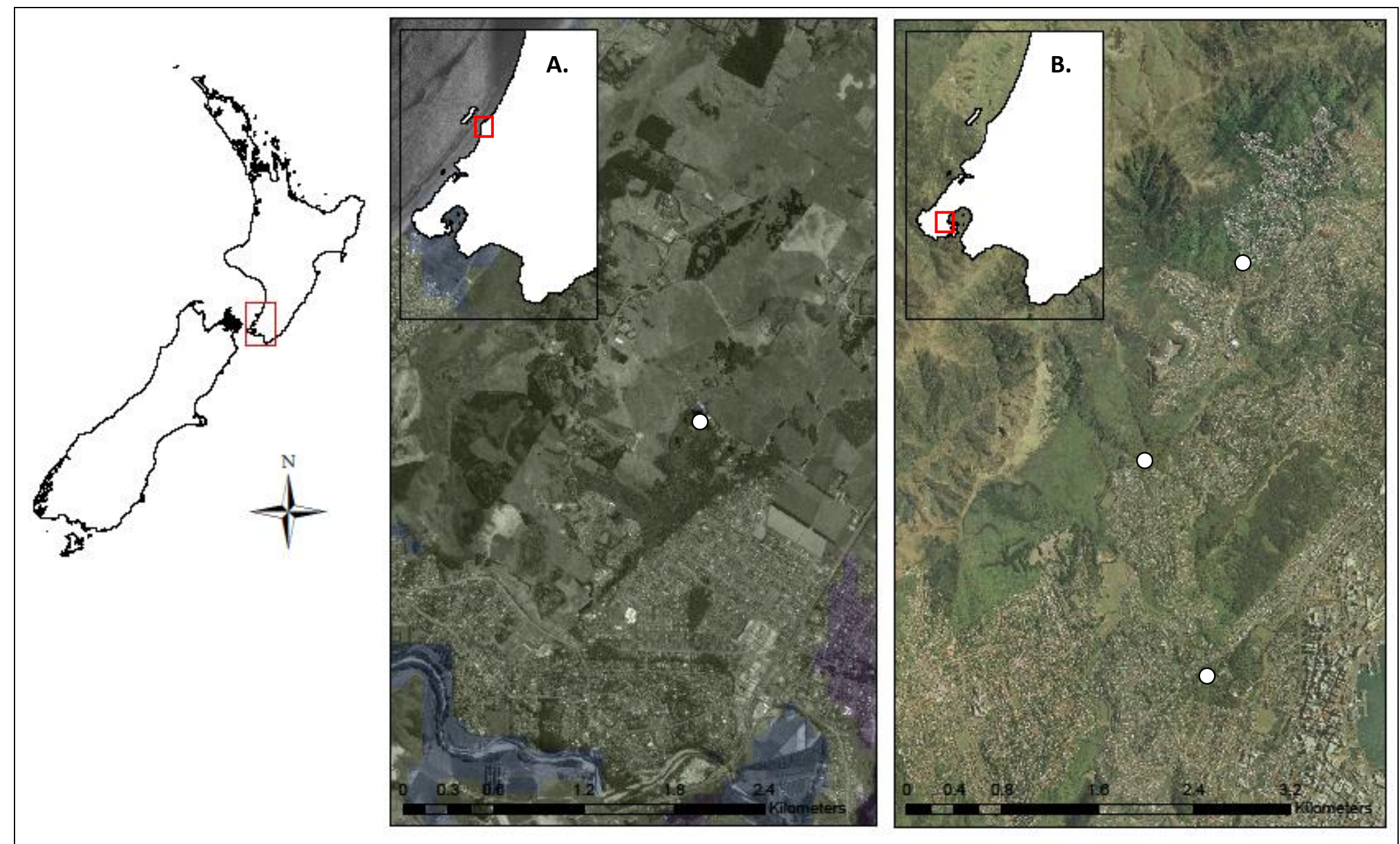

Figure 1. Map showing locations of kereru release sites: (A) the wild-rural landscapes surrounding Nga Manu Nature Reserve, near the Waikanae township $\left(40^{\circ} 51^{\prime} \mathrm{S}, 175^{\circ} 03^{\prime} \mathrm{E}\right)$, and (B) the suburban landscape of Wellington City $\left(41^{\circ} 17^{\prime} \mathrm{S} 174^{\circ} 46^{\prime} \mathrm{E}\right)$. Kereru release sites are shown with $\bigcirc$. 
Table 1. The kereru (Hemiphaga novaeseelandiae; New Zealand Pigeon) released during this study. Individuals were recorded as adults (A), juveniles (J), males (M), or females (F). The breeding season was considered as dates between September and February, and non-breeding season dates between March and August. Release locations in Wellington were Otari-Wilton's Bush (OWB), Wellington Botanic Gardens (WBG), and the suburbs of Days Bay and Ngaio (all hard releases). The Waikanae release location was Nga Manu Nature Reserve (NMNR; all soft releases). If conspecifics were present, the number of interactions with other kereru is indicated in brackets ( ). The data is organised by the date each individual was tagged. Individuals shaded in grey were not included in analyses due to incomplete data or different monitoring protocols from the other nine birds.

\begin{tabular}{|c|c|c|c|c|c|c|c|c|c|}
\hline Band no. & $\begin{array}{l}\text { Jess } \\
\text { colour(s) }\end{array}$ & $\begin{array}{l}\text { Age/ } \\
\text { Sex }\end{array}$ & $\begin{array}{l}\text { Weight } \\
(\mathrm{g})\end{array}$ & $\begin{array}{l}\text { Date } \\
\text { tagged }\end{array}$ & $\begin{array}{l}\text { Date } \\
\text { released }\end{array}$ & $\begin{array}{l}\text { Time in } \\
\text { captivity } \\
\text { (days) }\end{array}$ & $\begin{array}{l}\text { Release } \\
\text { location }\end{array}$ & $\begin{array}{l}\text { Conspecifics } \\
\text { (no. of } \\
\text { interactions) }\end{array}$ & Last known activity \\
\hline S-53668 & Green/- & $\mathrm{A} / \mathrm{F}$ & 600 & 29 March, 2007 & 8 May 2007 & 40 & Days Bay & No & Lost - no transmitter signal $(15 / 6 / 07)$ \\
\hline S-53678 & Blue/Yellow & $\mathrm{A} / \mathrm{F}$ & 630 & 7 July 2008 & 10 August, 2008 & 34 & OWB & Yes (6) & Alive - re-sighted (17/9/08) \\
\hline S-53679 & Green/Black & $\mathrm{A} / \mathrm{M}$ & 570 & 10July $2008 *$ & 30 October, 2008 & 7 & OWB & Yes (3) & Lost - no transmitter signal $(4 / 12 / 08)$ \\
\hline S-53670 & -/Blue & $\mathrm{A} / \mathrm{M}$ & 675 & 5 August 2008 & 14 August, 2008 & 424 & NMNR & Yes (9) & Alive - re-sighted $(23 / 10 / 08)$ \\
\hline S-53681 & Yellow/- & $\mathrm{A} / \mathrm{F}$ & 570 & 5 August, 2008 & 14 August, 2008 & 280 & NMNR & Yes (4) & Lost - no transmitter signal $(4 / 12 / 08)$ \\
\hline S-53683 & -/White & $\mathrm{A} / \mathrm{F}$ & 525 & 27 February, 2009 & 4 June, 2009 & 224 & NMNR & Yes $(0)$ & Alive - re-sighted $(5 / 7 / 09)$ \\
\hline S-53684 & Black/Blue & $\mathrm{J} / \mathrm{F}$ & 485 & 8 April, 2009 & 4 May, 2009 & 30 & WBG & Yes (16) & Died - found in a tree $(13 / 5 / 09)$ \\
\hline S-53676 & White/- & $\mathrm{J} / \mathrm{F}$ & 652 & 8 May, 2009 & 8 May, 2009 & 30 & Ngaio & Yes (9) & Alive - re-sighted $(6 / 6 / 10)$ \\
\hline S-53685 & Red/Red & $\mathrm{A} / \mathrm{M}$ & 640 & 12 May, 2009 & 4 June, 2009 & 595 & NMNR & Yes (7) & Lost - no transmitter signal $(17 / 7 / 09)$ \\
\hline S-53687 & Yellow/Yellow & $\mathrm{A} / \mathrm{F}$ & 630 & 12 May, 2009 & 28 October, 2009 & 1266 & NMNR & Yes (1) & Alive - re-sighted (1/12/09) \\
\hline
\end{tabular}

*Date originally tagged as a wild bird (see Chapter 3), but was found injured by member of public and taken into rehabilitation on 23 October 2008 
Each bird was captured in its aviary a minimum of three days pre-release and fitted with a tail-mounted radio-transmitter (SIRTrack Limited, Havelock North, NZ) between the two central retrices using quick-bond glue and dental floss (see Appendix 2). I attempted to fit transmitters as soon as possible after permission was given for release by rehabilitators in order to minimise the amount of time a bird remained in captivity. Tail-mounted transmitters weighed less than $5 \mathrm{~g}$ and did not require recapture for removal as they are shed by the bird during moult. In addition, all birds were marked with a unique, numbered metal leg band and coloured leg jesses of nylon-reinforced PVC for visual identification of individuals in the field. Leg jesses also enabled location of marked birds after transmitter batteries were exhausted or the transmitter was shed before the end of its battery life (battery life was approx. 14 months). Each bird was assessed for body condition by dividing the weight (g) by the tarsus length $(\mathrm{cm})$ to correct for variation in size. Between three and five contour feathers were taken for DNA sexing at the Equine Parentage and Animal Genetics Service Centre, Massey University, Palmerston North. I conducted all molecular work under the supervision of experienced technicians using the centre's non-discloseable techniques (Appendix 3).

Kereru at NMNR in Waikanae were soft-released from an aviary on-site, while those released in Wellington by NBRWT were hard-released at the location where they were found injured. After release, I visually located each radio-tagged individual on foot using a radio-receiver and hand-held yagi antenna (SIRTrack Limited, Havelock North, NZ). Kereru were located at least once every two hours during day-light hours every day until they initially settled. Settling was determined by the cease of frequent long-distance movements and the resumption of normal feeding behaviour as compared to wild conspecifics. After this, kereru were located 
and observed a minimum twice daily for another five days to ensure no further movement, then weekly until the end of the study or a bird was unable to be located. On the rare occasion when a bird was not visually sighted but known to be hidden in nearby canopy, the location was marked from point of the strongest radio signal. All locations were marked with a hand held Garmin GPS with a maximum error of $\pm 15 \mathrm{~m}$.

All things being equal individual birds should take similar times and travel similar distances to settle before resuming normal feeding behaviour postrehabilitation. However, such times and distances are likely to be strongly linked to the landscape structure, availability of resources, and interactions with conspecifics. For example, it is reasonable to assume that in a patchy landscape kereru may have to travel further to find available food sources than in the more densely forested areas. Thus, I used the time taken to initially settle (days) and the linear distance travelled to initially settle $(\mathrm{kms})$ as the dependent variables in my analyses, and considered them separately in order to account for variation in landscape structure at release sites.

\section{COMPILING THE CANDIDATE HYPOTHESES}

I derived a candidate set of hypotheses from previous studies that had described or predicted factors contributing to avian rehabilitation success. Although the studies upon which I based my hypotheses had varying definitions of rehabilitation success (usually a predetermined temporal measure of survival), I was interested in how these same variables (fixed-effects; Table 2) would perform within an earlier and possibly critical timeframe post-release. Further, I was interested in whether these variables predicted earlier behavioural indicators of longer-term survival, such as the ability to settle by resuming normal feeding patterns and reintegrating socially with wild conspecifics. Thus, these hypotheses were based upon studies that described various combinations of individual characteristics (age, sex), 
rehabilitation experience (injury, condition on admittance, time of year admitted, and time in captivity), release characteristics (condition at release, release type, time of year released, level of urbanisation, and novel release site), and post-release experience (presence of conspecifics and social interactions)(Table 3).

Table 2. Description of the predictors (fixed-effects) featured in the candidate set of 18 hypotheses in Table 4 . Note that the predictor "injury" was reduced to a binary variable (obvious injury/not obvious injury) during statistical analysis in order to reduce the number of parameters in the models. Predictors that were not included in the final set of 11 hypotheses are shaded in grey (see Table 2 and "Compiling the candidate model set").

\begin{tabular}{llll}
\hline & Predictor (fixed effects) & Variable type & Measure \\
\hline $\begin{array}{l}\text { Individual } \\
\text { characteristics }\end{array}$ & Age & Binary & juvenile/adult \\
& Sex & Binary & male/female \\
\hline $\begin{array}{l}\text { Rehabilitation } \\
\text { experience }\end{array}$ & Injury (degree of trauma) & Category & wing/chest/head/superficial \\
& Condition on admittance & Continuous & weight* tarsus length \\
& Time of year admitted & Category & breeding/non-breeding \\
& Time in captivity & Continuous & days \\
\hline $\begin{array}{l}\text { Release } \\
\text { characteristics }\end{array}$ & Condition at release & Continuous & weight* tarsus length \\
& Release type & Binary & hard/soft \\
& Time of year released & Binary & breeding/non-breeding \\
& Level of urbanisation & Category & wild/exurban/green suburban \\
& Novel release site & Binary & yes/no \\
\hline $\begin{array}{l}\text { Post-release } \\
\text { experience }\end{array}$ & Presence of conspecifics & Binary & yes/no \\
\hline & Interactions with conspecifics & Continuous & number of times \\
\hline
\end{tabular}

The first five hypotheses were based upon the small number of avian rehabilitation studies which included mostly owls (hypotheses $1 \& 2$; Fajardo et al. 2000; Griffiths et al. 2010), and oiled seabirds (hypotheses 3, 4 \& 5; Anderson et al. 2000; Goldsworthy et al. 2000; Sharp 1996). Since the scientific literature on postrelease monitoring of rehabilitated birds was sparse, I also included hypotheses based on the mammalian rehabilitation literature where the predictors of success or survival 
were comparable within an avian context (hypotheses $6 \& 7$; Ben-David et al. 2002;

Molony et al. 2006). I then added three hypotheses based upon the only other studies of rehabilitated kereru, which included post-release survival of juvenile kereru (hypothesis 8; Powlesland \& Willans 1996), habitat use post-release (hypothesis 9; Daglish 2005), and predictors of kereru rehabilitation success (hypothesis 10; Daglish 2005). Two more hypotheses were included that described the best predictor of wildlife release rates (hypothesis 11; Molony et al. 2007), and the rehabilitator protocols specific to this study (hypothesis 12). Finally, I added five more hypotheses consisting of one to two predictors to explore the early stages of spatial and temporal settlement patterns in kereru (hypotheses 13-18). 
Table 3. Predictors (fixed-effects) featured in the candidate set of 18 hypotheses for wildlife rehabilitation success. Hypotheses are: post-release survival of (1) owls (Fajardo et al. 2000); (2) hard-released juvenile owls (Griffiths et al. 2010); (3) oiled seabirds (Sharp 1996); and (4) oiled penguins (Goldsworthy et al. 2000); (5) survival, condition and behaviour of oiled coots (Anderson et al. 2000); (6) degree of oiling, captivity, age and release site in river otters (Ben-David et al. 2002); (7) translocation and captivity in hedgehogs (Molony et al. 2006); (8) post-release survival of juvenile kereru (Powlesland \& Willans 1996); (9) post-release habitat use by kereru (Daglish 2005); (10) predictors of kereru rehabilitation success (Daglish 2005); (11) best predictor of wildlife release rates (Molony et al. 2007); (12) rehabilitator protocol; (13) sex of the animal; (14) condition at release; (15) amount of time spent in captivity; (16) time of year released; (17) competition with conspecifics; and (18) interactions with conspecifics. Note that the predictor "injury" includes degree of physical trauma experienced, including oiling. Models shaded in grey were excluded from the final candidate set of models. The $\circ$ denotes predictors that were excluded from the analysis in order to test models that included fewer parameters.

\begin{tabular}{|c|c|c|c|c|c|c|c|c|c|c|c|c|c|c|c|c|c|c|c|}
\hline & & \multicolumn{18}{|c|}{ HYPOTHESES, full set } \\
\hline & & 1 & 2 & 3 & 4 & 5 & 6 & 7 & 8 & 9 & 10 & 11 & 12 & 13 & 14 & 15 & 16 & 17 & 18 \\
\hline $\begin{array}{l}\text { Individual } \\
\text { characteristics }\end{array}$ & $\begin{array}{l}\text { Age } \\
\text { Sex }\end{array}$ & $\bullet$ & & & $\bullet$ & & $\bullet$ & & & & 0 & & & $\bullet$ & & & & & \\
\hline $\begin{array}{l}\text { Rehabilitation } \\
\text { experience }\end{array}$ & $\begin{array}{l}\text { Injury (degree of trauma) } \\
\text { Condition on admittance } \\
\text { Time of year admitted } \\
\text { Time in captivity (days) }\end{array}$ & $\bullet$ & & o & $\bullet$ & $\bullet$ & $\bullet$ & $\bullet$ & & & $\begin{array}{l}\bullet \\
\\
\circ\end{array}$ & & $\bullet$ & & & $\bullet$ & & & \\
\hline $\begin{array}{l}\text { Release } \\
\text { characteristics }\end{array}$ & $\begin{array}{l}\text { Condition at release } \\
\text { Release type (hard vs. soft) } \\
\text { Time of year released } \\
\text { Level of urbanisation } \\
\text { Novel release site }\end{array}$ & $\bullet$ & & $\bullet$ & $\bullet$ & $\bullet$ & $\bullet$ & $\bullet$ & $\bullet$ & $\bullet$ & & & $\bullet$ & & $\bullet$ & & & $\bullet$ & \\
\hline $\begin{array}{l}\text { Post-release } \\
\text { experience }\end{array}$ & $\begin{array}{l}\text { Presence of conspecifics } \\
\text { Interactions with conspecifics }\end{array}$ & & & & & & & & $\bullet$ & & & & & & & & & $\bullet$ & $\bullet$ \\
\hline
\end{tabular}




\section{COMPILING THE CANDIDATE MODEL SET \& STATISTICAL APPROACH}

In this study, I applied an information-theoretic (I-T) approach to compare models as competing hypotheses for early settlement patterns in rehabilitated kereru, arguably the most high risk period, post-release. The I-T approach works via two components: formulation of a set of candidate models, and selection of a model(s) for use in inference making. The development of a set of a priori models assumes a level of careful thinking and objective hypothesis formulation. A priori models can also prevent data mining, over-analysis, and the misuse of traditional multivariate analysis methods, all of which can lead to spurious relationships and Type II errors (Burnham \& Anderson 2002). Further, the ranking of the candidate models relative to each other, from useful to essentially useless, provides a quantitative measure of the plausibility and confidence in the "best" model given the data (Burnham \& Anderson 2002). In this way, the effects that may be more important than others can be teased apart by further examining the variables included within the "best" models.

The candidate hypotheses described earlier (Table 3), is to the best of my knowledge, the most complete set of individual characteristics that could influence post-release behaviour among kereru. However, several of the fixed-effects identified in the literature could not be measured or controlled for during data collection. For example, each rehabilitation centre followed different release type protocols that I could not manipulate (i.e. soft- vs. hard-release). In addition, while one centre minimised time in captivity and as a result released kereru throughout the year, the other centre held kereru in captivity until seasonal weather conditions were more favourable and more food resources were potentially available. Further, as a consequence of my small sample size, I attempted to minimise model sizes (i.e., number of parameters) because larger model sizes approach my sample size $(n=11)$. 
My full set of hypotheses was thus reduced to a candidate set of 11 models for analysis, consisting of only one to two parameters (Table 4).

Hypotheses for the time taken to settle and the distance travelled to settle were represented by linear regression models using the statistical program $\mathrm{R}$ ( $\mathrm{R}$ Core Development Team, 2010). The release site (i.e. Wellington or Waikanae) was included as a random effect in each model, due to my inability to experimentally control rehabilitator protocols dictating where a bird was released. I also included the random effect alone as a base model (\#19; Table 3), in order to determine how much the rehabilitator protocols that I could not control explained post-release movements. Akaike's information criterion adjusted for small sample size (AICc; Burnham \& Anderson 2002) was then used to contrast and assess strength of evidence for competing models. The use of AIC in model selection provided not only a measure of the relative goodness-of-fit for each statistical model, but also included a penalty for the number of estimated parameters to avoid over-fitting (Burnham \& Anderson 2002). I selected the model with the smallest $\mathrm{AIC}_{\mathrm{c}}$ value as the best among the models being compared, where models within two units of the best model were considered equally and most substantially supported, models within four to seven units received considerably less support, and greater than ten units essentially no support (Burnham $\&$ Anderson 2002). I also examined the Akaike weights $\left(\omega_{\mathrm{i}}\right)$ to further quantify the plausibility of each model as being the best model given my data (Burnham \& Anderson 2002). 


\section{Results}

The most common causes of admission into rehabilitation in this study were superficial injuries, including stunning and external bleeding, followed by breaks and strains to the wings (Figure 2). Differing rehabilitator protocols, resources, and the injury a bird had sustained, dictated the time spent in captivity which ranged from seven to 1266 days (Waikanae $n=6$, mean $=557.8$ days, $\mathrm{SE} \pm 188.34$, range $=224-1266$ days; Wellington $n=5$, mean $=28.2$ days, $S E \pm 5.61$, range $=7-40$ days $)$. Of the 11 kereru released, one from the Wellington group died within nine days (S-53684 "Black/Blue") and another from Waikanae shed its transmitter at release (S- 53686 "Blue/White"), thus leaving nine kereru for analysis (Table 1).

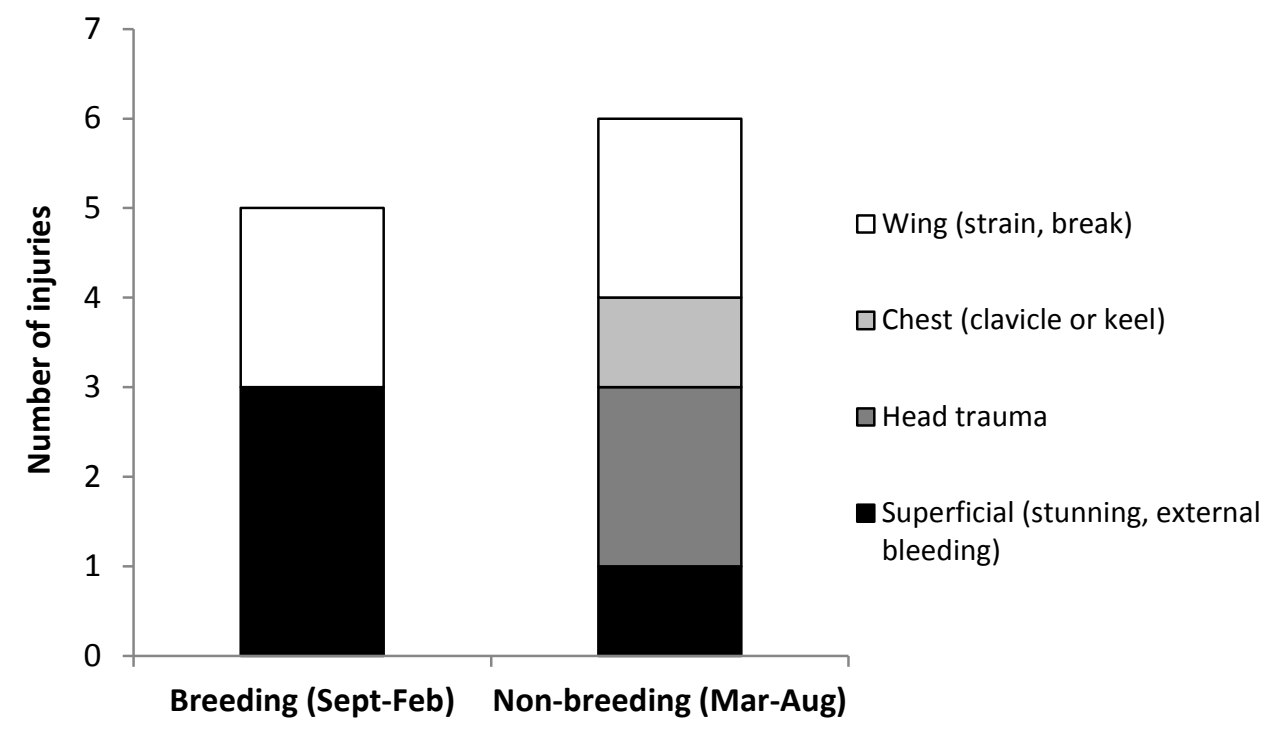

Figure 2. The type of injury sustained by the 11 kereru in this study in relation to the time of year admitted into rehabilitation. Note that the two juvenile kereru in this study were admitted during the non-breeding season from injuries sustained from suspected collisions with buildings; one was stunned and the other had a broken clavicle. 
The time taken for the nine kereru used in the modelling to reach an initial settling point varied from zero to eight days (mean $=4.78, \mathrm{SE} \pm 0.80$ ), while the distance travelled before initially settling varied from zero to $2.35 \mathrm{~km}$ (mean=0.89, $\mathrm{SE} \pm 0.32$ ).

Models for the time taken to settle and the distance travelled before settling were similar (Table 4). Most hypotheses under examination for both dependent variables were not supported (i.e. $\Delta \mathrm{AIC}_{\mathrm{c}}>10$; Table 4). Models that incorporated time spent in captivity, the level of urbanisation at the release site, or more than a single variable performed particularly poorly (Table 4). The models that received the most support, and thus formed the confidence set of models, were the sex of the bird (time, $\Delta \mathrm{AIC}_{\mathrm{c}}=0, \omega_{\mathrm{i}}=0.54$, Table $3 \mathrm{a}$; distance, $\Delta \mathrm{AIC}_{\mathrm{c}}=2.1, \omega_{\mathrm{i}}=0.21$, Table $4 \mathrm{~B}$ ), the random effect of the release site (time, $\Delta \mathrm{AIC}_{\mathrm{c}}=1.7, \omega_{\mathrm{i}}=0.23$, Table $4 \mathrm{~A}$; distance, $\Delta \mathrm{AIC}_{\mathrm{c}}=0, \omega_{\mathrm{i}}=0.60$, Table $4 \mathrm{~B}$ ), the best predictor of wildlife release rates (injury only; time, $\Delta \mathrm{AIC}_{\mathrm{c}}=2.8, \omega_{\mathrm{i}}=0.13$, Table $4 \mathrm{~A}$; distance, $\Delta \mathrm{AIC}_{\mathrm{c}}=4.1, \omega_{\mathrm{i}}=0.08$, Table $4 \mathrm{~B}$ ), and the time of year released (time, $\Delta \mathrm{AIC}_{\mathrm{c}}=4.8, \omega_{\mathrm{i}}=0.05$, Table $4 \mathrm{~A}$; distance, $\Delta \mathrm{AIC}_{\mathrm{c}}=5.0$, $\omega_{\mathrm{i}}=0.05$, Table 4B). Together, the sum of the weights of these three models was greater than 0.95. Models for the condition at release and interactions with conspecifics also received moderate support (i.e time, $\Delta$ AIC $5-9, \Sigma \omega_{\mathrm{i}}=0.04$, Table $4 \mathrm{~A}$; distance, $\Delta$ AIC 5-9, $\Sigma \omega_{\mathrm{i}}=0.06$, Table 4B). 
Table 4. Outcomes of 11 candidate models for: (A) time to settle (in days) post-release, and (B) distance to settle (kms) post-release. The variables included in each model, number of parameters $(\mathrm{K}), \mathrm{AIC}_{\mathrm{c}}$ values, $\mathrm{AIC}_{\mathrm{c}}$ differences $\left(\Delta_{\mathrm{i}}\right)$, and Akaike weight $\left(\omega_{\mathrm{i}}\right)$ are shown. Models are ranked from the smallest to largest $\mathrm{AIC}_{\mathrm{c}}$ value with the best supported models (confidence set, i.e. $\sum \omega>0.95$ ) shown in bold. Note that model nos. $3 \& 10$ exclude predictors from the original hypotheses ("injury" and "age"/"time of year admitted", respectively), in order to test biologically intuitive variations of the models that include fewer parameters.

\begin{tabular}{|c|c|c|c|c|c|c|}
\hline Model no. & Hypothesis, candidate set of models & Predictors (fixed effects) & $\bar{K}$ & $\overline{\mathrm{AIC}_{\mathrm{c}}}$ & $\Delta \mathrm{AIC}_{\mathrm{c}}$ & $\omega_{i}$ \\
\hline 13 & Sex of the bird & sex & 3 & 44.0 & 0 & 0.54 \\
\hline 19 & SITE (no fixed effects) & - & 1 & 45.7 & 1.7 & 0.23 \\
\hline 11 & Best predictor of wildlife release rates (Molony et al. 2007) & injury & 3 & 46.8 & 2.8 & 0.13 \\
\hline 16 & Time of year released & time of year released & 3 & 48.8 & 4.8 & 0.05 \\
\hline 14 & Condition at release & condition at release & 3 & 49.6 & 5.7 & 0.03 \\
\hline 18 & Interactions with conspecifics & interactions & 3 & 51.2 & 7.2 & 0.01 \\
\hline 9 & Post-release habitat use by kereru (Daglish 2005) & level of urbanisation & 4 & 54.3 & 10.4 & 0.00 \\
\hline 17 & Competition with conspecifics & time of year released + interactions & 4 & 54.7 & 10.7 & 0.00 \\
\hline 15 & Amount of time spent in captivity & time in captivity & 3 & 61.6 & 17.7 & 0.00 \\
\hline 10 & Predictors of kereru rehabilitation success (Daglish 2005) & injury + time in captivity & 4 & 64.1 & 20.1 & 0.00 \\
\hline 3 & Oiled seabirds (Sharp 1996) & time in captivity + condition at release & 4 & 65.7 & 21.7 & 0.00 \\
\hline
\end{tabular}

\begin{tabular}{|c|c|c|c|c|c|c|}
\hline Model no. & Hypothesis, candidate set of models & Predictors (fixed effects) & $\mathrm{K}$ & $\mathrm{AIC}_{\mathrm{c}}$ & $\Delta \mathrm{AIC}_{\mathrm{c}}$ & $\omega_{\mathrm{i}}$ \\
\hline 19 & SITE (no fixed effects) & - & 1 & 29.1 & $\mathbf{0}$ & 0.60 \\
\hline 13 & Sex of the bird & sex & 3 & 31.2 & 2.1 & 0.21 \\
\hline 11 & Best predictor of wildlife release rates (Molony et al. 2007) & injury & 3 & 33.2 & 4.1 & 0.08 \\
\hline 16 & Time of year released & time of year released & 3 & 34.1 & $\mathbf{5 . 0}$ & 0.05 \\
\hline 18 & Interactions with conspecifics & interactions & 3 & 34.5 & 5.4 & $\mathbf{0 . 0 4}$ \\
\hline 14 & Condition at release & condition at release & 3 & 35.7 & 6.6 & 0.02 \\
\hline 9 & Post-release habitat use by kereru (Daglish 2005) & level of urbanisation & 4 & 40.0 & 10.9 & 0.00 \\
\hline 17 & Competition with conspecifics & time of year released + interactions & 4 & 41.2 & 12.1 & 0.00 \\
\hline 15 & Amount of time spent in captivity & time in captivity & 3 & 45.9 & 16.8 & 0.00 \\
\hline 3 & Oiled seabirds (Sharp 1996) & time in captivity + condition at release & 4 & 51.3 & 22.2 & 0.00 \\
\hline 10 & Predictors of kereru rehabilitation success (Daglish 2005) & injury + time in captivity & 4 & 51.4 & 22.3 & 0.00 \\
\hline
\end{tabular}


Male kereru took longer to settle than female kereru (males $n=3$, mean=7 days, $\mathrm{SE} \pm 1.00$; females $\mathrm{n}=6$, mean=3.7 days, $\mathrm{SE} \pm 0.76$ ). Those birds that sustained obvious physical trauma (i.e. broken bones, external bleeding) varied greatly in the time taken to settle, while those without obvious physical trauma (i.e. stunned, internal head injury) were more uniform in their time taken to settle (Figure 3A).

In terms of the random effect for release type, all Waikanae kereru were soft-released into a novel site, and all Wellington kereru were hard-released at the site from which they were found injured, except for one individual in Wellington that was hard-released at a novel site because its injury location was unknown. Since the difference between release site treatments was only one bird that took far less time to settle than the other birds soft-released at the same site, it was not possible to determine if this was an effect of novel release site or of release type (Figure 3B). 

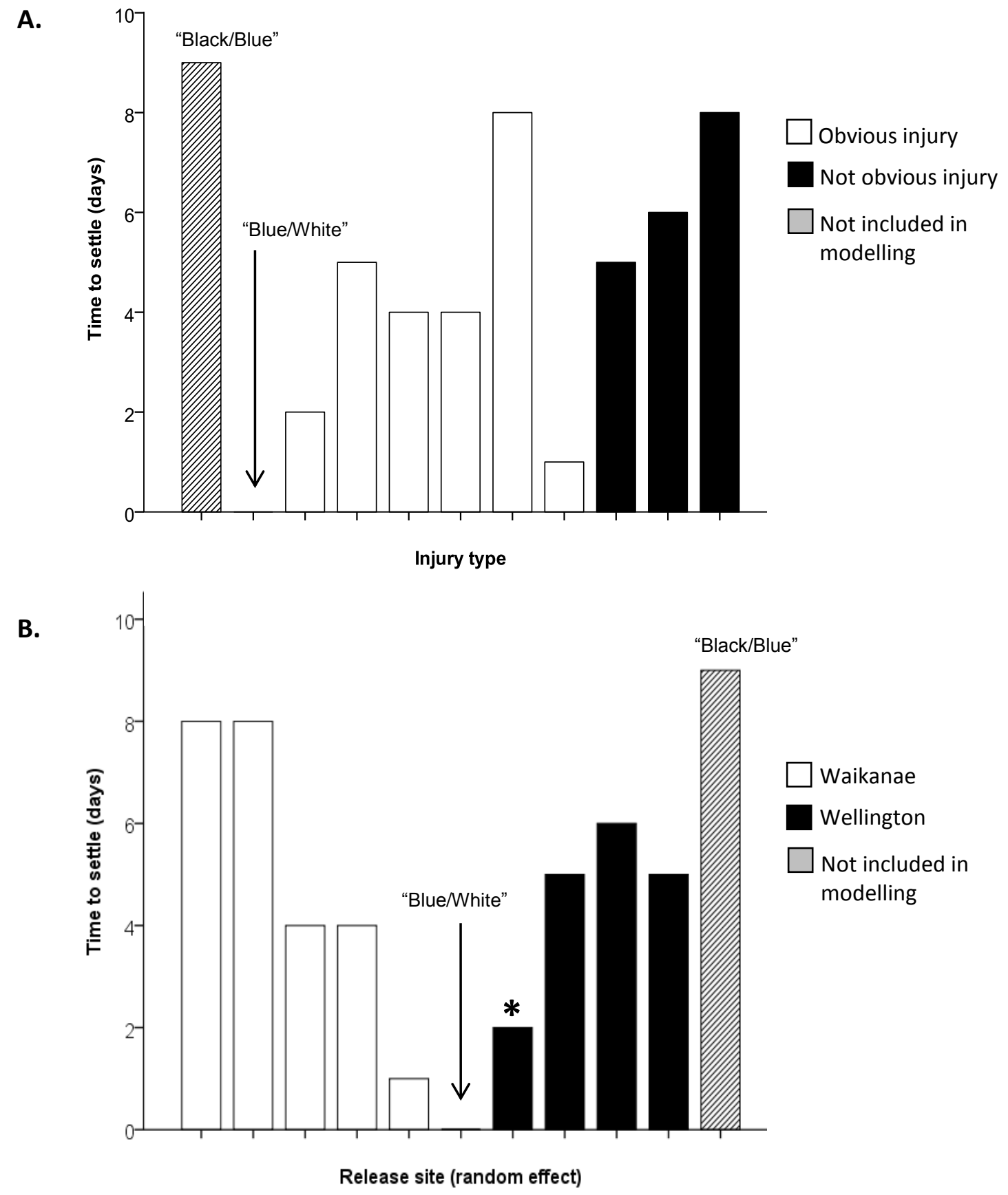

Figure 3. The time taken to settle (in days) for: (A) kereru with an obvious physical injury $(n=6)$ and those without an obvious physical injury $(n=3)$, and $(\mathbf{B})$ kereru soft-released in a novel site in Waikanae $(n=5)$ and hard-released in a familiar site in Wellington $(n=4)$. Data from two kereru that were excluded from the modelling are also included for comparison: "Blue/Black" (obvious physical injury, released in Wellington) and "Blue/White" (obvious physical injury, released in Waikanae). The * denotes the only Wellington bird to be hardreleased at a novel site. 
Male kereru travelled further $(\mathrm{n}=3$, mean $=1.60, \mathrm{SE} \pm 1.24$, range $=0.18-2.35 \mathrm{~km})$ than female kereru $(\mathrm{n}=6$, mean $=0.54, \mathrm{SE} \pm 0.25$, range $=0-1.57 \mathrm{~km})$ before settling. Kereru released in Waikanae had longer flight distances between suitable habitat patches and generally travelled further to settle than kereru released in Wellington (Figure 4). Interestingly, irrespective of the release site, those birds that experienced more social interactions with conspecifics travelled greater linear distances before settling than birds that experienced fewer interactions (Figure 4).

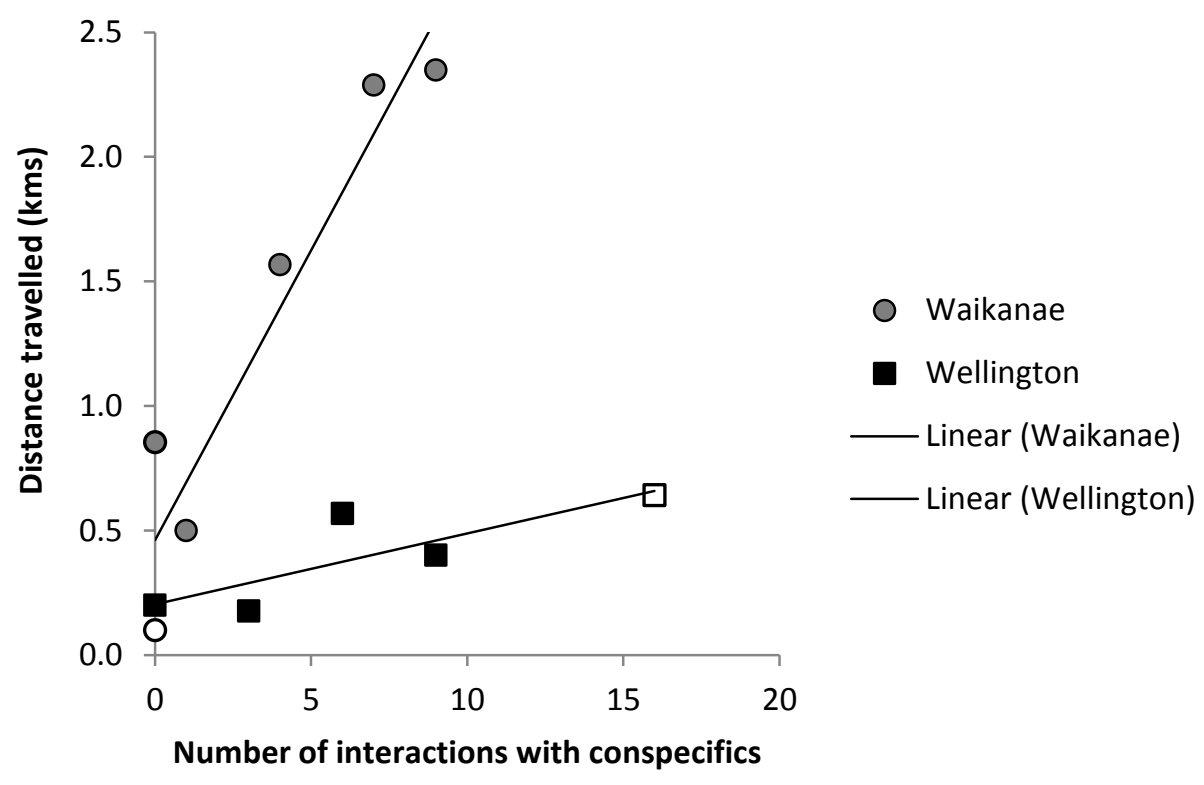

Figure 4. The distance travelled (in $\mathrm{kms}$ ) in relation to the number of interactions experienced with conspecifics for kereru released in Waikanae $(n=6)$ and Wellington $(n=5)$. Hollow data markers represent kereru that were not included in the modelling: "Black/Blue" ( $\square)$, a Wellington bird that died after nine days, and "Blue/White" (०), a Waikanae bird that was monitored following a different protocol because it dropped its transmitter a few hours post-release. 
Although not all the birds were included in the modelling due to incomplete data, inclusion of these omitted individuals in all the figures was particularly informative. For example, "Black/Blue" (Table 1), a juvenile bird released in Wellington, was repeatedly observed being chased by multiple wild birds, was never seen to feed, and continued to move until it died nine days after its release. Post-mortem examination revealed a broken clavicle and severe internal bleeding, most likely caused by sustained pressure on the newly healed area from frequent movements and aggressive wing beating encounters. In contrast, "Blue/White", an adult bird released in Waikanae, shed its transmitter at release and was therefore also discounted from modelling. Although the cause for this shedding is unknown, it may have been the result of increased physical stress on the tail feathers during handling and transmitter attachment, as kereru are known to easily drop tail feathers when frightened (Appendix 5).

\section{Discussion}

Survival in rehabilitated animals requires the resumption of wild behaviours such as feeding, finding suitable roost sites, and maintenance behaviours (i.e. preening). This study demonstrated that the ability of rehabilitated kereru to resume these behaviours may be associated with a variety of measures and that the early post-release phases after rehabilitation are likely critical periods in the rehabilitation process.

In this study, the time individual kereru spent in captivity varied, however there was also an overall difference in the number of days kereru were held in captivity at each release site due to differing rehabilitator protocols. Kereru in Wellington were in captivity from seven to 40 days, whereas kereru in Waikanae spent from 200 to 1266 days in captivity. Interestingly, no support was found in either set of hypotheses for any of the models that included the time spent in captivity prior to release. However, time in captivity may be 
encapsulated by the site random effect, which accounts for the differing rehabilitator protocols. There are varying opinions in the literature on the importance of the time spent in captivity on post-release survival of rehabilitated animals. For example, hedgehogs held in captivity prior to translocation, whether treated for an injury or not, had a better survival rate following release than individuals translocated with minimum time spent in captivity (Molony et al. 2006). In contrast, the duration of captivity during rehabilitation of oiled penguins was not found to influence post-release survival (Goldsworthy et al. 2000). Despite differing results, there is consensus that extended periods of time in captivity can be harmful and lead to increased stress, exposure to disease, or human habituation. In my study, although no effect of time in captivity was found, it is important to remember that I had a very small sample size and other variables were likely affecting post-release behaviour. Therefore, release as soon as an animal has recovered is recommended (Mander et al. 2003).

My confidence set of models for both distance travelled and time to settle were the random effect of the release site alone, the sex of the bird, the time of year released, and the severity of injury. The severity of injury an animal sustains in relation to its ability to survive after rehabilitation has important implications in animal welfare and conservation. Given the time and investment required for rehabilitating injured animals, rehabilitators must decide on whether or not an animal is treatable. While many studies have traditionally used release rates as a measure of rehabilitation success, this study also found that the injury a kereru sustained (i.e. an obvious physical trauma such as a broken bone, or not obvious such as stunning), also best explained post-release settlement patterns in kereru. Among birds that experienced an obvious physical trauma there was considerable variation in the time taken to settle. In contrast, birds that did not experience an obvious physical injury were more uniform in their post-release behaviour. Given that time spent in captivity received no support in our analyses, I suggest that kereru that are simply stunned or stressed, from flying into a window for 
example, should be released as soon as possible following resumption of normal behaviours within an aviary (such as feeding or preening). This is of particular importance as it is known that even brief periods of handling can cause notable distress in kereru (Powlesland \& Willans 1996; Appendix 5). Additionally, DOC guidelines recommend animals be released as soon as they are recovered and to minimise the time spent in captivity (Mander et al. 2003). This issue is more complex, however, where more major injuries have been sustained, such as broken bones. In studies of oiled seabirds, the degree of oiling was significantly negatively related to survival post-release (Goldsworthy et al. 2000; Sharp 1996). The range of injuries that can occur in an urban environment are highly variable - from predation attempts or starvation, to human-related accidents such as collisions with cars or windows. Thus, it would be inappropriate to make generalizations regarding treatment of serious injuries without a larger sample size. At present we require more detail regarding which bird is best rehabilitated, where the process extends into measures of post-release survival and behavioural re-integration into the wild.

The model that included only the random effect of release site was one of the top models in both sets of hypotheses. One factor that may have contributed to these differences in movement patterns between release sites was whether the birds were hard- or soft-released. Kereru in Wellington with NBRWT are hard-released directly from a carrier at the site from which they were found injured. In contrast, following treatment from injury or illness, kereru at NMNR in Waikanae are placed into a recovery aviary, then moved into a larger softrelease aviary from which they are allowed to leave at their own will once a hatch is opened. Each aviary move requires extended acclimatisation periods, thus extending the time spent in captivity. Soft release is often recommended in avian rehabilitation studies, as it allows individuals time to settle into an aviary, familiarize themselves with local sights and sounds, and choose when to depart once the aviary is opened. This may significantly reduce the stress 
levels at the time of release, as animals are allowed time to recover from handling and transport (Molony et al. 2006). It may also alter the initial behaviour of the animals, as they might be less likely to disperse to unsuitable areas (DIckens et al. 2009). Additionally, soft release has been recommended by researchers who state that their primary aim is to increase the local population, as it has been shown to reduce the distance birds disperse when compared to hard release programs (Fajardo et al. 2000). In contrast, Griffiths et al (2010) suggested that that there was no difference in survival among juvenile owls that were soft released compared to those that were hard-released. And in fact, in a study of two juvenile hard-released kereru, there was no evidence of any negative impacts of the release technique on their survival (Powlesland \& Willans 1996). At present, my findings among rehabilitated kereru are equivocal and further detailed experimental studies are required to determine the most appropriate release type.

Familiarity with the landscape may also strongly influence the movements and settlement times in rehabilitated kereru. Previous studies have suggested that rehabilitated animals generally do not move very far from release sites (Daglish 2005; Sharp 1996). In a study of over 20 years of banding data, recovery locations for oiled seabirds (Guillemots) in North America were closer to release locations than for non-oiled birds (Sharp 1996). Rehabilitated kereru released in the Dunedin Botanic Gardens also remained within a few hundred metres of the release sites, although the novelty of the sites is unknown as all the birds were soft released from an on-site aviary (Daglish 2005). Wild kereru movements are characterised by periods of time within small core areas, with long-distance flights usually in response to seasonal food availability (Clout et al. 1986). In my study, kereru that remained close to the release sites had very few interactions with wild conspecifics, and settled into the sedentary foraging patterns characteristic of wild kereru that have found a suitable, or favoured food source (Campbell 2006; Clout et al. 1986; Mander et al. 1998). However, 
many of the birds made several long distance flights away from release sites before settling. These movements may have been related to food availability since the hypothesis including the time of year released received moderate support in model selection. Alternatively, long distance movements may have been in response to interactions with resident conspecifics in the early stages post-release.

Despite their reputation for being relatively docile birds, resident kereru at release sites were frequently observed aggressively interacting with rehabilitated kereru. Although the model that included the number of interactions received only moderate support, when examined within the context of the distance travelled within each release site, an interesting pattern emerged. Those birds that experienced more social interactions with resident birds made more frequent flights and travelled further to settle than birds that encountered fewer interactions. These interactions included wing beating displays characteristic of defending a favoured food source (Clout et al. 1991; James \& Clout 1996) and chasing during the breeding season (Mander et al. 1998). Whether these behaviours were indeed an aggressive response to resource competition, or were related to a mating display, is unknown.

Interestingly, in the only other study of rehabilitated kereru, released kereru were seen in the company of conspecifics, although no mating or display behaviours were ever observed. This lead the author to suggest that rehabilitated kereru interacted comfortably with and behaved similarly to wild individuals (Daglish 2005). Additionally, Powlesland and Willans (1996) suggested that one characteristic that may have influenced the survival of hand-reared juvenile kereru during the first month after release was the presence wild kereru from which the released birds could follow and learn from. It is noteworthy that I observed several rehabilitated kereru engaging in social interactions with conspecifics that appeared by all accounts to be agonistic. There are significant gaps in our understanding of post-release behaviour and sociality in kereru. My data suggest that affiliative or aggressive social 
behaviour is an important consideration when releasing kereru that have been removed from their wild counterparts for any amount of time.

Among all the kereru released in this study, the two birds that experienced the greatest number of aggressive encounters were juvenile females. While neither bird travelled very far from their release sites, the frequency of movements made were much higher than in adult birds. One of these birds ("Black/Blue", not included in modelling) never settled and died after only nine days from a broken clavicle and severe internal bleeding, most likely caused by sustained pressure on the newly healed area from frequent movements and aggressive wing beating encounters. This bird was never seen to feed and was repeatedly chased by multiple adults each time it was observed. It was eventually found expired in a tree in a residential backyard within $1 \mathrm{~km}$ from her release site. The second bird ("White", included in the modelling) never moved further than $200 \mathrm{~m}$ from the release site, despite continuous harassment from resident birds. Although frequently observed feeding in nearby trees, this young kereru continued to return to the release site for supplemental food provided by the rehabilitator and nearby residents.

These kereru highlight some of the issues of faced by rehabilitators working in urban settings. In the case of "Black/Blue", the negative interactions with wild conspecifics were unforeseen. While social conflict is probably not directly manageable, juvenile kereru may be susceptible to more harassment than adults when re-introduced into the wild. Although "White" was observed feeding in the wild it also never fully integrated back among conspecifics. This is likely due to the fact that people in surrounding neighbourhoods continued to feed this bird whenever it appeared in their backyards (Figure 5). Indeed, the general public often believe that wildlife requires their assistance because they believe the animal to be helpless. Until further studies are conducted, caution and careful consideration is recommended when releasing juvenile kereru. 


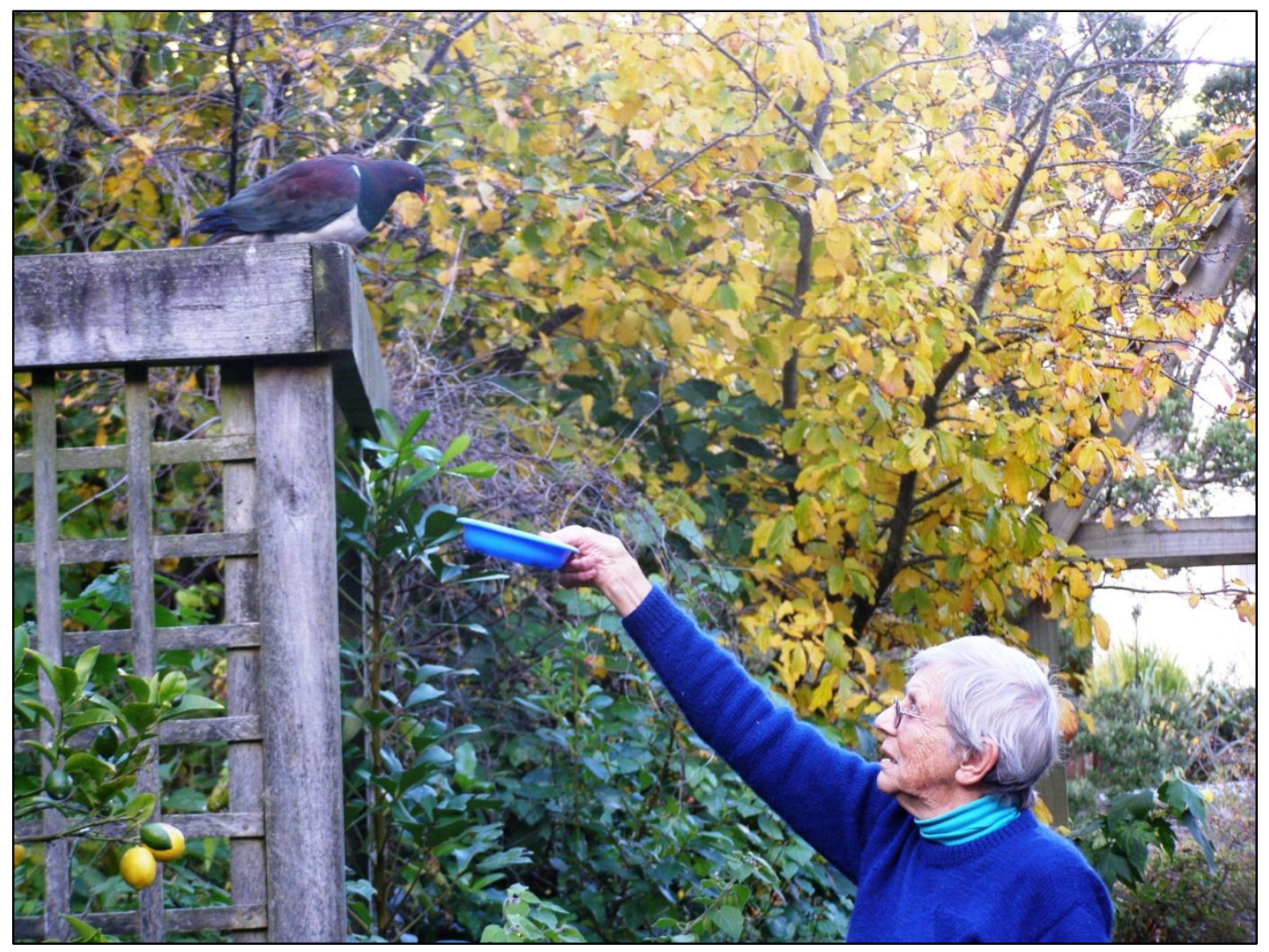

Figure 5. After landing in a residential yard in Wellington, a rehabilitated kereru is fed by a member of the public. Photo: Monica Awasthy.

\section{Conclusion}

The debate surrounding rehabilitation programs is associated with the high monetary and labour investment without evidence of benefit on the one hand, and the human emotional need to assist injured or stranded animals on the other. Rehabilitation is often advocated as an effective method for population recovery in wildlife management and conservation programs. However, many biologists do not see the conservation value in rehabilitation, particularly when it is done as a reactive exercise and rarely undertaken from a scientific or cost-benefit viewpoint. My study demonstrates that although the conservation value of rehabilitation programs remains questionable, they can offer scientists with fortuitous opportunities to study 
little known behaviours of native species that are re-integrating with wild conspecifics and can add valuable data to the depauperate literature. My results suggest that the site of release, severity of injury and the sex of bird are important predictors of early post-release movements and settlement patterns in kereru. These results are, however, preliminary and we still require studies with larger sample sizes and more experimental control of the parameters that may affect the reintegration success of a reintroduced bird. In the meantime, the focus of rehabilitation should shift to being more preventative and proactive (for example education and risk reduction), rather than simply a reactive exercise because rehabilitation has a high failure. Rehabilitators should also carefully consider whether the investment to save severely injured animals is justified if it prolongs their suffering post-release.

\section{References}

Anderson, D. W., F. Gress, and D. M. Fry. 1996. Survival and dispersal of oiled brown pelicans after rehabilitation and release. Marine Pollution Bulletin 32:711-718.

Anderson, D. W., S. H. Newman, P. R. Kelly, S. K. Herzog, and K. P. Lewis. 2000. An experimental soft-release of oil-spill rehabilitated American coots (Fulica americana): I. Lingering effects on survival, condition and behavior. Environmental Pollution 107:285-294.

Ben-David, M., G. M. Blundell, and J. E. Blake. 2002. Post-release survival of river otters: Effects of exposure to crude oil and captivity. Journal of Wildlife Management 66:1208-1223.

Burnham, K. P., and D. R. Anderson 2002. Model selection and multimodel inference: A practical information-theoretic approach. Springer-Verlag, New York.

Campbell, K. L. 2006. A study of home ranges, movements, diet and habitat use of kereru (Hemiphaga novaeseelandiae) in the southeastern sector of Banks Peninsula, New Zealand. Unpubl. M.Sc. thesis. Lincoln University, New Zealand.

Clout, M. N., P. D. Gaze, J. R. Hay, and B. J. Karl. 1986. Habitat use and spring movements of New Zealand pigeons at Lake Rotoroa, Nelson Lakes National Park. Notornis 33:37-44.

Clout, M. N., and J. R. Hay. 1989. The importance of birds as browsers, pollinators and seed dispersers in New Zealand forests. New Zealand Journal of Ecology 12:27-33. 
Clout, M. N., B. J. Karl, and P. D. Gaze. 1991. Seasonal movements of New Zealand pigeons from a lowland forest reserve. Notornis 38:37-47.

Daglish, L. 2005. City pigeons : Kererū (Hemiphaga novaeseelandiae) in the urban Dunedin environment : abundance, habitat selection and rehabilitation outcomes. Unpubl. M.Sc. thesis. University of Otago.

Dickens, M. J., D. J. Delehanty, J. M. Reed, and L. M. Romero. 2009. What happens to translocated game birds that 'disappear'? Animal Conservation 12:418-425.

Dubois, S., and D. Fraser. 2003. Conversations with stakeholders, part I: Goals, impediments, and relationships in wildlife rehabilitation. Journal of Wildlife Rehabilitation 26:1422.

Estes, J. A. 1992. Catastrophes and conservation: Lessons learned from sea otters and the Exxon Valdez. Science 254:1596.

Estes, J. A. 1998. Concerns about rehabilitation of oiled wildlife. Conservation Biology 12:1156-1157.

Fajardo, I., G. Babiloni, and Y. Miranda. 2000. Rehabilitated and wild barn owls (Tyto alba): dispersal, life expectancy and mortality in Spain. Biological Conservation 94:287-295.

Goldsworthy, S. D., M. Giese, R. P. Gales, N. Brothers, and J. Hamill. 2000. Effects of the Iron Baron oil spill on little penguins (Eudyptula minor). II. Post-release survival of rehabilitated oiled birds. Wildlife Research 27:573-582.

Griffiths, R., M. Campbell, and R. Clubb. 2010. Survivorship of rehabilitated juvenile Tawny Owls (Strix aluco) released without support food, a radio-tracking study. Avian Biology Research 3:1-6.

Guy, A.J., Stone, O.M.L., and Curnoe. D. 2012. Assessment of the release of rehabilitated vervet monkeys into the Ntendeka Wilderness Area, KwaZulu-Natal, South Africa: a case study. Primates 53:171-179.

Hill, M. T. 2003. Diet, dispersal and distribution of kereru (Hemiphaga novaeseelandiae) in a lowland podocarp-hardwood forest. Unpubl. M.Sc. thesis. . Massey University.

Howard, P., and D. N. Jones. 2004. A qualitative study of wildlife feeding in south-east Queensland. . Pages 55-62 in S. K. Burger, and D. Lunney, editors. Urban Wildlife: More than Meets the Eye. Royal Zoological Society of NSW, Sydney.

James, R. E., and M. N. Clout. 1996. Nesting success of New Zealand Pigeons (Hemiphaga novaeseelandiae) in response to a rat (rattus rattus) poisoning programme at Wenderholm Regional Park. New Zealand Journal of Ecology 20:45-51.

Lander, M. E., J. T. Harvey, K. D. Hanni, and L. E. Morgan. 2002. Behavior, movements, and apparent survival of rehabilitated and free-ranging harbor seal pups. Journal of Wildlife Management 66:19-28. 
Mander, C., L. Adams, and A. Riley. 2003. Wild City Neighbours: a guide to native bird rehabilitation. Department of Conservation Science Publishing, Wellington. Available at http://www.doc.govt.nz/upload/documents/science-andtechnical/BirdRehabGuide.pdf.

Mander, C., R. Hay, and R. Powlesland. 1998. Monitoring and management of kereru (Hemiphaga novaeseelandiae). Department of Conservation Technical Series No. 15, Wellington, New Zealand.

Miller, E. A. 2000. Minimum standards for Wildlife Rehabilitation. 3rd edition. St. Cloud, MN. National Wildlife Rehabilitators Association.

Miskelly, C. M., J. E. Dowding, G. P. Elliot, R. A. Hitchmough, R. G. Powlesland, H. A. Robertson, P. M. Sagar, R. P. Scofield, and G. A. Taylor. 2008. Conservation status of New Zealand Birds, 2008. Notornis 55:117-135.

Molony, S. E., P. J. Baker, L. Garland, I. C. Cuthill, and S. Harris. 2007. Factors that can be used to predict release rates for wildlife casualties. Animal Welfare 16:361-367.

Molony, S. E., C. V. Dowding, P. J. Baker, I. C. Cuthill, and S. Harris. 2006. The effect of translocation and temporary captivity on wildlife rehabilitation success: An experimental study using European hedgehogs (Erinaceus europaeus). Biological Conservation 130:530-537.

Moore, M., G. Early, K. Touhey, S. Barco, F. Gulland, and R. Wells. 2007. Rehabilitation and release of marine mammals in the United States: Risks and benefits. Marine Mammal Science 23:731-750.

Powlesland, R. G., L. R. Moran, and D. M. Wotton. 2011. Satellite tracking of kereru (Hemiphaga novaeseelandiae) in Southland, New Zealand: impacts, movements and home range. New Zealand Journal of Ecology 35:229-235.

Powlesland, R. G., and M. Willans. 1996. "Hard release" of captive-reared New Zealand Pigeons (Hemiphaga n. novaeseelandiae). Notornis 44:57-59.

R Development Core Team. 2010. R: A Language and Environment for Statistical Computing. R Foundation for Statistical Computing, Vienna, Austria. Available at: http://www.R-project.org/.

Sharp, B. E. 1996. Post-release survival of oiled, cleaned seabirds in North America. Ibis 138:222-228. 


\section{CHAPTER FIVE}

\section{Enhancing an urban conservation education program with children through local wildlife research experience}

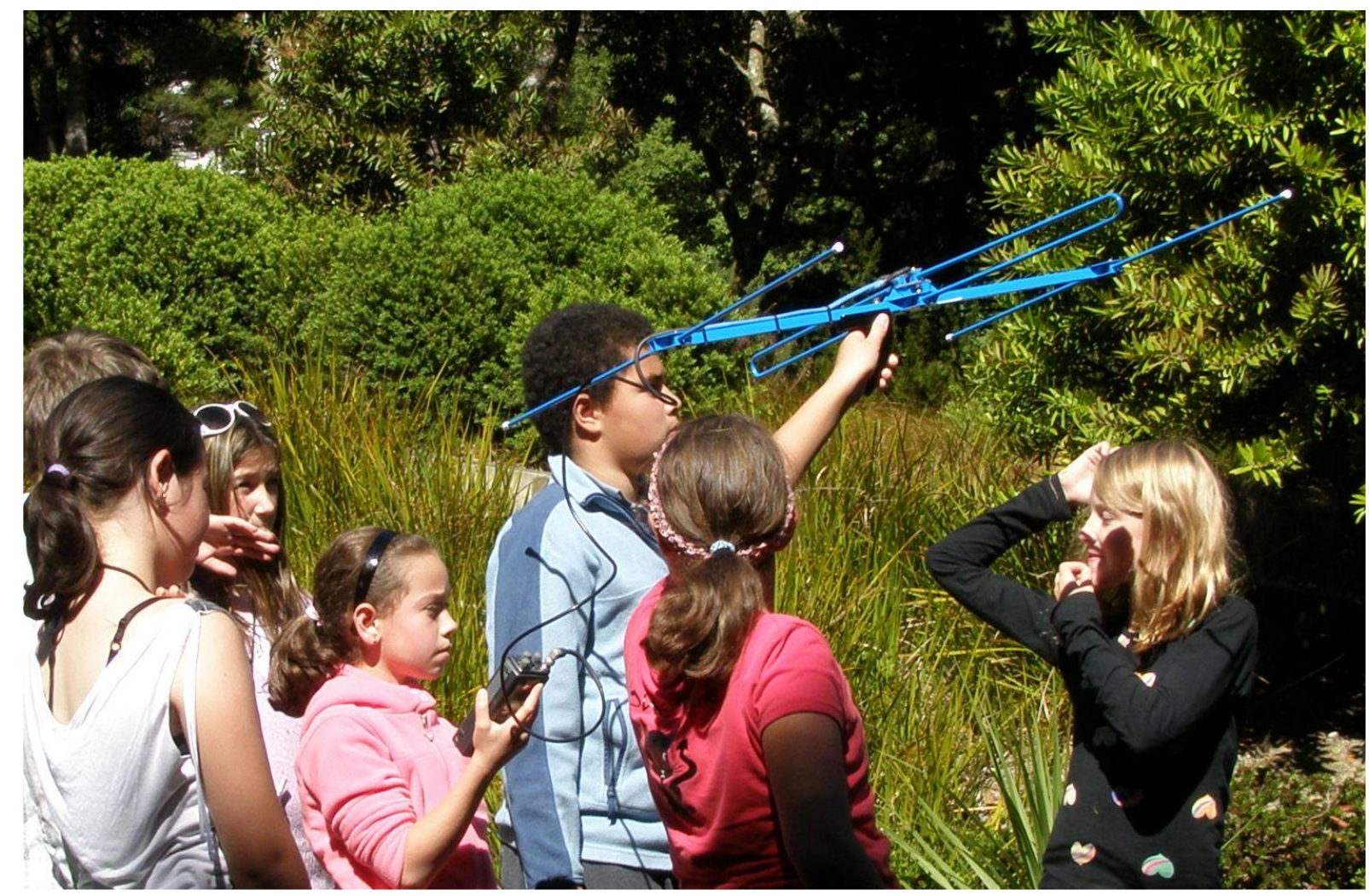

Students of the Gifted Kids Programme radio-tracking wild kereru at Otari-Wilton's Bush, Wellington. Photo by Monica Awasthy.

Author's note: Chapter 5 has been published as: “Awasthy, M., Popovic, A.Z. \& Linklater, W.L. 2012. Experience in local urban wildlife research enhances a conservation education programme with children. Pacific Conservation Biology 18:41-46."

The manuscripts co-authors' roles were restricted to supervision and advice (W.L. Linklater) and assistance with lesson plans and programme delivery (A.Z. Popovic). 


\begin{abstract}
The "extinction of [ecological] experience" is a concern for children in urban centres. Urban environments, traditionally the refuge of exotic human-commensal species, are being increasingly colonised by native species. I used a native bird as a focal species for integrating urban biological research and environmental education (EE) in conservation. I tested whether incorporating biological researchers into classroom teaching and hands-on experiences with radio-telemetry of wild birds increased wildlife knowledge, environmental awareness and intentions to act amongst children from local schools. I found no significant increases in knowledge after the EE program. However, those children who participated in exercises with researchers in local green space demonstrated a greater level of nature awareness than groups who participated in the schoolyard, and retained this level three months after the program completion. I illustrate the importance of incorporating biological research in conservation education in urban centres.
\end{abstract}




\section{Introduction}

Children living in urban areas may be experiencing a growing separation from nature (Louv 2005) and perhaps the "extinction of [ecological] experience" (Pyle 1978). Over 50\% of the world's population and its children now live in or near cities (Obaid 2007; Sadik 1999) with depauperate biodiversity dominated by human-commensal species (McKinney 2002, 2006). While people living in urban areas are less 'connected' with the natural world (Miller 2005), their early life experiences and perceptions of nature may be essential to conservation (Tanner 1980).

Environmental education (EE) aims to provide people with the opportunity to gain awareness of the environment and its associated problems through knowledge acquisition, and to develop conservation skills (Thompson et al. 2003). This leads to an increase in conservation values and concern, thus promoting ecological literacy (Brewer 2001; Orr 1989) and environmentally responsible behaviour (ERB; Hungerford \& Volk 1990). However, engaging children in learning that promotes a sense of connection and concern with their local environment and its conservation is a key challenge (Louv 2005). EE programs promoting and evaluating ERB (Brewer 2002b; Zint et al. 2002), local conservation issues (Brewer 2002b; Zint et al. 2002), environmental awareness (Fisman 2005), environmental sensitivity (Chawla 1998), perceptions of nature (Simmons 1994; Wals 1994) and effective evaluation and teaching methods (Jull 2003; Sobel 1998) are well documented in the literature. Despite this, scientifically robust assessments of program effectiveness remain scarce (Carleton-Hug \& Hug 2010), particularly within the biological literature.

The typical approach to EE has been a focus on "wilderness", and so urban-living children usually learn inside the classroom (Fisman 2005). Trips to distant wilderness to learn about nature are necessarily rare, if they occur at all. Urban green-spaces near schools and schoolyards themselves, however, also offer opportunities to teach about nature and local 
conservation issues (Brewer 2002a). Indeed such opportunities may better engage interest because sustained contact with a given place and direct contact with nature best cultivates children's environmental knowledge and concern (Sobel 1998) and develops ecological literacy (Orr 1989). Children also attach greater value to experiences that are mentored by 'expert guests' - people outside their day-to-day experience to whom peers and teachers attribute a priori value and who bring with them memorable new experiences and skills (e.g., wildlife telemetry). It is argued that local knowledge, coupled with the specialist knowledge of a biologist, is more potent than either kind of knowledge on its own (Christie \& White 1997 as cited in Evans et al. 2006).

Interest in animals is a primary motivator for participation in environmental programs (Owen et al. 2009), and individual species are the most common entity used by conservation groups (Van Weelie \& Wals 2002). Thus, wildlife biologists conducting research in urban centres potentially provide the means to enhance the magnitude and longevity of learning in EE. Collaborations between biologists and teachers in cities may be a remarkable, but rarely utilised, opportunity for teachers to enhance their EE curriculum and for wildlife biologists to add conservation value to their research programs. Urban wildlife research has increased in recent years as well as the importance of including human-dimensions in wildlife research (Alberti et al. 2003). Indeed, advances in urban avian studies (Marzluff et al. 2001) have provided opportunities for integrating researchers into research and teaching where conservation occurs (Brewer 2002b) and where children live, although the effectiveness of such EE efforts is rarely tested.

The kereru, or New Zealand pigeon (Hemiphaga novaeseelandiae: Columbidae) is a large-bodied, easily recognisable, fruit eating pigeon that disperses the larger seeds of many native trees (Heather \& Robertson 2005). Although once in nationwide decline, kereru have become more abundant in New Zealand's urban landscapes and have been recently re- 
classified as "not threatened" (Miskelly et al. 2008). Its iconic status and ecological, perhaps keystone role (Clout \& Hay 1989), make it an ideal focal species for integrating biological research and EE initiatives towards their conservation.

Concurrently with a research program investigating kereru urban landscape use in Wellington City, New Zealand (Chapter 3), I developed an EE program with a school teacher (A.Z. Popovic) which incorporated a biologist into classroom, schoolyard and urban greenspace teaching. My objective was to empirically evaluate the effect of participation in radiotelemetry exercises guided by researchers in the schoolyard, and with similar exercises involving wild kereru in local green space, on children's urban wildlife knowledge, nature awareness and intention to act. I hypothesized that students who participated in radiotelemetry exercises with wild kereru in local green space would show a marked improvement in all areas of assessment over students who remained in the schoolyard, and that those improvements would persist long after the conclusion of our EE program.

\section{Methods}

\section{PARTICIPANTS AND EE PROGRAM}

Three classes of children from the Gifted Kids Programme at Rata School and Wilford Schools in Lower Hutt City, New Zealand participated in our program. Participants ranged in age from 10-12 years, with the majority of the "green space" radio-telemetry group aged 11 years $(73 \%)$ and the majority of the "schoolyard" group aged 12 years $(71 \%)$. This age range is at a critical learning junction and thus considered the most appropriate for EE and outreach programs (Kellert 1985). Males comprised a larger percentage of participants in the "green space" group (64\%) than the "schoolyard" group (53\%). All participants reported living within $8 \mathrm{~km}$ of the school and had written permission through parents or guardians to partake in the program and evaluations. 
The four week teacher/biologist integrative EE program consisted of a two-hour session every week for each of the three participating classrooms during March and April 2008. The first three sessions of the program were identical in delivery and materials for each class, and consisted of group activities, role-playing and traditional lectures. The fourth session involved a participatory radio-telemetry workshop for which classes were randomly assigned to a treatment group: two classes of 16 children received radio-telemetry experience at our urban green space research site at Otari Native Botanic Garden and Wilton's Bush Reserve (Otari-Wilton's Bush), a remnant and restored forest reserve in Wellington City with resident and radio-tagged kereru $(n=32$; green space), and a class of 16 children who participated in radio-telemetry exercises in their schoolyard ( $\mathrm{n}=16$; schoolyard).

The radio-telemetry workshops involved a brief review of bird identification, instructions on how to record wildlife observations in a notebook, and an explanation of how to use the radio telemetry equipment. For both treatment groups, participants were divided into smaller groups of 3-5 students and were each assigned a transmitter frequency. Frequencies assigned to green space participants were associated with transmitters attached to wild kereru, whereas frequencies assigned to schoolyard participants were associated with transmitters hidden throughout the schoolyard.

\section{STUDY DESIGN AND EVALUATION}

I evaluated whether green space radio-telemetry of wild kereru (i) increased children's general knowledge of local urban wildlife, (ii) improved their identification skills of New Zealand birds, and (iii) increased nature awareness in their neighbourhood when compared to the same activity conducted in the schoolyard. I used knowledge questionnaires and cognitive mapping (Sobel 1998) to assess general wildlife knowledge and nature awareness. Knowledge questionnaires and cognitive maps were delivered one week prior (pre-program), one week afterwards (post-program), and then again three months after 
(retention) the conclusion of the EE program. I also employed reflective journals to assess behavioural intentions and new knowledge. Reflective journals were completed only once immediately after the program's conclusion.

Knowledge questionnaires consisted of two listing and 15 multiple choice questions designed to measure native bird identification skills, and knowledge of local urban wildlife, particularly kereru (Appendix 6). The questionnaire was piloted on a similar-aged group of children not participating in the program to ensure that both content and delivery were developmentally appropriate. All questionnaires were then administered to program participants by the same classroom teacher to reduce possible variations in reading and writing ability of each child. Questionnaires were divided into two categories for analysis: general wildlife, including kereru, knowledge, and bird identification ability.

Cognitive mapping techniques measure changes in a child's awareness of nature. It involves interpreting a child's drawings to assess their relationships and attitudes to a particular place (Kitchin 1997), and has been applied to measure their awareness of the natural features in their surroundings (Fisman 2005). Maps were administered by the class teacher following methods outlined by Sobel (1998) and altered by Fisman (2005) using the statement "I would like you to draw a picture of your neighbourhood. You may draw anything you like as long as you include your house." Each drawing was assessed by placing a grid over the map and counting the total number of cells occupied by natural features. Natural features were defined as any non-artificial structure, and a cell was considered occupied if any portion of it was filled by these features.

To test whether participating in radio-telemetry affected evaluation scores I used multivariate analyses of variance (MANOVA). Separate MANOVAs were run for each evaluation type (general wildlife knowledge, bird identification and nature awareness) in which the effect sizes between treatments (pre-post, post-retention, pre-retention) was the 
dependent variable and participation in radio-telemetry (green space or schoolyard) was the between subjects factor. If significant interactions between treatments were found, paired ttests with a decision criterion $p=0.05$ were applied. All tests were carried out in statistical package SPSS (2008).

Following the EE program completion, students were asked to write two-page reflective journals on their learning experiences, which were prompted by the questions "What did you learn that you didn't know before?" and "Why is it important to know these things?" Phrases were extracted and categorized into three main themes: practical knowledge, ecological knowledge, and future or conservation actions. Mann-Whitney U tests were used to determine whether differences between categories were statistically significant.

\section{Results}

The MANOVAs for general wildlife knowledge and bird identification revealed no statistically significant main effects. However, it is important to examine trends despite the small sample size of this study. Scores for general wildlife knowledge increased in both radio-telemetry groups from the pre- to post-program testing periods. However, knowledge retention scores in both groups declined (Figure 1A). Interestingly, bird identification scores showed no changes across treatments or between groups (Figure 1B).

For map scores, the MANOVA revealed significant main effects of radio-telemetry in post- to retention treatments $\left(\mathrm{F}_{1,28}=7.014, p=.013\right)$ and in pre- to retention treatments $\left(\mathrm{F}_{1,32}\right.$ $=7.471, p=.010)$. These interactions reflect that scores were higher among groups who participated in radio-telemetry exercises in the green space after the EE program than before (pre vs. post: $\mathrm{df}=26, \mathrm{t}=-2.168, p=.039$ ) and these scores remained higher three months after the program than before the program (pre vs. retention: $\mathrm{df}=22, \mathrm{t}=-2.582, p=.017$ ) (Figure 1C). Irrespective of treatment group, all children drew maps that were heavily focussed upon man-made structures before undertaking the EE program. However, post- 
program maps drawn by green space participants included a greater percentage of natural features and included greater detail than those maps drawn by school yard participants (Figure 2).

Green space participants also scored significantly higher in the future or conservation actions category of their reflective journals than schoolyard participants (Man-Whitney U; U $=40.5, p=.04)$, whereas responses of both groups in practical and ecological knowledge categories did not differ. Immediate or personally achievable actions were listed most frequently by green space participants including choosing a biology or conservation career, planting more trees for birds and keeping pets such as cats inside. In contrast, schoolyard participants focused on an awareness of, or concern with actions, listing such things as protecting birds for future generations. 

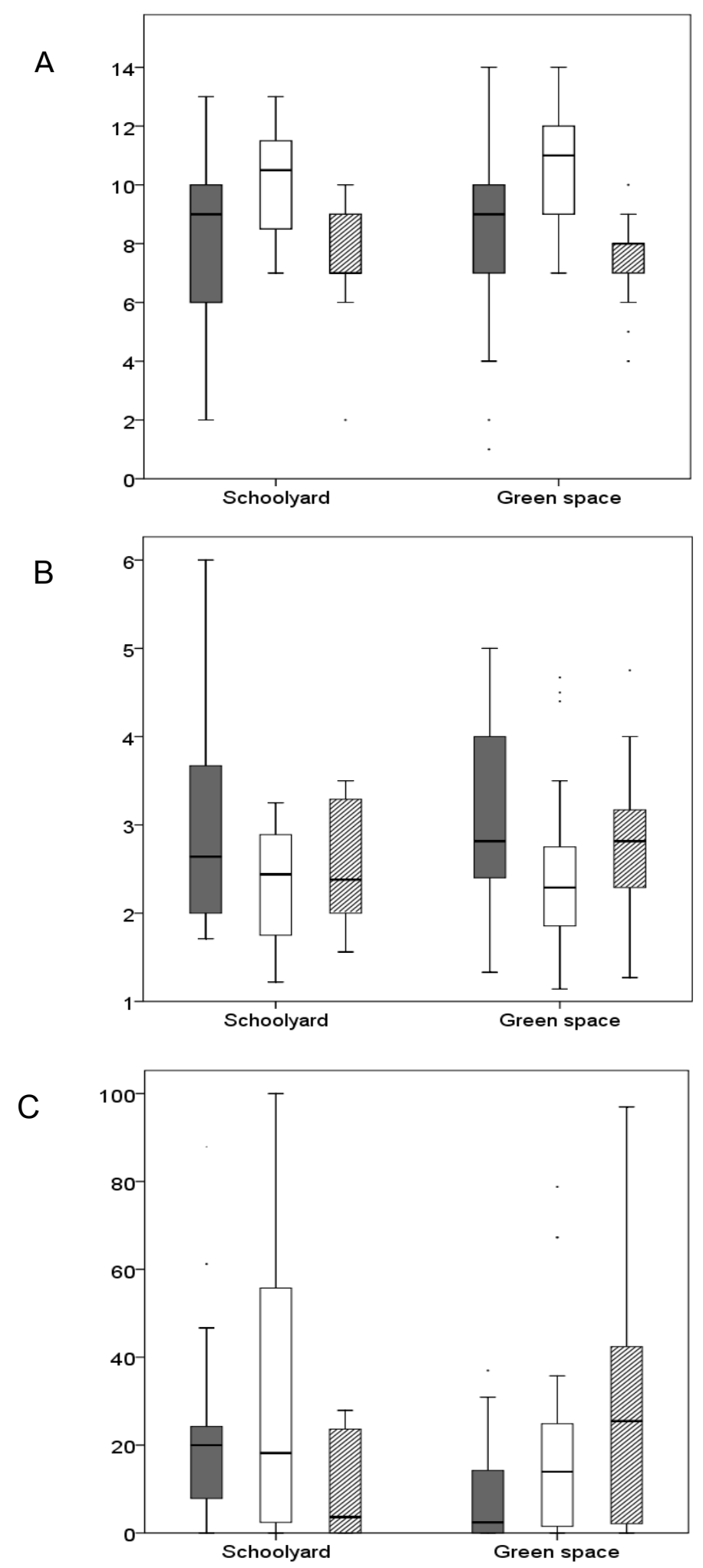

Figure 1. Comparison of schoolyard participants and green space participants for pre- (gray bars), post- (white bars), and retentive (hatched bars) EE program evaluation scores, measured by (A) number of correct knowledge questionnaire answers, (B) number of native New Zealand birds correctly identified, and (C) percentage of nature in cognitive map drawings. 


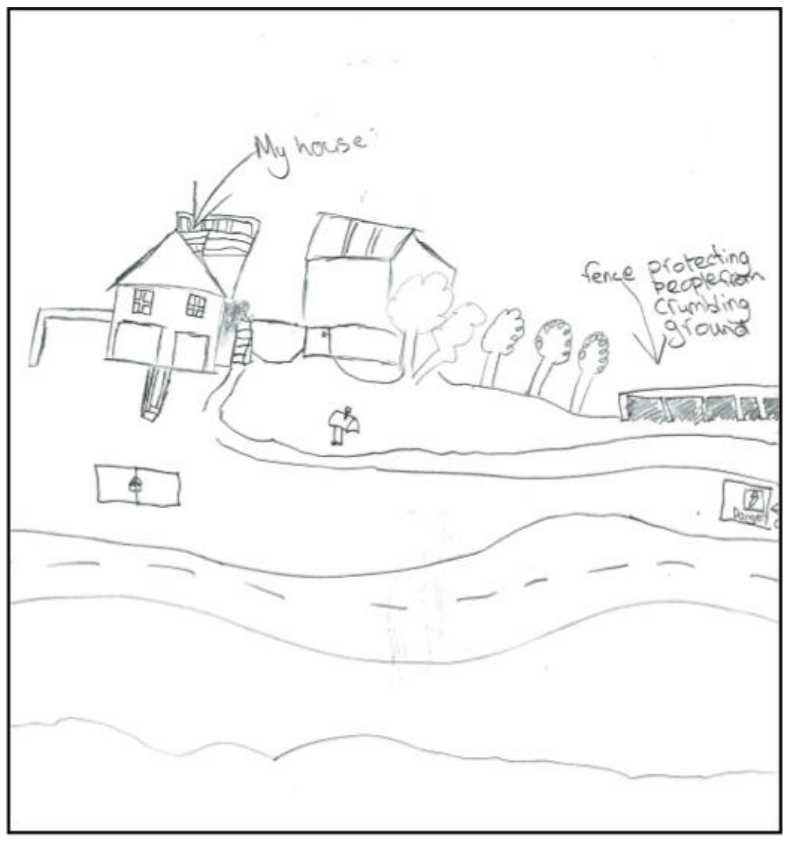

Pre-program map

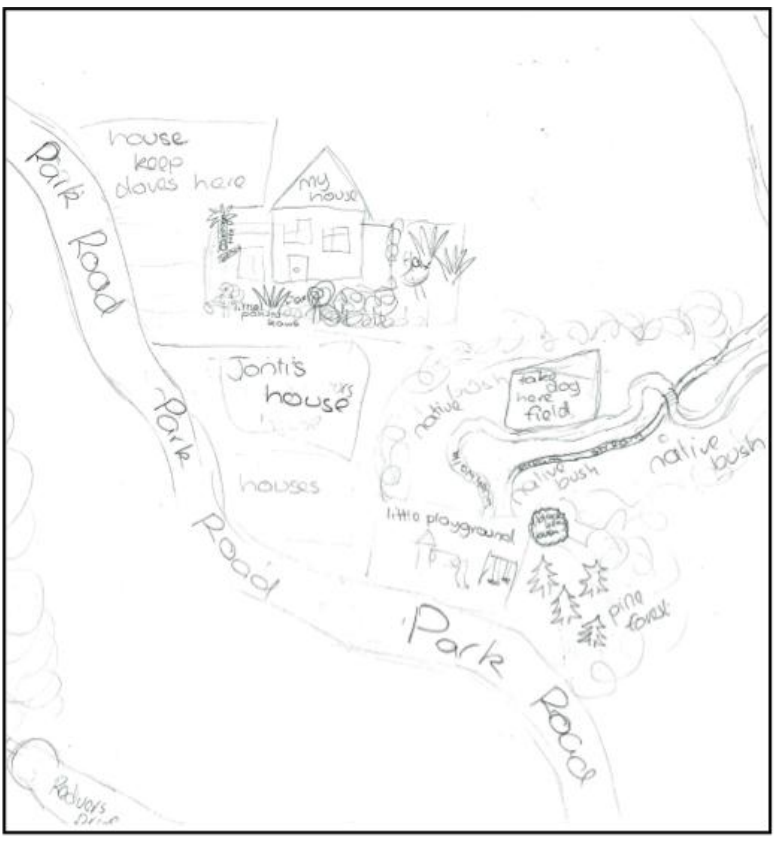

Post-program map

Figure 2. Examples of a pre- and post-program map drawn by a green space participant. Note that in the post-program map much more detail is given about the types of plants and animals around their house, including where a neighbour keeps doves.

\section{Discussion}

This study sought to determine the effectiveness of an integrative environmental education (EE) program on children's urban wildlife knowledge, nature awareness and intentions to act. I evaluated the effects of two different radio-telemetry experiences using knowledge questionnaires, cognitive mapping and reflective journals. I found significant increases in nature awareness and intentions to act in children who participated in radiotelemetry exercises with biologists in local green space over those children who remained in the schoolyard. Most importantly, this suggests that had my study only employed knowledge assessments or bird identification exercises, I may have erroneously concluded that radiotelemetry with wild kereru and the integration of a biologist into the class room is an ineffective EE teaching tool. Thus, my findings suggest that the integration of a biologist into 
classroom learning, coupled with hands-on interactions within local green space, significantly improves EE programs for children.

These findings have important implications for augmenting environmentally responsible behaviour (ERB) in children. Chawla (1998) proposed that outdoor and local experiences positively affect environmental sensitivity and that simply engaging in or observing urban nature first-hand can be the foundation upon which to build future values. Further, contact with nature during childhood appears to strongly influence positive behaviour towards the environment (Muller \& Werner 2010). Tanner (1980) described the importance of a "youthful experience outdoors" in influencing the lives of prominent conservationists later in life. His study recognized the importance of understanding the formative influences of children growing up "quite removed from nature" in a rapidly urbanising world. Therefore, in designing my program it was particularly important that the children in my study, who were raised in urban settings, were introduced to the concept that their surroundings are in fact natural. Prior to the EE program, all of the children produced drawings during cognitive mapping exercises that focused largely on the man-made structures in their local environment. However, those who participated in radio-telemetry activities in green space demonstrated a marked increase in awareness of the flora and fauna of that same local environment. In contrast, those students who remained in the schoolyard showed no such increase in nature awareness. These results provide clear support for Tanner's suggestions and I propose that they can be extended to include those people living in urban settings. The increase in awareness of nature in my study is thus a very encouraging step towards building the foundations of ERB necessary for successful conservation programs, particularly those that aim to have lasting value.

One the main priorities in conservation biology today is achieving a more scientifically literate public (Brewer 2001; Trombulak et al. 2004). People must be well 
informed about the environment and its related issues before they can make meaningful contributions to the processes that affect it (Dreyfus 1995). However, the significance of knowledge acquisition in environmental and conservation education programs has been highly debated in the literature. Some authors claim an increase in knowledge to be "a trivial influence on future commitment [to act]" while others argue that an increase in knowledge is highly correlated with positive attitudes and values towards the environment (Bogner 1998). Children are highly impressionable and there is no doubt that bringing them into close contact with their environment improves their knowledge of nature. In my program I found no differences in knowledge assessment scores between children that participated in radiotelemetry in local green space and those that remained in the schoolyard. I therefore attribute any knowledge acquisition to the three weeks of in class lessons on local wildlife. However, I found no evidence of knowledge retention three months after the completion of our EE program. Retention tests are applied to ensure that knowledge has settled, and in both groups the mean retention scores were lower than the mean pre-program scores. These results may indicate a loss of interest in the subject material three months after the program concluded. Thus, I suggest that children require regular EE programs in which the content varies in order for longer-term knowledge retention, attitude and behavioural changes in conservation to be ultimately met (Bogner 1998).

Although I found an increase in general wildlife knowledge, I found no improvement in bird identification skills among either group of children during any testing period. Evans et al. (2006) found that UK school children's knowledge of birds came primarily from popular media and books, rather than from actually observing them in the wild. They found that children were unable to identify common species (i.e. those that were found around them daily), but were familiar with charismatic species. In our study we used native bird species in an attempt to increase children's engagement in their local environment. However, in New 
Zealand birds like the kereru could be considered as charismatic and iconic species that are already well known to children. Thus, the lack of improvement may be because identification skills of these bird species were already high.

Despite the lack of improvement in bird identification and poor knowledge retention, it is important to note that children who participated in radio-telemetry in green space listed more examples of immediate or personally achievable conservation actions in their reflective journals than schoolyard participants. This suggests that integrating hands-on experiences within the local environment may be key for future EE programs seeking to enhance ERB in children. However, does stating an intention to act lead to a tangible action? An important consideration for future EE programs with children may be to include additional activities that promote environmental and conservation action, such as developing a school garden or community-wide plantings for local native birds. Such activities may help to bridge the gap between an intention to act and a tangible action.

\section{Conclusions}

Brewer (2002b) summarised the five common elements of successful outreach and partnership programs: allowing participants research experience, collaboration with teachers, guidance for scientists in communicating to a non-scientific audience, accuracy in data collection, and program assessment. Further, Randler et al. (2005) found that effective EE programs in biodiversity should focus on a small number of species, start in primary schools, take place outdoors and be linked with classroom teaching. My results suggest that along with these guidelines, the integration of a biologist into the classroom coupled with outdoor research experience in local green space can enhance the effectiveness of conservation education and outreach programs with children living in urban areas. The engagement of biologists in $\mathrm{EE}$ is an important step towards fostering an environmentally literate public 
(Brewer 2001; Hungerford \& Volk 1990; Muller \& Werner 2010). In fact, graduate students are an underutilised resource in such programs, and integrating them into classroom teaching can benefit both scientists and the community (Wellnitz et al. 2002). Most importantly, the methods I present are broadly relevant and easily applicable in any conservation research program that takes place where children live and learn. Thus, this study can advance discussion about the role that biologists can play in the classroom, the use of novel teaching tools in EE programs, and the importance of empirically evaluating education programs in order to achieve long-term conservation goals.

\section{References}

Alberti, M., J. M. Marzluff, E. Shulenberger, G. Bradley, C. Ryan, and C. Zumbrunnen. (2003) Integrating humans into ecology: opportunities and challenges for studying urban ecosystems. BioScience, 53:1169-1179.

Awasthy, M. (2007) Urban bird research: a study of kereru in Wellington, New Zealand. Proceedings of the 2007 Australasian Regional Association of Zoological Parks and Aquaria, Wellington, New Zealand.

Bogner, F. X. (1998) The influence of short-term outdoor ecology education on long-term variables of environmental perspective. The Journal of Environmental Education, 29:17-29.

Brewer, C. (2001) Cultivating conservation literacy: "Trickle-down" education is not enough. Conservation Biology, 15:1203-1205.

Brewer, C. (2002a) Conservation education partnerships in schoolyard laboratories: a call back to action. Conservation Biology, 06:577-579.

Brewer, C. (2002b) Outreach and partnership programs for conservation education where endangered species conservation and research occur. Conservation Biology, 16:4-6.

Carleton-Hug, A., and J. W. Hug. (2010) Challenges and opportunities for evaluating environmental education programs. Evaluation and Program Planning, 33:159-164.

Chawla, L. (1998) Significant life experiences revisited: A review of research on sources of environmental sensitivity. The Journal of Environmental Education, 29:11-21.

Clout, M. N., and J. R. Hay. (1989) The importance of birds as browsers, pollinators and seed dispersers in New Zealand forests. New Zealand Journal of Ecology, 12:27-33. 
Dreyfus, A. (1995) Biological knowledge as a prerequisite for the development of values and attitudes. Journal of Biological Education, 29:215-219.

Evans, S., S. Dixon, and J. Heslop. (2006) Pupils' knowledge of birds: how good is it and where does it come from? School Science Review, 88:93-98.

Fisman, L. (2005) The effects of local learning on environmental awareness in children: An empirical evaluation. The Journal of Environmental Education, 36:39-50.

Heather, B., and H. Robertson. (2005) The Field Guide to the Birds of New Zealand. Viking, Auckland.

Hungerford, H. R., and T. L. Volk. (1990) Changing learner behavior through environmental education. Journal of Environmental Education, 21:8-21.

Jull, P. M. M. (2003) Evaluating environmental education and outreach programs. Available at: http://www.ecy.wa.gov/pubs/0407017.pdf.

Kellert, S. R. (1985) Attitudes towards animals: Age-related development among children. Journal of Environmental Education, 16:29-39.

Kitchin, R. M. (1997) Exploring spatial thought. Environment and Behavior, 29:123-156.

Louv, R. (2005) Last child in the woods: saving our children from nature-deficit disorder. Viking, Penguin Books., Auckland, New Zealand.

Marzluff, J. M., R. Bowman, and R. Donnelly, Eds. (2001) Avian ecology and conservation in an urbanizing world. Kluwer Academic Publishers, Boston, MA, USA.

McKinney, M. L. (2002) Urbanization, biodiversity, and conservation. Bioscience, 52:883890.

McKinney, M. L. (2006) Urbanization as a major cause of biotic homogenization. Biological Conservation, 127:247-260.

Miller, J. R. (2005) Biodiversity conservation and the extinction of experience. Trends in Ecology \& Evolution, 20:430-434.

Miskelly, C. M., J. E. Dowding, G. P. Elliot, R. A. Hitchmough, R. G. Powlesland, H. A. Robertson, P. M. Sagar, R. P. Scofield, and G. A. Taylor. (2008) Conservation status of New Zealand Birds, 2008. Notornis, 55:117-135.

Muller, N., and P. Werner (2010) Urban biodiversity and the case for implementing the convention on biological diversity in towns and cities. In Urban Biodiversity and Design. Eds. Muller, N., Werner, P., and Kelcey, J.G. Wiley-Blackwell, Oxford.

Obaid, T. A. (2007) The State of the World Population 2007 - Unleashing the Potential of Urban Growth. United Nations Population Fund, New York.

Orr, D. W. (1989) Ecological literacy. Conservation Biology, 3:334-335. 
Owen, K., D. Murphy, and C. Parsons. (2009) ZATPAC: A model consortium evaluates teen programs. Zoo Biology, 28:429-446.

Pyle, R. M. (1978) The extinction of experience. Horticulture, 56:64-67.

Randler, C., A. Ilg, and J. Kern. (2005) Cognitive and emotional evaluation of an amphibian conservation program for elementary school students. The Journal of Environmental Education, 37:43-52.

Sadik, N. (1999) The State of the World Population 1999 - 6 Billion: A Time for Choices. United Nations Population Fund, New York.

Simmons, D. A. (1994) Urban children's preferences for nature: Lessons learned for environmental education. Children's Environments, 11:28-40.

Sobel, D. (1998) Mapmaking with Children: Sense-of-Place Education for the Elementary Years. Heinemann, Portsmouth, NH.

SPSS for Windows. 2008. Release 16.0.2., Chicago, IL.

Tanner, T. (1980) Significant life experiences. The Journal of Environmental Education, 11:20-24.

Thompson, G., J. Hoffman, and S. Staniforth. (2003) Measuring the success of environmental education programs. Available at: http://www.peecworks.org/PEEC/PEEC_Inst/.

Trombulak, S. C., K. S. Omland, J. A. Robinson, J. J. Lusk, T. L. Fleischner, G. Brown, and M. Domroese. (2004) Principles of Conservation Biology: Recommended Guidelines for Conservation Literacy from the Education Committee of the Society for Conservation Biology. Conservation Biology, 18:1180-1190.

Van Weelie, D., and A. Wals. (2002) Making biodiversity meaningful through environmental education. International Journal of Science Education, 24:1143-1156.

Wals, A. E. J. (1994) Nobody planted it, it just grew! Young adolescents' perceptions and experiences of nature in the context of urban environmental education. Children's Environments, 11:1-27.

Wellnitz, T., N. MacRury, A. Child, and D. Benson. (2002) Spreading the wealth: graduate students and educational outreach. Conservation Biology, 16:560-563.

Zint, M., A. Kraemer, H. Northway, and M. Lim. (2002) Evaluation of the Chesapeake Bay Foundation's Conservation Education Programs. Conservation Biology, 16:641-649. 
CHAPTER 6. General Discussion

The main objectives of this thesis were (1) to advance current knowledge of kereru ecology within urbanised landscapes and to explore the concept of kereru as an "urban adapted" or "matrix sensitive" species, and (2) to examine the role of people in urban avian ecology, from the perspectives of both the researcher and the public. To achieve this I assessed kereru habitat selection at multiple scales, harnessed fortuitous opportunities to study little known behaviours, and explored methods of enhancing the relationship and engagement of people with the natural world through citizen science and environmental education. In this chapter, I synthesise the main findings of my thesis and discuss them in relation to the wider literature. I also include some future research considerations.

\section{Kereru in urbanised landscapes}

\section{THE IMPORTANCE OF MULTI-SCALE HABITAT SELECTION}

The factors affecting habitat selection of highly mobile avian species within urbanised landscapes have seldom been quantified at multiple spatial scales. Several studies have shown that urban-dwelling animals respond to and utilise a variety of habitat variables at multiple ecological scales (for example, Australian fauna reviewed in Garden et al. 2006). For example, landscape cues used to establish suitable breeding territories may differ from those used to select a feeding site (Hostetler 2001). Since the structure and composition of the urban landscape is the result of decisions made by humans at varying scales (i.e., private gardens vs. city parks; Hostetler 2001), considering a single scale of selection can only provide researchers with a partial picture of habitat selection in these complex modified systems. 
Kereru studies to date have focussed on single scales of selection ranging from annual home range placement to the procurement of food items (Appendix 1). Chapters 2 and 3 demonstrated that kereru respond to various combinations of both the historically important (or 'non-urban') and human-modified habitat features of urbanised landscapes at differing scales of selection. To the best of my knowledge, this thesis reports on the first study quantifying kereru habitat selection at the broad, regional scale (first-order selection; Johnson 1980; although see Robertson et al. 2007 for a distribution of kereru by general habitat type). Broad-scale patterns of selection were found in relation to possum control and the built environment (first-order; Chapter 2), as well as finer scale patterns of site selection in relation to possum control, native food and conspecifics (third-order; Chapter 3).

The results of Chapter 2 demonstrated that kereru were selecting more sites with intermediate building and road coverage and where possum (Trichosurus vulpecula) control measures were present. This finding may be explained by viewing the large scale possum control as creating safe habitat within the suburban landscape when the threat from predators is absent or the competition for food with introduced mammals is reduced. Thus, novel food resources in residential areas become available, and the energy expended to avoid predators is lessened. Many studies have shown positive effects of predator control on kereru survival and nesting in various areas of New Zealand, including Whirinaki Forest Park near Rotorua (Powlesland et al. 2003), Wenderholm Regional Park near Auckland (Clout et al. 1995; James \& Clout 1996), and Motatau in Northland (Innes et al. 2004). It has also been shown that removal of mammalian competitors can increase favoured food availability for kereru (Dijkgraaf 2002). My findings confirm the importance of possum control for kereru habitat selection at the regional scale and lend support to the idea that buildings and roads do not deter kereru from inhabiting urbanised areas. 
Following these analyses, I quantified winter range selection among a marked population of kereru in the Wellington region in Chapter 3. Interestingly, I found kereru winter range selection was explained by a model without fixed-effects. That is, there was high variation between individual birds that was unexplained by candidate models and predictors. In fact, selection was happening at the third-order (i.e. sites within the winter range), most likely because of the complexity of the structural composition of the habitat (i.e. garden-level management). Highly mobile species such as kereru that can meet their food requirements should be successful within urban landscapes as they are able to navigate and exploit novel and native habitat patches (McDonald-Madden et al. 2005). Kereru are large birds capable of long distance flight that spend most of their time foraging due to the low nutritional quality of their food resources (Dijkgraaf 2002). These results follow patterns in previous studies that suggest that local rather than regional habitat factors are more important in determining avian community composition within urban areas (Clergeau et al. 2001; Evans et al. 2009). In addition if the landscape is viewed as a perforation, rather than a fragmented area, then Wellington could be considered "suitably modified" for kereru as they are able to meet many of their ecological requirements within its boundaries.

There is a great need for understanding habitat structure and land use at a finer scale, especially considering the lack of knowledge about privately owned gardens. Although now recognised as one of the most important habitat areas for native wildlife in urbanised landscapes, residential areas have received very little attention due to the inaccessibility of privately owned lands (Goddard et al. 2009). However, technological advances, particularly those including satellite imagery, have allowed researchers to classify habitat in fine-grained detail (for example in Dunedin; Freeman \& Buck 2003). Researchers should consider developing similar maps in other cities, and use them in concert with on-the-ground field 
work and volunteered information about their gardens and gardening habits from citizen scientists.

In addition, future studies should consider social behaviour in both wild and rehabilitated animals. Very little is known about kereru sociality, yet it consistently emerged in my thesis as an important variable in both the selection of sites in suburban Wellington (Chapter 3) and the ability of an injured bird to re-integrate with wild conspecifics postrehabilitation (Chapter 4). Clearly, more research is required to fully understand whether these behaviours are affiliative, aggressive, or that birds are simply using other birds as cues for good feeding sites.

\section{CLASSIFYING THE RESPONSE OF KERERU TO URBANISATION}

Blair (2001) and McKinney (2002) classified species that are "often found within the matrix of human land uses that occur in the suburban landscapes" as urban adaptors. These animals typically include "edge species", which are adapted to forest edges or surrounding open areas, can exploit many foods, and respond positively to the elimination of natural predators by human activities (McKinney 2002). My thesis showed that although kereru are able to exploit exotic food sources introduced into the landscape by people, they select habitat where there is a native food source present (Chapter 3). In addition, while the definition of an urban adaptor references a response to the elimination of natural predators, kereru also showed selection for habitat in relation to the control of introduced possums (Chapters 2 and 3), although whether this is in response to predation or competition for food remains unknown.

Garden et al. (2006) later expanded McKinney's (2002) definition to include the spatial complexity of the built and natural areas of the urban environment, whereby species that are matrix sensitive "perceive the built matrix as unsuitable with a lack of food and shelter resources, a barrier to movement and an area of increased risk of predation." These 
species are often restricted to patches of suitable habitat and thus populations can become fragmented (Garden et al. 2006). While the definition provided by Garden et al. (2006) gives a useful summation across species that considers habitat, kereru do not appear to fit precisely under this defined category. Instead, kereru may be best classified under an expanded definition that better reflects the urbanised habitat that they select. The study area in this thesis (Wellington) is perhaps best described as an area that is perforated, rather than fragmented, by built structures. Highly urbanised areas such as city centres dominated by built structures and impervious surfaces represent unsuitable habitat, whereas lower densities of roads and buildings (i.e. suburban areas) appear to provide the required or preferred resources for kereru (Chapter 2). The suitability of such habitat types is likely enhanced by the reduction or elimination of possums, as they compete for favoured food sources and defoliate trees (Chapters 2 and 3). Importantly, within these suburban areas kereru do not avoid built structures, as evidenced by frequent injuries sustained from flying into buildings or swooping down in front of cars (Chapter 4) and their use of power lines as perch sites (Pers. obs.).

In addition, the long distance movements recorded in this study (i.e., "Black/Red" in Chapter 3, and the rehabilitated birds in Chapter 4), together with evidence from a large body of existing literature on kereru movements (Appendix 1) suggests that kereru are able to easily move within and between suitable habitat areas and urbanisation is not likely to cause fragmentation of populations, even in other urban areas that are highly fragmented. Unlike most passerines and similar to raptors, some kereru also most likely have annual home ranges that extend beyond the boundaries of urban areas and therefore do not necessarily need to meet all of their ecological requirements within these landscapes.

In summary, my findings suggest that kereru exploit the preferred food sources within the urban landscape and respond positively to the removal of introduced predators and food 
competitors. While this highlights that kereru may be urban adapted, they are seldom seen within high levels of urbanisation. Instead my findings show kereru prefer the areas of low to intermediate levels of urbanisation that contain suitable food sources, which suggests they are also matrix sensitive. Given the current classifications of species responses to urbanisation, kereru are perhaps best understood as being both an urban adapted and matrix sensitive species, where the definition is expanded to include kereru's ability to move within and outside of unsuitable areas due to their high mobility.

\section{The human dimensions of urban avian ecology}

\section{THE ROLE OF WILDLIFE REHABILITATION}

While it is encouraging to see increasing numbers of kereru in urbanised areas, this environment is often the cause of injuries not normally sustained in the wildlands. The most frequent causes of injury and death to urban kereru are window and vehicle strikes (37\% of admissions in Dunedin; Daglish 2005). These events are directly linked to human-made structures, and therefore there is perhaps a sense of responsibility among people to remedy these situations through rehabilitating injured animals. However, rehabilitation programs of urban species are rarely evaluated and the conservation value of these programs remains highly contested by scientists. In this thesis, I tested multiple hypotheses based upon previous studies of rehabilitated wildlife to determine the variables that contribute to the early postrelease settlement of rehabilitated kereru. Results suggested that the site of release, severity of injury and the sex of the bird were the most important predictors. Although these results are preliminary, and larger sample sizes are required, they do suggest that rehabilitator protocols (i.e. hard- vs. soft-release, time in captivity and release site) should be controlled for a clearer understanding of the effectiveness of rehabilitation programs.

In the meantime, the focus of rehabilitation should shift to being more preventative and proactive (for example education and risk reduction), rather than simply a reactive and 
emotional exercise. Given that the most common causes of injury for kereru are window and car strikes, if people mitigate the potential hazards faced by kereru within suburban areas then the numbers of animals that require rehabilitation will lower. For example, window strikes could be reduced by hanging deterrents, placing decals, tinting or angling the glass to reduce reflection (Cousins , 2010). Car strikes could also be reduced by avoiding planting favoured food sources along the sides of roads. Rehabilitators should consider each admission on a case-by-case basis and in the most severe cases should confidently euthanize when the chances of long-term survival are low, particularly from an animal welfare point of view. Perhaps most importantly my findings point to the need for more empirical evaluations of rehabilitations protocols and programs before firm conclusions can be drawn regarding their effectiveness in conservation. Rehabilitation can also offer scientists fortuitous opportunities to study behavioural re-integration of native species, whilst providing an opportunity to educate the public. Wildlife conservation, and larger environmental problems, can only be solved if humans are integrated into their solutions (Alberti et al. 2003; Grimm et al. 2000).

\section{CITIZEN SCIENCE AND ENVIRONMENTAL EDUCATION}

The value of citizen science projects to researchers in urban ecology is immense. In Chapter 2 I was able to harness the enthusiasm of volunteers to cover a geographic area that far exceeded what I would have been capable of surveying on my own, and over a long time period. By acknowledging the biases of my dataset and working within them, I was able to explore questions about kereru habitat selection within urbanised areas at a broad scale in a novel way. Although citizen science projects have been around since the early 1900s, only recently are ecologists recognising their potential in advancing biological knowledge, particularly in urban landscapes. 
The results of Chapter 2 also have important implications for future citizen science projects such as the Kereru Discovery Project (KDP) and the value of such projects to the general public. Firstly, advances in web-based and mobile technology have allowed for interactive and instantaneous feedback to those submitting information. This 'feedback loop' is necessary to maintain interest in such projects, as it involves the return of information to the public. Secondly, Cooper et al. (2007) suggest the adaptive management of the urban matrix via citizen science where both the ecological treatments and the social outcomes are measured and then subsequently used to inform revised management strategies. In my study I found a mismatch between the actual ecology of kereru in urbanised landscape and the behaviour of KDP participants. For example, although the presence of water received no support in my modelling, almost $73 \%$ of participants reported providing a water source for birds (unpublished data). Thus, the information collected and analysed by scientists should be used to inform the volunteers who collected it. This will help not only to maintain motivation in the project, but will enhance environmental stewardship among participants. The people who are involved in citizen science projects are well-meaning and often well-educated, but they require biologically-informed practical resources to guide their conservation efforts. Finally, participating in these projects has the potential to motivate local conservation action and more environmentally responsible behaviour in citizen scientists due to knowledge acquisition and thus indirectly science education (Cooper et al. 2007).

The process of creating an environmentally aware and responsible population should ultimately begin in childhood. Children living in urban areas may be experiencing a growing separation from nature (Louv 2005) and perhaps the "extinction of [ecological] experience" (Pyle 1978). Over 50\% of the world's population and its children now live in or near cities (Obaid 2007; Sadik 1999). While people living in urban areas are less 'connected' with the natural world (Miller 2005), their early life experiences and perceptions of nature may be 
essential to conservation (Tanner 1980). I undertook a teacher-biologist collaborative environmental education program that combined in-class learning with an experiment on the effects of participation in local urban kereru field research. Although I found no change in knowledge acquisition, an important and encouraging result emerged, as children who participated in exercises with researchers in local green space demonstrated a greater level of nature awareness than groups who participated in the schoolyard. Further, they retained this level three months after the program completion.

As the world becomes increasingly urbanised, biologists undertaking urban ecological research are becoming the best placed people to facilitate and shape early experiences, perceptions and attitudes of the public to nature. In my experience, the minimal time and resource commitment volunteered to an enthusiastic and grateful teacher was significantly outweighed by the excitement of the students and the visible shift towards an awareness of nature in their own neighbourhoods. In addition, the motivation for my research and personal satisfaction I received from sharing knowledge about kereru were beyond my expectations. I would strongly encourage future ecological research within urbanised landscapes to include empirically evaluated public education programs.

\section{References}

Alberti, M., J. M. Marzluff, E. Shulenberger, G. Bradley, C. Ryan, and C. Zumbrunnen. 2003. Integrating humans into ecology: opportunities and challenges for studying urban ecosystems. BioScience 53:1169-1179.

Blair, R. B. 2001. Birds and butterflies along urban gradients in two ecoregions of the U.S. Pages 33-56 in J. L. Lockwood, and M. L. McKinney, editors. Biotic Homogenization. , Norwell (MA): Kluwer.

Clergeau, P., J. Jokimaki, and J. P. L. Savard. 2001. Are urban bird communities influenced by the bird diversity of adjacent landscapes? Journal of Applied Ecology 38:11221134.

Clout, M. N., K. Denyer, R. E. James, and I. G. McFadden. 1995. Breeding success of New Zealand pigeons (Hemiphaga novaeseelandiae) in relation to control of introduced mammals. New Zealand Journal of Ecology 19:209-212. 
Cooper, C. B., J. Dickinson, T. Phillips, and R. Bonney. 2007. Citizen science as a tool for conservation in residential ecosystems. Ecology and Society 12:11. [online] URL:http://www.ecologyandsociety.org/vol12/iss12/art11/.

Daglish, L. 2005. City pigeons : Kererū (Hemiphaga novaeseelandiae) in the urban Dunedin environment : abundance, habitat selection and rehabilitation outcomes. Unpubl. M.Sc. thesis. University of Otago.

Dijkgraaf, A. C. 2002. Phenology and frugivory of large-fruited species in northern New Zealand and the impacts of introduced mammals. Unpubl. Ph.D. thesis. University of Auckland, New Zealand.

Evans, K. L., S. E. Newson, and K. J. Gaston. 2009. Habitat influences on urban avian assemblages. Ibis 151:19-39.

Freeman, C., and O. Buck. 2003. Development of an ecological mapping methodology for urban area in New Zealand. Landscape and Urban Planning 63:161-173.

Garden, J., C. McAlpine, A. Peterson, D. Jones, and H. Possingham. 2006. Review of the ecology of Australian urban fauna: A focus on spatially explicit processes. Austral Ecology 31:126-148.

Goddard, M. A., A. J. Dougill, and T. G. Benton. 2009. Scaling up from gardens: biodiversity conservation in urban environments. Trends in Ecology \& Evolution 25:90-98.

Grimm, N. B., J. Morgan Grove, S. T. A. Pickett, and C. L. Redman. 2000. Integrated Approaches to Long-TermStudies of Urban Ecological Systems. BioScience 50:571584.

Hostetler, M. 2001. The importance of multi-scale analyses in avian habitat selection studies in urban environments in J. M. Marzluff, R. Bowman, and R. Donnelly, editors. Avian ecology and conservation in an urbanizing world. Kluwer Academic Publishers, Norwell, MA.

Innes, J., G. Nugent, K. Prime, and E. B. Spurr. 2004. Responses of kukupa (Hemiphaga novaeseelandiae) and other birds to mammal pest control at Motatau, Northland. New Zealand Journal of Ecology 28:73-81.

James, R. E., and M. N. Clout. 1996. Nesting success of New Zealand Pigeons (Hemiphaga novaeseelandiae) in response to a rat (rattus rattus) poisoning programme at Wenderholm Regional Park. New Zealand Journal of Ecology 20:45-51.

Johnson, D. H. 1980. The comparison of usage and availability measurements for evaluating resource preferences. Ecology 61:65-71.

Louv, R. 2005. Last child in the woods: saving our children from nature-deficit disorder. Viking, Penguin Books., Auckland, New Zealand. 
McDonald-Madden, E., S. G. Schreiber, D. M. Forsyth, D. Choquenot, and T. F. Clancy. 2005. Factors affecting Grey-headed Flying-fox (Pteropus poliocephalus:

Pteropodidae) foraging in the Melbourne metropolitan area, Australia. Austral Ecology 30:600-608.

McKinney, M. L. 2002. Urbanization, biodiversity, and conservation. Bioscience 52:883-890.

Miller, J. R. 2005. Biodiversity conservation and the extinction of experience. Trends in Ecology \& Evolution 20:430-434.

Obaid, T. A. 2007. The State of the World Population 2007 - Unleashing the Potential of Urban Growth. United Nations Population Fund, New York.

Powlesland, R. G., D. E. Wills, A. C. L. August, and C. K. August. 2003. Effects of a 1080 operation on kaka and kereru survival and nesting success, Whirinaki Forest Park. New Zealand Journal of Ecology 27:125-137.

Pyle, R. M. 1978. The extinction of experience. Horticulture 56:64-67.

Robertson, C. J. R., P. Hyvonen, M. J. Fraser, and C. R. Pickard 2007. Atlas of bird distribution in New Zealand 1999-2004. The Ornithological Society of New Zealand, Inc., Wellington, New Zealand.

Sadik, N. 1999. The State of the World Population 1999 - 6 Billion: A Time for Choices. United Nations Population Fund, New York.

Tanner, T. 1980. Significant life experiences. The Journal of Environmental Education 11:2024. 


\section{APPENDIX 1. Summary of kereru studies 1981-2010}

\begin{tabular}{|c|c|c|c|c|c|c|c|c|c|c|c|c|c|}
\hline \multirow[t]{2}{*}{ Author(s) ${ }^{\mathrm{a}}$} & \multirow{2}{*}{$\begin{array}{l}\text { Study } \\
\text { Dates }\end{array}$} & \multirow[t]{2}{*}{ Study Location } & \multirow{2}{*}{$\begin{array}{l}\text { Level of } \\
\text { Urban- } \\
\text { isation }^{b}\end{array}$} & \multirow{2}{*}{$\begin{array}{l}\text { Number of } \\
\text { Tagged Birds }\end{array}$} & \multicolumn{5}{|c|}{ Factors Examined $^{c}$} & \multirow{2}{*}{$\begin{array}{c}\text { Home } \\
\text { Range } \\
\text { (ha) }\end{array}$} & \multirow{2}{*}{$\begin{array}{c}\text { Core } \\
\text { Range } \\
\text { (ha) }\end{array}$} & \multirow{2}{*}{$\begin{array}{l}\text { Nesting } \\
\text { Success } \\
\text { Rate }^{d}\end{array}$} & \multirow{2}{*}{$\begin{array}{c}\text { Native/ } \\
\text { Exotic Plant } \\
\text { Species } \\
\text { Utilised }\end{array}$} \\
\hline & & & & & HR & DT & SD & BR & BE & & & & \\
\hline $\begin{array}{l}\text { Dunn, P.L. } \\
\text { (1981) }\end{array}$ & $\begin{array}{l}\text { May } \\
1977- \\
\text { Apr } \\
1978\end{array}$ & $\begin{array}{l}\text { Dunedin city (+ } 2 \\
\text { sites native bush) }\end{array}$ & $0-2$ & 0 & & $x$ & $x$ & & & & & & Both (urban) \\
\hline $\begin{array}{l}\text { Clout, M.N. } \\
\text { et al (1986) }\end{array}$ & $\begin{array}{l}\text { Jun } \\
1983- \\
\text { Jan } \\
1985\end{array}$ & $\begin{array}{l}\text { Lake Rotoroa, } \\
\text { Nelson Lakes }\end{array}$ & 0 & 2 & $x$ & $x$ & & & & Not given & Not given & & Native \\
\hline $\begin{array}{l}\text { Clout, M.N. } \\
\text { et al (1991) } \\
\text { Clout, M.N. } \\
\text { et al (1995) }\end{array}$ & $\begin{array}{l}\text { Oct } \\
1983- \\
\text { Apr } \\
1991\end{array}$ & $\begin{array}{l}\text { Pelorus Bridge, } \\
\text { Marlborough; Mohi } \\
\text { Bush, Hawkes Bay; } \\
\text { Wenderholm RP, } \\
\text { Auckland }\end{array}$ & $0-1$ & $\begin{array}{l}75 \mathrm{~PB} ; \\
16 \mathrm{MB} \text { : } \\
11 \mathrm{WRP}\end{array}$ & $x$ & $x$ & & $x$ & $x$ & Not given & Not given & $\begin{array}{l}22 \% \text { PB } \\
(n=45) \\
0 \% M B \\
(n=9) \\
0 \% \text { WRP } \\
(n=27)\end{array}$ & Native \\
\hline $\begin{array}{l}\text { Pearson, P.E. } \\
\text { \& Climo, } \\
\text { G.C. (1993) }\end{array}$ & $\begin{array}{l}\text { Oct } \\
1990- \\
\text { Nov } \\
1990\end{array}$ & Chatham Island & 0 & $\begin{array}{l}3 \text { ( } 2 \text { radio } \\
\text { tracking) }\end{array}$ & & $x$ & & & $x$ & & & & Native \\
\hline
\end{tabular}

\footnotetext{
anpublished thesis italicised

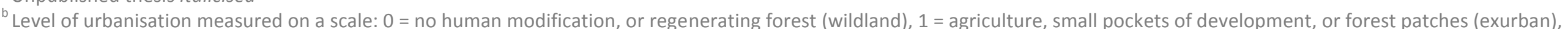
2 = spread our low-level dwellings (suburban), 3 = concentrated densities of impervious surfaces, including high-rise buildings (urban)

${ }^{c}$ Factors examined included: $\mathrm{HR}=$ home range, including movements, $\mathrm{HU}=$ habitat use, $\mathrm{DT}=$ diet, $\mathrm{SD}=$ seed dispersal, $\mathrm{BR}=\mathrm{breeding}, \mathrm{BE}=\mathrm{behaviour}$

${ }^{d}$ Expressed as the percentage of nests to successfully fledge chicks
} 


\begin{tabular}{|c|c|c|c|c|c|c|c|c|c|c|c|c|c|}
\hline \multirow[t]{2}{*}{ Author(s) ${ }^{\mathrm{a}}$} & \multirow{2}{*}{$\begin{array}{l}\text { Study } \\
\text { Dates }\end{array}$} & \multirow[t]{2}{*}{ Study Location } & \multirow{2}{*}{$\begin{array}{l}\text { Level of } \\
\text { Urban- } \\
\text { isation }^{b}\end{array}$} & \multirow{2}{*}{$\begin{array}{l}\text { Number of } \\
\text { Tagged Birds }\end{array}$} & \multicolumn{5}{|c|}{ Factors Examined $^{c}$} & \multirow{2}{*}{$\begin{array}{l}\text { Home } \\
\text { Range } \\
\text { (ha) }\end{array}$} & \multirow{2}{*}{$\begin{array}{l}\text { Core } \\
\text { Range } \\
\text { (ha) }\end{array}$} & \multirow{2}{*}{$\begin{array}{l}\text { Nesting } \\
\text { Success } \\
\text { Rate }^{\text {d }}\end{array}$} & \multirow{2}{*}{$\begin{array}{c}\text { Native/ } \\
\text { Exotic Plant } \\
\text { Species } \\
\text { Utilised }\end{array}$} \\
\hline & & & & & HR & DT & SD & BR & $\mathrm{BE}$ & & & & \\
\hline $\begin{array}{l}\text { Pierce, R.J. \& } \\
\text { Graham, P.J. } \\
(1995)\end{array}$ & $\begin{array}{l}\text { Jul } \\
\text { 1991- } \\
\text { Aug } 1993\end{array}$ & $\begin{array}{l}\text { Lady Alice \& } \\
\text { Coppermine } \\
\text { Islands, Northland; } \\
\text { Maungataperere, } \\
\text { Northland }\end{array}$ & $0-1$ & $11 \mathrm{M}$ & $x$ & $x$ & & $x$ & & $80-402$ & $50-200$ & $\begin{array}{l}63 \% \\
\text { LAI \& } \\
\text { CMI } \\
(n=16) \\
19 \% M \\
(n=31)\end{array}$ & $\begin{array}{l}\text { Both (mostly } \\
\text { native) }\end{array}$ \\
\hline $\begin{array}{l}\text { James, R.E. } \\
\text { (1995) }\end{array}$ & $\begin{array}{l}\text { Mar } \\
1993- \\
\text { Feb } \\
1994\end{array}$ & $\begin{array}{l}\text { Wenderholm } \\
\text { Regional Park, } \\
\text { Auckland }\end{array}$ & $0-1$ & 16 & & $x$ & & $x$ & $x$ & & & $\begin{array}{l}18.5 \% \\
(n=70)\end{array}$ & \\
\hline $\begin{array}{l}\text { Bell, } R \\
(1996)\end{array}$ & $\begin{array}{l}\text { Oct } \\
1994- \\
\text { Sept } \\
1995\end{array}$ & $\begin{array}{l}\text { Wenderholm } \\
\text { Regional Park, } \\
\text { Auckland }\end{array}$ & $0-1$ & $\begin{array}{l}9 \text { (seed trials) } \\
6 \text { (radio } \\
\text { tracking) }\end{array}$ & $x$ & $x$ & $x$ & & $x$ & $\begin{array}{l}8.38- \\
109.8\end{array}$ & $1.46-6.14$ & & Native \\
\hline $\begin{array}{l}\text { Powlesland, } \\
\text { R.G. et al } \\
\text { (1996) } \\
\text { Grant, A.D. } \\
\text { et al (1997) } \\
\text { Flux, l. et al } \\
\text { (2001) }\end{array}$ & $\begin{array}{l}1978- \\
1994 \\
\text { census } \\
\text { July } \\
1991- \\
\text { Dec } \\
1994\end{array}$ & Chatham Island & $0-1$ & $\begin{array}{l}27 \text { adults (9 } \\
\text { radio tracking) } \\
65 \text { nestlings } \\
\text { ( } 6 \text { radio } \\
\text { tracking) }\end{array}$ & $x$ & $x$ & & $x$ & & & & $\begin{array}{l}68 \% \\
(n=101)\end{array}$ & Native \\
\hline $\begin{array}{l}\text { Powlesland, } \\
\text { R.G. et al } \\
\text { (1999) }\end{array}$ & $\begin{array}{l}\text { Jul 1999- } \\
\text { Aug } \\
1999\end{array}$ & Chatham Island & $0-1$ & 0 & & & & $x$ & & & & $\begin{array}{l}? ? \\
(n=7)\end{array}$ & \\
\hline
\end{tabular}

anpublished thesis italicised

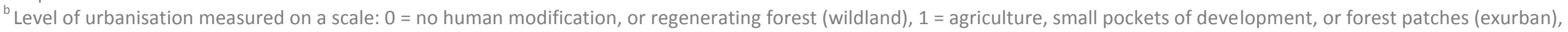
2 = spread our low-level dwellings (suburban), 3 = concentrated densities of impervious surfaces, including high-rise buildings (urban)

${ }^{c}$ Factors examined included: $\mathrm{HR}=$ home range, including movements, $\mathrm{HU}=$ habitat use, $\mathrm{DT}=$ diet, $\mathrm{SD}=$ seed dispersal, $\mathrm{BR}=\mathrm{breeding}, \mathrm{BE}=\mathrm{behaviour}$

${ }^{\mathrm{d}}$ Expressed as the percentage of nests to successfully fledge chicks 


\begin{tabular}{|c|c|c|c|c|c|c|c|c|c|c|c|c|c|}
\hline \multirow[t]{2}{*}{ Author(s) ${ }^{a}$} & \multirow{2}{*}{$\begin{array}{l}\text { Study } \\
\text { Dates }\end{array}$} & \multirow[t]{2}{*}{ Study Location } & \multirow{2}{*}{$\begin{array}{l}\text { Level of } \\
\text { Urban- } \\
\text { isation }^{\text {b }}\end{array}$} & \multirow{2}{*}{$\begin{array}{l}\text { Number of } \\
\text { Tagged Birds }\end{array}$} & \multicolumn{5}{|c|}{ Factors Examined $^{c}$} & \multirow{2}{*}{$\begin{array}{l}\text { Home } \\
\text { Range } \\
\text { (ha) }\end{array}$} & \multirow{2}{*}{$\begin{array}{c}\text { Core } \\
\text { Range } \\
\text { (ha) }\end{array}$} & \multirow{2}{*}{$\begin{array}{l}\text { Nesting } \\
\text { Success } \\
\text { Rate }^{d}\end{array}$} & \multirow{2}{*}{$\begin{array}{c}\text { Native/ } \\
\text { Exotic Plant } \\
\text { Species } \\
\text { Utilised }\end{array}$} \\
\hline & & & & & HR & DT & SD & BR & BE & & & & \\
\hline $\begin{array}{l}\text { Karan, A. } \\
\text { (2000) }\end{array}$ & $\begin{array}{l}\text { May } \\
1998-J u n \\
1999\end{array}$ & $\begin{array}{l}\text { North Shore, } \\
\text { Auckland }\end{array}$ & 2 & & & $x$ & $x$ & & & & & & $\begin{array}{l}\text { Native } \\
(18 / 11)\end{array}$ \\
\hline $\begin{array}{l}\text { Dijkgraaf, } \\
\text { A.C. (2002) }\end{array}$ & $\begin{array}{l}\text { Oct } \\
1994- \\
\text { Feb } \\
1998\end{array}$ & $\begin{array}{l}\text { Wenderholm RP } \\
(+5 \text { sites north and } \\
\text { south of Auckland })\end{array}$ & $0-1$ & 0 & & $x$ & $x$ & & & & & & Native \\
\hline $\begin{array}{l}\text { Harwood, } \\
\text { H.P. (2002) }\end{array}$ & $\begin{array}{l}\text { Jan } \\
2000- \\
\text { Feb } \\
2001\end{array}$ & $\begin{array}{l}\text { North Shore, } \\
\text { Auckland }\end{array}$ & 2 & 1 & & $x$ & & & $x$ & & & & $\begin{array}{l}\text { Both (mostly } \\
\text { exotic) }\end{array}$ \\
\hline $\begin{array}{l}\text { Powlesland, } \\
\text { R.G. et al } \\
(2003)\end{array}$ & $\begin{array}{l}\text { Oct } \\
1998- \\
\text { Jun } \\
2002\end{array}$ & $\begin{array}{l}\text { Whirinaki Forest } \\
\text { Park }\end{array}$ & 0 & 74 & & ‘ & & $x$ & $x$ & & & $\begin{array}{l}25 \% \\
(n=8 \\
1998 / 99) \\
75 \% \\
(n=14 \\
2001 / 02)\end{array}$ & \\
\hline $\begin{array}{l}\text { Hill, M.T. } \\
\text { (2003) }\end{array}$ & & $\begin{array}{l}\text { Whirinaki Forest } \\
\text { Park }\end{array}$ & 0 & & $x$ & $x$ & $x$ & & & $13.9-704.2$ & $\begin{array}{l}2.3-12.2 \\
(1.1-26.7)\end{array}$ & & Native \\
\hline $\begin{array}{l}\text { Innes, J. et al } \\
\text { (2004) } \\
\text { Thorsen, M } \\
\text { et al (2004) }\end{array}$ & $\begin{array}{l}\text { Oct } \\
1996- \\
\text { Nov } \\
2001\end{array}$ & $\begin{array}{l}\text { Motatau, } \\
\text { Northland }\end{array}$ & 0 & 23 & & & & $x$ & & & & $\begin{array}{l}32 \% \\
(n=44)\end{array}$ & \\
\hline
\end{tabular}

anpublished thesis italicised

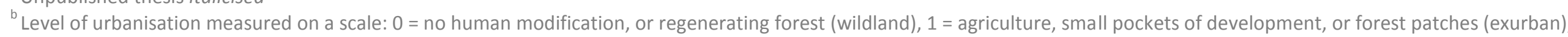
2 = spread our low-level dwellings (suburban), 3 = concentrated densities of impervious surfaces, including high-rise buildings (urban)

${ }^{c}$ Factors examined included: $\mathrm{HR}=$ home range, including movements, $\mathrm{HU}=$ habitat use, $\mathrm{DT}=$ diet, $\mathrm{SD}=$ seed dispersal, $\mathrm{BR}=$ breeding, $\mathrm{BE}=\mathrm{behaviour}$

${ }^{d}$ Expressed as the percentage of nests to successfully fledge chicks 


\begin{tabular}{|c|c|c|c|c|c|c|c|c|c|c|c|c|c|}
\hline \multirow[t]{2}{*}{ Author(s) ${ }^{\mathrm{a}}$} & \multirow{2}{*}{$\begin{array}{l}\text { Study } \\
\text { Dates }\end{array}$} & \multirow[t]{2}{*}{ Study Location } & \multirow{2}{*}{$\begin{array}{l}\text { Level of } \\
\text { Urban- } \\
\text { isation }^{b}\end{array}$} & \multirow{2}{*}{$\begin{array}{l}\text { Number of } \\
\text { Tagged Birds }\end{array}$} & \multicolumn{5}{|c|}{ Factors Examined $^{c}$} & \multirow{2}{*}{$\begin{array}{l}\text { Home } \\
\text { Range } \\
\text { (ha) }\end{array}$} & \multirow{2}{*}{$\begin{array}{c}\text { Core } \\
\text { Range } \\
\text { (ha) }\end{array}$} & \multirow{2}{*}{$\begin{array}{l}\text { Nesting } \\
\text { Success } \\
\text { Rate }^{d}\end{array}$} & \multirow{2}{*}{$\begin{array}{c}\text { Native/ } \\
\text { Exotic Plant } \\
\text { Species } \\
\text { Utilised }\end{array}$} \\
\hline & & & & & HR & DT & SD & BR & BE & & & & \\
\hline $\begin{array}{l}\text { Schotborgh, } \\
\text { H.M. (2005) }\end{array}$ & $\begin{array}{l}\text { Feb } \\
2004- \\
\text { Mar } \\
2005\end{array}$ & $\begin{array}{l}\text { Banks Peninsula } \\
\text { (Lyttelton Harbour) }\end{array}$ & $1-2$ & 15 & $x$ & $x$ & $x$ & $x$ & $x$ & $1.8-22.2$ & $0.01-0.28$ & $\begin{array}{l}35 \% \\
(n=20)\end{array}$ & $\begin{array}{l}\text { Both } \\
(11 / 12)\end{array}$ \\
\hline $\begin{array}{l}\text { Daglish, L. } \\
\text { (2005) }\end{array}$ & $\begin{array}{l}\text { Jan } \\
2004- \\
\text { Mar } \\
2005\end{array}$ & Dunedin & $0-3$ & 6 (rehab) & & & & & & & & & \\
\hline $\begin{array}{l}\text { Prendergast, } \\
\text { S.T. (2006) }\end{array}$ & $\begin{array}{l}\text { Feb } \\
2004- \\
\text { Mar } \\
2005\end{array}$ & Banks Peninsula & 1 & 15 & & & & $x$ & $x$ & & & $\begin{array}{l}35 \% \\
(n=20)\end{array}$ & \\
\hline $\begin{array}{l}\text { Campbell, } \\
\text { K.L. (2006) }\end{array}$ & $\begin{array}{l}\text { Feb } \\
2005- \\
\text { Feb } \\
2006\end{array}$ & $\begin{array}{l}\text { Banks Peninsula } \\
\text { (Hinewai Reserve) }\end{array}$ & 1 & 15 & $x$ & $x$ & $x$ & $x$ & $x$ & $1.8-40.1$ & $0.3-4.5$ & $\begin{array}{l}17 \% \\
(n=12)\end{array}$ & $\begin{array}{l}\text { Both } \\
(15 / 6)\end{array}$ \\
\hline $\begin{array}{l}\text { Wotton, } \\
\text { D.M. } \\
\text { (2007) }\end{array}$ & & $\begin{array}{l}\text { New Plymouth; } \\
\text { Banks Peninsula }\end{array}$ & & & & $x$ & $x$ & & & & & & Both \\
\hline
\end{tabular}

anpublished thesis italicised

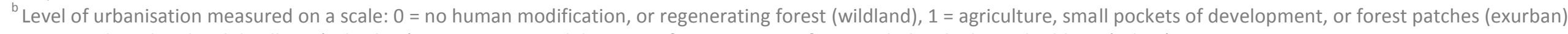
2 = spread our low-level dwellings (suburban), 3 = concentrated densities of impervious surfaces, including high-rise buildings (urban)

${ }^{\mathrm{c}}$ Factors examined included: $\mathrm{HR}=$ home range, including movements, $\mathrm{HU}=$ habitat use, $\mathrm{DT}=$ diet, $\mathrm{SD}=$ seed dispersal, $\mathrm{BR}=$ breeding, $\mathrm{BE}=$ behaviour

${ }^{\mathrm{d}}$ Expressed as the percentage of nests to successfully fledge chicks 


\section{APPENDIX 2. Attaching tail-mounted transmitters on New Zealand pigeon or kereru (Hemiphaga novaeseelandiae) and Feral pigeon (Columba livia)}

Author's note: This document was originally written as a contribution towards the development of a Standard Operating Procedure (SOP) by the Department of Conservation (DOC) on the attachment of tail-mounted transmitters on birds.

Gummer, H. (Compiler) 2011. DRAFT Standard Operating Procedures for attaching radio and data-storage tags to birds: feather/skin mounts (tape/ties/glue). Department of Conservation, Wellington, New Zealand.

Here, I give a detailed account of the methods I employed during my thesis on two species of pigeons.

The use of tail-mounted transmitters in telemetry studies is becoming increasingly popular. These types of transmitters are light-weight (less than $8 \mathrm{~g}$ for pigeons), easy to attach, do not burden the bird like traditional harnesses, and do not require re-capture of the bird as they are naturally shed during moult. Here I describe the attachment of tail-mounted transmitters (SIRTrack Limited, Havelock North, NZ; Figure 1) on New Zealand pigeons (kereru; Hemiphaga novaeseelandiae) and Feral pigeons (Columba livia).

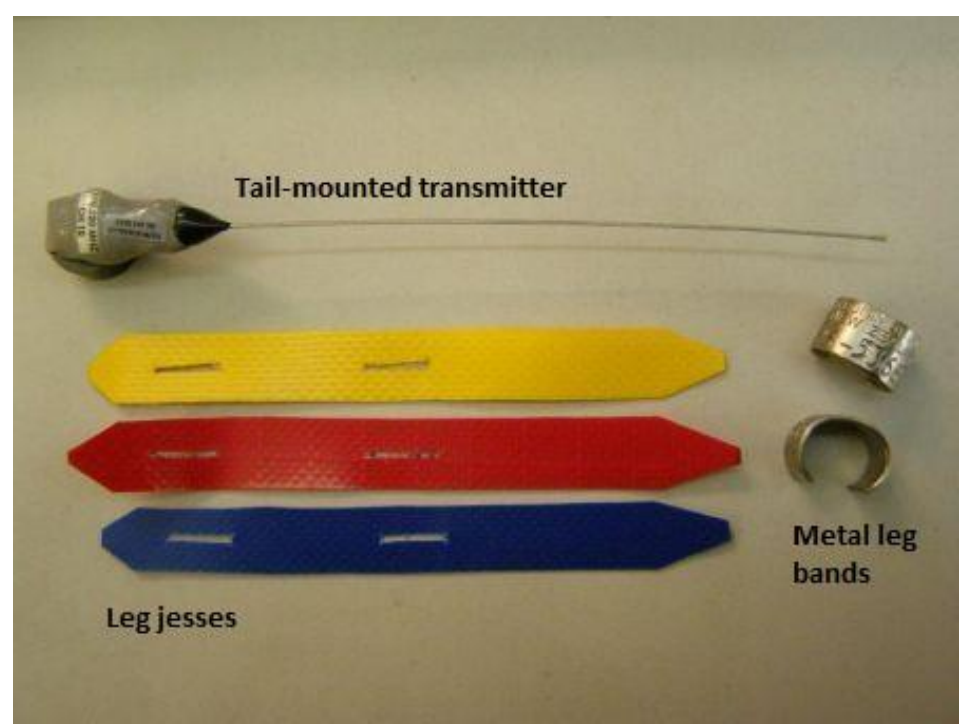

Figure 1. Tail-mounted transmitters from SIRTrack Ltd. used on pigeons - together with PVC coated canvas leg jesses and metal leg bands, the total weight was less than $8 \mathrm{~g}$. 
Tail-mounted transmitters are attached at the base of the tail between the two middle retrices (tail feathers). Placement should be low enough to allow enough room for the bird to access their preen gland, but high enough that the tail coverts cover it to expose only the antenna (Figure 2).

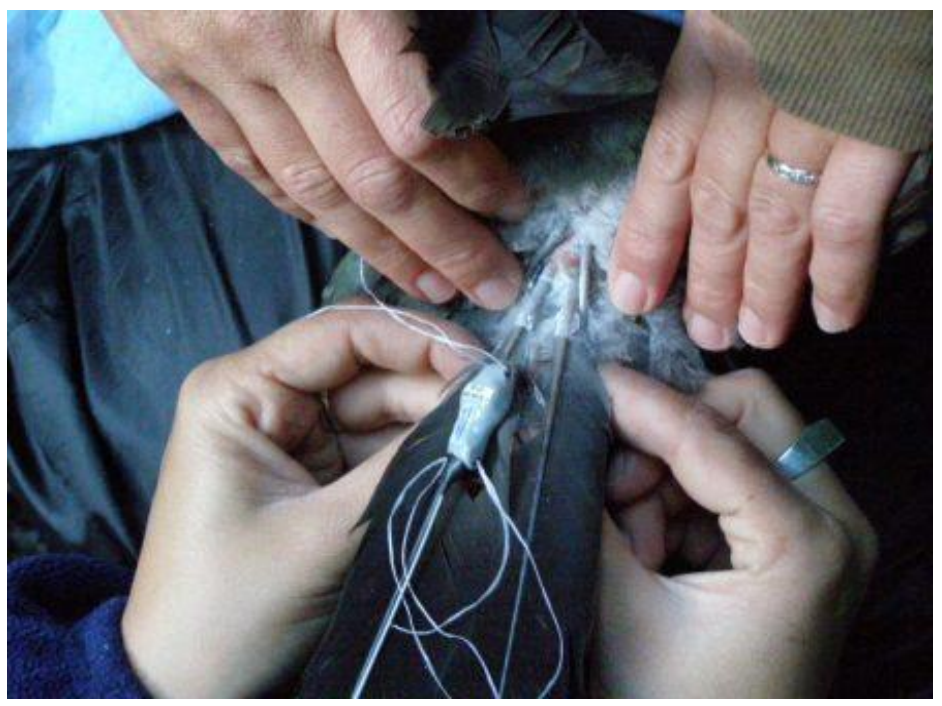

Figure 2. Exposing the base of the tail by moving the tail coverts aside to expose the preen gland.

Four pieces of waxed, unscented dental floss are used to secure the transmitter in place, by weaving two pieces through the top hole and around the feathers on each side, and two across the bottom the same way (Figure 3). This way, the transmitter is more securely attached and the feathers have more mobility. The transmitter rests between the feather shafts with enough space for them to separate during flight without "hanging". Everything is double knotted onto the transmitter and quick drying super-glue applied at each hole, on all the knots and along the shaft of the feather where it meets the floss. Care is taken not to get any on the actual feather or anywhere near the preen gland. 

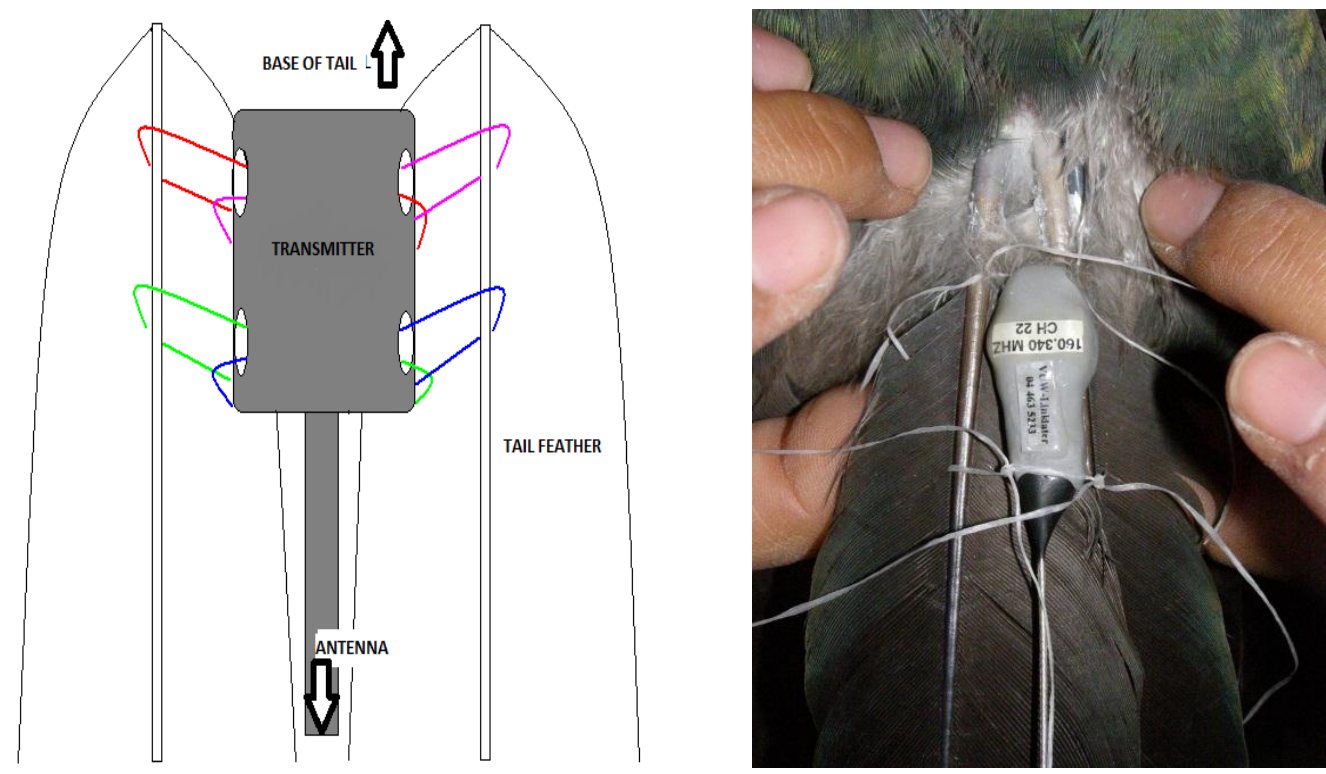

Figure 3. Diagram and photo showing how dental floss is used to secure the transmitter to the feathers. Note that each knot and attachment point should also be glued in place.

Do not release the bird for a minimum 8-10 minutes after applying the glue in order to allow everything to set before release. If possible, hold the bird for longer. New Zealand pigeons do not tend to react very well to handling and excess handling and stress can lead to tail feather loss (see Appendix 5). Thus, we minimised the amount of time that New Zealand pigeons were held. Feral pigeons, on the other hand, are fairly non-reactive and calm when placed into a cardboard box or darkened animal carrier, and so can be held this way for 10-15 minutes (or longer if necessary) to allow enough time for the glue to set. In addition, the antennae can be tied along the feather shaft if desired, although it was deemed unnecessary for the pigeons in our studies. Once the bird is released, you should only be able to see the antenna coming out from the base of the tail (Figure 4). 


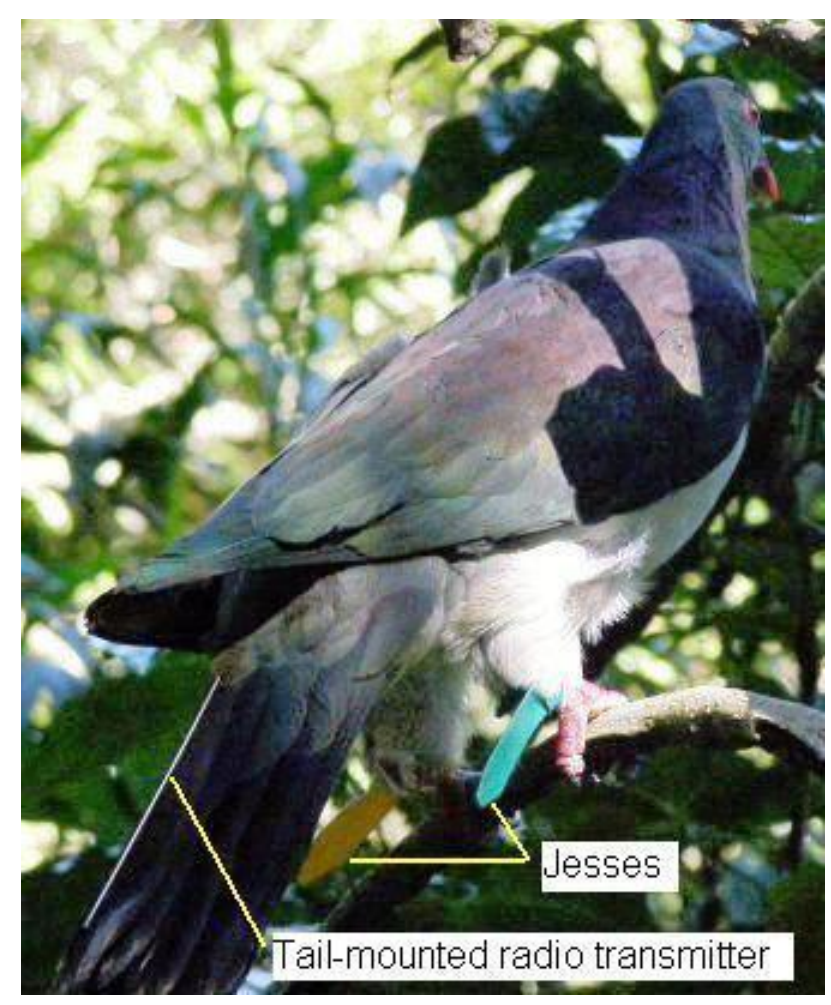

Figure 4. Kereru with a tail-mounted transmitter. Note that the antenna is not tied along the length of the tail feathers. 


\section{APPENDIX 3. Sexing adult kereru using morphometrics, plumage and DNA}

\section{Introduction}

Kereru (Hemiphaga novaeseelandiae) are large-bodied, arboreal fruit-eating pigeons widely distributed throughout New Zealand (Robertson et al. 2007) and have increased in numbers due to reduced predation pressures (Miskelly et al. 2008; Powlesland \& Miskelly 9 July 2008). Kereru display a similar morphology to other pigeons in the Columbidae family, with a small head, a straight soft-based bill and loosely attached feathers (Heather \& Robertson 2005).

Kereru are considered sexually monomorphic (Heather \& Robertson 2005), although some sexual differences in bill and wing length have been reported (Gill 2006). There is also anecdotal evidence that sexual differences exist in body mass, tail shape, and plumage. Most field studies of kereru to date have used behaviour to determine individual sex (Campbell 2006; Clout et al. 1995; Flux et al. 2001; James 1995; Powlesland et al. 2003; Thorsen et al. 2004), but these observations are limited to the breeding season when male and female kereru have distinct temporal patterns of nest attentiveness (James 1995). Alternatively, DNA analysis is a highly accurate method of determining a bird's sex at all times of the year. However, DNA analysis can be expensive, requires the collection of feathers or blood, and must be completed in a laboratory. Nevertheless, the ability to sex individuals allows genderspecific studies of population structure, habitat use, foraging behaviour, migration patterns, and many other sex-related life history parameters (Brady et al. 2009). Thus, a reliable method for sexing kereru in the field is highly desirable. 
Here, I describe and compare methods for determining the sex of adult kereru using morphometrics, plumage, and DNA analysis.

\section{Methods}

During Feb 2007-Dec 2008, 11 adult kereru were captured in canopy-height mist-net rigs (Dilks et al. 1995), which were set up near foraging or roosting sites around the visitor centre at Otari-Wilton's Bush, Wellington as part of a study on wild kereru (Chapter 3). From Feb 2008-Dec 2009, 12 additional adult kereru were captured in aviaries at Nga Manu Nature Reserve in Waikanae, and Native Bird Rescue Wellington Trust in Wellington, as part of a study on rehabilitated kereru (Chapter 4; note that one kereru died before release and so although included in the sexing study, was not included in the analysis of the earlier chapter).

For each kereru captured I quantified: (1) weight, (2) natural wing chord, (3) tail length, (4) tarsus, (5) bill length, and (6) bill width. All measurements were made following those of Gill (2006), the North American Bird Bander's Guide (2001) and the New Zealand Bird Bander's Guide. The weight of each bird was measured using a $1000 \mathrm{~g}$ pesola spring scale to the nearest 5 grams. Wing chord was measured using the right wing, unflattened from the wrist of the folded wing to the longest feather, on a stop-ended ruler. Tail length was measured between the two central retrices from the base to the tip of the tail, using a ruler. I measured the tarsus from the ankle notch to the edge of the bent over right foot, using dial callipers. I also used the callipers to measure bill length from the top of the nares to the tip of the bill, and bill width at the base of the nares.

To determine statistical differences between morphometrics of adult kereru, independent sample t-tests were applied to each measurement using statistical software SPSS (2008). Since differences between feeding regimes may exist between rehabilitated and wild kereru, these two groups were also analysed separately for weight. 
To assess differences in plumage between the sexes, I examined the following for each kereru: (1) head and nape colour - light, medium, or dark purple; (2) throat colour light, medium, or dark blue; and (3) colour from eye to nares - light, medium, or dark streak (Figure 1.). It was also noted whether any of these colour areas joined (i.e. there was no separation between colour areas).

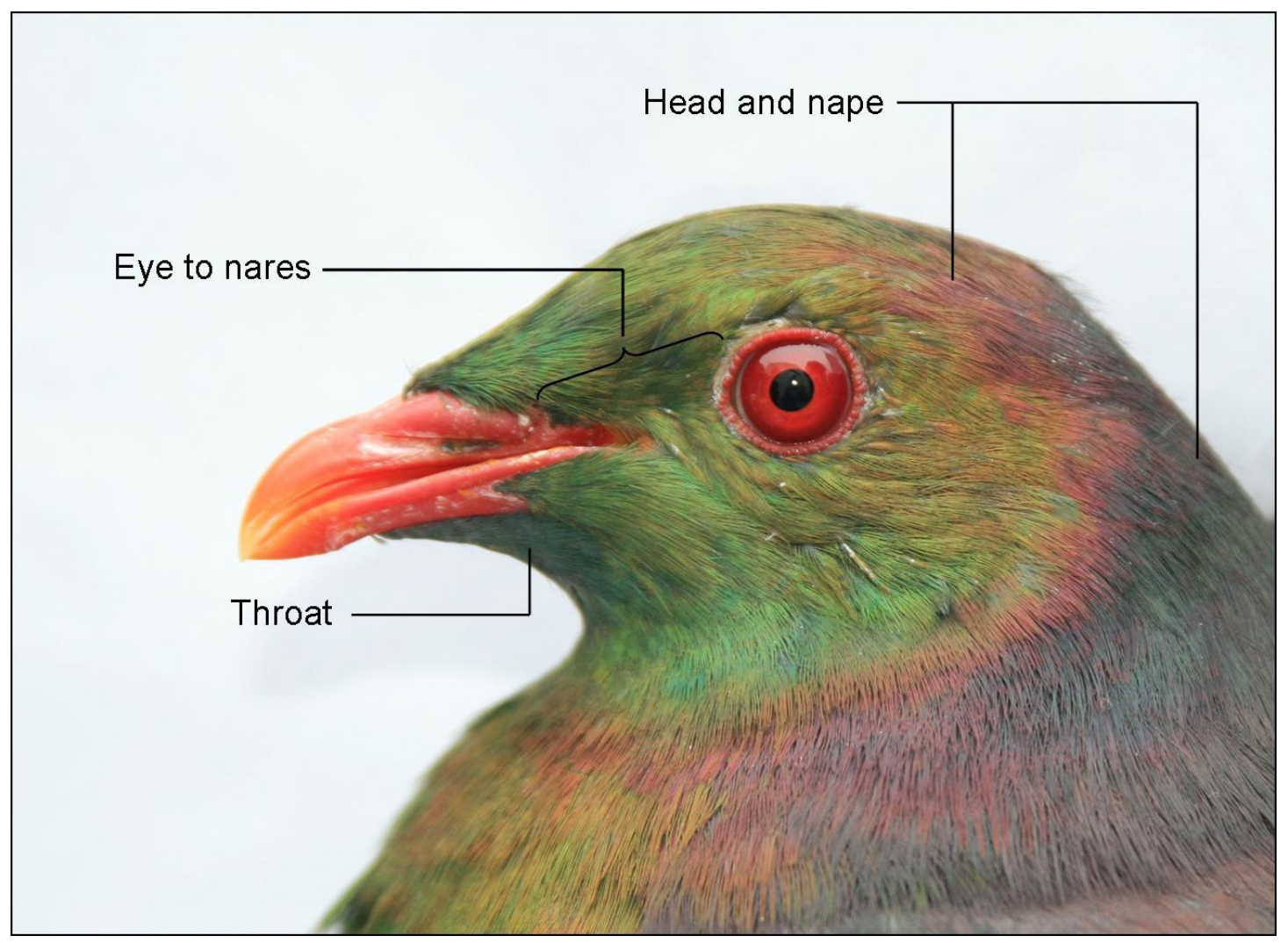

Figure 1. Areas of each kereru that were assessed for plumage differences. Photo of an adult male (verified by DNA analysis) by E.Greene.

The sex of each bird was verified by polymerase chain reaction (PCR) analysis of DNA from 2-3 contour feathers taken from the breast of each kereru and then stored in paper envelopes at room temperature until genetic analysis. I conducted all genetic analyses using licensed protocols at the Equine Parentage and Animal Genetic Services Centre at Massey University in Palmerston North. These protocols are non-disclosable, but see Ellegren (1996) and Griffiths et al (1998) for further information. 


\section{Results}

Molecular sexing techniques identified the sex of all 23 kereru, including 14 females and 9 males. There were no significant differences in any morphometrics between male and female adult kereru (Table 1). Weights could be considered as approaching significance $(p=0.08)$ between males and females, with females having a larger range in weights than males (Figure 2). No significant difference in weight was found between wild and rehabilitated kereru $(\mathrm{df}=21, \mathrm{t}=0.728, \mathrm{p}=0.281)$. Although significant differences in morphometric measurements between the sexes in other studies, my study did not reveal the same results (Table 2).

Table 1. Mean $( \pm \mathrm{SE})$ body measurements of adult kereru.

\begin{tabular}{llll}
\hline Variable & Males $(\mathrm{N}=9)$ & Females $(\mathrm{N}=14)$ & $P$-value (t-test) \\
\hline Weight & $638.4 \pm 12.8$ & $585.5 \pm 25.1$ & 0.08 \\
& Range: $570-685$ & Range: $415-713$ & \\
Wing chord & $250.8 \pm 2.9$ & $245.0 \pm 4.6$ & 0.37 \\
& Range: $235-259$ & Range: $192-266$ & \\
Tail length & $179.1 \pm 4.3$ & $175.3 \pm 3$ & 0.46 \\
& Range: $146-188$ & Range: $145-190$ & \\
Tarsus & $35.0 \pm 1.5$ & $35.9 \pm 0.5$ & 0.57 \\
& Range: $31.4-40.3$ & Range: $32.5-39.1$ & \\
Bill length & $17.8 \pm 0.4$ & $17.5 \pm 0.3$ & 0.53 \\
& Range: $16.5-20.0$ & Range: $15.8-19.5$ & \\
Bill width & $8.8 \pm 0.5$ & $8.9 \pm 0.4$ & 0.87 \\
& Range: $6.7-11.5$ & Range: $6.9-12.1$ & \\
\hline
\end{tabular}

Table 2. Comparison of studies of kereru morphology. Significant differences in metrics between the sexes are denoted by the following: * $\mathrm{p}<0.05$, ** $\mathrm{p}<0.01$, and $* * * \mathrm{p}<0.001$. Metrics that were found to be approaching significance are denoted by an " $x$ ".

\begin{tabular}{lccc}
\hline Metric & Higgins \& Davies (1996) & Gill (2006) & Awasthy (2011) \\
\hline Weight & $* *$ & $* *$ & $\mathrm{x}$ \\
Wing chord $^{\mathrm{a}}$ & $*$ & & \\
Tail length & & $* *$ & \\
Tarsus & & & \\
Bill length & & & \\
Bill width & & & \\
\hline
\end{tabular}

${ }^{a}$ Measurement method differed for each study (flattened straightened, flattened un-straightened, and un-flatted un-straightened). Higgins \& Davies (1996) give only approximate measurements. 


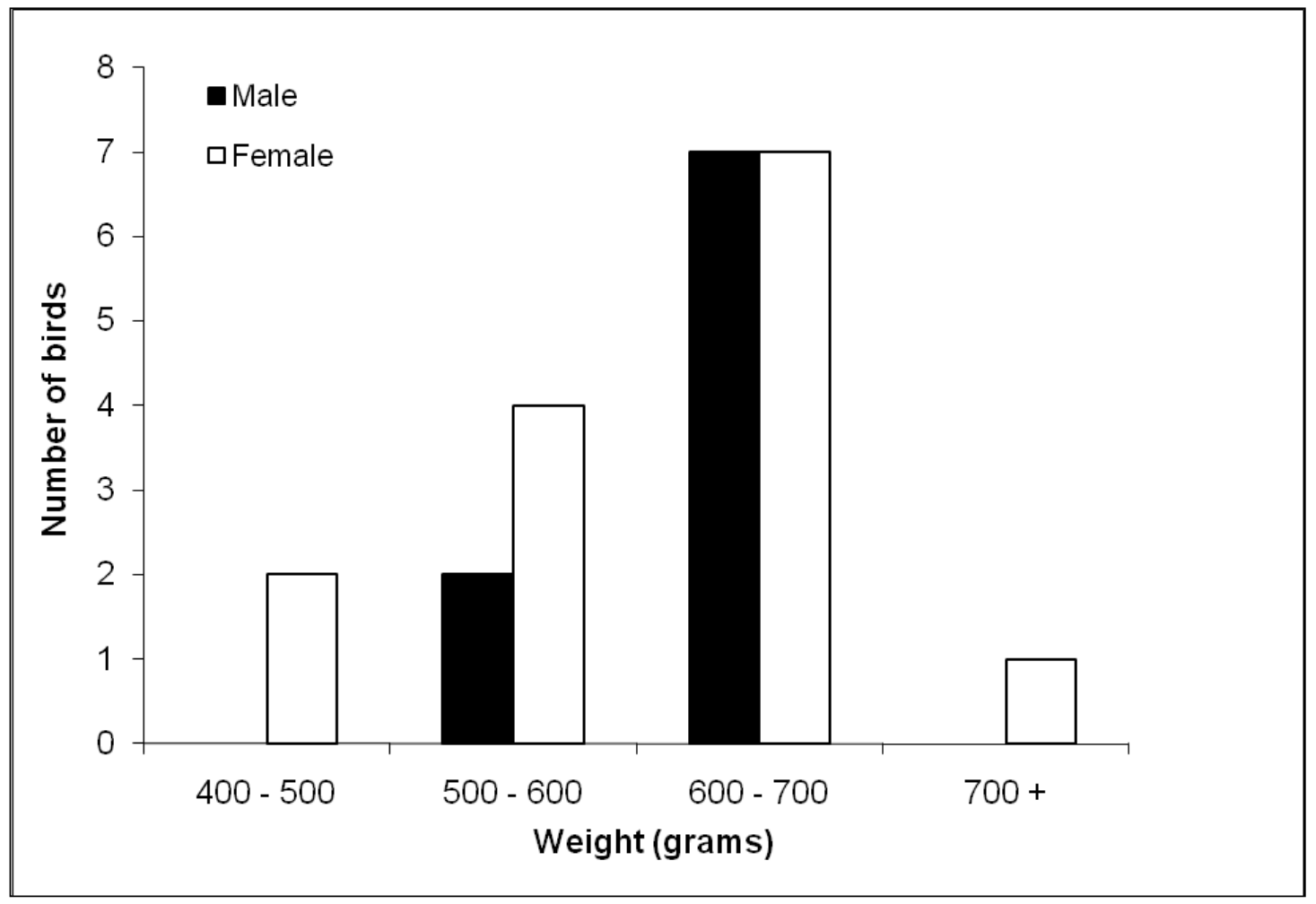

Figure 2. Histogram of weights of adult male $(n=9)$ and adult female $(n=14)$ kereru in Wellington and the Kapiti Coast.

Although some weak patterns in plumage emerged between males and females, no definitive differences were found. Males frequently displayed darker purple napes and heads than females, and had smaller and darker blue patches on their chins. However, a much larger sample size is required to confirm these observations.

\section{Discussion}

Although behavioural observations have been used to sex kereru in the field during the breeding season (Campbell 2006; Clout et al. 1995; Flux et al. 2001; James 1995; Powlesland et al. 2003; Thorsen et al. 2004), my results suggest that the only reliable and accurate way to sex adult kereru throughout the year is with DNA analysis. 
There does not appear to be consistency between morphometric results, although this may be due to differences in the condition of the birds being measured in each study (Table 2). Both Higgins and Davies (1996) and Gill (2006) found a significant difference between male and female kereru wing chord lengths. This study, however, found that average wing chord lengths did not differ (Table 1).

My sample size was small and lacked spread throughout the year, so a seasonal comparison of weights was not possible. However, Gill (2006) found no significant difference between the sexes, nor did he find an effect of season. Gill also suggests that frozen weights should be compared to fresh weights. Such a comparison might indicate if fresh and frozen weights are in fact comparable, or if frozen weights are simply not useful for developing a field technique for sexing kereru. The heaviest bird captured in this study was a female weighing 713g, in comparison to Gill (2006) who reported a defrosted male kereru weight of $780 \mathrm{~g}$. However, it is impossible to make any conclusions about this difference being an effect of season or fresh vs. frozen birds without larger sample sizes and further comparisons of sample types and measurements.

In terms of sex ratios, Gill (2006) found that 60 (63\%) of the pigeons in his study were females and $35(37 \%)$ were males. Despite my small sample size, I also found a skew in the sex ratio towards females. Of the 23 pigeons caught during this study, 14 (61\%) were females and $9(39 \%)$ were males. Females tended to have greater activity levels in the mornings during capture attempts and larger home ranges than males in this study (pers. obs.) Thus, their frequent movements may have made them easier to capture. It is not clear as to whether this skew is representative of the entire population of kereru in New Zealand or is limited to Wellington and the Kapiti Coast. 
Although the patterns of moult I observed differed from previous studies, my observations confirm those of Higgins \& Davies (1996) and Gill (2006), where kereru probably experience a slow and continuous moult.

Further studies of the plumage and moult of adult kereru might discern differences between the sexes. Qualitative assessments of other avian species previously believed to be sexually monomorphic have revealed distinct plumage differences between males and females (for example see Brady et al. 2009). At present, DNA analysis is the only reliable method for sexing kereru. Thus kereru effectively remain externally sexually monomorphic.

\section{References}

Brady, R. S., J. D. Paruk, and A. J. Kern. (2009) Sexing adult Northern Shrikes using DNA, morphometrics, and plumage. Journal of Field Ornithology, 80:198-205.

Campbell, K. L. (2006) A study of home ranges, movements, diet and habitat use of kereru (Hemiphaga novaeseelandiae) in the southeastern sector of Banks Peninsula, New Zealand. Unpubl. M.Sc. thesis. Lincoln University, New Zealand.

Clout, M. N., K. Denyer, R. E. James, and I. G. McFadden. (1995) Breeding success of New Zealand pigeons (Hemiphaga novaeseelandiae) in relation to control of introduced mammals. New Zealand Journal of Ecology, 19:209-212.

Dilks, P., G. Elliot, and C. O'Donnell. (1995) Mist netting techniques. Ecological Management (3), Department of Conservation, Wellington.

Ellegren, H. (1996) First gene on the avian W chromosome (CHD) provides a tag for universal sexing of non-ratite birds. Proceedings of the Royal Society London B, 263:1635-1641.

Flux, I. A., R. G. Powlesland, P. J. Dilks, and A. D. Grant. )2001) Breeding, survival, and recruitment of Chatham Island pigeon (Hemiphaga chathamensis). Notornis, 48:197206.

Gill, B. J. (2006) Post-mortem examination of the New Zealand pigeons (Hemiphaga novaeseelandiae) from the Auckland area. New Zealand Journal of Zoology, 33:31-37.

Griffiths, R., M. C. Double, K. Orr, and R. J. G. Dawson. (1998) A DNA test to sex most birds. Molecular Ecology, 7:1071-1075.

Heather, B., and H. Robertson (2005) The Field Guide to the Birds of New Zealand. Viking, Auckland. 
Higgins, P. J., and S. J. J. F. Davies, editors. (1996) Handbook of Australian, New Zealand and Antarctic birds. Vol 3. Snipe to pigeons. Oxford University, Melbourne.

James, R. E. (1995) Breeding ecology of the New Zealand Pigeon at Wenderholm Regional Park, Unpubl. M.Sc. thesis. University of Auckland, New Zealand.

Miskelly, C. M., J. E. Dowding, G. P. Elliot, R. A. Hitchmough, R. G. Powlesland, H. A. Robertson, P. M. Sagar, R. P. Scofield, and G. A. Taylor. (2008) Conservation status of New Zealand Birds, 2008. Notornis, 55:117-135.

North American Banding Council. (2001) The North American Bander's Study Guide. Available at: http://www.nabanding.net/manuals/STUDYGUIDE.PDF.

Powlesland, R. G., and C. M. Miskelly. (9 July 2008) Kereru status re-evaluated. Kereru News No. 65 [email newsletter].

Powlesland, R. G., D. E. Wills, A. C. L. August, and C. K. August. (2003) Effects of a 1080 operation on kaka and kereru survival and nesting success, Whirinaki Forest Park. New Zealand Journal of Ecology, 27:125-137.

Robertson, C. J. R., P. Hyvonen, M. J. Fraser, and C. R. Pickard (2007) Atlas of bird distribution in New Zealand 1999-2004. The Ornithological Society of New Zealand, Inc., Wellington, New Zealand.

SPSS for Windows (2008) Release 16.0.2., Chicago, IL.

Thorsen, M., J. Innes, G. Nugent, and K. Prime. (2004) Parental care and growth rates of New Zealand pigeon (Hemiphaga novaeseelandiae) nestlings. Notornis, 51:136-140. 


\section{APPENDIX 4. Table of food sources known to be eaten by kereru}

Authors's note: The following table was developed as part of the Kereru Discovery Project online resources (available at: www.kererudiscovery.org.nz). Although this table includes native and introduced species across the entire mainland New Zealand, it is important to note here that my study was limited to those food species found within the Greater Wellington Region and the Kapiti Coast. Plant species that kereru in my Wellington study (Chapter 3) were observed feeding on are highlighted in yellow. 


\section{Native species known to be eaten by kererü}
$\mathrm{F}=$ fruit and/or seeds
$\mathrm{Fl}=$ flowers
$\mathrm{L}=$ leaves and/or buds $\mathrm{T}=$ twigs
Fungi= fruiting bodies

\begin{tabular}{|c|c|c|c|c|}
\hline Scientific Name & Common Name & Maori Name & Food & Links to additional Information \\
\hline Alectryon excelsus & Tea tree & Titoki & $\mathrm{F}$ & http://www.nzpcn.org.nz/vascular_plants/detail.asp?plant|D=1523 \\
\hline Aristotelia serrata & Wineberry & Makomako & F/L & http://www.nzpcn.org.nz/vascular_plants/detail.asp?plant|D=1549 \\
\hline Asplenium bulbiferum & $\begin{array}{l}\text { Hen and chickens } \\
\text { fern }\end{array}$ & $\begin{array}{l}\text { Manamana, } \\
\text { pikopiko }\end{array}$ & $\mathrm{L}$ & http://www.nzpcn.org.nz/vascular_plants/detail.asp?PlantID=1557 \\
\hline Asplenium flaccidum & Hanging spleenwort & Makawe o & $\mathrm{L}$ & http://www.nzpcn.org.nz/vascular_plants/detail.asp?Plant|D=1558 \\
\hline Astelia banskii & Coastal astelia, & $\begin{array}{l}\text { Shore } \\
\text { kowharawhara }\end{array}$ & $\mathrm{F}$ & http://www.nzpcn.org.nz/vascular_plants/detail.asp?Plant|D=1564 \\
\hline Astelia nervosa & Astelia & & $\mathrm{F}$ & http://www.nzpcn.org.nz/vascular_plants/detail.asp?Plant|D=1570 \\
\hline Beilschmiedia tarairi & & Taraire & $\mathrm{F}$ & http://www.nzpcn.org.nz/vascular_plants/detail.asp?plant|D=1577 \\
\hline Beilschmiedia tawa & & Tawa & $\mathrm{F}$ & http://www.nzpcn.org.nz/vascular_plants/detail.asp?Plant|D=1578 \\
\hline Beilschmiedia tawaroa & & Tawaroa & $\mathrm{F}$ & http://www.edgeplants.co.nz/catalogue/N/20.html \\
\hline Calystegia tuguriorum & New Zealand bindweed & Pohuhue & $\mathrm{L}$ & http://www.nzpcn.org.nz/vascular_plants/detail.asp?Plant|D=1620 \\
\hline Carmichaelia spp. & Tree broom & & $\mathrm{L}$ & http://www.nzpcn.org.nz/vascular_plants/detail.asp?Plant|D=1637 \\
\hline Carpodetus serratus & & Putaputaweta & $\mathrm{F} / \mathrm{L}$ & http://www.nzpcn.org.nz/vascular_plants/detail.asp?Plant|D=1647 \\
\hline Clematis paniculata & New Zealand clematis & & $\mathrm{L}$ & http://www.nzpcn.org.nz/vascular_plants/detail.asp?Plant|D=1729 \\
\hline Coprosma areolata & $\begin{array}{l}\text { Thin/vein-leaved } \\
\text { coprosma }\end{array}$ & Mikimiki & $\mathrm{L}$ & http://www.nzpcn.org.nz/vascular_plants/detail.asp?Plant|D=1747 \\
\hline
\end{tabular}




\begin{tabular}{|c|c|c|c|c|}
\hline Coprosma foetidissima & Stinkwood & Hupiro & L & $\begin{array}{l}\text { http://www.pfaf.org/database/plants.php?Coprosma+foetidissima } \\
\text { http://web.ujf-grenoble.fr/JAL//nz/ima-AP/foret/inco.jpg }\end{array}$ \\
\hline Coprosma grandifolia & & $\begin{array}{l}\text { Kanono, } \\
\text { raurekau }\end{array}$ & $\mathrm{F}$ & http://www.nzpcn.org.nz/vascular_plants/detail.asp?PlantID=1763 \\
\hline Coprosma linariifolia & Yellow-wood & Mikimiki & $\mathrm{F}$ & $\begin{array}{l}\text { http://www.ccc.govt.nz/parks/TheEnvironment/StreamsidePlanting } \\
\text { Guide/CoprosmaLinariifolia.asp }\end{array}$ \\
\hline Coprosma lucida & & Karamu & $\mathrm{F}$ & http://www.ibiblio.org/pfaf/cgi-bin/arr_html?Coprosma+lucida \\
\hline Coprosma paviflora & Leafy coprosma & & $\mathrm{F}$ & http://www.nzpcn.org.nz/vascular_plants/detail.asp?PlantID=1771 \\
\hline Coprosma propinqua & & Mingimingi & L & http://www.nzpcn.org.nz/vascular_plants/detail.asp?PlantID=1774 \\
\hline Coprosma pseudocuneata & & & $\mathrm{F}$ & http://www.nzpcn.org.nz/vascular_plants/detail.asp?Plant|D=1788 \\
\hline Coprosma repens & $\begin{array}{l}\text { Mirror bush, } \\
\text { looking-glass plant }\end{array}$ & Taupata & $\mathrm{F}$ & http://www.nzpcn.org.nz/vascular_plants/detail.asp?Plant|D=1776 \\
\hline Coprosma rhamnoides & Twiggy coprosma & & $\mathrm{F}$ & http://www.nzpcn.org.nz/vascular_plants/detail.asp?PlantID=1777 \\
\hline Coprosma robusta & & Karamu & $\mathrm{F}$ & http://www.nzpcn.org.nz/vascular_plants/detail.asp?PlantID=1779 \\
\hline Coprosma rotundifolia & $\begin{array}{l}\text { Round-leaved } \\
\text { coprosma }\end{array}$ & & $\mathrm{L}$ & http://www.nzpcn.org.nz/vascular_plants/detail.asp?PlantID=1780 \\
\hline Cordyline australis & Cabbage tree & Ti kouka & $\mathrm{F}$ & http://www.nzpcn.org.nz/vascular_plants/detail.asp?PlantID=1790 \\
\hline Coriaria arborea & & Tutu & $\mathrm{F}$ & http://www.nzpcn.org.nz/vascular_plants/detail.asp?PlantID=1795 \\
\hline Corynocarpus laevigatus & & Karaka & $\mathrm{F}$ & http://www.nzpcn.org.nz/vascular_plants/detail.asp?PlantID=1808 \\
\hline Cyathea smithii & Smith's tree fern & Katote & L & http://www.nzpcn.org.nz/vascular_plants/detail.asp?PlantID=1823 \\
\hline Dacrycarpus dacrydioides & $\begin{array}{l}\text { White pine, } \\
\text { kahikatea }\end{array}$ & Kaikahikatea & $\mathrm{F}$ & http://www.nzpcn.org.nz/vascular_plants/detail.asp?PlantID=2155 \\
\hline
\end{tabular}




\begin{tabular}{|c|c|c|c|c|}
\hline Dacrydium cupressinum & Red pine & Rimu & $\mathrm{F} / \mathrm{L}$ & http://www.nzpcn.org.nz/vascular_plants/detail.asp?Plant|D=2156 \\
\hline Dicksonia squarrosa & Tree fern & & $\mathrm{L}$ & http://www.nzpcn.org.nz/vascular_plants/detail.asp?PlantID=1837 \\
\hline Dysoxylum spectabile & & Kohekohe & $\mathrm{F}$ & http://www.nzpcn.org.nz/vascular_plants/detail.asp?PlantID=1871 \\
\hline Earina autumnalis & Easter orchid & Raupeka & $\mathrm{L}$ & http://www.nzpcn.org.nz/vascular_plants/detail.asp?Plant|D=1872 \\
\hline Elaeocarpus dentatus & & Hinau & $\mathrm{F}$ & http://www.nzpcn.org.nz/vascular_plants/detail.asp?PlantID=1876 \\
\hline Elaeocarpus hookerianus & & Pokaka & $\mathrm{F}$ & http://www.nzpcn.org.nz/vascular_plants/detail.asp?PlantID=1877 \\
\hline Fuchsia excorticata & New Zealand tree fuchsia & Kotukutuku & $\mathrm{Fl} / \mathrm{L} / \mathrm{F}$ & http://www.nzpcn.org.nz/vascular_plants/detail.asp?PlantID=1948 \\
\hline Gaultheria antipoda & $\begin{array}{l}\text { Bush snowberry, } \\
\text { fools beech }\end{array}$ & & $\mathrm{F}$ & http://www.nzpcn.org.nz/vascular_plants/detail.asp?PlantID=1959 \\
\hline Geniostoma ligustrifolium & & Hangehange & $\mathrm{F}$ & http://www.nzpcn.org.nz/nz_threatenedplants/detail.asp?PlantlD=50 \\
\hline Grammitis billardieri & Finger fern & & L & http://davesgarden.com/pf/showimage/41974.html/ \\
\hline Griselinia littoralis & Broadleaf & $\begin{array}{l}\text { Papauma, } \\
\text { kapuka }\end{array}$ & F/L & http://www.nzpcn.org.nz/vascular_plants/detail.asp?PlantID=2004 \\
\hline Griselinia lucida & & Puka & $\mathrm{F}$ & http://www.nzpcn.org.nz/vascular_plants/detail.asp?Plant|D=2005 \\
\hline Hedycarya arborea & Pigeonwood & Porokaiwhiria & $\mathrm{F}$ & http://www.nzpcn.org.nz/vascular_plants/detail.asp?Plant|D=820 \\
\hline Hoheria augustifolia & $\begin{array}{l}\text { Narrow-leaved } \\
\text { lacebark }\end{array}$ & & $\mathrm{L}$ & http://www.nzpcn.org.nz/vascular_plants/detail.asp?PlantID=1417 \\
\hline Hoheria populnea & Lacebark & Houhere & $\mathrm{L}$ & http://www.nzpcn.org.nz/vascular_plants/detail.asp?PlantID=840 \\
\hline Hoheria glabrata & Mountain lacebark & & L & http://www.nzpcn.org.nz/vascular_plants/detail.asp?Plant|D=837 \\
\hline Ixerba brexioides & & Tawari & $\mathrm{F}$ & http://www.nzpcn.org.nz/vascular_plants/detail.asp?PlantID=1419 \\
\hline
\end{tabular}




\begin{tabular}{|c|c|c|c|c|}
\hline Knightsia excelsa & $\begin{array}{l}\text { New Zealand } \\
\text { honeysuckle }\end{array}$ & Rewarewa & $\mathrm{Fl} /$ buds & http://www.ibiblio.org/pfaf/cgi-bin/arr_html?Knightia+excelsa \\
\hline Lagarostrobos colensoi & Silver oine & & $\mathrm{F}$ & http://www.ibiblio.org/pfaf/cgi-bin/arr_html?Lagarostrobus+colensoi \\
\hline Leptospermum scoparium & Tea tree & Manuka & $\mathrm{L}$ & http://www.nzpcn.org.nz/vascular_plants/detail.asp?Plant|D=2361 \\
\hline Libocedrus plumosa & New Zealand cedar & $\begin{array}{l}\text { Kawaka, } \\
\text { kaikawaka }\end{array}$ & $\mathrm{F}$ & http://www.nzpcn.org.nz/vascular_plants/detail.asp?PlantID=287 \\
\hline Litsea calicaris & & $\begin{array}{l}\text { Mangeao, } \\
\text { tangeao }\end{array}$ & $\mathrm{F}$ & http://www.nzpcn.org.nz/vascular_plants/search_results.asp \\
\hline Lophomyrtus bullata & New Zealand myrtle & Ramarama & $\mathrm{F}$ & http://www.nzpcn.org.nz/vascular_plants/detail.asp?Plant|D=1425 \\
\hline Lophomyrtus obcordata & New Zealand myrtle & Rohutu & $\mathrm{F}$ & http://www.nzpcn.org.nz/vascular_plants/detail.asp?PlantID=962 \\
\hline Macropiper excelsum & Pepper tree & Kawakawa & $\mathrm{F}$ & http://www.nzpcn.org.nz/vascular_plants/detail.asp?PlantID=986 \\
\hline Melicytus chathamicus & Chatham Island mahoe & & $\mathrm{F}$ & http://www.nzpcn.org.nz/nz_threatenedplants/detail.asp?Plant|D=59 \\
\hline Melicytus lanceolatus & & Mahoe wao & $\mathrm{F} / \mathrm{FI} / \mathrm{L}$ & http://www.nzpcn.org.nz/vascular_plants/detail.asp?PlantlD=991 \\
\hline Melicytus micranthus & $\begin{array}{l}\text { Small-leaved/ } \\
\text { swamp mahoe }\end{array}$ & Mahoe & $\mathrm{L}$ & http://www.nzpcn.org.nz/vascular_plants/detail.asp?PlantID=993 \\
\hline Melicytus ramiflorus & $\begin{array}{l}\text { Whiteywood, cow } \\
\text { leaf }\end{array}$ & Mahoe & $\mathrm{F} / \mathrm{Fl} / \mathrm{L}$ & http://www.nzpcn.org.nz/vascular_plants/detail.asp?PlantID=995 \\
\hline Metrosideros diffusa & $\begin{array}{l}\text { White/climbing } \\
\text { rata }\end{array}$ & Akatea & $\mathrm{L}$ & http://www.nzpcn.org.nz/vascular_plants/detail.asp?PlantID=1004 \\
\hline Metrosideros umbellata & Southern rata & Rata & $\mathrm{L}$ & http://www.nzpcn.org.nz/vascular_plants/detail.asp?PlantID=1000 \\
\hline
\end{tabular}




\begin{tabular}{|c|c|c|c|c|}
\hline Mida salicifolia & $\begin{array}{l}\text { Willow-leafed maire, } \\
\text { New Zealand } \\
\text { sandalwood }\end{array}$ & Maire & $\mathrm{F}$ & $\begin{array}{l}\text { http://www.nzpcn.org.nz/nz_threatenedplants/detail.asp?PlantlD=1 } \\
86\end{array}$ \\
\hline Muehlenbeckia australis & $\begin{array}{l}\text { Large-leaved } \\
\text { muehlenbeckia }\end{array}$ & Pohuehue & L & http://www.nzpcn.org.nz/vascular_plants/detail.asp?PlantID=1012 \\
\hline Muehlenbeckia complexa & $\begin{array}{l}\text { Small-leaved/ } \\
\text { scrambling pohuehue, } \\
\text { wire vine }\end{array}$ & Pohuehue & L & http://www.nzpcn.org.nz/vascular_plants/detail.asp?PlantID=1013 \\
\hline Myoporum laetum & & Ngaio & $\mathrm{F}$ & http://www.nzpcn.org.nz/vascular_plants/detail.asp?Plant|D=1014 \\
\hline Myrsine australis & Red matipo/mapou & Mapou, mapau & $\mathrm{F}$ & http://www.nzpcn.org.nz/vascular_plants/detail.asp?PlantID=1030 \\
\hline Myrsine divaricata & Weeping matipo & & $\mathrm{F}$ & http://www.nzpcn.org.nz/vascular_plants/detail.asp?PlantID=1032 \\
\hline Myrsine salicina & & Toro & $\mathrm{F}$ & http://www.nzpcn.org.nz/vascular_plants/detail.asp?PlantID=1034 \\
\hline Neomyrtus pendunculata & New Zealand myrtle & Rohutu & $\mathrm{F}$ & http://www.nzpcn.org.nz/vascular_plants/detail.asp?PlantID=1429 \\
\hline Nertera spp. & & & $\mathrm{F}$ & http://www.nzpcn.org.nz/vascular_plants/detail.asp?PlantID=2264 \\
\hline Nestegis cunninghamii & Black maire & Maire & $\mathrm{F}$ & http://www.nzpcn.org.nz/vascular_plants/detail.asp?PlantID=1055 \\
\hline Nestegis lanceolata & White maire & & $\mathrm{F}$ & http://www.nzpcn.org.nz/vascular_plants/detail.asp?PlantID=1056 \\
\hline Nestegis montana & Narrow-leaved maire & Oro-oro & L & http://www.nzpcn.org.nz/vascular_plants/detail.asp?PlantID=1057 \\
\hline Nothofagus menziesii & Silver beech & Tawhai & $\mathrm{Fl} / \mathrm{L}$ & http://www.nzpcn.org.nz/vascular_plants/detail.asp?Plant|D=1059 \\
\hline
\end{tabular}




\begin{tabular}{|c|c|c|c|c|}
\hline Nothofagus truncata & Hard beech & Tawhairaunui & $\mathrm{FI} / \mathrm{L}$ & http://www.nzpcn.org.nz/vascular_plants/detail.asp?PlantID=1062 \\
\hline Parsonsia capsularis & New Zealand jasmine & & $\mathrm{L}$ & http://www.nzpcn.org.nz/vascular_plants/detail.asp?PlantID=1128 \\
\hline Parsonsia heterophylla & Native jasmine & & $\mathrm{L}$ & http://www.nzpcn.org.nz/vascular_plants/detail.asp?PlantlD=1129 \\
\hline Pennantia corymbosa & Ducksfoot & Kaikomako & $\mathrm{F} / \mathrm{L}$ & http://www.nzpcn.org.nz/vascular_plants/detail.asp?Plant|D=1131 \\
\hline Peraxilla colensoi & Scarlet mistletoe & $\begin{array}{l}\text { Korukoru, pirita, } \\
\text { roeroe }\end{array}$ & $\mathrm{FI}$ & $\begin{array}{l}\text { http://www.nzpcn.org.nz/nz_threatenedplants/detail.asp?PlantID=19 } \\
7\end{array}$ \\
\hline Peraxilla tetrapetala & Red mistletoe & $\begin{array}{l}\text { Pikirangi, } \\
\text { pirinoa }\end{array}$ & $\mathrm{Fl}$ & $\begin{array}{l}\text { http://www.nzpcn.org.nz/nz_threatenedplants/detail.asp?PlantlD=19 } \\
8\end{array}$ \\
\hline $\begin{array}{l}\text { Phyllocladus } \\
\text { trichomanoides }\end{array}$ & Celery pine & Tanekaha & $\mathrm{Fl} / \mathrm{L}$ & http://www.nzpcn.org.nz/vascular_plants/detail.asp?PlantID=1146 \\
\hline Microsorum pustulatum & Hound's tongue & $\begin{array}{l}\text { Kowhaowhao, } \\
\text { kowaowao }\end{array}$ & $\bar{L}$ & http://www.plantoftheweek.org/week268.shtml \\
\hline Pisonia brunoniana & & Parapara & $\mathrm{F}$ & http://www.nzpcn.org.nz/nz_threatenedplants/detail.asp?Plant|D=30 \\
\hline Pittosporum eugenioides & Lemonwood & Tarata & $F$ & http://www.nzpcn.org.nz/vascular_plants/detail.asp?PlantID=1164 \\
\hline Plagianthus regius & Ribbonwood & Manatu & $\mathrm{L} / \mathrm{T}$ & http://www.nzpcn.org.nz/vascular_plants/detail.asp?PlantID=1171 \\
\hline Planchonella costata & & Tawapou & $\mathrm{F}$ & $\begin{array}{l}\text { http://www.bushmansfriend.co.nz/xurl/PagelD/9165/ArticlelD/- } \\
\text { 36698/function/moreinfo/content.html }\end{array}$ \\
\hline Podocarpus nivalis & Snow totara & & $\mathrm{F}$ & http://www.nzpcn.org.nz/vascular_plants/detail.asp?Plant|D=1204 \\
\hline Podocarpus totara & Lowland totara & Totara & $\mathrm{F}$ & http://www.nzpcn.org.nz/vascular_plants/detail.asp?PlantID=1205 \\
\hline Polystichum richardii & Common shield fern & Pikopiko & $\mathrm{L}$ & http://www.fronds.co.nz/product.html?p=26 \\
\hline
\end{tabular}




\begin{tabular}{|c|c|c|c|c|}
\hline Pouteria costata & & Tawapou & $\mathrm{F}$ & http://www.nzpcn.org.nz/vascular_plants/detail.asp?PlantID=2285 \\
\hline Prumnopitys ferruginea & Brown pine & Miro & F/L & http://www.nzpcn.org.nz/vascular_plants/detail.asp?PlantlD=809 \\
\hline Prumnopitys taxifolia & Black pine & Matai & $\mathrm{F}$ & http://www.nzpcn.org.nz/vascular_plants/detail.asp?PlantID=1223 \\
\hline Pseudopanax arboreus & Five-finger & $\begin{array}{l}\text { Whauwhaupaku, } \\
\text { puahou }\end{array}$ & $\mathrm{F}$ & http://www.nzpcn.org.nz/vascular_plants/detail.asp?PlantID=1224 \\
\hline $\begin{array}{l}\text { Pseudopanax } \\
\text { chathamicus }\end{array}$ & $\begin{array}{l}\text { Chatham Island } \\
\text { lancewood }\end{array}$ & Hoho & $\mathrm{F}$ & $\begin{array}{l}\text { http://www.nzpcn.org.nz/nz_threatenedplants/detail.asp?PlantID=6 } \\
59\end{array}$ \\
\hline Pseudopanax crassifolius & Lancewood & Horoeka & $\mathrm{F} / \mathrm{L}$ & http://www.nzpcn.org.nz/vascular_plants/detail.asp?PlantID=1226 \\
\hline Pseudopanax colensoi & Three-finger & Orihou & $\mathrm{F}$ & http://www.nzpcn.org.nz/vascular_plants/detail.asp?PlantID=1225 \\
\hline Pseudopanax edgerleyi & & Raukawa & $\mathrm{L}$ & http://www.ibiblio.org/pfaf/cgi-bin/arr_html?Pseudopanax+edgerleyi \\
\hline Pseudopanax simplex & & Haumakaroa & L & $\begin{array}{l}\text { http://nzflora.landcareresearch.co.nz/default.aspx?NamelD=Landc } \\
\text { areresearch.co.nz/PS1/NK/1302480 }\end{array}$ \\
\hline Pseudowintera axillaris & Pepper tree & & $\mathrm{F}$ & http://www.nzpcn.org.nz/vascular_plants/detail.asp?PlantlD=802 \\
\hline Pseudowintera colorata & Lowland peppertree & Horopito & $\mathrm{F}$ & http://www.nzpcn.org.nz/vascular_plants/detail.asp?PlantID=1231 \\
\hline Rhopalostylis sapida & & Nikau & $\mathrm{F}$ & http://www.nzpcn.org.nz/vascular_plants/detail.asp?PlantID=1290 \\
\hline Ripogonum scandens & Supplejack & Kareao & $\mathrm{F}$ & http://www.nzpcn.org.nz/vascular_plants/detail.asp?PlantID=1291 \\
\hline Rubus australis & $\begin{array}{l}\text { Bush lawyer, } \\
\text { swamp lawyer }\end{array}$ & Tataramoa & $\mathrm{F}$ & http://www.nzpcn.org.nz/vascular_plants/detail.asp?PlantID=1293 \\
\hline Rubus cissoides & Bush lawyer & Tataramoa & $\mathrm{FL}$ & http://www.nzpcn.org.nz/vascular_plants/detail.asp?PlantID=1294 \\
\hline Rubus schmidelioides & $\begin{array}{l}\text { White-leaved } \\
\text { bush lawyer }\end{array}$ & Tataramoa & $\mathrm{FL}$ & http://www.nzpcn.org.nz/vascular_plants/detail.asp?PlantID=1296 \\
\hline Schefflera digitata & Seven-finger & Patē & $\mathrm{F}$ & http://www.nzpcn.org.nz/vascular_plants/detail.asp?PlantID=1312 \\
\hline
\end{tabular}




\begin{tabular}{|c|c|c|c|c|}
\hline $\begin{array}{l}\text { Solanum aviculare \& S. } \\
\text { laciniatum }\end{array}$ & Bullibulli & Poroporo & $\mathrm{F}$ & http://www.nzpcn.org.nz/vascular_plants/detail.asp?Plant|D=2319 \\
\hline Solanum nodiflorum & $\begin{array}{l}\text { American } \\
\text { nightshade }\end{array}$ & & $\mathrm{F}$ & http://www.pfaf.org/database/plants.php?Solanum+americanum \\
\hline Sonchus spp. & Sow thistle & & $\bar{L}$ & http://www.ibiblio.org/pfaf/cgi-bin/arr_html?Sonchus+kirkii \\
\hline Sophora microphylla & $\begin{array}{l}\text { South Island/ } \\
\text { weeping kowhai }\end{array}$ & Kowhai & $\mathrm{Fl} / \mathrm{L}$ & http://www.nzpcn.org.nz/vascular_plants/detail.asp?Plant|D=1334 \\
\hline Sophora tetraptera & Kowhai & Kowhai & $\mathrm{Fl} / \mathrm{L}$ & http://www.nzpcn.org.nz/vascular_plants/detail.asp?Plant|D=1336 \\
\hline Streblus heterophyllus & $\begin{array}{l}\text { Small-leaved } \\
\text { milktree }\end{array}$ & Turepo & $\mathrm{F}$ & http://www.nzpcn.org.nz/vascular_plants/detail.asp?Plant|D=1345 \\
\hline Syzygium maire & Swamp maire & Maire tawake & $\mathrm{F}$ & http://www.nzpcn.org.nz/vascular_plants/detail.asp?PlantID=1347 \\
\hline Tetrapathaea tetrandra & $\begin{array}{l}\text { New Zealand } \\
\text { passionfruit }\end{array}$ & Kohia & $\mathrm{F}$ & http://www.nzpcn.org.nz/vascular_plants/detail.asp?Plant|D=1130 \\
\hline Tupeia antarctica & & & $\mathrm{F}$ & http://www.ibiblio.org/pfaf/cgi-bin/arr_html?Tupeia+antarctica \\
\hline Vitex lucens & & Puriri & $\mathrm{F}$ & http://www.nzpcn.org.nz/vascular_plants/detail.asp?Plant|D=1394 \\
\hline Weinmannia racemosa & & Kamahi & $\mathrm{F} / \mathrm{FI} / \mathrm{L}$ & http://www.nzpcn.org.nz/vascular_plants/detail.asp?Plant|D=1405 \\
\hline Winika cunninghamii & & & $\mathrm{L}$ & http://www.kaimaibush.co.nz/Orchids/Winika.html \\
\hline
\end{tabular}




\section{Introduced species known to be eaten by kereru}
$F=F r u i t$ and/or seeds
FL=Flowers
L=leaves and/or buds

\begin{tabular}{|c|c|c|c|}
\hline Scientific Name & Common Name/s & Food & \\
\hline Acacia spp. & Wattle & $\mathrm{Fl} / \mathrm{L}$ & http://shaman-australis.com.au/shop/index.php?cPath=21_26_72 \\
\hline Acmena smithii & Monkey apple, lilly-pilly & $\mathrm{F}$ & $\begin{array}{l}\text { http://www.metrotrees.com.au/treehandbook/page- } \\
\text { listings/acmena-smithii.html }\end{array}$ \\
\hline Archontophoenix alexandrae & Alexander palm & $\mathrm{F}$ & $\begin{array}{l}\text { http://www.junglemusic.net/palms/archontophoenix- } \\
\text { alexandrae.htm }\end{array}$ \\
\hline Archontophoenix cunninghamiana & Bangalow palm, Piccabeen palm & $\mathrm{F}$ & $\begin{array}{l}\text { http://www.pacsoa.org.au/palms/Archontophoenix/cunningha } \\
\text { miana.html }\end{array}$ \\
\hline Asparagus scandens & Climbing asparagus & $\mathrm{F}$ & http://www.rnzih.org.nz/pages/asparagusscandens.htm \\
\hline Brassica napus & Swede & $\mathrm{L}$ & $\begin{array}{l}\text { http://www.hort.purdue.edu/newcrop/duke_energy/Brassica_ } \\
\text { napus.html }\end{array}$ \\
\hline Chamaecyparis lawsoniana & Winston Churchill palm & $\mathrm{L}$ & $\begin{array}{l}\text { http://www.cnr.vt.edu/dendro/dendrology/syllabus/factsheet.c } \\
\text { fm?ID=204 }\end{array}$ \\
\hline Chamaecytisus palmensis & Tree lucerne, tagasaste & $\mathrm{L} / \mathrm{FI}$ & $\begin{array}{l}\text { http://www.esc.nsw.gov.au/Weeds/Sheets/trees/T\%20Tree\% } \\
\text { 20lucerne\%20or\%20tagasaste.htm }\end{array}$ \\
\hline Clerondendron bungei & & $\mathrm{L}$ & http://www.ibiblio.org/pfaf/cgi-bin/arr_html?Clerodendrum+bungei \\
\hline
\end{tabular}




\begin{tabular}{|c|c|c|c|}
\hline Cotoneaster spp. & Cotoneaster & $\mathrm{F}$ & http://www.ibiblio.org/pfaf/cgi-bin/arr_html?Cotoneaster+simonsii \\
\hline Crataegus spp. & Hawthorn & $\mathrm{F}$ & $\begin{array}{l}\text { http://www.cnr.vt.edu/dendro/dendrology/syllabus/factsheet.c } \\
\text { fm?ID=45 }\end{array}$ \\
\hline Cyttaria gunnii & Beech strawberries & Fungi & http://fungimap.rbg.vic.gov.au/fsp/sp022.html \\
\hline Cytisus scoparius & Common/Scottish Broom & $\mathrm{L} / \mathrm{FI}$ & $\begin{array}{l}\text { http://tncweeds.ucdavis.edu/esadocs/cytiscop.html } \\
\text { http://www.issg.org/database/species/ecology.asp?si=441\&fr } \\
=1 \& \text { sts= }\end{array}$ \\
\hline Elaeagnus $\times$ reflexa & Elaeagnus & $\mathrm{F}$ & http://www.pfaf.org/database/plants.php?Elaeagnus+x+reflexa \\
\hline Eriobotrya japonica & Loquat & $\mathrm{F}$ & http://www.floridata.com/ref/E/eriobot.cfm \\
\hline Erythrina spp. & Flame tree, coral tree & $\bar{L}$ & http://shaman-australis.com.au/shop/index.php?cPath=21_34_74 \\
\hline Eucalyptus spp. & Gum & $\mathrm{L}$ & http://www.ebop.govt.nz/weeds/Weed275.asp \\
\hline Euonymus japonicus & Spindle tree & $\mathrm{F}$ & http://www.pfaf.org/database/plants.php?Euonymus+japonicus \\
\hline Ficus sur & Broom cluster fig & $\mathrm{F}$ & http://www.ibiblio.org/pfaf/cgi-bin/arr_html?Ficus+coronata \\
\hline Fraxinus spp. & Ash & $\mathrm{L}$ & $\begin{array}{l}\text { http://www.cfl.scf.rncan.gc.ca/collectionscfl/hosttrees/ } \\
\text { deciduous/ash.html }\end{array}$ \\
\hline Hibiscus spp. & Hibiscus & $\mathrm{L}$ & http://www.floridata.com/ref/h/hibis_mu.cfm \\
\hline Ilex aquifolium & Holly & $\mathrm{F}$ & $\begin{array}{l}\text { http://www.bbc.co.uk/gardening/plants/plant_finder/plant_pag } \\
\text { es/2886.shtml }\end{array}$ \\
\hline
\end{tabular}




\begin{tabular}{|c|c|c|c|}
\hline Laburnum spp. & Laburnum & $\mathrm{L} / \mathrm{FI}$ & http://hort.ufl.edu/trees/LABSPPA.pdf \\
\hline Ligustrum ovalifolium & Golden privet & $\mathrm{F}$ & http://www.geocities.com/ jimclatfelter/ligustov.html \\
\hline Ligustrum lucidum & Tree privet & $\mathrm{F}$ & $\begin{array}{l}\text { http://ag.arizona.edu/pima/gardening/aridplants/Ligustrum_lu } \\
\text { cidum.html }\end{array}$ \\
\hline Lotus spp. & Lotus/trefoil spp. & L & $\begin{array}{l}\text { http://www.fao.org/ag/AGP/agpc/doc/Gallery/pictures/lotcor/l } \\
\text { otuscor.htm }\end{array}$ \\
\hline Lupinus spp. & Lupin & $\mathrm{L}$ & http://www.fao.org/ag/AGA/AGAP/frg/afris/Data/257.HTM \\
\hline Magnolia spp. & Magnolia & $\mathrm{Fl}$ & $\begin{array}{l}\text { http://www2.fpl.fs.fed.us/TechSheets/HardwoodNA/pdf_files/ } \\
\text { magnoleng.pdf }\end{array}$ \\
\hline Malus spp. & Crabapple & $\mathrm{L}$ & $\begin{array}{l}\text { http://www.gardeningexpress.co.uk/ProductDetails.asp?Prod } \\
\text { uctID=12612 }\end{array}$ \\
\hline Melia azedarach & Chinaberry, white cedar, Persian lilac & $\mathrm{F}$ & http://www.hear.org/pier/species/melia_azedarach.htm \\
\hline Nasturtium officinale & Watercress & $\mathrm{L}$ & http://www.pfaf.org/database/plants.php?Nasturtium+officinale \\
\hline Phoenix canariensis & Phoenix palm & $\mathrm{F}$ & $\begin{array}{l}\text { http://cals.arizona.edu/pima/gardening/aridplants/Phoenix_ca } \\
\text { nariensis.html }\end{array}$ \\
\hline Phytolacca octandra & Inkweed & $\mathrm{F}$ & http://www.dowagro.com/nz/resource/inkweed.htm \\
\hline Populus alba & White/silver poplar & L & http://www.issg.org/database/species/ecology.asp?si=261\&fr=1\&sts \\
\hline Prunus spp. & Flowering cherry, plum & F/L & http://en.wikipedia.org/wiki/Prunus_serrulata \\
\hline Psidium cattleianum & Guava, strawberry guava & $\mathrm{F}$ & http://www.hear.org/Pier/species/psidium_cattleianum.htm \\
\hline Pyrus spp. & Pear & L & http://www.ibiblio.org/pfaf/cgi-bin/arr_html?Pyrus+communis \\
\hline
\end{tabular}




\begin{tabular}{|c|c|c|c|}
\hline Rosa eglanteria & Roses & $\mathrm{F}$ & http://en.wikipedia.org/wiki/Rosa_eglanteria \\
\hline Rosa rubiginosa & Sweet briar & $\mathrm{F}$ & http://www.hedging.co.uk/acatalog/product_10301.html \\
\hline Salix spp. & Willow spp. & $\mathrm{L}$ & http://www.rnzih.org.nz/pages/salixcinerea.htm \\
\hline Sambucus nigra & European elder, elderberry & $\mathrm{F}$ & http://2bnthewild.com/plants/H263.htm \\
\hline Solanum nigrum & Black nightshade & $\mathrm{F}$ & http://www.hear.org/pier/species/solanum_nigrum.htm \\
\hline Solanum pseudocapsicum & Jerusalem cherry & $\mathrm{F}$ & $\begin{array}{l}\text { http://www.esc.nsw.gov.au/weeds/Sheets/herbs/H\%20Madie } \\
\text { ra\%20cherry.htm }\end{array}$ \\
\hline Solanum tuberosum & Potato & L & http://www.floridata.com/ref/s/sola_tub.cfm \\
\hline Sorbus aucuparia & Rowan, mountain ash & $\mathrm{F} / \mathrm{L}$ & $\begin{array}{l}\text { http://www.cnr.vt.edu/DENDRO/DENDROLOGY/syllabus/fact } \\
\text { sheet.cfm?ID=321 }\end{array}$ \\
\hline Sorbus rosaceae & Rowan, whitebeam & $\mathrm{F}$ & http://en.wikipedia.org/wiki/Sorbus \\
\hline Syzygium australe & Brush cherry & $\mathrm{F}$ & http://www.ibiblio.org/pfaf/cgi-bin/arr_html?Syzygium+australe \\
\hline Tilia spp. & Lime tree, linden & $\mathrm{L}$ & http://en.wikipedia.org/wiki/Lime_tree \\
\hline Trachycarpus fortunei & Chinese fan palm, chusan palm & $\mathrm{F}$ & http://www.pacsoa.org.au/palms/Trachycarpus/fortunei.html \\
\hline Trifolium spp. & Clover & $\mathrm{L}$ & http://en.wikipedia.org/wiki/Clover \\
\hline Tropaeolum speciosum & Chilean flame creeper & & http://www.fothergills.co.uk/en/tropaeolum-speciosum-2321.aspx \\
\hline Ulmus carpinifolia/minor & Field/smooth-leafed elm & $\mathrm{L} / \mathrm{Fl} / \mathrm{F}$ & http://www.hort.uconn.edu/plants/u/ulmcar/ulmcar1.html \\
\hline Vicia spp. & Vetch spp. & $\mathrm{L}$ & $\begin{array}{l}\text { http://www.fao.org/ag/AGP/AGPC/doc/Gbase/DATA/Pf00050 } \\
\text { 6.HTM }\end{array}$ \\
\hline Virgilia oroboides/capensis & Cape lilac, tree-in-a-hurry & $\mathrm{Fl} / \mathrm{L}$ & http://www.plantzafrica.com/planttuv/virgilia.htm \\
\hline Washingtonia filifera & Washingtonia palm spp. & $\mathrm{F}$ & http://www.floridata.com/ref/w/wash_fil.cfm \\
\hline Washingtonia robusta & Washingtonia palm spp. & $\mathrm{F}$ & http://www.floridata.com/ref/w/wash_rob.cfm \\
\hline
\end{tabular}




\section{APPENDIX 5. Fright moult in kereru}

Author's note: Appendix 5 has been published as the short note: “Awasthy, M. (2010) "Fright moult" in kereru (New Zealand pigeon, Hemiphaga novaeseelandiae) during capture results in loss of tail feathers. Notornis, 57: 37-38."

Autotomy, the ability of an animal to shed body parts as a means of escape when being attacked, is a unique anti-predator response common in many species such as molluscs, polychetes, arthropods and lizards (Lindstrom \& Nilsson 1988). "Fright moult" or "schreckmauser" of feathers from the rump, back and breast in birds may be a similar response for evading capture (Moller et al. 2006), since the rump is often the closest part of the body to a pursuing predator, and the loss of a tail does not doom the survival of the individual (Dathe 1955). Alternatively, "fright moult" could be used to confuse a predator in pursuit the same way an octopus uses ink (Lindstrom \& Nilsson 1988).

Kereru (Hemiphaga novaeseelandiae) are large, arboreal fruit-eating pigeons (Family Columbidae) that are widely distributed throughout New Zealand (Robertson et al. 2007) and have recently increased in numbers due to reduced predation pressures (Powlesland \& Miskelly 2008; Miskelly et al. 2008). Kereru display a similar general morphology to other pigeons, with a small head, a straight soft-based bill and loosely attached feathers (Heather \& Robertson 2005), and like arboreal fruit doves, are strong flyers with large wings and tails (Goodwin 1983). The plumage of columbiform birds is dense and is easily detached from the thin skin (Gill 2000). This loose feather attachment may make them particularly prone to feather loss in threatening situations and has important implications for kereru capture using mist-nets. This note describes a case of "fright moult" in kereru during mist-netting that resulted in the loss of tail feathers. 
On 28 Mar 2007, a kereru was captured in a mist-net at Otari-Wilton's Bush, Wellington as part of a project investigating the ecology of kereru in urban areas (Awasthy 2007). The bird was an adult of unknown sex, weighing $595 \mathrm{~g}$ at capture. An experienced bander (D. Jones) immediately grasped the bird firmly around the body without pulling the tail. The bird was not struggling or entangled in the mist net, but was held in the lower shelf by its own weight. Upon first contact with the bird, an immediate expulsion of feathers occurred from the rump, resulting in the complete loss of all but 1 tail feather and all surrounding contour feathers (Figure 1). Since the bird was in moult, half-grown retrices were also dropped resulting in blood from some follicles (Figure 2). The feathers were collected and weighed ( $8 \mathrm{~g}$, less than $0.02 \%$ of total body weight) and the bird taken into captivity to allow feather re-growth. In captivity, the bird was assessed to be in "good condition" defined by prominent pectoral musculature, an average body weight (see Heather \& Robertson 2005), an absence of feather mites and faeces comparable to those of healthy wild conspecifics (pers. obs.). Although it is assumed the loss of a tail does not doom an individual, it does nevertheless impede normal flight, as one of the aerodynamic functions of the tail is the control of direction (Thomas 1993). The kereru escaped captivity 3 days after capture but was sighted at the study site on 1 Apr 2007, where it displayed an obvious impediment in flight, swerving without the ability to steer or fly in a straight line. Of the 24 birds captured during this study, this was the only bird to drop its entire tail. 


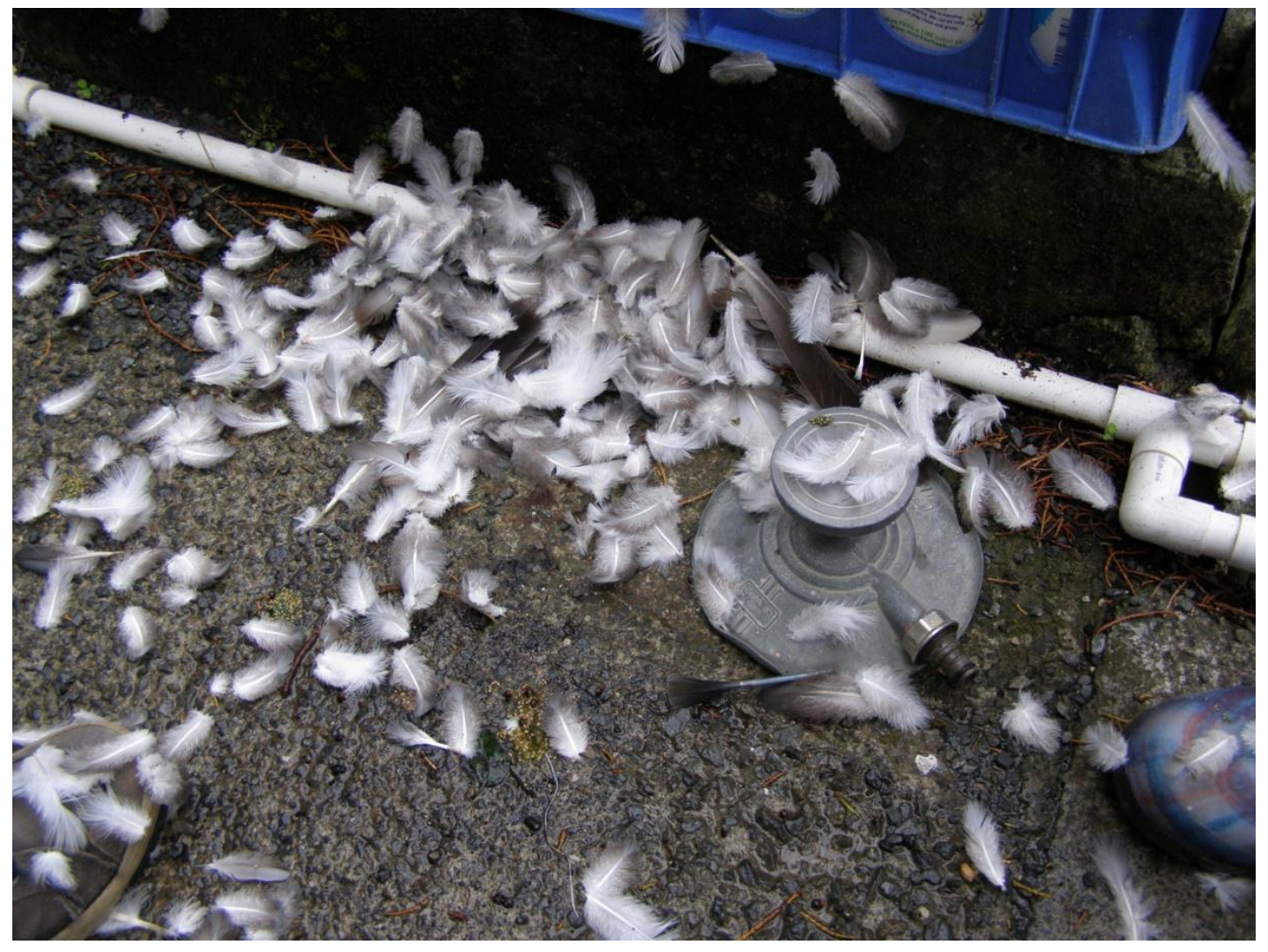

Figure 1. Feather of kereru shed during capture in a mist net.

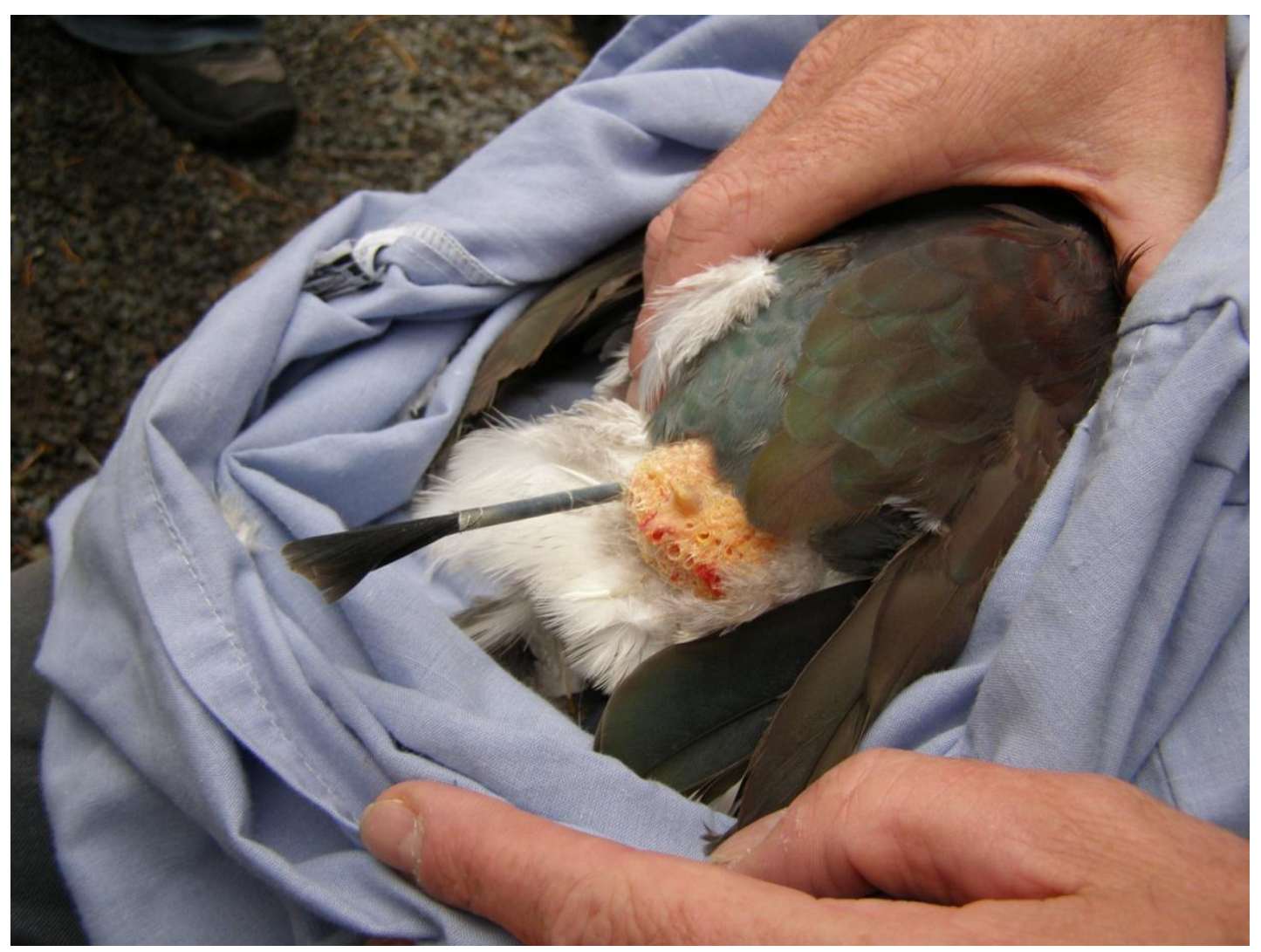

Figure 2. Rump of kereru with all but one sheathed tail feather lost during capture in a mist net. 
A similar occurrence of complete tail loss was observed during a Department of Conservation (DOC) study in Southland (R. Powlesland, pers.comm.). Of the 28 kereru mistnetted in total, only 1 dropped all of its tail feathers when entangled in a mist net. The kereru that lost its tail was captured on 29 Mar 2004, and then taken into captivity, where it was recaptured in the aviary on $1 \mathrm{Jul} 2004$ with an almost fully grown tail. A radio-tag was fitted and the kereru successfully released at the study site. At another site in Taranaki, no kereru were reported to have dropped tail feathers in the 22 kereru mist-netted (R. Powlesland, pers.comm.).

Whether the sudden loss of the tail evolved as an anti-predator response in kereru is not clear. Prior to the human introduction of mammalian predators, kereru were sometimes taken as prey by falcons and harriers (Wotton 2007), and the loss of the tail during a chase might enable an individual to escape. However, observations are needed on predatory pursuits between kereru and their aerial predators to determine if the loss of the tail ever occurs in the manner I observed in the netted bird, and if such a sacrifice increases the chances of survival.

Although the occurrence of tail loss appears to be relatively low, it is important for those studying kereru to be aware that mist-netting and handling can result in tail loss. The effects of sudden tail loss can be quite severe, but kereru suffering tail loss can recover in captivity and maintain enough mobility to allow them to feed. The trigger for tail loss is not known, but likely involves both physical contact and increased stress due to handling. Without such information, protocols that minimise both contact and handling time of kereru by researchers may be the best strategy to avoid excessive levels of tail loss. 


\section{References}

Awasthy M. (2007) Urban bird research: a study of kereru in Wellington, New Zealand. In: Proceedings of the 2007 Australasian Regional Association of Zoological Parks and Aquaria, Wellington, New Zealand.

Dathe H. (1955) Uber die Schreckmauser. Journal of Ornithology, 96: 5-14.

Gill F.B. (2000) Ornithology. 2nd edn. W.H. Freeman and Company, New York.

Goodwin D. (1983) Pigeons and doves of the world. 3rd edn. Cornell University Press, Ithaca, New York.

Heather B.D.; Robertson H.A. (2005) The Field Guide to the Birds of New Zealand. Revised edn. Viking, Auckland.

Lindstrom A.; Nilsson J. (1988) Birds doing it the octopus way: fright moulting and distraction of predators. Ornis Scandinavica, 19: 165-166.

Miskelly C.M.; Dowding J.E.; Elliot G.P.; Hitchmough R.A.; Powlesland R.G.; Robertson H.A.; Sagar P.M.; Scofield R.P.; Taylor G.A. (2008) Conservation status of New Zealand Birds, 2008. Notornis, 55: 117-135.

Moller A.P.; Nielsen J.T.; Erritzoe J. (2006) Losing the last feather: feather loss as an antipredator adaptation in birds. Behavioral Ecology, 17: 1046-1056.

Powlesland R.G.; Miskelly C.M. (9 July 2008) Kereru status re-evaluated. Kereru News No. 65 [email newsletter].

Robertson C.J.R.; Hyvonen P.; Fraser M.J.; Pickard C.R. (2007) Atlas of bird distribution in New Zealand 1999-2004. The Ornithological Society of New Zealand, Inc., Wellington, New Zealand.

Thomas A.L.R. (1993) On the aerodynamics of birds' tails. Philosophical Transactions of the Royal Society B, 340: 361-380.

Wotton D.M. (2007) Consequences of dispersal failure: kereru and large seeds in New Zealand. Ph.D. thesis, Univ. of Canterbury, Christchurch. 


\section{APPENDIX 6. Education program questionnaire}

Author's note: The following document is a copy of the questionnaire that was administered to school children who participated in the EE program. It was designed to be complimentary to a similar questionnaire that was administered to adults as part of a M.Sc. project on biodiversity knowledge, and so included additional questions that were not necessary to this study (questions 3 and 5). For the purpose of this study, only questions 1, 2, 4 and 6 were included in my analyses. 


\section{Urban Wildlife Survey (Children's Version) Kereru Discovery Project}

Boy / Girl (circle one)

Age

Teacher and School

1. Write down as many bird species as you can in five minutes.

2. Circle the birds on your list that you think are native to (from) New Zealand.

3. Write down as many animals as you can in five minutes, that you see in your neighbourhood.

4. Write the name of the bird species pictured below in the blank spaces provided, or tick the 'don't know' box if unsure.

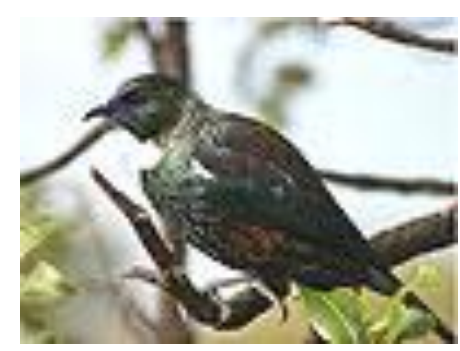

Bird 1

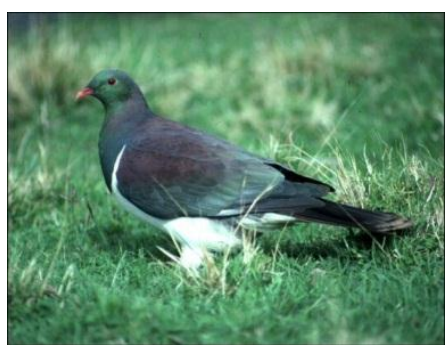

Bird 2

Don't know

Don't know 


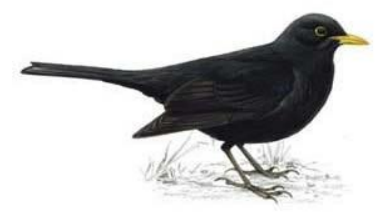

Bird 3

Don't know

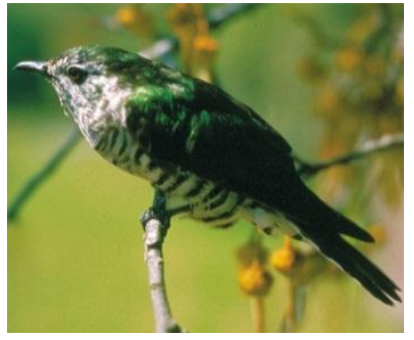

Bird 4

$\square \quad$ Don't know

5. What colour are the flowers of the kowhai tree?

$\square$ Red

$\square$ Purple

$\square$ Yellow

$\square$ White

$\square$ Don't know

6. Kereru facts - tick whether you think the statement is true, false, or you don't know

\begin{tabular}{|c|l|l|l|l|}
\hline & & True & False & $\begin{array}{c}\text { Don't } \\
\text { Know }\end{array}$ \\
\hline 1 & Kereru are found all around the world & & & \\
\hline 2 & Kereru are black and white coloured birds & & & \\
\hline 3 & Kereru can fly very long distances & & & \\
\hline 4 & Kereru were hunted for food by Maori & & & \\
\hline 5 & Kereru eat insects & & & \\
\hline 6 & Kereru build nests in trees and on the ground & & & \\
\hline 7 & Kereru lay one egg in a nest & & & \\
\hline 8 & Cats are a threat to kereru & & & \\
\hline 9 & Kereru can only live in the forest & & & \\
\hline 10 & Kereru are threatened & & & \\
\hline
\end{tabular}


